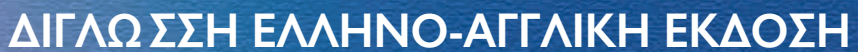
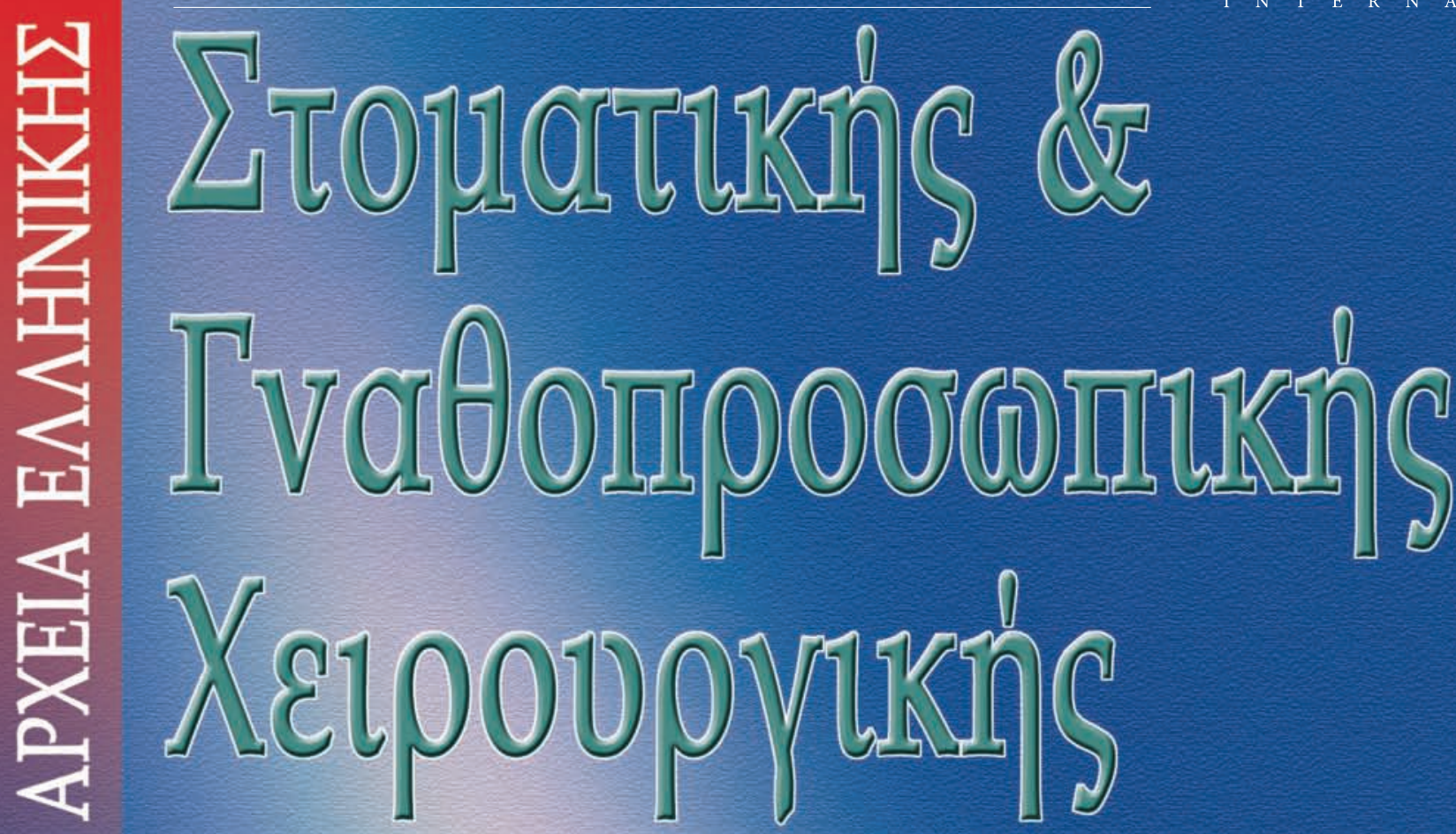

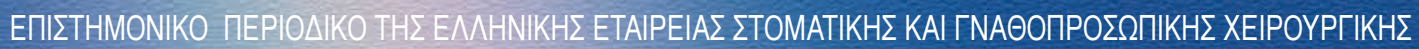

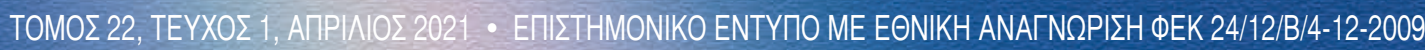

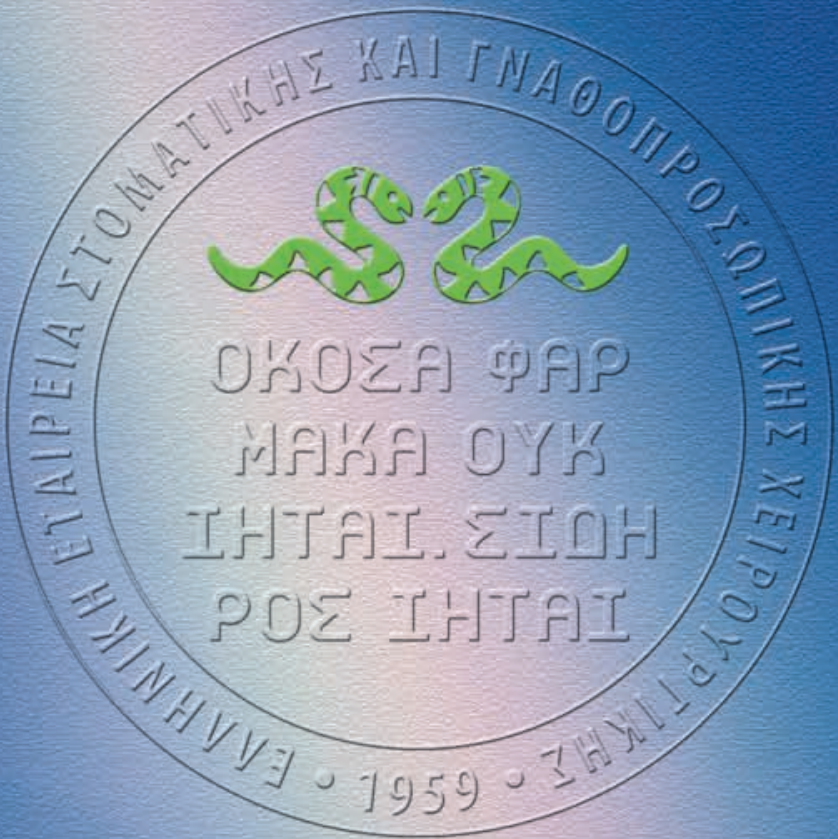

BILINGUAL GREEK - ENGLISH EDITION

\section{Hellenic Archives}

of Oral \& Maxillofacial Surgery

OFFICIAL PUBLICATION OF THE HELLENIC ASSOCIATION FOR ORAL AND MAXILLOFACIAL SURGERY

Vol 22, No 1, April 2021 


\section{PHDEחIX

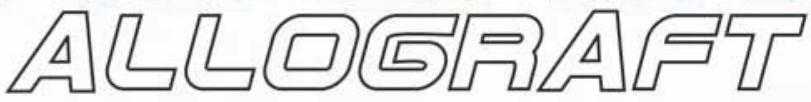 The implant's partner}

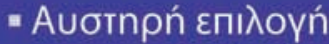

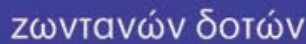

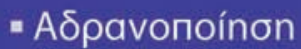
ı́́v, Baктnрíwv

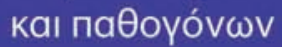

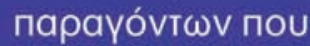
прока入oúv

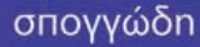

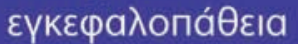

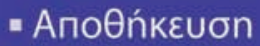

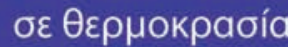
$\delta \omega \mu a t i ́ o u$

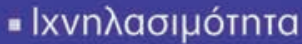

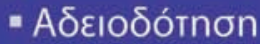
anó TIS

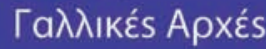

Yyzías

(AFSSaPS)

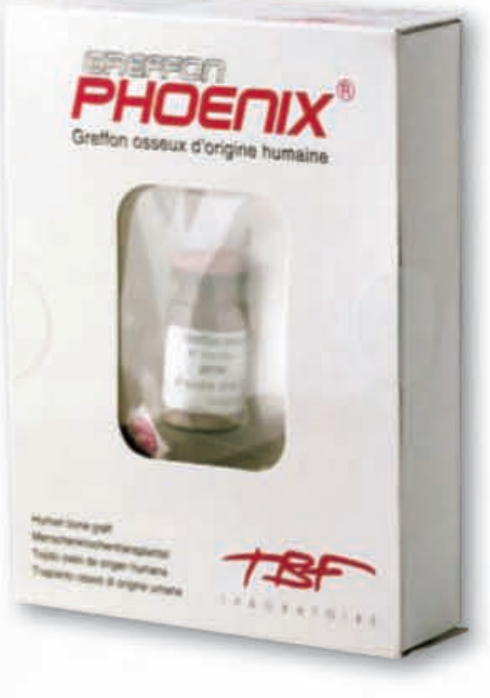

Пávw anó 60.000 ootıká

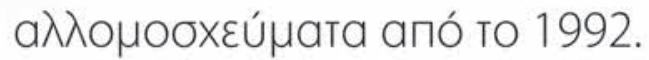

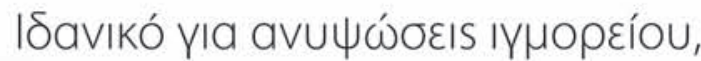

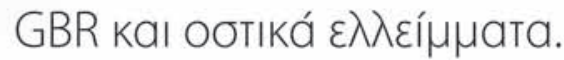

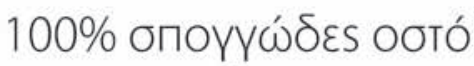

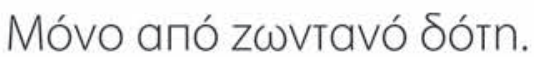

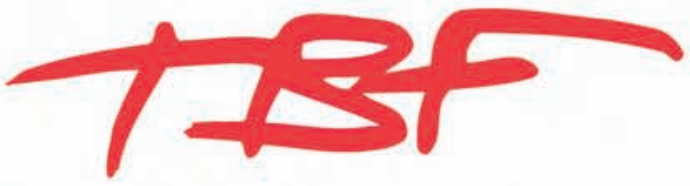

TISSUE ENGINEERING

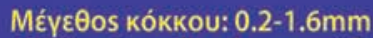

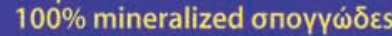
обто́ бє кóкKоus
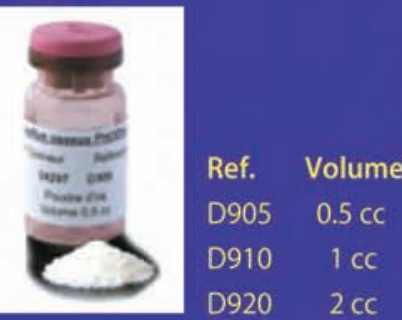

BLOCKS $100 \%$ mineralized

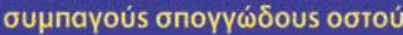
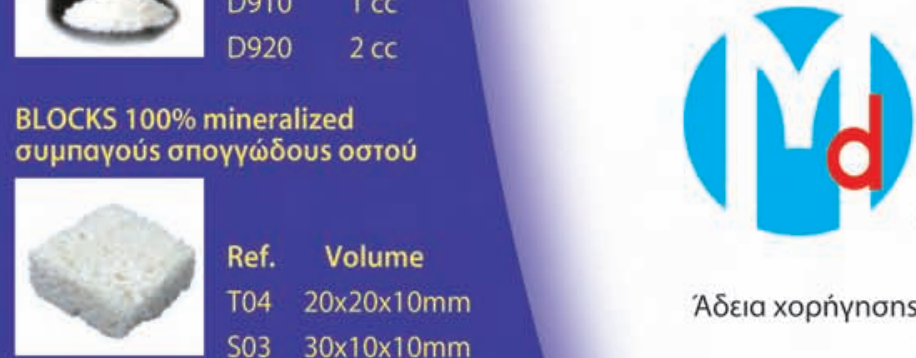

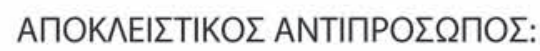

$\triangle$.MAYPAEI $\triangle O \Pi O Y \wedge O \Sigma$ A.E. O $\triangle$ ONTIATPIKA EIDH

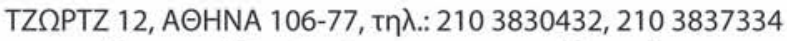

e-mail: mavraid@otenet.gr, www.mavraidopoulos.gr

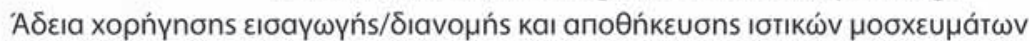

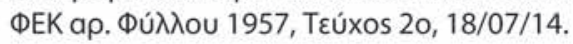




\section{ANKYLOS}

$\Delta$

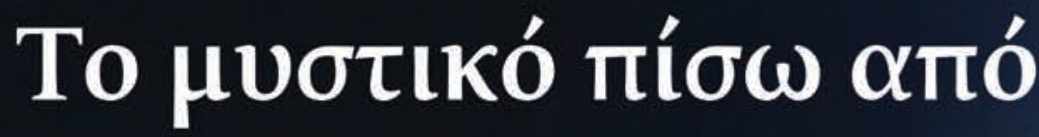

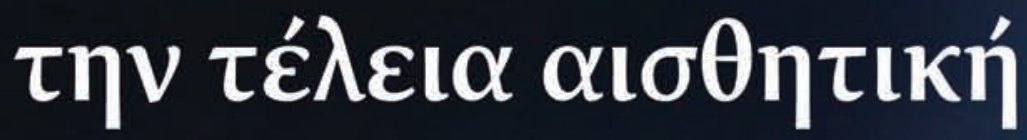
$\pi p 0 \sigma \theta i ́ \omega v$

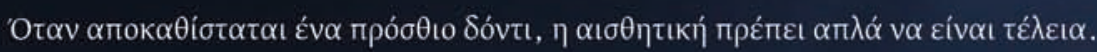

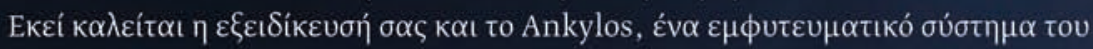

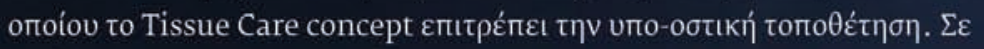

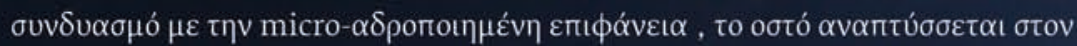

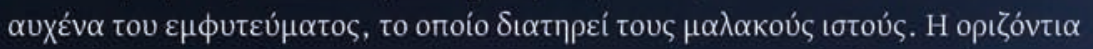

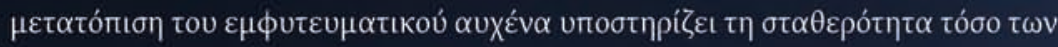

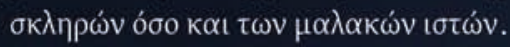

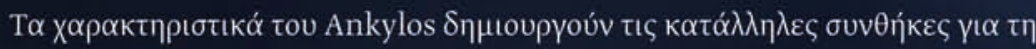
$\mu \alpha \kappa \rho о \pi \rho \dot{\theta} \varepsilon \sigma \mu \eta \eta$

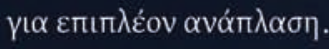

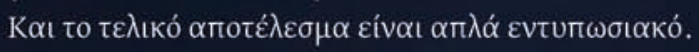

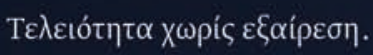

Ankylos by Dentsply Sirona Implants

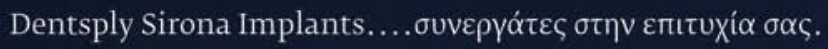




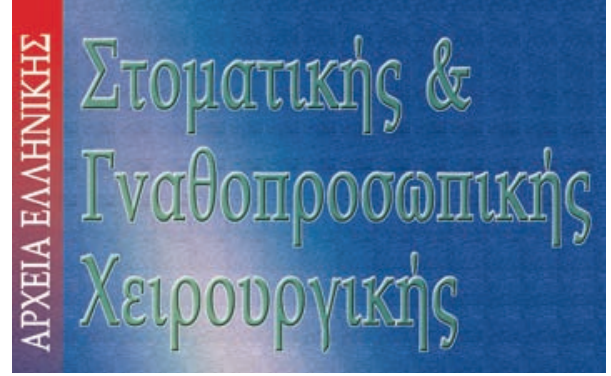

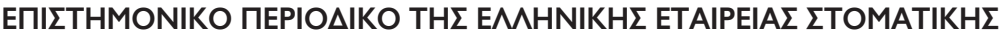

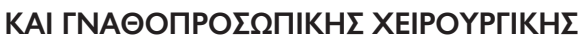 online www.haoms.org}

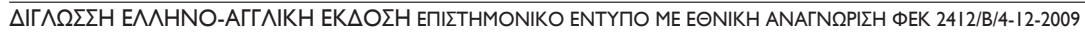

Abstracted/Indexed in: Index Copernicus, Google Scholar, Publons ISSN II08-829 X

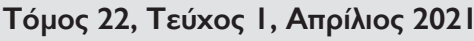

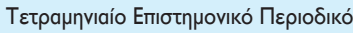

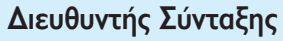

AӨaváoı Kupyíons

MD, DDS, MSc, PhD, ScD

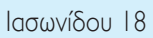

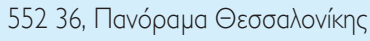

$\operatorname{T\eta \lambda }: 2313$ 307413

e-mail: archives@haoms.org

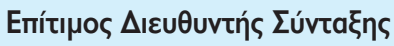

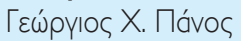

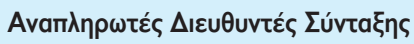

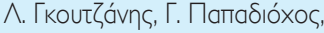

B. Пвтoívns, H. Xpovás

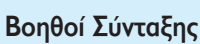

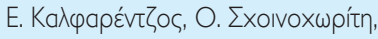

$\triangle$. Tátons

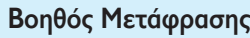

А. А入в६о́по

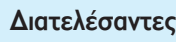

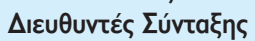

2000-2004

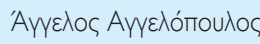

2005-2007

Iwávnฺ latpoú

2008-2012

Гє́́pyıos X. Пávos

2012-2016

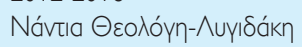

2016-2020

Avaotáoıos I. Mu^wvás

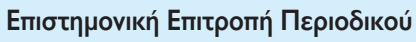

Julio Acero, Spain, George Dimitroulis, Australia, Takashi Fujibayashi, Japan, Orhan Guven, Turkey, John Helfrick, USA, Nicholas Kalavrezos,

United Kingdom, Anastasios Kanatas, United Kingdom, Philip Pyrgousis, USA Henri Thuau, United Kingdom

\begin{tabular}{|c|c|}
\hline 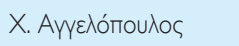 & N. ^aßapí́nৎ \\
\hline 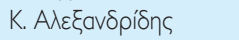 & 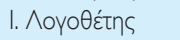 \\
\hline 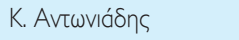 & A. Matıákns \\
\hline 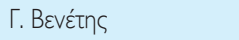 & 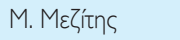 \\
\hline 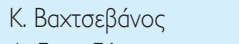 & K. MoupoúZ̄n \\
\hline ^. Гkouţávns & A. Muৗwvás \\
\hline ^. Zoułoúnns & Г. Пávos \\
\hline 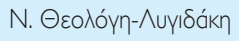 & Г. Паvт́́̉aৎ \\
\hline B. $\Theta \omega \mu$ aî́ं̄ & 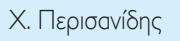 \\
\hline Г. Koגoútooৎ & Г. По入ußর́ns \\
\hline I. latpoú & Г. Рáłnпৎ \\
\hline E. Kovoo入ákn & 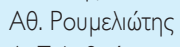 \\
\hline М. ^ałapí́ou & A. ¿kiaßoúvou \\
\hline
\end{tabular}

X. ¿koutźpns

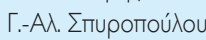

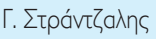

Ф. Тदर́рuтос

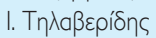

¿. Tpıapín's

П. Тбітбóтоuৗos

П. Хрібто́тоuৗos

Е. Хриоона́ $\lambda \nmid \eta$

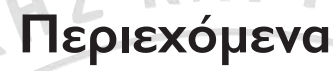

Editorial

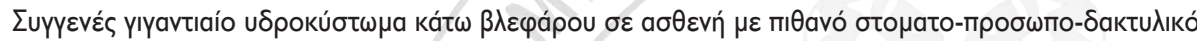

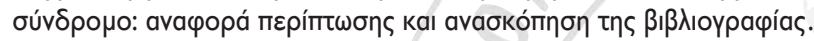

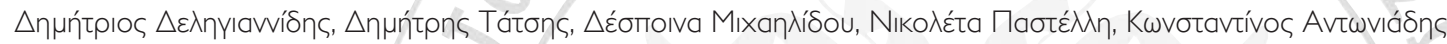

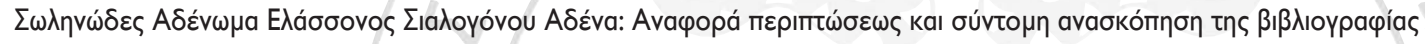

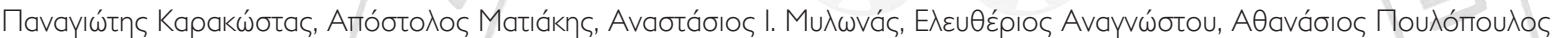

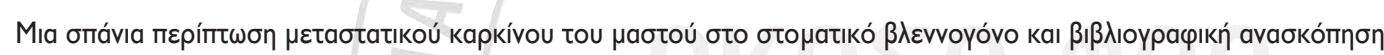

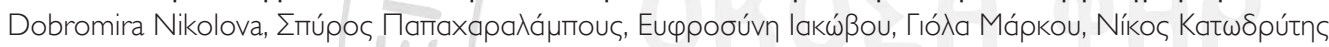

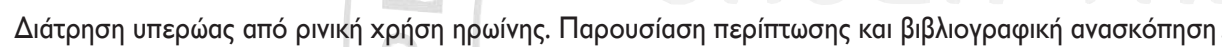

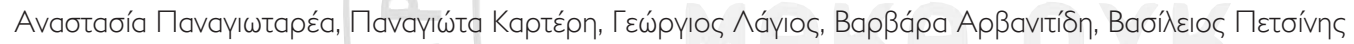

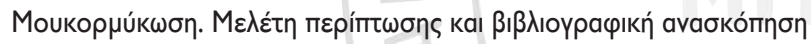

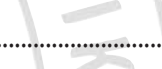

S. Karthik, A. Shanmugam, S.R. Janani, E.C. Dhinakaran, R.N. Mugundan

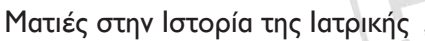

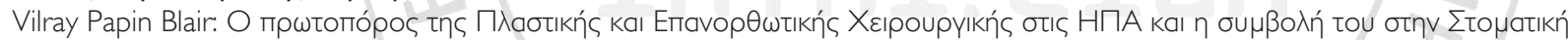

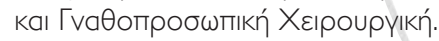

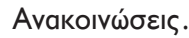

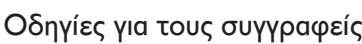

Іоıоктпбі́́

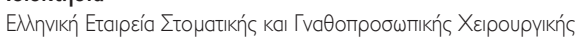

Maı́vopou 23, 11528 A日ńva

Tn入.: 2107211845 , Fax: 2107215082

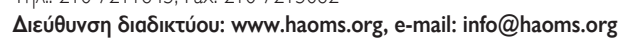

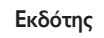

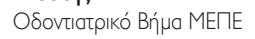

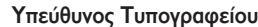

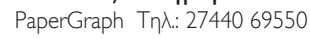

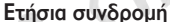

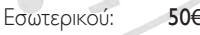

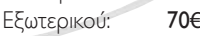

ФoItntés: $\quad 35 €$

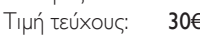

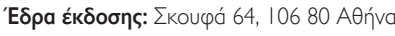

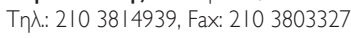

e-mail: odvima@otenet.gr,www.odvima.gr 
Triannual Scientific Journal

\section{Editor - in - Chief}

Athanassios Kyrgidis

MD, DDS, MSc, PhD, ScD

lasonidou 18

552 36, Panorama Thessaloniki, Greece

Tel.: +302313 307413

e-mail: archives@haoms.org

Honorary Editor-in Chief

George Ch. Panos

Associate Editors

L. Goutzanis, I. Papadiochos,

V. Petsinis, I. Chronas

\section{Assistant Editors}

E. Kalfarentzos, O. Schoinohoriti,

D. Tatsis

\begin{tabular}{llll}
$\begin{array}{ll}\text { Former } \\
\text { Editors-in-Chief }\end{array}$ & \multicolumn{2}{l}{ Scientific Committee } \\
Julio Acero, Spain, George Dimitroulis, Australia, Takashi Fujibayashi, Japan \\
2000-2004 & Orhan Guven, Turkey, John Helfrick, USA, Nicholas Kalavrezos, \\
Angelos Angelopoulos & United Kingdom, Anastasios Kanatas, United Kingdom, Philip Pyrgousis, USA, & \\
2005-2007 & Henri Thuau, United Kingdom & \\
loannis latrou & Ch. Angelopoulos & M. Lazaridou & Ch. Skouteris \\
$2008-2012$ & C. Alexandridis & I. Logothetis & G.-A. Spyropoulou \\
George Ch. Panos & K. Antoniadis & A. Matiakis & G. Strantzalis \\
$2012-2016$ & K. Vachtsevanos & M. Mezitis & F. Tzerbos \\
Nadia Theologie-Lygidakis & G. Venetis & K. Mourouzis & I. Tilaveridis \\
$2016-2020$ & L. Goutzanis & A. Mylonas & S. Triaridis \\
Anastassios I. Mylonas & L. Zouloumis & G. Panos & P. Tsitsopoulos \\
& N. Theologie-Lygidakis & G. Pantelas & P. Christopoulos \\
& V. Thomaidis & Ch. Perisanidis & E. Chrysomalli \\
& I. latrou & G. Polyzois & \\
& G. Koloutsos & G. Rallis &
\end{tabular}

Vol 22, No I, April 202 I

\section{Contents}

Editorial

Congenital giant lower eyelid hidrocystoma in a patient with possible orofacial digital syndrome: case report and literature review...

Dimitrios Deligiannidis, Dimitris Tatsis, Despoina Michailidou, Nikoleta Pastelli, Konstantinos Antoniades

Canalicular adenoma of minor salivary gland: Report of a case and a brief review of the literature

Panagiotis Karakostas, Apostolos Matiakis, Anastassios I. Mylonas, Eleftherios Anagnostou, Athanasios Poulopoulos

A rare case report of metastatic breast carcinoma in the Oral mucosa and literature review

Dobromira Nikolova, Spyros Papacharalambous, Efrosini lacovou, Yiola Marcou, Nicos Katodritis

Palatal perforation from intranasal abuse of heroin. Case report and literature review

Anastasia Panagiotarea, Panagiota Karteri, Georgios Lagios, Barbara Arvanitidi, Vassilios Petsinis

Mucormycosis. Case report and literature review.

S. Karthik, A. Shanmugam, S.R. Janani, E.C. Dhinakaran, R.N. Mugundan

Glances in the History of Medicine.

Vilray Papin Blair: The pioneer of Plastic and Reconstructive Surgery in the USA, and his contribution in Oral and Maxillofacial Surgery.

Announcements

Guide for Authors.

\section{Owner}

Hellenic Association for Oral and Maxillofacial Surgery

23 Meandrou Street, 11528 Athens, Greece

Tel.: +30210 7211845, Fax: +30210 7215082

Website: www.haoms.org, e-mail: info@haoms.org

Publisher

Odontiatriko Vima MEPE

Printing

PaperGraph Tel. +30 2744069550
Annual Subscription Rates

Annual fee (domestic): $\quad 50 €$

Annual fee (international): $\quad 70 €$

Students:

Single Copy:

$35 €$

$30 €$

Publishing Office: 64 Skoufa Str., 10680 Athens Greece

Tel: +30 210 3814939 Fax: +302103803327

e-mail: odvima@otenet.gr,www.odvima.gr 


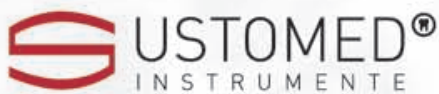

\section{Bone-Fixation-Set}

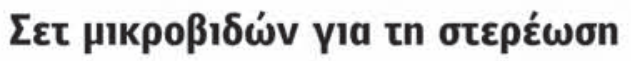

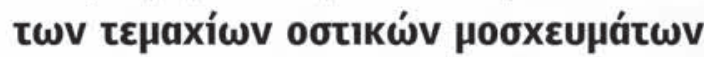

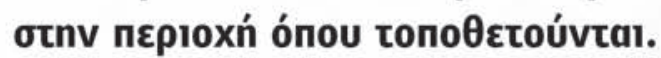

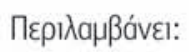

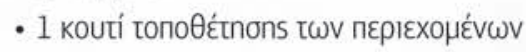

- 1 katoaßíi

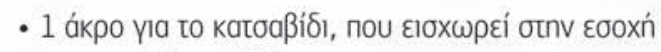

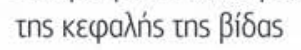

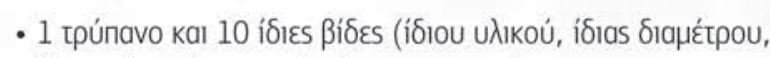

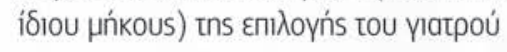

\section{ГERMETPIA TQN MIKPOBIAQN}

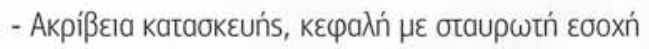

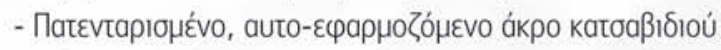

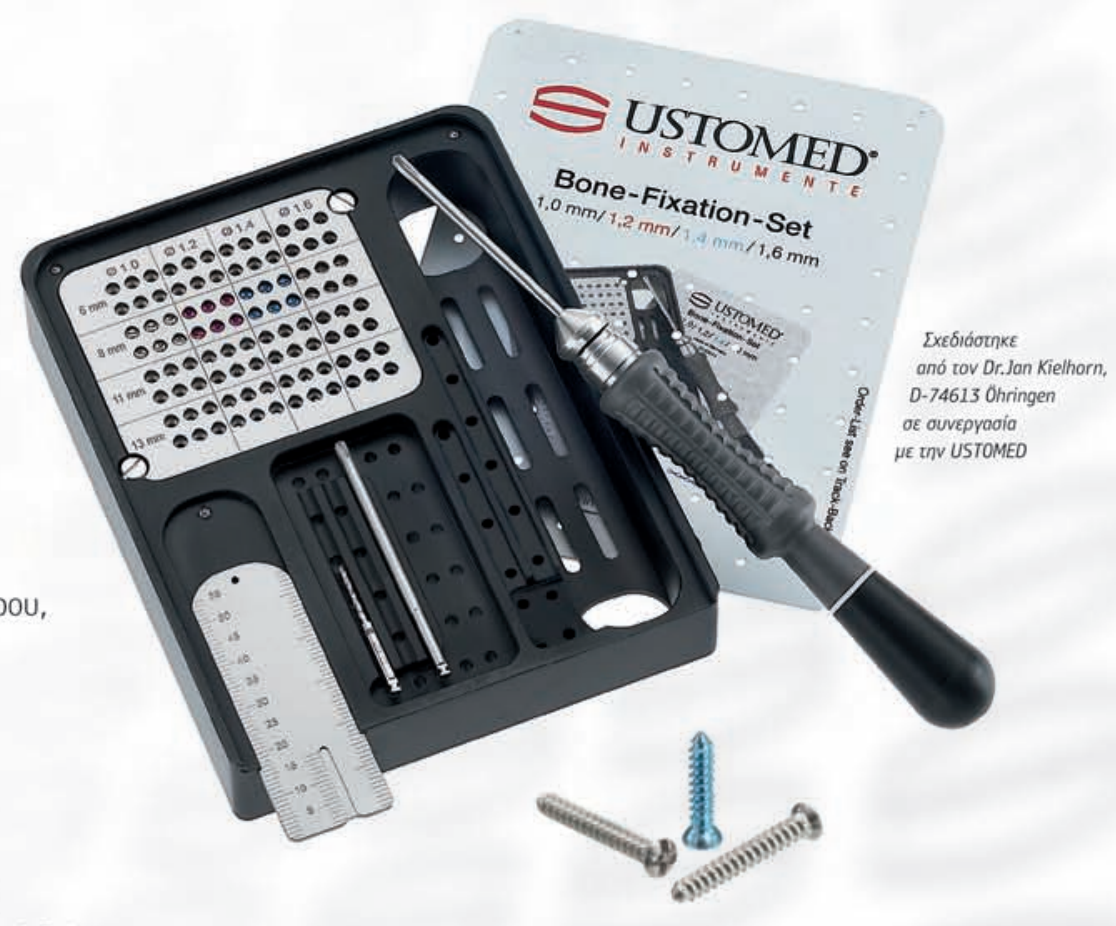

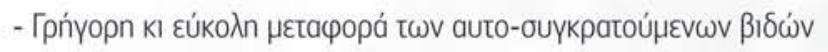

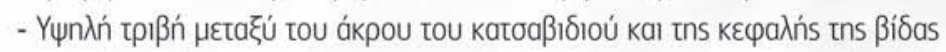

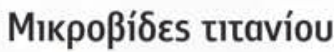

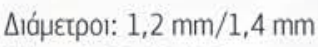

Mńkn: $6,8,11,13$ mm

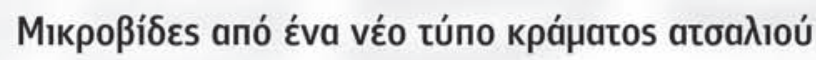
(implant steel alloy)

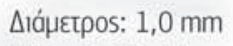

Mńkn: $8,11,13 \mathrm{~mm}$

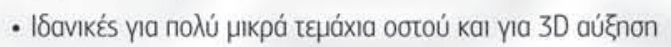

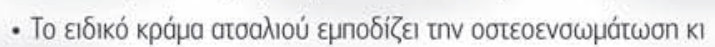

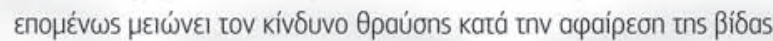

\section{T-Fix Membrane screw}

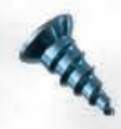

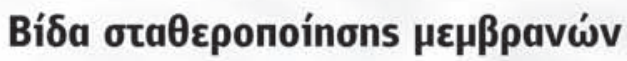

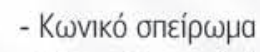

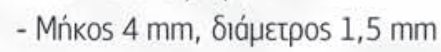

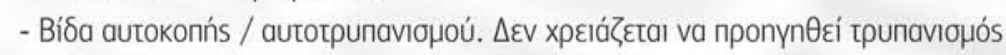

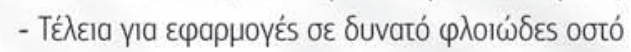

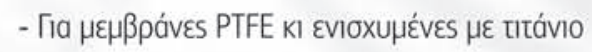

\section{Mı入тıáōns} Bitoapónoudos A.E.

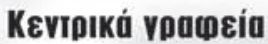

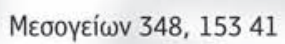
Aү. Парабкєuń, AӨńva

(C) 2106541340

ㄱ) 2106541618

주의o@vitsaropoulos.gr

\section{Ynokaráornua}

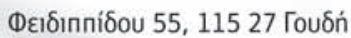

() 2107795747

$\odot$ vitsaropoulos.gr

If facebook.com/vitsaropoulos 


\section{Editorial}

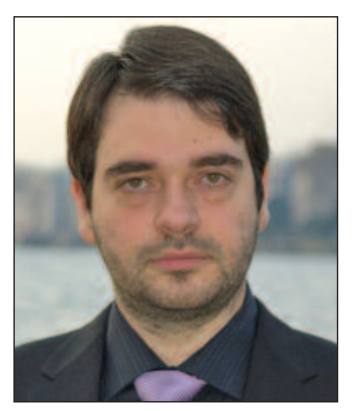

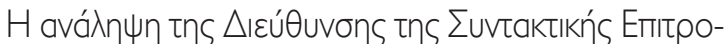

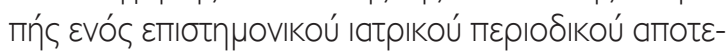

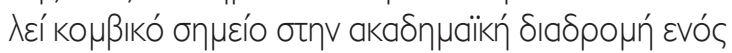

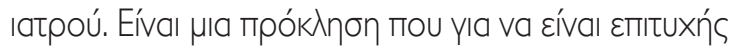

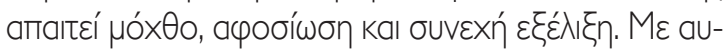

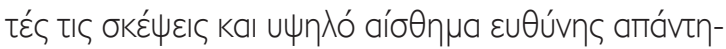

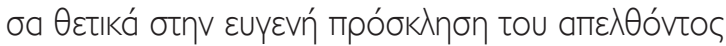

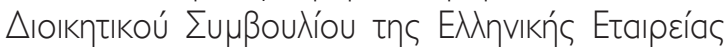

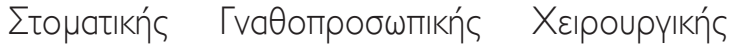
(

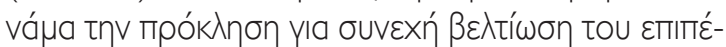

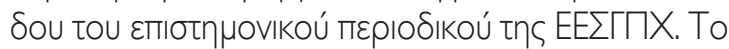

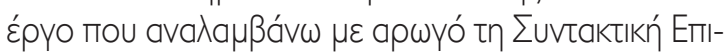

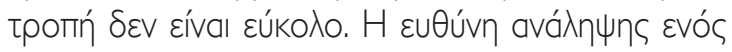

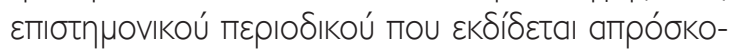

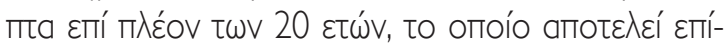

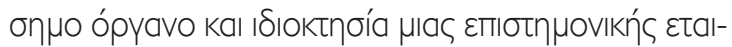

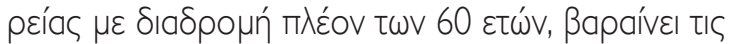

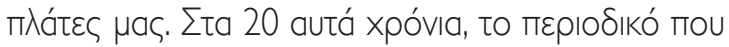

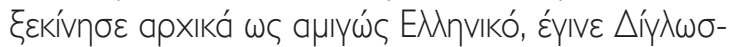

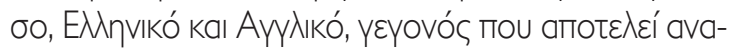

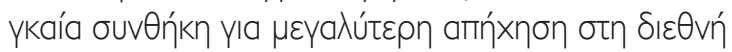

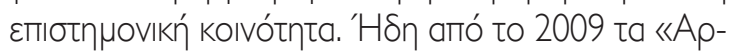

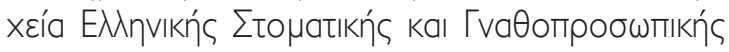

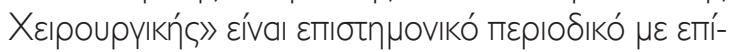

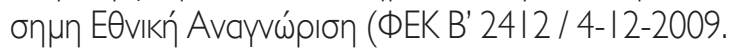

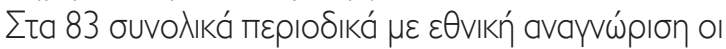

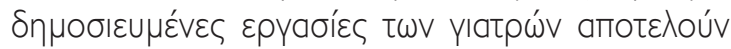

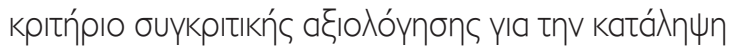

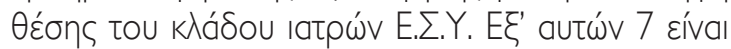

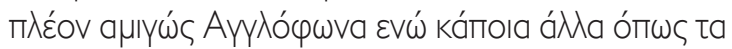

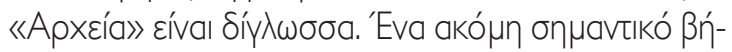

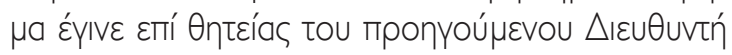

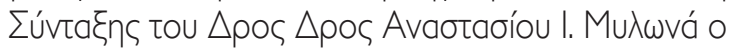

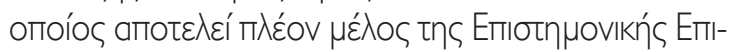

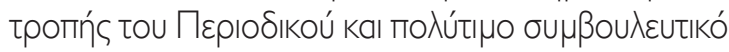

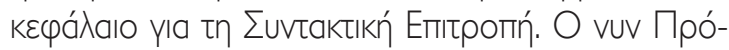

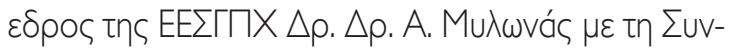

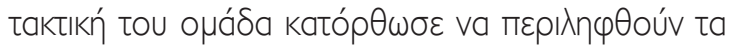

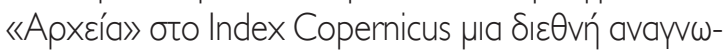

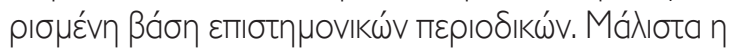

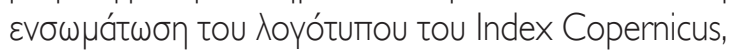

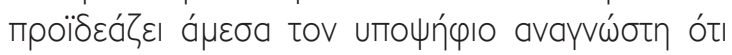

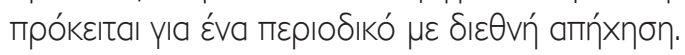

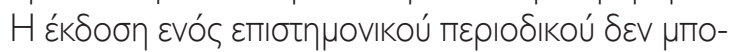

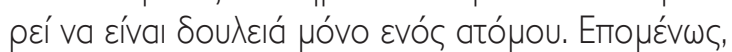

Taking over the Management of the Editorial Committee of a scientific medical journal is a key point in a doctor's academic career. It is a challenge that in order to be successful requires effort, dedication and continuous development. With these thoughts and a high sense of responsibility, I responded positively to the noble invitation of the outgoing Board of Directors of the Hellenic Association of Oral and Maxillofacial Surgery (HAOMS), accepting the invitation and at the same time the challenge for continuous improvement of the scientific level. The work I undertake with the help of the Editorial Board is not easy. The responsibility of undertaking a scientific journal that has been published smoothly for more than 20 years, which is the official journal and owned by of a scientific company with a history of more than 60 years, puts a huge burden on our shoulders. In these 20 years, the journal, which initially started as purely Greek, became Bilingual, Greek and English, a fact that is a necessary condition for greater impact in the international scientific community. Since 2009 the "Archives of Hellenic Oral and Maxillofacial Surgery" is a scientific journal with official National Recognition (Government Gazette B' 2412 / 4-12-2009). In the 83 total journals with national recognition the published works of doctors are a benchmark for appointment to the Greek National Health System. Seven of them are now purely English while some others such as the "Archives" are bilingual. Another important step was taken during the tenure of the former Editor-In-Chief of Dr. Dr. Anastassios I. Mylonas who is now a member of the Scientific Committee of the Journal and a valuable advisor for the Editorial Board. In fact, the incorporation of the Index Copernicus logo immediately foreshadows the prospective reader that it is a journal with international impact.

Publishing a scientific journal cannot be the work of just one person. Therefore the first concern of an Editor-In-Chief is to appoint the Editorial Board, his collaborators, with whom he must share common visions and goals, in order to enable the project to progress. After first thanking the members of the Editorial Board who left, that is, the President 


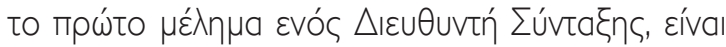

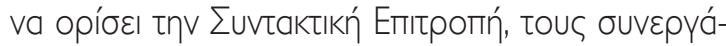

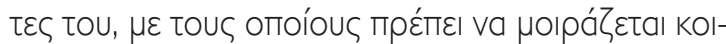

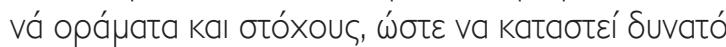

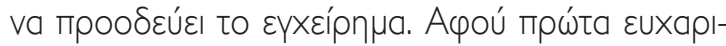

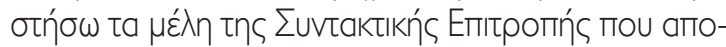

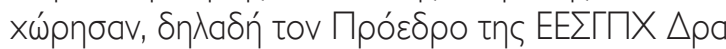

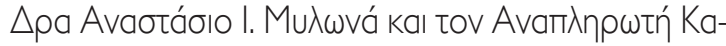

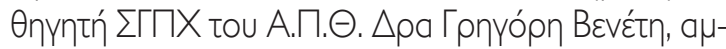

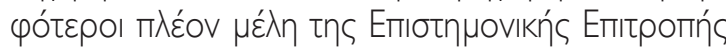

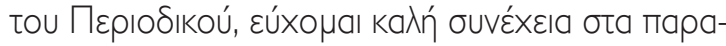

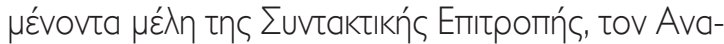

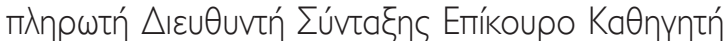

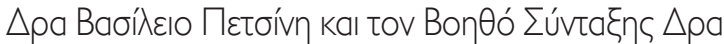

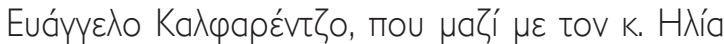

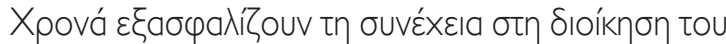

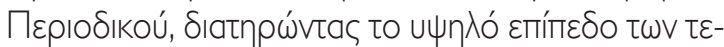

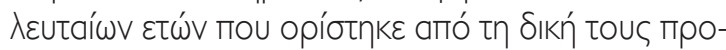

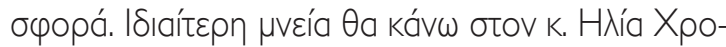

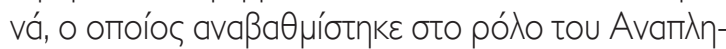

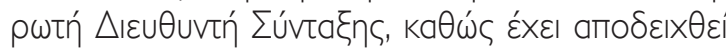

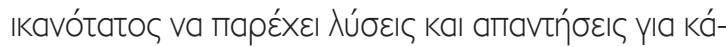

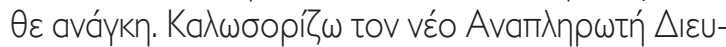

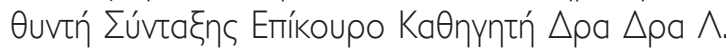

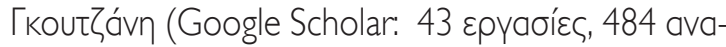

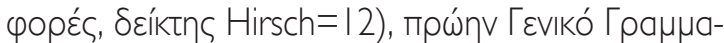

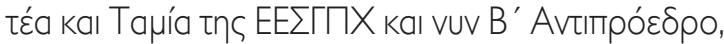

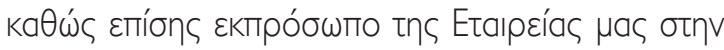

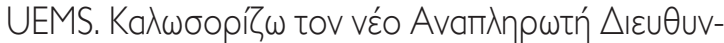

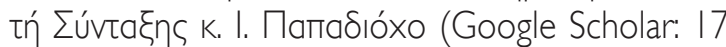

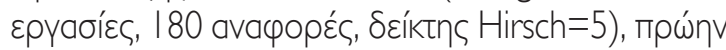

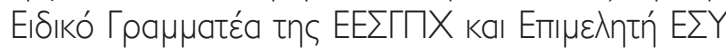

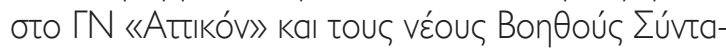
छns ka Oupavía ¿xoıvoxwpítn (Google Scholar: 19

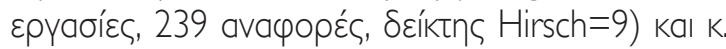

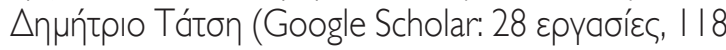

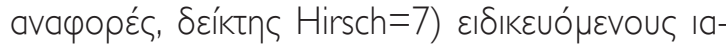

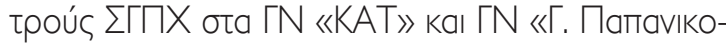

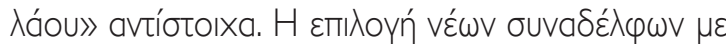

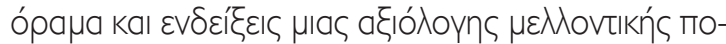

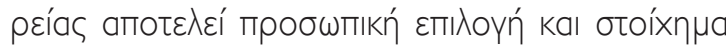

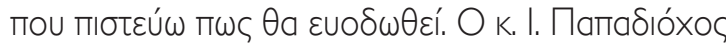

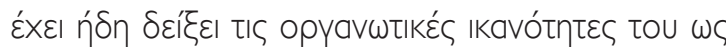

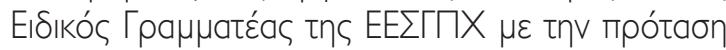

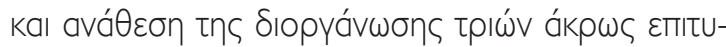

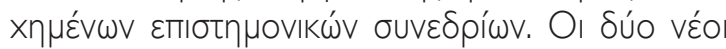

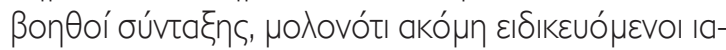

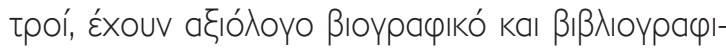

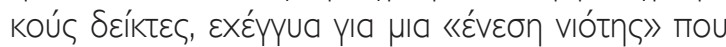

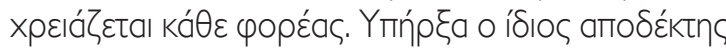

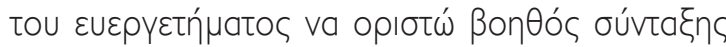

of HAOMS Dr. Dr. Anastassios I. Mylonas and the Associate Professor of OMFS of AUTh. Dr. Grigoris Venetis, now both members of the Scientific Committee of the Journal, I wish good luck to the remaining members of the Editorial Board, the Associate Editor, Assistant Professor Dr. Vassilios Petsinis and the Assistant Editor Dr. Evangelos Kalfarentzos, who together with Mr. llias Chronas ensure the continuity in the management of the Journal, maintaining the high level of the last years set by their own offer.

I will make a special mention of the former Assistant Editor Mr. llias Chronas, who from his upgraded role of Associate Editor will continue to contribute to the Journal, as he has proven to be very capable of providing solutions and answers for every need. I welcome the new Associate Editor, Assistant Professor Dr. Dr. L. Goutzanis (Google Scholar: 43 papers, 484 citations, Hirsch index = 12), former General Secretary and Treasurer of HAOMS, currently Vice President and UEMS delegate of HAOMS. I welcome the new Associate Editor Mr. I. Papadiochos (Google Scholar: 17 papers, 180 citations, Hirsch index = 5), former Secretary for Continuing Education of the HAOMS and NHS Consultant at Attikon General Hospital and the new Assistant Editors (Ms. Ourania Schoinohortiti) Scholar: 19 papers, 239 citations, Hirsch index =9) and Mr. Dimitrios Tatsis (Google Scholar: 28 papers, I 8 citations, Hirsch index =7) OMFS residents in GN "KAT" and GN "G. Papanikolaou" respectively. The selection of new colleagues with perspectives and indications of a remarkable future course is a personal choice and a bet that I believe will succeed. Mr. I. Papadiochos has already shown his organizational skills as Special Secretary of the HAOMS with the proposal and assignment of the organization of three highly successful scientific conferences. The two new editors, although still resident doctors, have remarkable biographical and bibliographic indicators, guarantees of an "injection of youth" that every institution needs. In the past I also had the privilege of being appointed assistant editor while being a resident doctor. I participated as a resident in the methodological information-training seminars of the peer reviewers of the journal "Hippokratia" which in 2005 had become English while in 2008 it was included in the PubMed database. In 201 I , being sen- 


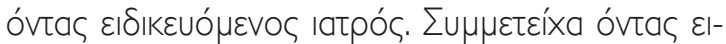

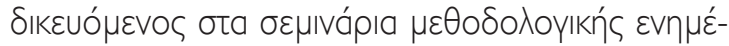


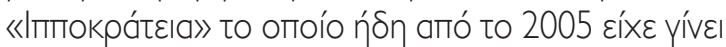

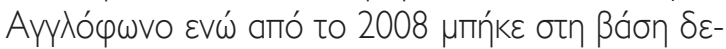

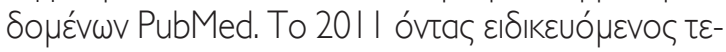

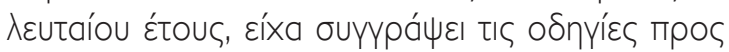

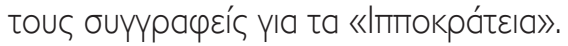

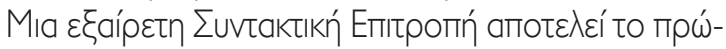

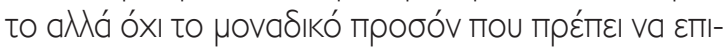

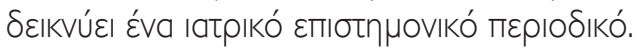

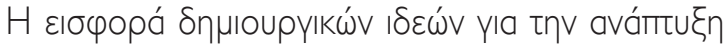

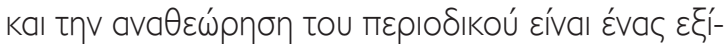

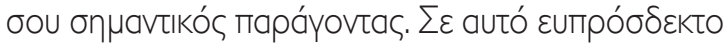

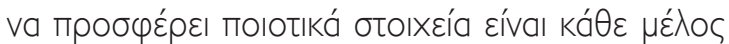

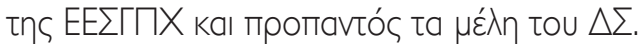

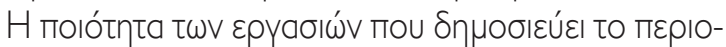

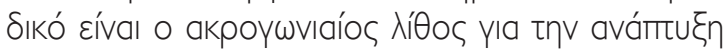

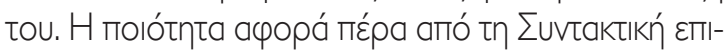

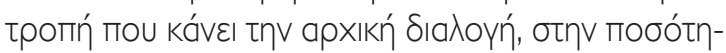

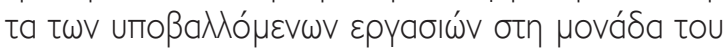

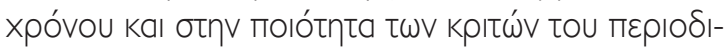

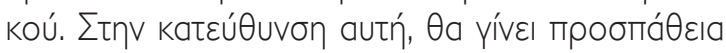

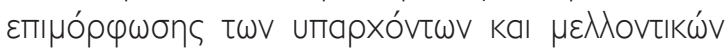

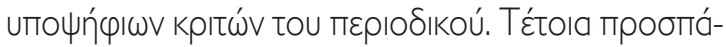

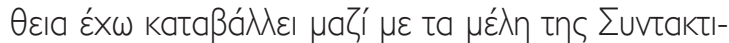

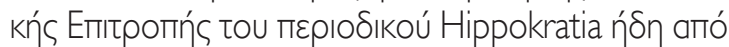

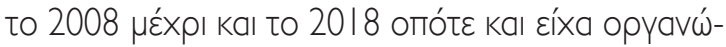

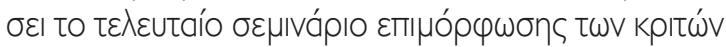

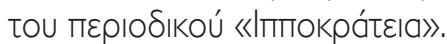

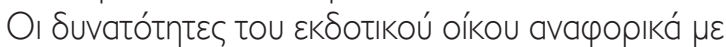

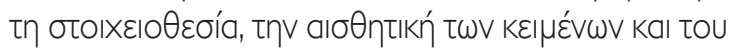

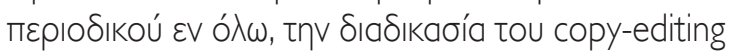

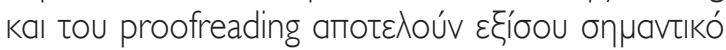

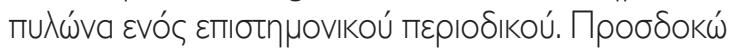

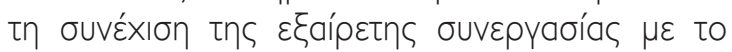

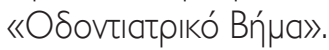

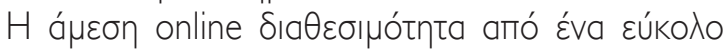

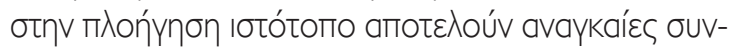

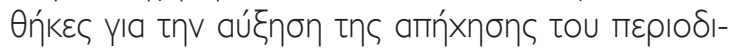

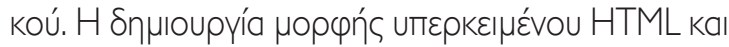

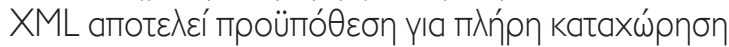

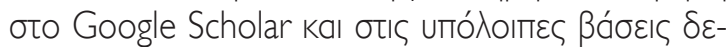

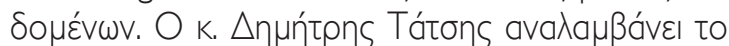

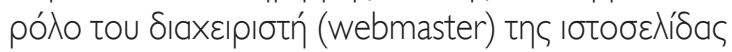

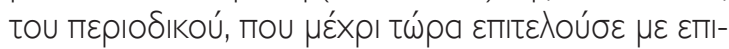

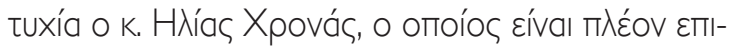

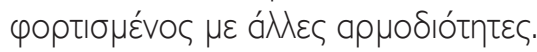

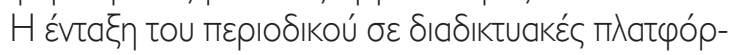

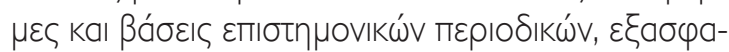

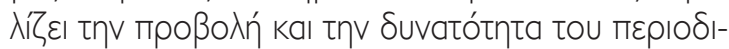

ior registrar, I had authored the instructions to the authors for the "Hippokratia".

The capabilities of the publishing house regarding the typewriting, the aesthetics of the texts and the journal as a whole, the process of copy-editing and proofreading are equally important pillars of a scientific journal. I look forward to continuing the excellent collaboration with "Odontiatriko Vima".

The immediate online availability of an easy-to-navigate website is a prerequisite for increasing the journal's popularity. Creating HTML and XML hypertext format is a prerequisite for full registration in Google Scholar and other databases. Mr. Dimitris Tatsis assumes the role of webmaster of the journal's website, which until now was successfully performed by Mr. llias Chronas, who is now in charge of other responsibilities.

The inclusion of the journal in online platforms and databases of scientific journals, ensures the promotion and the possibility of the journal to function as a medium, a body for the promotion of scientific knowledge and therefore to serve the purpose of its existence. The increased popularity of a journal, beyond the above pillars, is ensured by its participation in more and more databases of medical journals. To this end, and following the efforts of the previous Editorial Board to include the journal to the Index Copernicus, this Editorial Board has already registered the journal in the Publons database. The latter serves to recognize the work provided by the peer reviewers of the "Archives". Therefore, the reviewers of the manuscripts of the "Archives", can receive recognition (credit) for the review services they offer to the journal simply by forwarding the thank you email for their review from the Editorial Board to the email reviews@publons.com.

The goals of the Editorial Board include other databases such as Google Scholar, IATROTEK online, Directory of Open Access Journals (DOAJ), PubMed Central, PubMed, Scopus and Journal Citation Reports (JCR). With the latter the journal receives a journal official impact factor. The process is different and with a different degree of difficulty requirements for each of the above. The course is long and the goal will not be possible without the assistance of the authors, those who will submit their work for peer review and publication in the journal. 


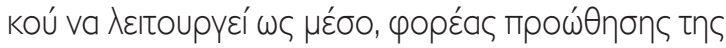

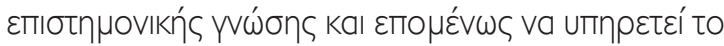

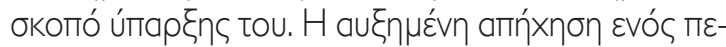

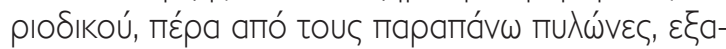

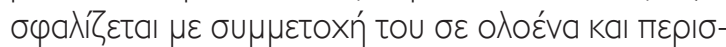

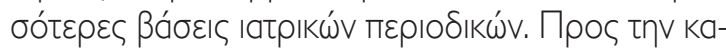

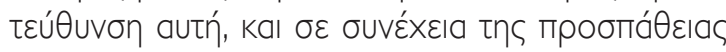

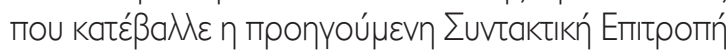

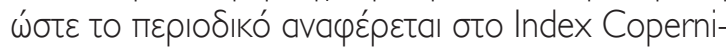

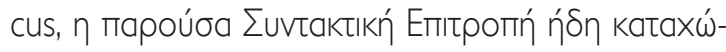

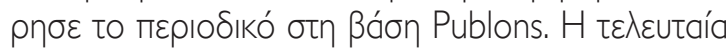

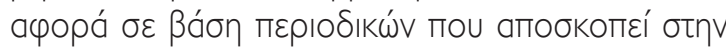

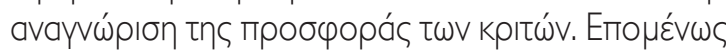

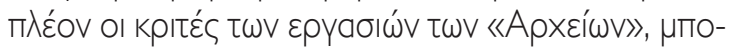

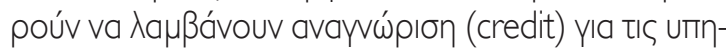

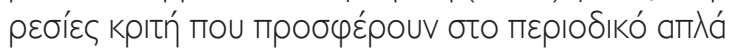

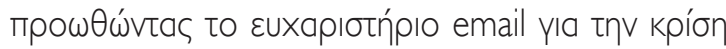

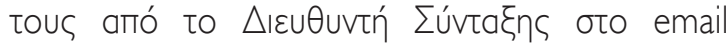
reviews@publons.com.

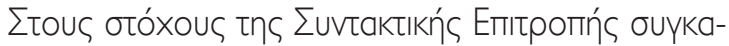

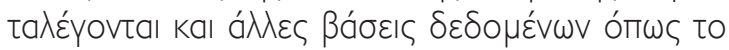
Google Scholar, to IATROTEK on-line, to Directory of Open Access Journals (DOAJ), to PubMed Central, to PubMed, to Scopus ka to Journal Citation

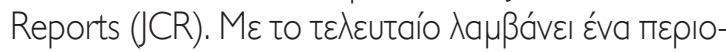

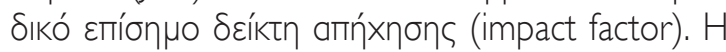

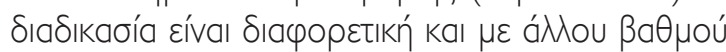

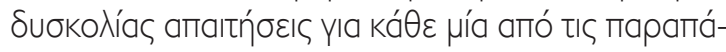

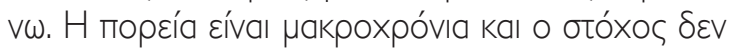

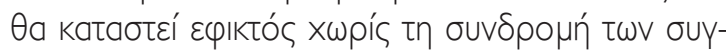

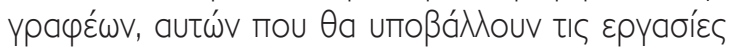

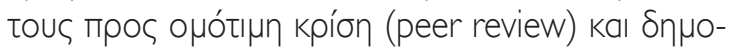

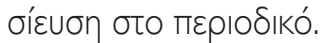

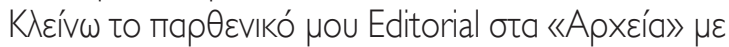

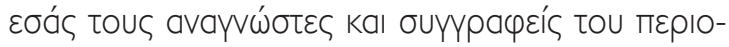

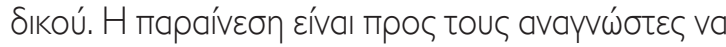
yívouv ouyypa

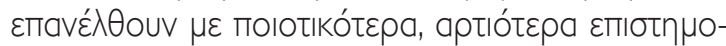

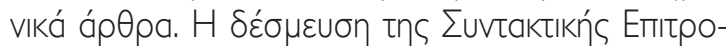

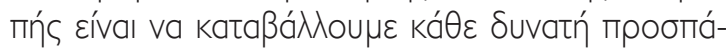

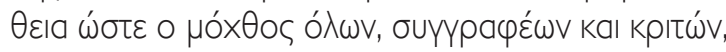

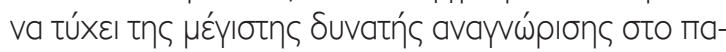

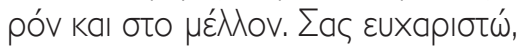

\section{$\Delta \rho$. AӨaváoıos Kupyíons}

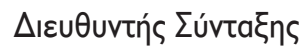

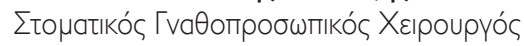

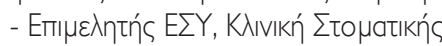

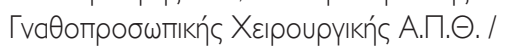

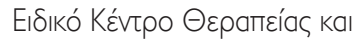

Апоката́otaons tou kapkívou tns

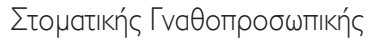

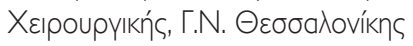

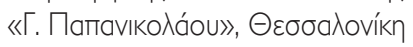

I close my maiden Editorial in the "Archives" with you, the readers and authors of the journal. The urge is for readers to become authors. To those already authors, to revert with better, more complete scientific articles. The commitment of the Editorial Board is to make every effort to ensure that the efforts of all, authors and reviewers, receive the maximum possible recognition in the present and in the future. Thank you,

\section{Athanassios Kyrgidis MD, DDS, MSc, PhD, ScD Editor-In-Chief}

Oral \& Maxillofacial Surgeon - Consultant, Department of Oral \& Maxillofacial Surgery, Aristotle University of Thessaloniki, Specialized Cancer Treatment and Reconstruction Center, General Hospital of Thessaloniki "George Papanikolaou", Thessaloniki 


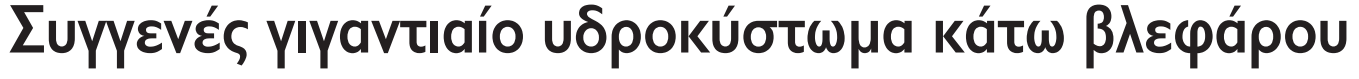

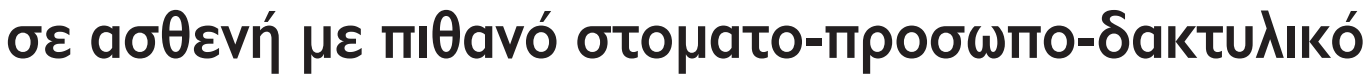

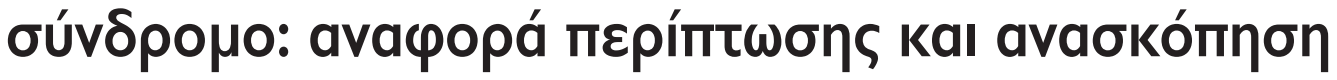

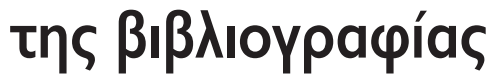

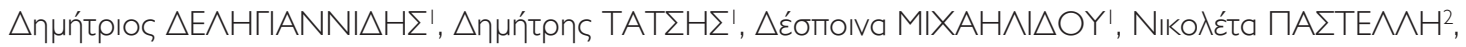
KwVotavtívos ANTSNIA $\triangle \mathrm{H} \Sigma^{3}$

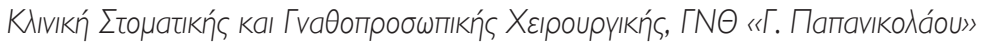

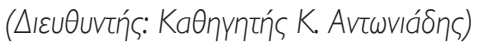

\section{Congenital giant lower eyelid hidrocystoma in a patient with possible orofacial digital syndrome: case report and literature review}

\author{
Dimitrios DELIGIANNIDIS, Dimitris TATSIS, Despoina MICHAILIDOU, Nikoleta PASTELLI, \\ Konstantinos ANTONIADES
}

Department of Oral and Maxillofacial Surgery, General Hospital G. Papanikolaou

(Head: ProfK. Antoniades)

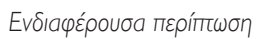
$\mu \varepsilon$ Віß入оурачіки́ Avабко́ппоп Case Report with Literature Review

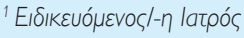
$\Sigma Г \Pi X$

${ }^{2}$ ПaӨołoyoavatómos,

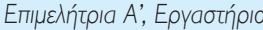

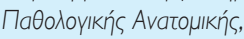
ГNO «Г. Папаvikodáou» ${ }^{3} \Sigma \Gamma \Pi X$, Känyntńs,

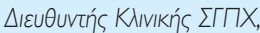
「NO «Г. Папаvikołáou»
}

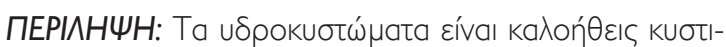

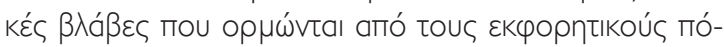

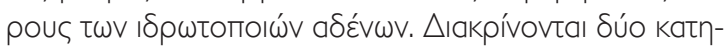

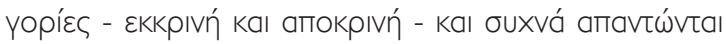

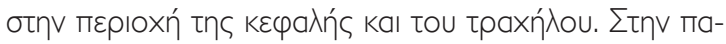

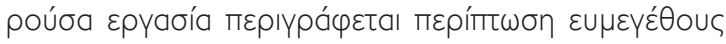

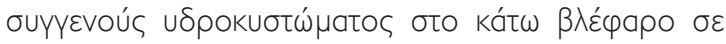

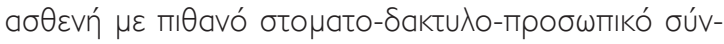

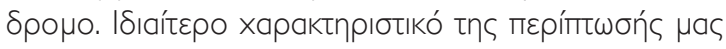

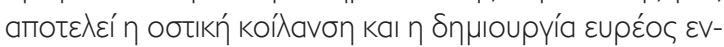

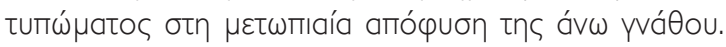

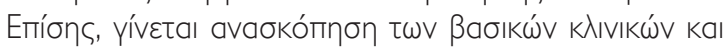

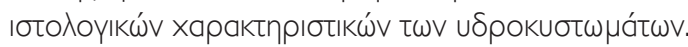

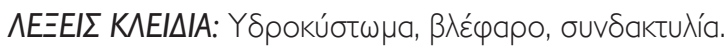

SUMMARY: Hidrocystomas are benign cystic lesions which arise from the secretory part of sweat glands. Hidrocystomas can be either eccrine or apocrine and are often found in the head and neck region. In this paper we present a case of a large congenital hidrocystoma of the lower eyelid in a patient with possible orofacial digital syndrome (ODS). A special feature in our case was the presentation of bone remodeling of the anterior surface of the maxilla. The basic clinical and histological features of hidrocystomas are also reviewed.

KEY WORDS: Hidrocystoma, eyelid, syndactyly. 


\section{EI $\Sigma$ АГ $\Omega \Gamma \mathrm{H}$}

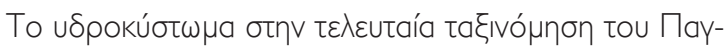

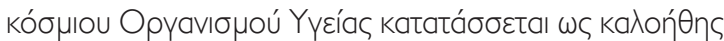

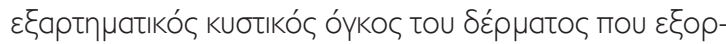

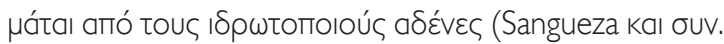

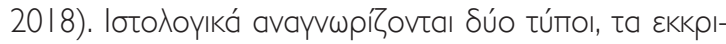

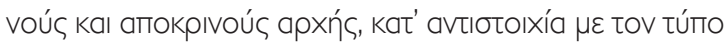

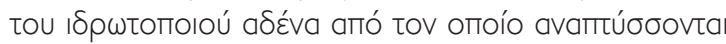
(Font 1996, de Viragh kal ouv. 1997). H عvtómı пn tou

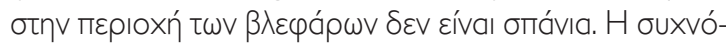

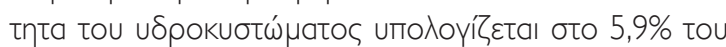

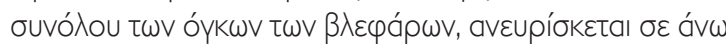

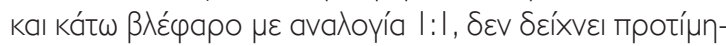

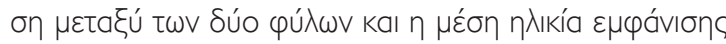

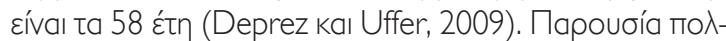

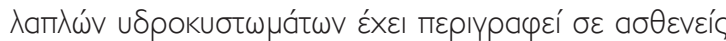

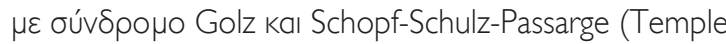
kal ouv. 1990, Hampton kaı ouv. 2005).

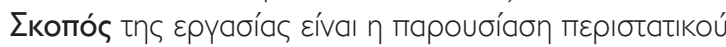

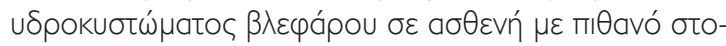

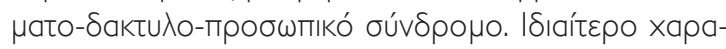

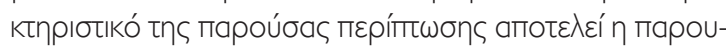

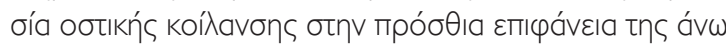

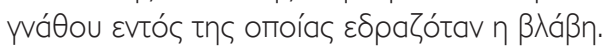

\section{ANАФOРА ПЕРІПТ $\Omega \Sigma \mathrm{H} \Sigma$}

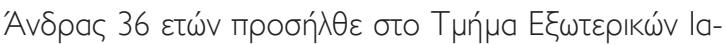

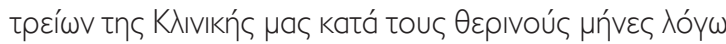

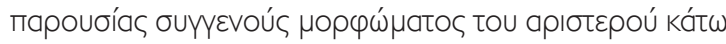

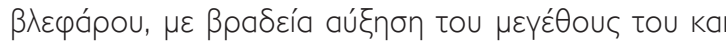

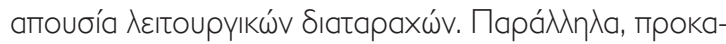

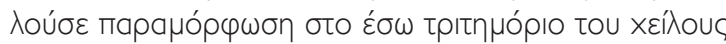

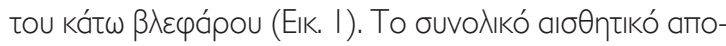

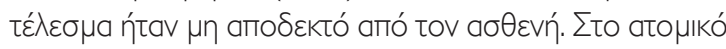

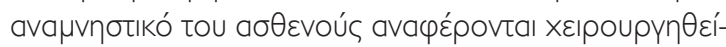

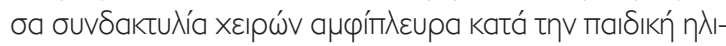

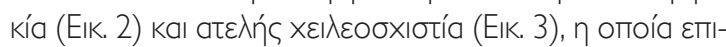

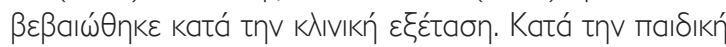

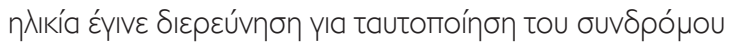
поU $\delta \varepsilon \vee$ апर́ $\delta \omega \sigma \varepsilon$.

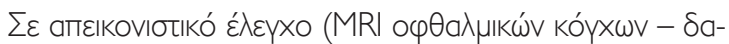

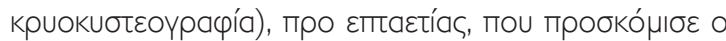

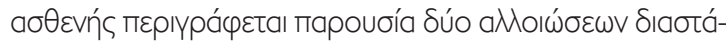

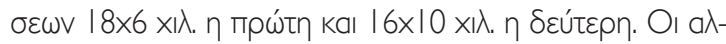

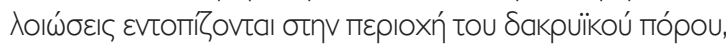

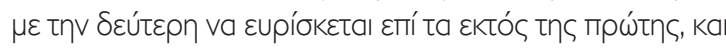

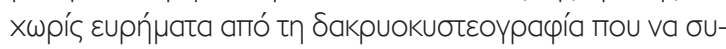

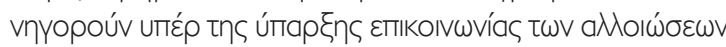

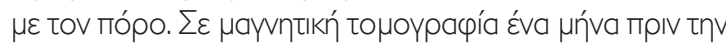
пр

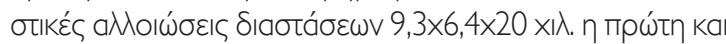

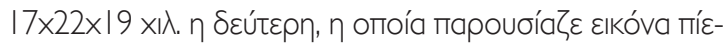

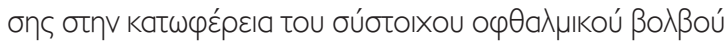

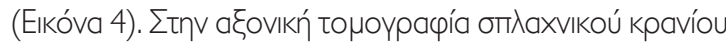

\section{INTRODUCTION}

Hidrocystoma is being classified as a benign adnexal cystic tumor of the skin, according to the latest classification of the World Health Organization, which originates from the sweat glands (Sangueza et al. 2018). Two types of the tumor are being recognized histologically, namely of eccrine and apocrine origin, in correspondence with the type of the sweat gland, from which they develop (Font 1996, de Viragh et al. 1997). The recognition of the tumor in the eyelid area is not rare. Hidrocystoma is estimated to occur in $5.9 \%$ of the total of eyelid tumors, located on the upper and lower eyelid in a $1: 1$ ratio, with no sex preference and mean patient age of 58 years (Deprez and Uffer 2009). Presence multiple hidrocystomas have been reported in patients with Golz and Schopf-Schulz-Passage syndromes (Temple et al. 1990, Hampton et al. 2005).

The purpose of this article is to present a case of eyelid hidrocystoma in a patient with possible orofacial digital syndrome (ODS). A special feature of the following case was the presentation of bone remodelling of the anterior surface of the maxilla, where the lesion was located.

\section{CASE REPORT}

A 36 year old man came to our outpatient clinic during the summer due to the presence of congenital formation of the lower left eyelid, with a slow increase in size and no functional disorders. At the same time, he presented
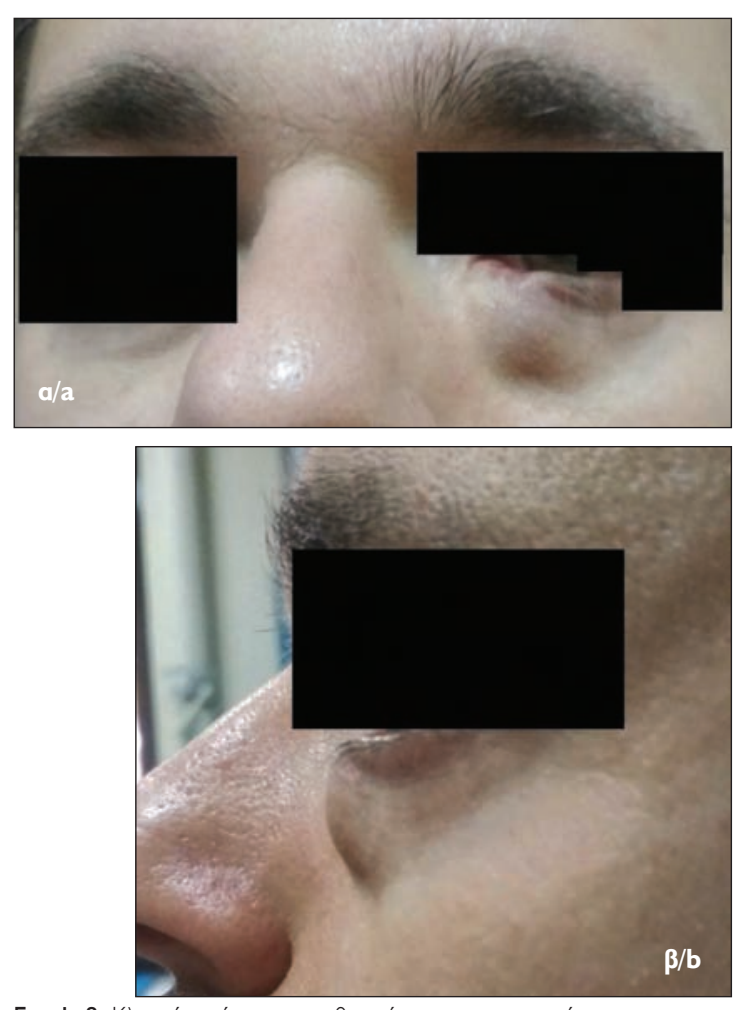

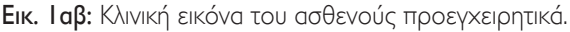

Fig. Iab: Preoperative clinical presentation of the patient. 


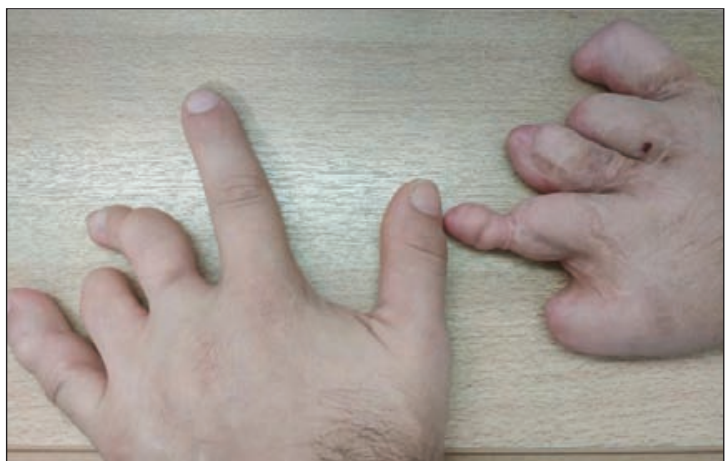

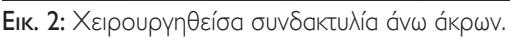

Fig. 2: Surgically treated syndactyly of the upper extremities.

поч ZПти́Ө

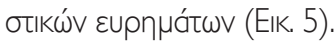

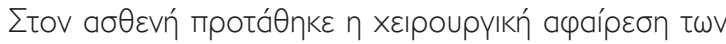
aגoı

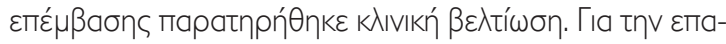

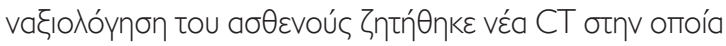
паратпри́Ө

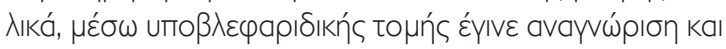

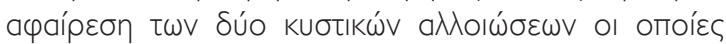

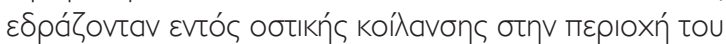

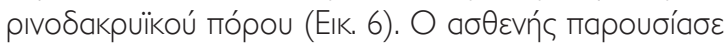

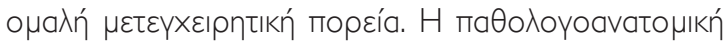

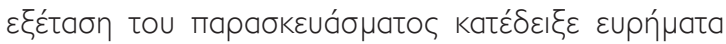

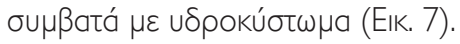

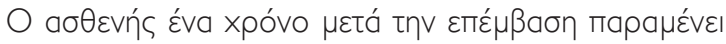

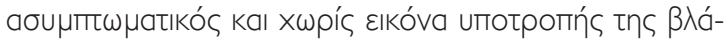
ßクৎ (EІK. 8).

\section{$\Sigma Y Z H T H \Sigma H$}

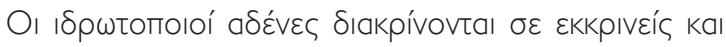

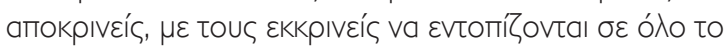

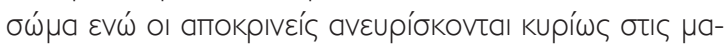

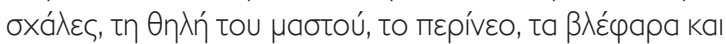

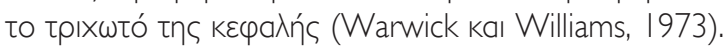

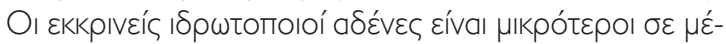

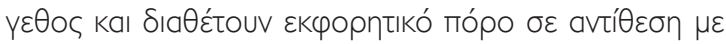

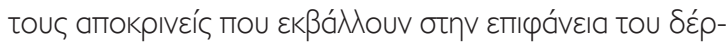

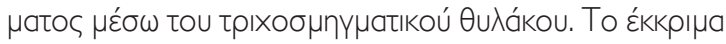

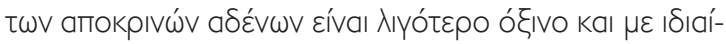

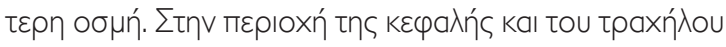

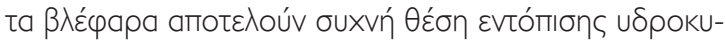

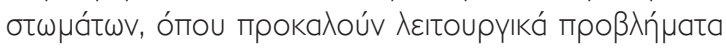

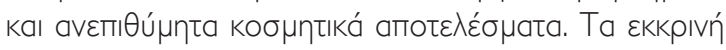

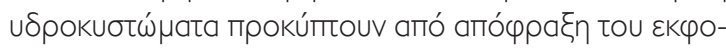

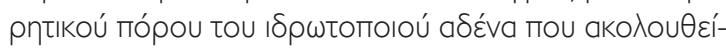

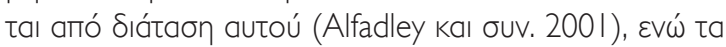

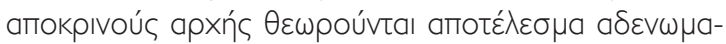

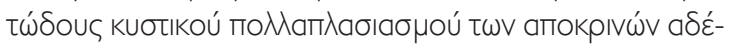
v $\omega v$ (Alagheband kaı Maida, 2004).

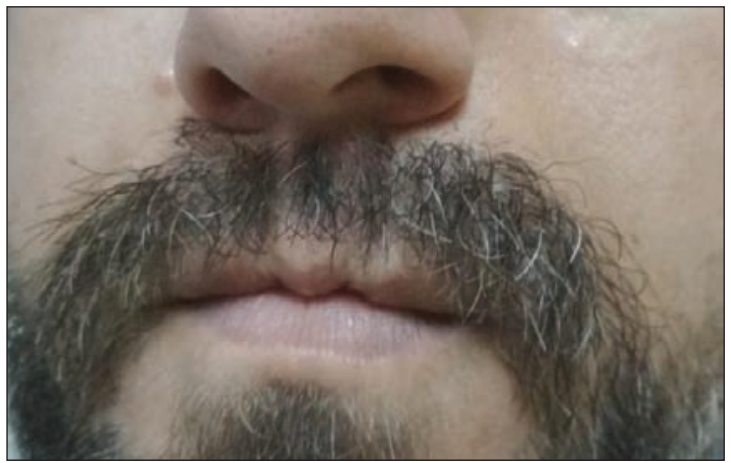

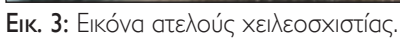

Fig. 3: Image of incomplete cleft lip.

with a deformation in the inner third of the eyelid's margin. (Fig. I). The total esthetic result was unacceptable from the patient's side. Patient's medical history includes syndactyly hand surgery during childhood and incomplete cleft lip (Fig. 3), which was confirmed during clinical examination. A clinical investigation was carried out for exploration of a possible diagnosis of the syndrome during childhood, that did not lead anywhere.

During an imaging assessment (orbital socket MRI-dacryocysteography), which was carried out 7 years ago (brought to us by the patient), two lesions were described, the first one measured $18 \times 6 \mathrm{~mm}$ and the second $16 \times 10 \mathrm{~mm}$. The lesions were located in the lacrimal duct region, with the second lesion located laterally to the first. There were not any findings from the dacryocysteography denoting presence of any communication of the lesions with the lacrimal duct. In an MRI carried out one month before his first clinical examination in our department, two lesions are detected, which were measured at $9.3 \times 6.4 \times 20$ $\mathrm{mm}$ and $17 \times 22 \times 19 \mathrm{~mm}$ respectively. The second lesion demonstrated pressure sings in the lower part of the ipsilateral eye bulb in the MRI (Fig. 4). In the viscerocranium $\mathrm{CT}$ that was asked from the patient we did not observe any change of the imaging findings (Fig. 5).

The surgical removal of these lesions was suggested to the patient. During the waiting period prior to surgery clinical improvement was observed. For the re-evaluation of the patient we asked for a new CT scan in which we observed decrease in the dimensions of the lesion. Eventually, we identified and removed the two cystic lesions by a subeyelid incision, which were both located inside a bony depression of the lacrimal duct region (Fig. 6). The patient's postoperative course was uncomplicated. The histopathological findings were consistent with hidrocystoma (Fig. 7). The patient remains asymptomatic and with no signs of regression of the lesion (Fig. 8).

\section{DISCUSSION}

The sweat glands are divided into eccrine and apocrine, 

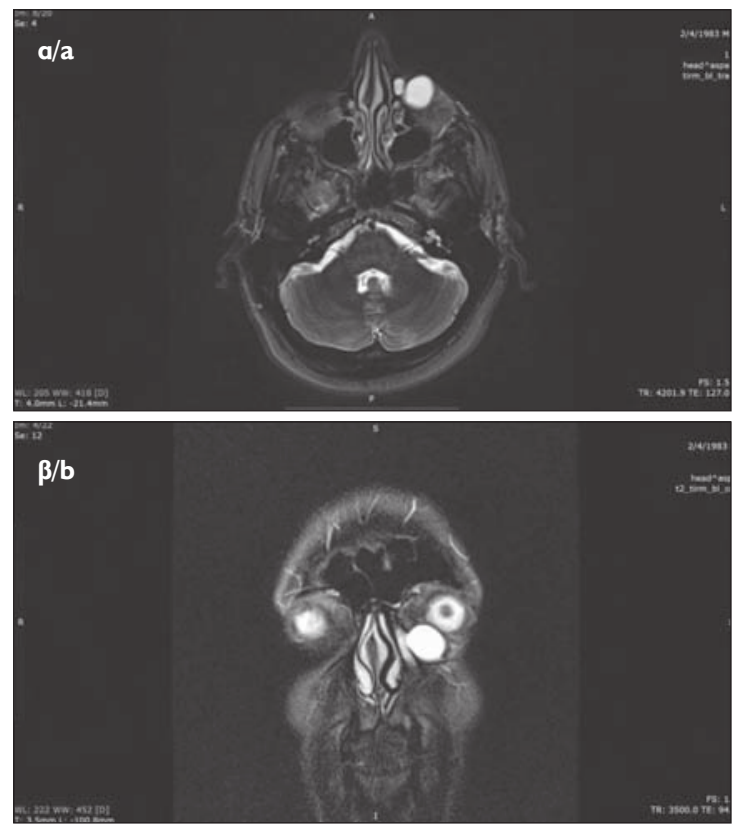

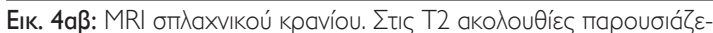

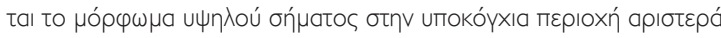

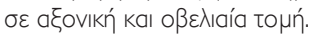

Fig. 4ab: MRI of visceral skull. In T2 sequences a high signaling formation is presented in the inferior orbital region on the left in axial and sagittal slice.

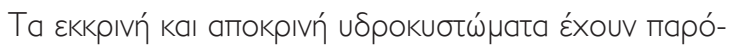

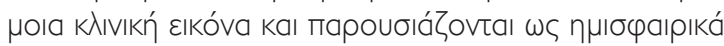

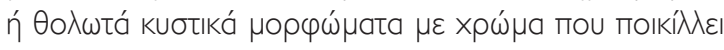

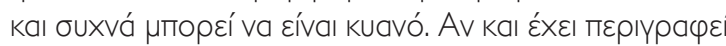

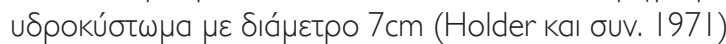

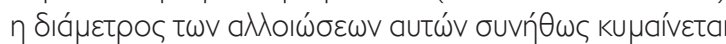

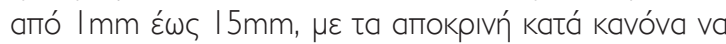

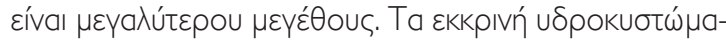

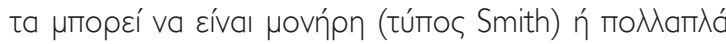

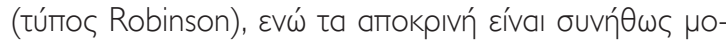

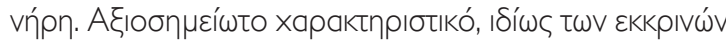

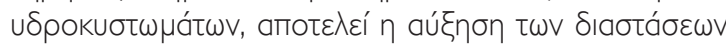

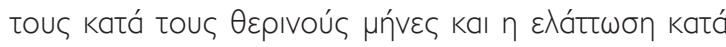

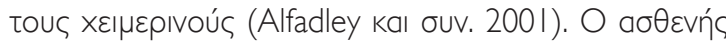

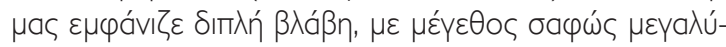

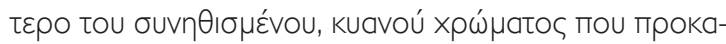

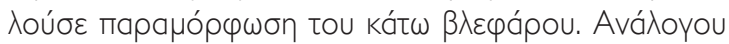

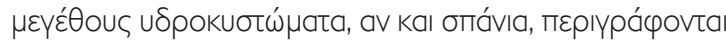

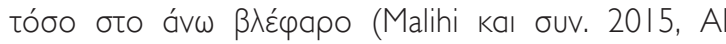

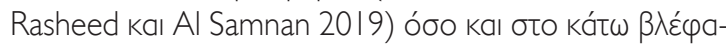

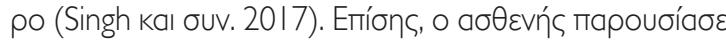

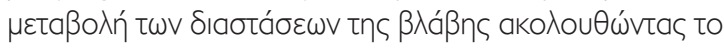

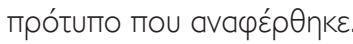

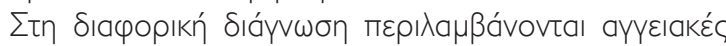

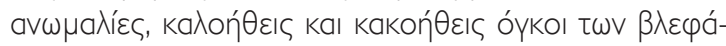

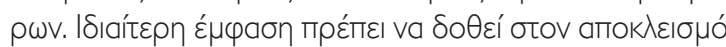

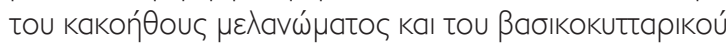

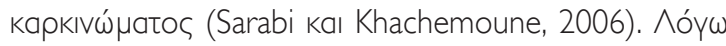

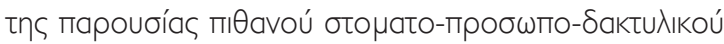
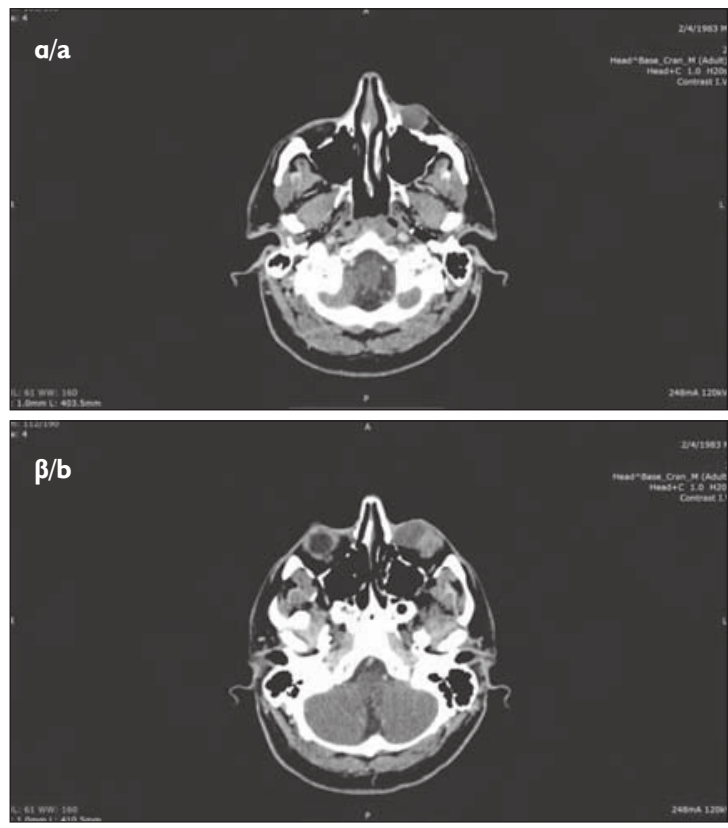

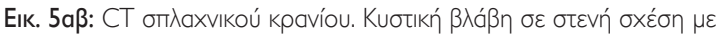

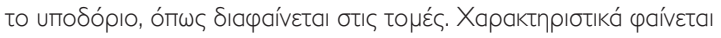

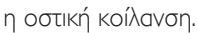

Fig. 5ab: CT of visceral skull. Cystic lesion in close relation to the subcutaneous layer, as appears in the slices. The characteristic bone cupping is obvious.

with the former being located all over the body and the latter mainly in the arm pits, the breast nipples, perineum, eyelids and the hair-bearing scalp (Warwick and Williams, 1973). The eccrine sweat glands are smaller in size and have an excretory duct, while the apocrine excrete on the surface of the skin through the smegmatic hair follicle. The excretion of the apocrine glands is less acidic and with a special smell. In the head and neck region hidrocystomas are usually detected in the eyelids, where they cause functional problems and undesired cosmetic results. Eccrine hidrocystomas originate from obstruction of the excretory duct of the sweat gland, followed by its distension (Alfadley et al. 200 I), while those of apocrine origin are considered the result of adenomatoid cystic proliferation of the apocrine glands (Alagheband and Maida, 2004).

Eccrine and apocrine hidrocystomas have a similar clinical presentation as hemispheric cystic formations with various colors, cyan being the most common. Even though a $7 \mathrm{~cm}$ diameter hidrocystoma has been reported (Holder et al. 197I), the usual diameter of these lesions usually ranges between I $\mathrm{mm}$ to $15 \mathrm{~mm}$, with apocrine hidrocystomas being usually larger. Eccrine hidrocystomas might be singular (Smith's type) or multiple (Robinson's type), while the apocrine ones are usually single. A distinct characteristic, especially of eccrine hidrocystomas, is their size increase during the summer months and their decrease in the winter months (Alfadley et al. 200 I). Our patient presented with a double lesion, with a clearly larger than usual size, of cyan color causing a deformation of the 


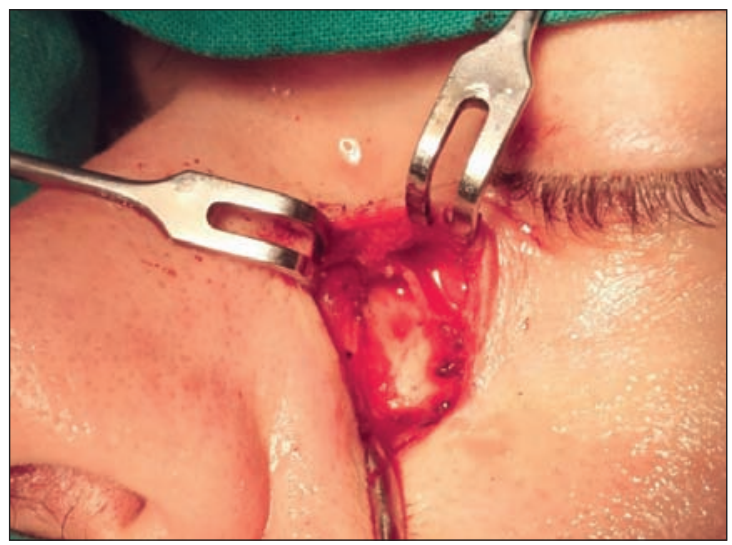

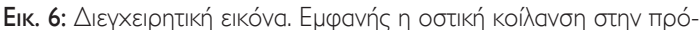

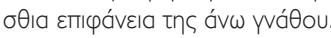

Fig. 6: Intraoperative image. The bone cupping in the front surface of the upper jaw is obvious.

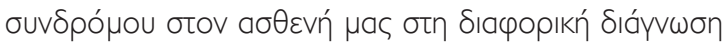

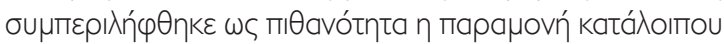

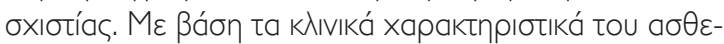

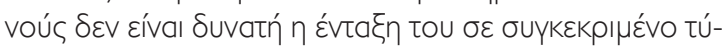

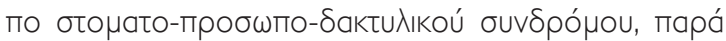

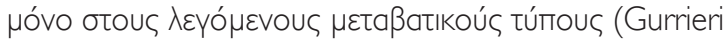
Kal ouv. 2007).

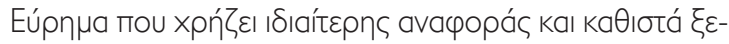

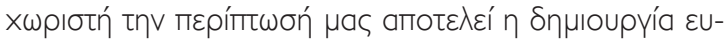

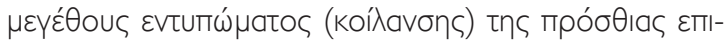

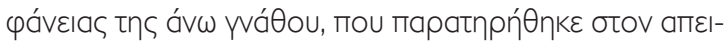

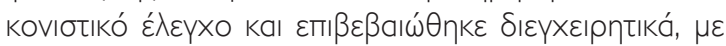

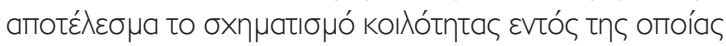

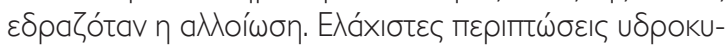

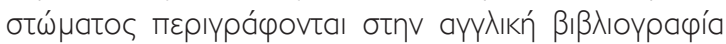

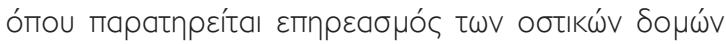

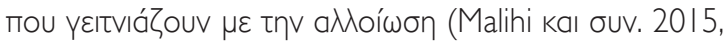
Al Rasheed kal Al Samnan 2019).

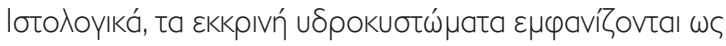

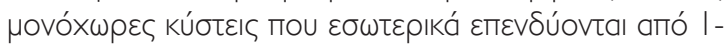
2 бтоß

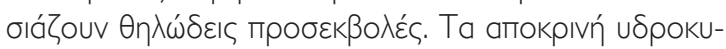

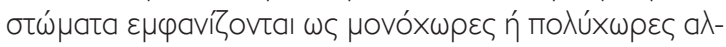

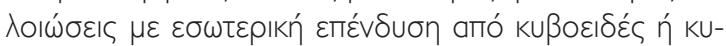

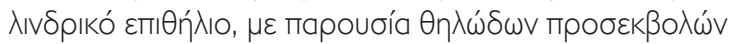

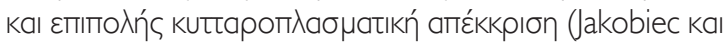

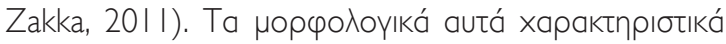

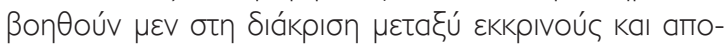

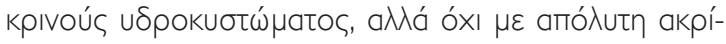

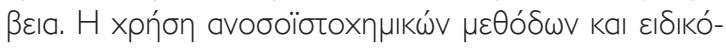

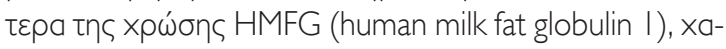

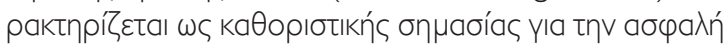

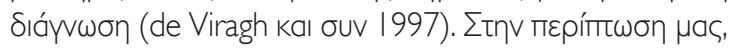

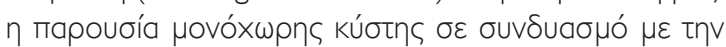

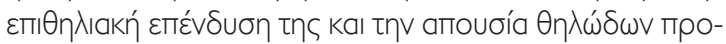

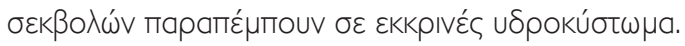

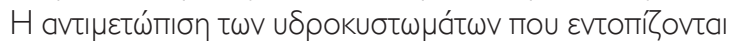
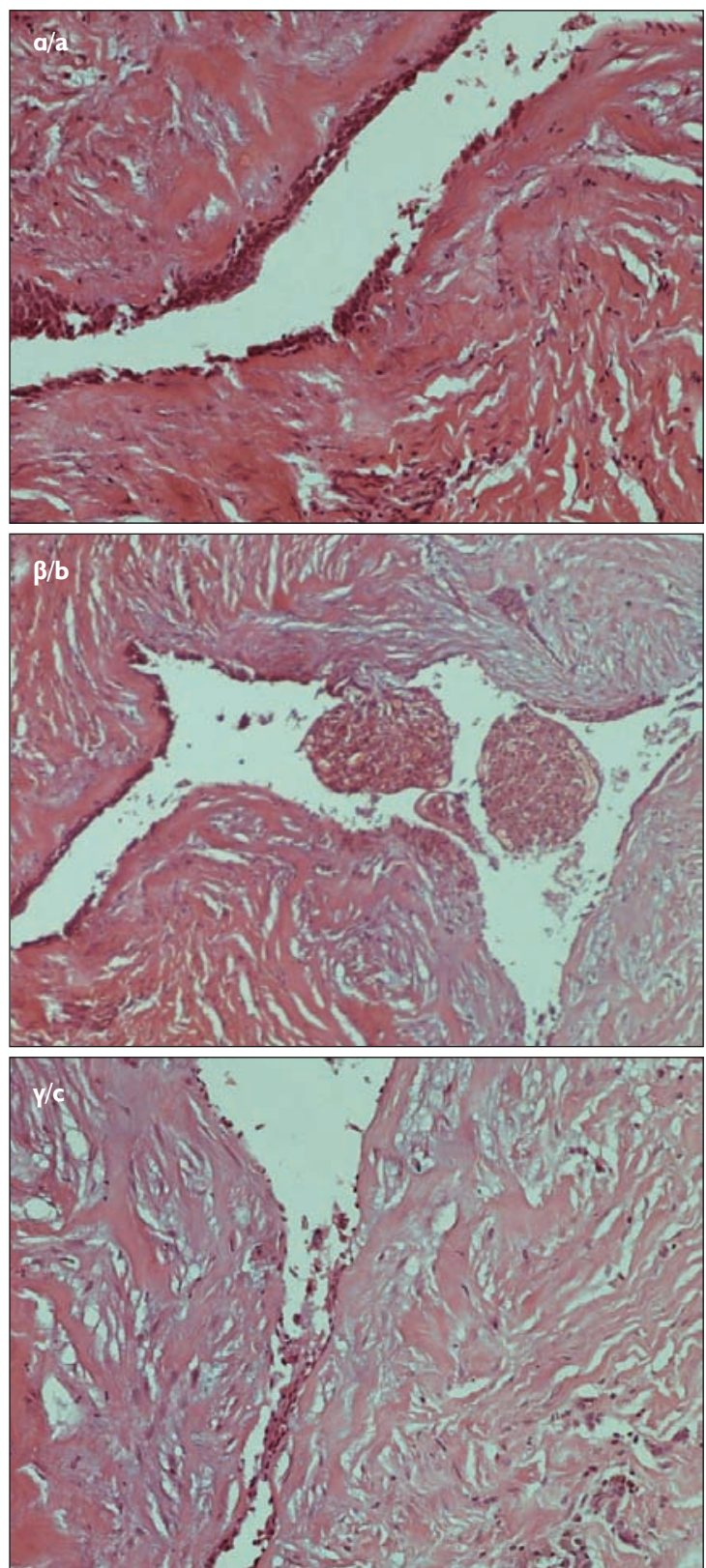

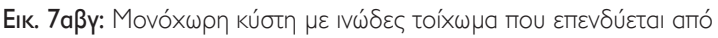

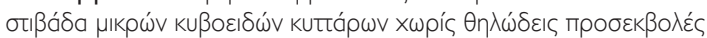

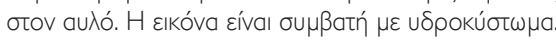

Fig. 7abc: Unilocular cyst with fibrous wall lined by a layer of small cuboidal cells without papillary projections into the lumen. The image is compatible with hidrocystoma.

lower eyelid. Hidrocystomas of similar size, even if they are rare, have been described in both the upper (Malihi et al. 2015, Al Rasheed and Al Samman 2019) and the lower eyelid (Singh et al. 20 17). Furthermore, the patient presented with a dimensional change of the lesion following the pattern mentioned earlier.

Differential diagnosis includes vascular abnormalities, benign and malignant tumors of the eyelids. Special emphasis is placed on the exclusion of malignant melanoma and 


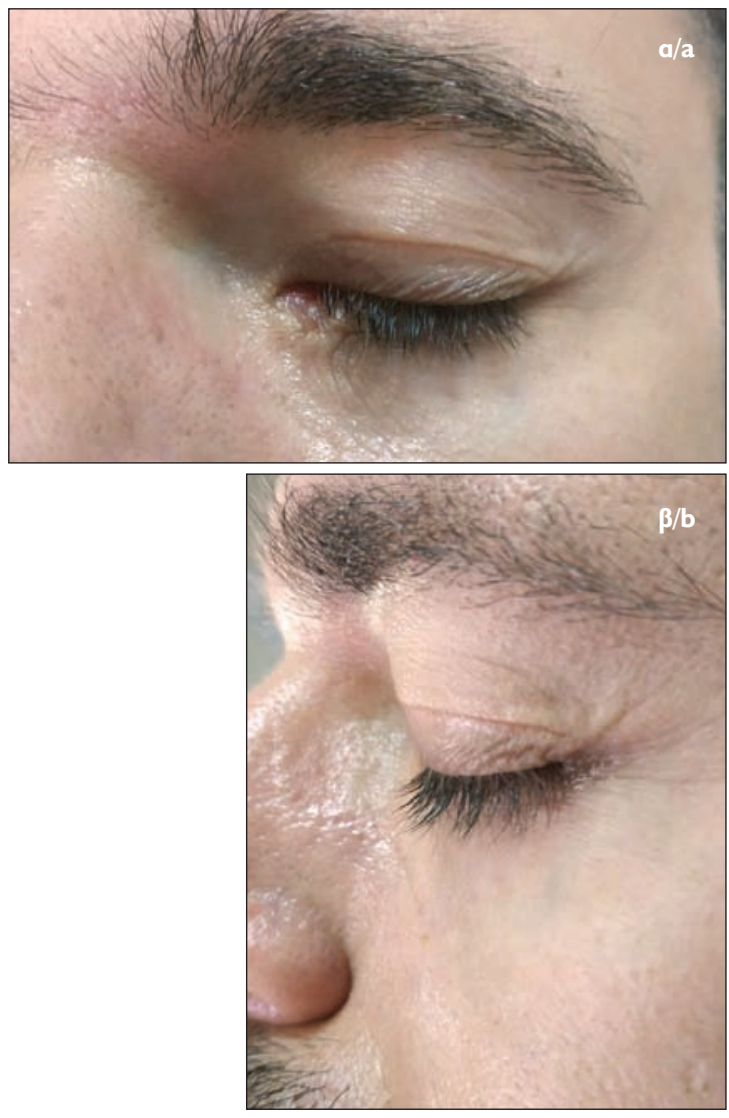

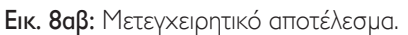

Fig. 8ab: Postoperative result.

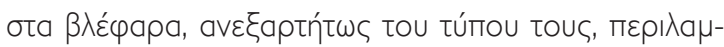

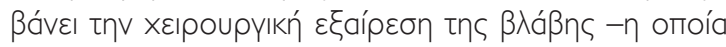

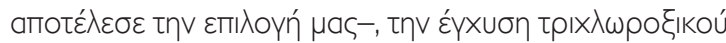

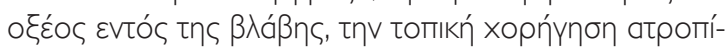

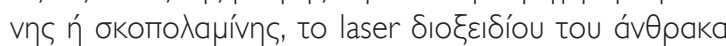

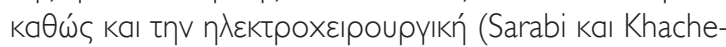
moune, 2006).

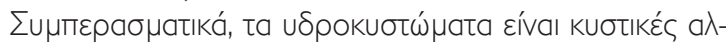

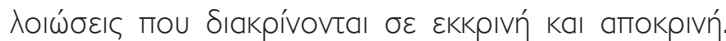

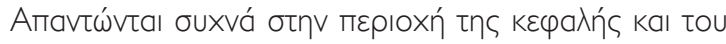

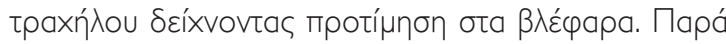

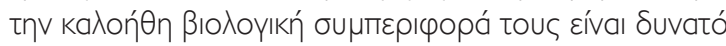

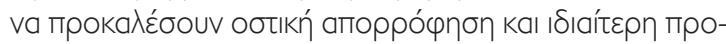

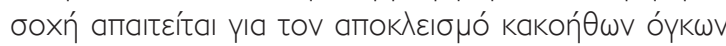

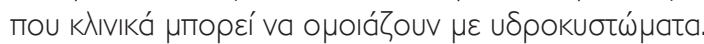

basal cell carcinoma (Sarabi and Klachemoune, 2006). Due to the presence of a possible orofacial digital syndrome we included in our patient's differential diagnosis a possible cleft lip remnant. According to the clinical characteristics of the patient it was impossible to classify him to a certain type of orofacial digital syndrome, only in the so called transitional types (Gurrieri et al. 2007).

A very special finding which makes our case distinct is the creation of a large bone impression (bone remodeling) in the anterior surface of the upper jaw, which was observed in the imaging control and confirmed during the surgery, resulting in the formation of a lesion-bearing cavity. Few cases of hidrocystoma have been described in the English literature where the adjacent bone structures to the lesion are affected (Malihi et al. 2015, Al Rasheed and AI Samnan 2019).

Histologically, eccrine hidrocystomas appear as unilocular cysts internally invested by 1-2 layers of low cuboidal cells, while papillary projections are absent. Apocrine hidrocystomas appear as unilocular or multilocular lesions internally invested by cuboidal or cylindrical epithelium, with papillary projections and superficial cystoplasmic excretion (Jakobiec and Zakka, 20 I I). These morphological characteristics are helpful in the distinction between eccrine and apocrine hidrocystoma, but not with absolute accuracy. The use of immunohistochemistry methods and especially HMFG tint (human milk fat globulin I), is characterized as of outmost importance for a safe diagnosis (de Viragh et al. 1997). In our case, the presence of a unilocular cyst in conjunction with its epithelial investment and the absence of papillary projections denote eccrine hidrocystoma.

The treatment of hidrocystomas located in the eyelids, regardless of their type, includes surgical removal of the lesion-which consisted of our treatment of choice in the present case-, infusion of trichloroacetic acid inside the lesion, local administration of atropine or scopolamine, $\mathrm{CO}_{2}$ laser as well as electrosurgery (Sarabi and Khachemoune, 2006).

In conclusion, hidrocystomas are cystic lesions divided in eccrine and apocrine. They are often located in the head and neck region with a preference in the eyelids. Despite their benign biological behavior it is possible to cause bone resorption and special attention must be given for the exclusion of malignant tumors that clinically resemble hidrocystomas. 


\section{BIBAIOГРAФIA/REFERENCES}

Al Rasheed R, Al Samnan M. Congenital giant orbital eccrine hidrocystoma. Am J Ophthalmol Case Rep. 2019 Dec; I6: 100570

Alagheband M., Maida M.F. Asymptomatic periorbital, bluish cystic papule. Cortl Forum. 2004 Jan; I7( I):36-4I

Alfadley A, Al Aboud K, Tulba A, Mazen M. Multiple eccrine hidrocystomas of the face. Int J Dermatol. 200 I;40:125-129

De Viragh PA, Szeimies RM, Eckert F. Apocrine cystadenoma, apocrine hidrocystoma, and eccrine hidrocystoma: three distinct tumors defined by expression of keratins and human milk fat globulin I. J CutanPathol 1997: 24: 249-255

Deprez M, Uffer S. Clinicopathological features of eyelid skin tumors. A retrospective study of 5504 cases and review of literature. Am J Dermatopathol 2009;3I (3):256 -262.

Font RL. Ophthalmic Pathology. An Atlas and Textbook. 3rd ed. Philadelphia: WB Saunders; 1996. Eyelids and lacrimal drainage system; pp. 2229-32.

Gurrieri F, Franco B, Toriello H, Neri G. Oral-facial-digital syndromes: review and diagnostic guidelines. Am J Med Genet A 2007 Dec 15; $143 \mathrm{~A}(24): 33$ | 4-23

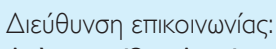

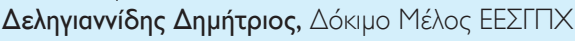

Г.N.Ө. Г. Папаviko $\lambda$ áou

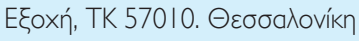

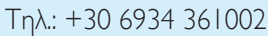

e-mail: deligiandim@gmail.com
Hampton PJ, Angus B, Carmichael AJ. A case of Schopf-Schulz-Passarge syndrome. ClinExpDermatol 2005;30(5): 528-530.

Holder WR, Smith JD, Mocega EE. Giant apocrine hidrocystoma. Arch Dermatol. 1971;104(5):522-3

JakobiecF, Zakka F. A reappraisal of eyelid eccrine and apocrine hidrocystomas: microanatomic and immunohistochemical studies of 40 lesions. Am J Ophthalmol.20 I I Feb; I 5 I (2):358-74.e2.

Mehrdad Malihi, Roger E. Turbin, Neena Mirani\& Paul D. Langer. Giant Orbital Hydrocystoma in Children: Case Series and Review of the Literature, Orbit20 I 5, 34:5,292-296

Sangueza OP, Cassarino DS, Glusac EJ, Kazakov DV, Requena L, Swanson PE, Vassalo C. WHO Classification of Skin Tumours. 4th ed. Chapter 3, p. I83. IARC, Lyon, 2018

Sarabi K, Khachemoune A.Hidrocystomas-a brief review. Med Gen Med 8(3):57, 2006

Singh M, Kaur M, Gautam N. Giant eccrine hidrocystoma of the eyelid. Indian J Dermatol Venereol Leprol 2017;83:267

Temple IK, MacDowall P, Baraitser M, Atherton DJ. Focal dermal hypoplasia (Goltz syndrome). J Med Genet 1990; 27(3): 180-187.

Warwick R, Williams PL .Gray's Anatomy, 35th ed. Longman Group Ltd: Edinburgh, 1973, pp | | 68-1 169.

\section{Address:}

Dimitrios Deligiannidis

"G. Papanikolaou" General Hospital of Thessaloniki

Exochi, 57010 Thessaloniki, Greece

Tel.: +306934361002

e-mail: deligiandim@gmail.com 



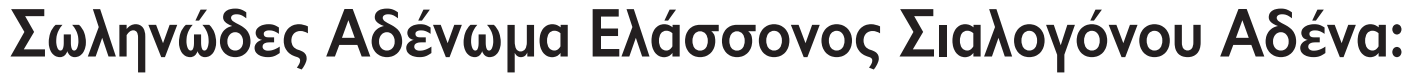

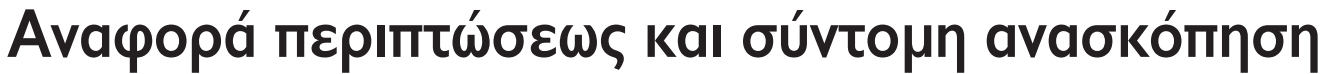

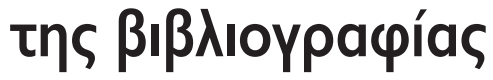

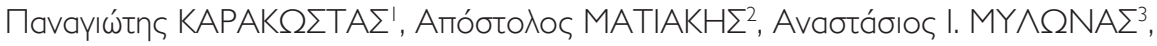

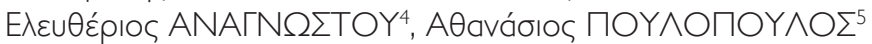

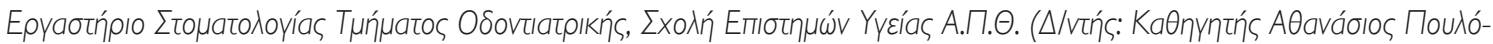

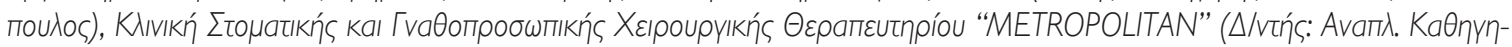

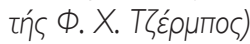

\section{Canalicular adenoma of minor salivary gland: Report of a case and a brief review of the literature}

\author{
Panagiotis KARAKOSTAS, Apostolos MATIAKIS, Anastassios I. MYLONAS, Eleftherios ANAGNOSTOU, \\ Athanasios POULOPOULOS
}

Department of Oral Medicine and Pathology, School of Dentistry, Aristotle University of Thessaloniki (Head: Professor Athanasios Poulopoulos), Department of Oral and Maxillofacial Surgery, "METROPOLITAN" Hospital (Head: Assoc. Professor F. Ch. Tzerbos)

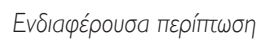

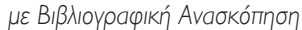
Case Report with Literature Review

${ }^{1}$ Odovtíatpos, Metantuxı-

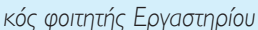

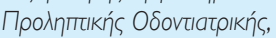

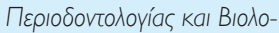

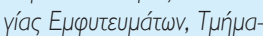

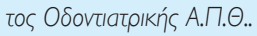

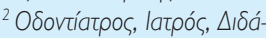

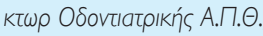

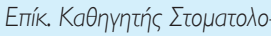

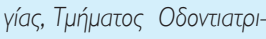
ки́ А.П.Ө.

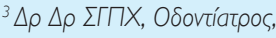

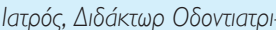
кń каı laтрıкńৎ E.K.П.A.

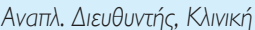

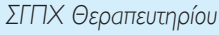
«METROPOLITAN». ${ }^{4}$ latpós ПaӨohoyoavatónos,

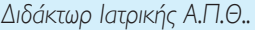
¿uvepyátns Epyađtnpíou ¿тонатоһoyías, Tuńnatos

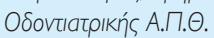

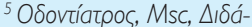

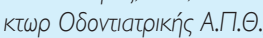

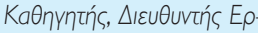

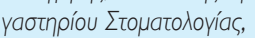

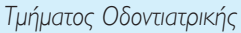
А.П.Ө.

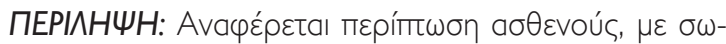

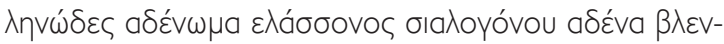

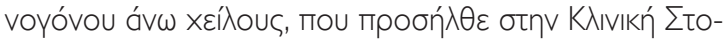

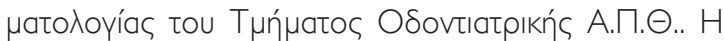

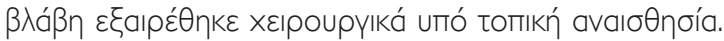

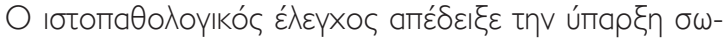

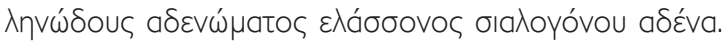

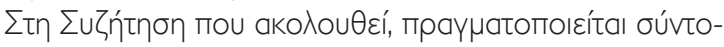

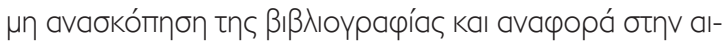

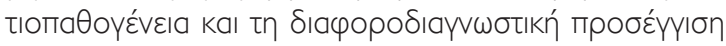

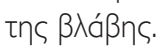

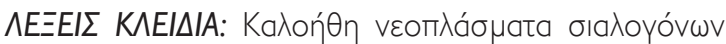

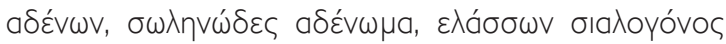

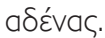

SUMMARY: We refer a case of a canalicular adenoma of minor salivary gland, located at the submucosal region of the upper lip. The patient's clinical state was thoroughly studied, along with the histopathological findings. Numerous histogenesis theories and the appropriate tumor treatment are mentioned, being always in accordance with the relative literature. Canalicular adenoma of minor salivary gland is a rare oral mucosa lesion. The differential diagnosis among many oral swellings is interesting. The surgical excision is the treatment of choice. The histological examination confirms the clinical diagnosis.

KEY WORDS: Benign salivary gland neoplasm, canalicular adenoma, minor salivary gland. 


\section{EI $\Sigma \mathrm{A} \Gamma \Omega \Gamma \mathrm{H}$}

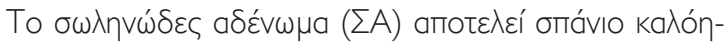

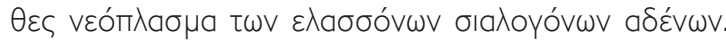

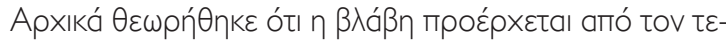

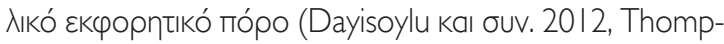

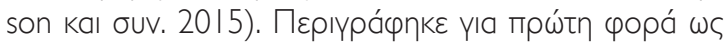

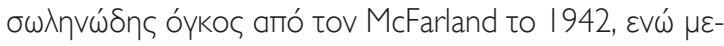

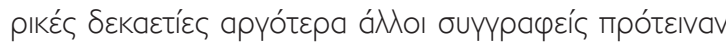

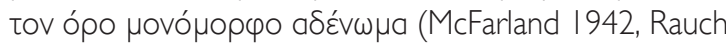

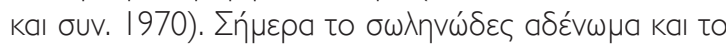

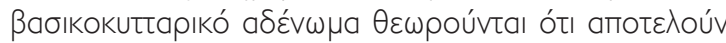

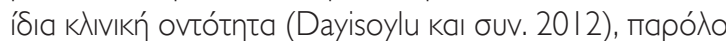

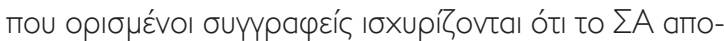

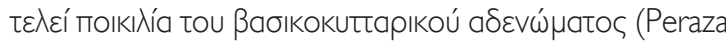

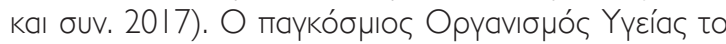

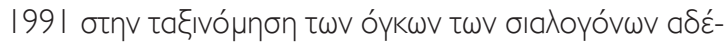

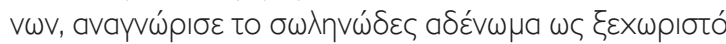
óyko (Dayisoylu kaı ouv. 20 I2, Samar kaı ouv. 20।4).

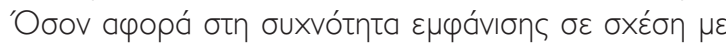

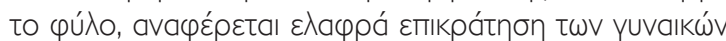

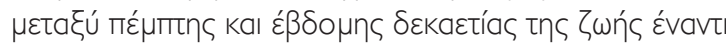

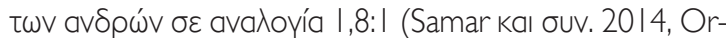

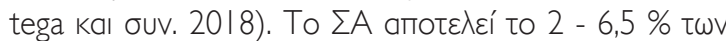

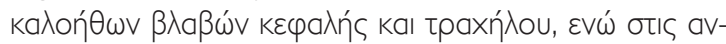

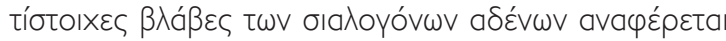
поообт́́ I-3 \% (Samar ka øuv. 20 14, Peraza ka øuv.

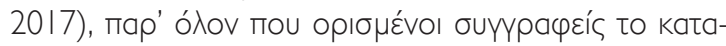

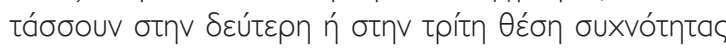

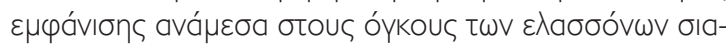

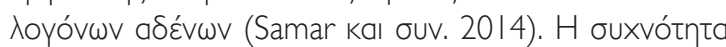

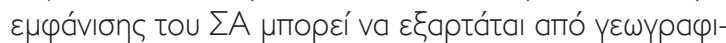

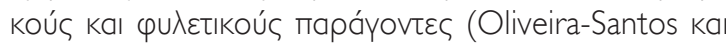

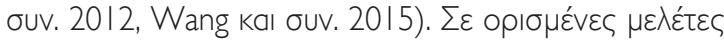

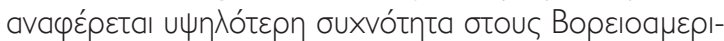

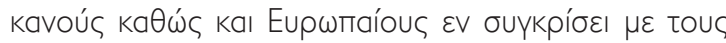
Aølátes (Wang kaı ouv. 2015).

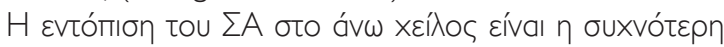

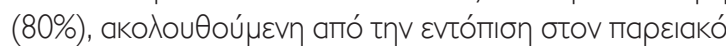

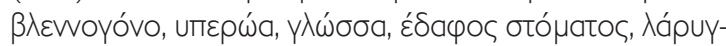

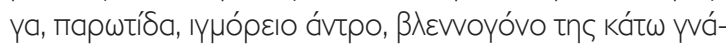

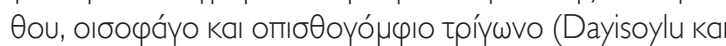
ouv. 2012, Samar kal ouv. 2014, Wang kal ouv. 2015, Ortega kal ouv. 2018).

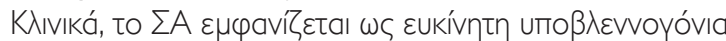

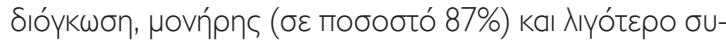

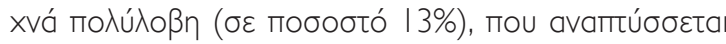

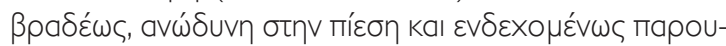

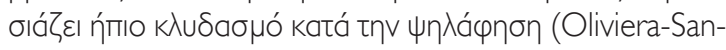
tos kaı ouv. 20 I2, Sivolella kaı ouv. 20 I4, Ortega kaı ouv.

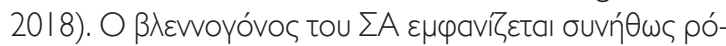

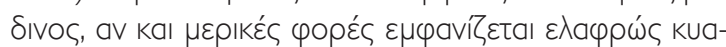

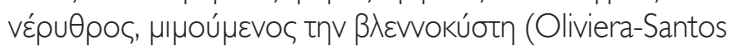
kal ouv. 2012, Samar kal ouv. 2014, Ortega kal ouv.

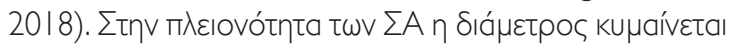
amó 0,5-2 cm (Rauch kaı ouv. 1970, Ortega kaı ouv.

\section{INTRODUCTION}

Canalicular adenoma (CA) constitutes a rare benign tumor which derives from minor salivary gland, although it was initially suggested that this lesion has a terminal duct origin (Dayisoylu et al. 20 I2, Thompson et al. 20 I5). McFarland was the first who described this lesion in 1942 as canalicular tumor, whereas some decades later other authors suggested the term monomorphic adenoma (McFarland 1942, Rauch et al. 1970). According to the latter term, CA and basal cell adenoma (BCA) thought to be the same entity (Dayisoylu et al. 2012). Few authors claimed that CA was merely a variant of BCA (Peraza et al. 2017). Nonetheless, the World Health Organization in 1991 (WHO) set a salivary gland tumors classification scheme, where CA was recognized as separated tumor (Dayisoylu et al. 20 I2, Samar et al. 20 I4). A female prevalence between the fifth and seventh decade with a female to male ratio $1.8: 1$ is reported (Samar et al. 2014, Ortega et al. 2018). CA represents 2$6.5 \%$ of all head and neck benign lesions, as well as I-3\% of all salivary tumors (Samar et al. 2014, Peraza et al. 2017). Commonly it is referred as the second or the third most frequent neoplasm of minor salivary glands (Samar et al. 20 I4). In addition, geographic and racial factors may influence the incidence of CA (Oliveira-Santos et al. 20I2, Wang et al. 20 I5). In some studies a higher frequency of CA is stated in North American and European populations compared to Asian populations (Wang et al. 20I5). The most frequent location of CA reported is upper lip (80\%), followed by buccal mucosa, palate, tongue, floor of mouth, larynx, parotid gland, maxillary sinus, mandible, oesophagus, retromolar area (Dayisoylu et al. 2012, Samar et al. 20 I4, Wang et al. 20 I5, Ortega et al. 2018). Clinically, the tumor appears to be a multifocal (13\%) or solitary (87\%), painless, mobile, slowly growing, firm or slightly fluctuant on palpation, submucosal swelling (Oliviera-Santos et al. 20 I2, Sivolella et al. 20 14, Ortega et al. 20 I8). The aforementioned mucosa appears usually

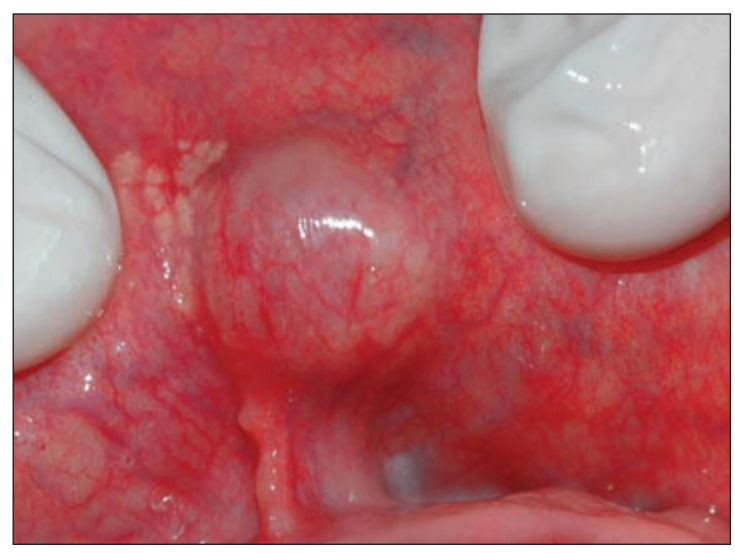

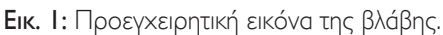

Fig. I: Preoperative appearance of the lesion. 


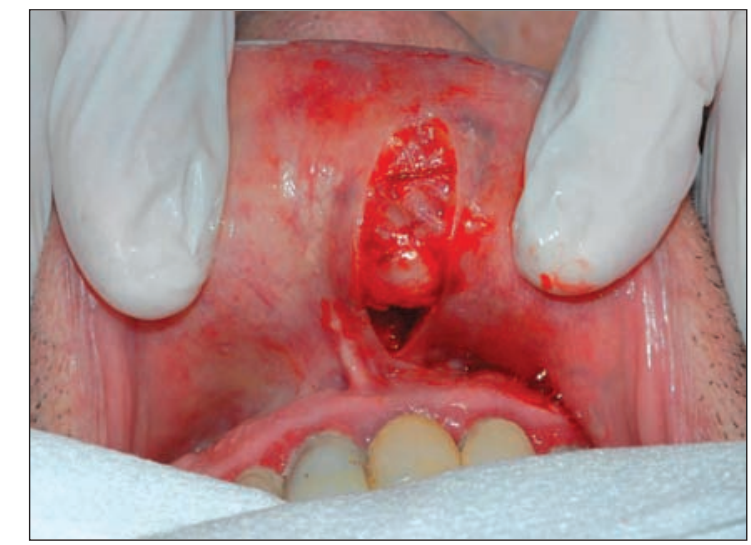

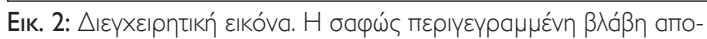

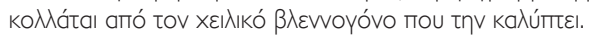

Fig. 2: Intraoperative appearance. The well defined lesion is surgically detached from the labial mucosa which covers it.

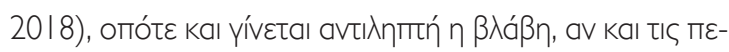

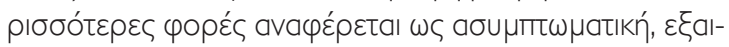

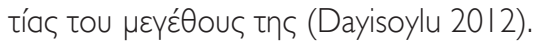

\section{ANAФOPA ПЕРІПТ $\Omega \Sigma \mathrm{H} \Sigma$}

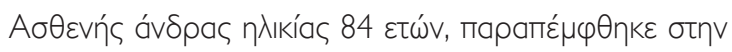

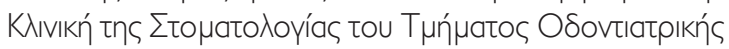

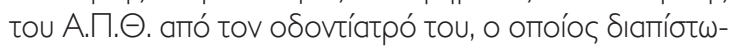

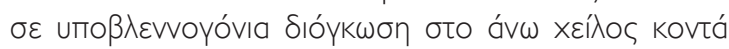

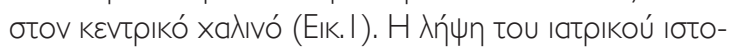

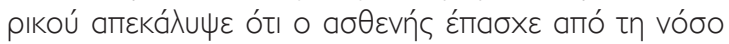

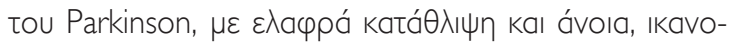

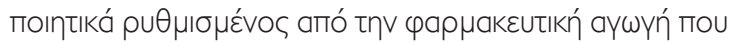

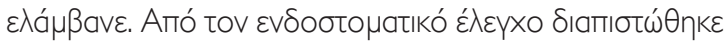

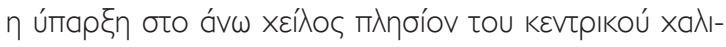

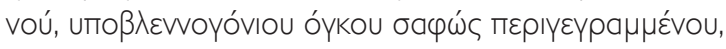

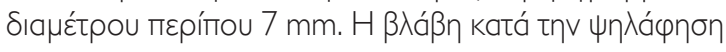

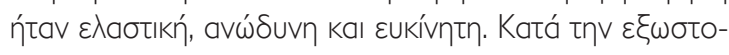

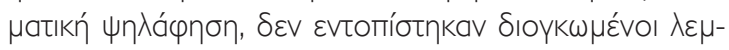

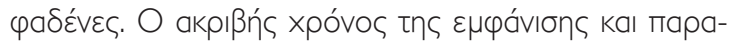

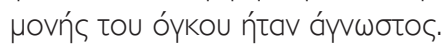

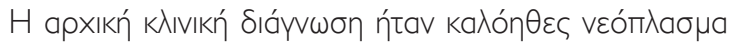

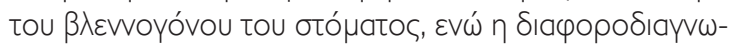

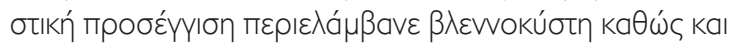

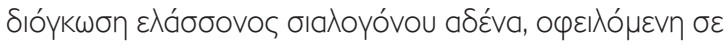

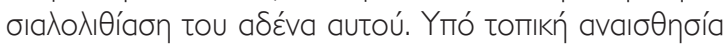

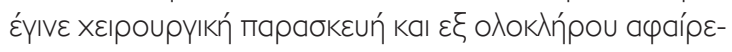

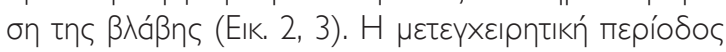

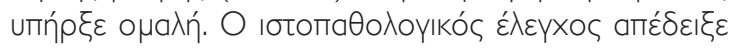

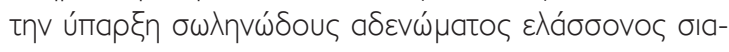

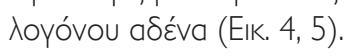

\section{$\Sigma \mathrm{YZHTH} \Sigma \mathrm{H}$}

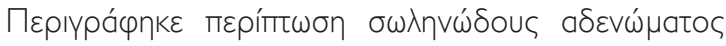

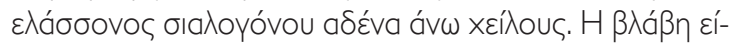

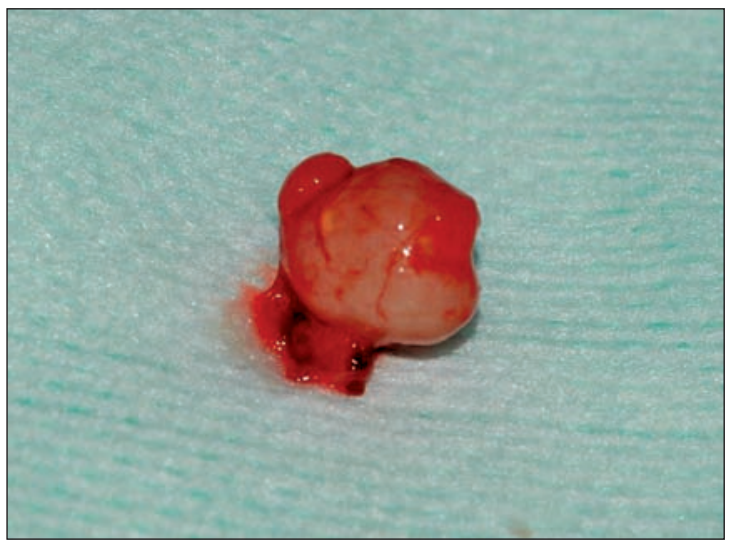

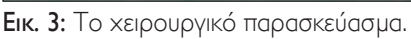

Fig. 3: The surgically excised lesion (surgical specimen).

pinkish, while in some cases its hue may also be redbluish mimicking a mucocele (Oliviera-Santos et al. 20 I2, Samar et al. 2014, Ortega et al. 2018). The majority of CA range between $0.5-2 \mathrm{~cm}$ in diameter (Rauch et al. 1970, Ortega et al. 2018). Most lesions are reported as asymptomatic until the size of the swelling becomes visible (Dayisoylu 2012).

\section{CASE REPORT}

An 84-years-old male patient was referred to the Department of Oral Medicine and Pathology, School of Dentistry, Aristotle University of Thessaloniki, by his dentist, who detected a submucosal swelling, located at the upper labial mucosa, close to the central frenum (Fig. I). His medical history included Parkinson's disease, depression and a moderate dementia, well-controlled by the appropriate medication. The intraoral examination revealed a well circumscribed submucosal tumor about 7 $\mathrm{mm}$ in diameter, covered by normal in color labial mucosa. The lesion was elastic, painless and movable in palpation. There were no swollen cervical lymph nodes. No clear information was given concerning the time when the lesion was primarily observed.

The initial clinical diagnosis included oral benign neoplasm, mucocele and minor salivary gland sialolithiasis. The tumor was surgically excised in toto under local anesthesia (Fig. 2, 3). The post-operative period was uneventful. Histological examination revealed a canalicular adenoma of a minor labial salivary gland (Fig. 4, 5).

\section{DISCUSSION}

A case of a CA is described. The tumor was an asymptomatic submucosal swelling in the upper labial mucosa. 


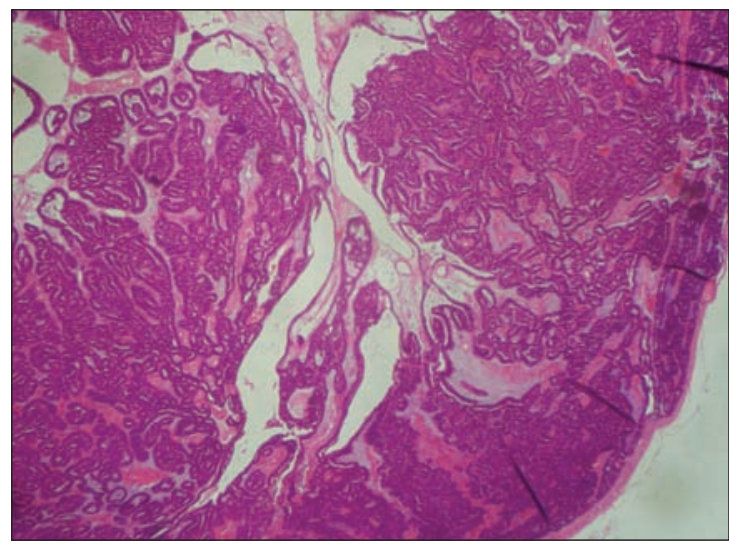

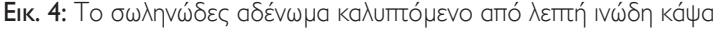
(A-E $\times 50)$

Fig. 4: Canalicular adenoma covered by thin fibrous capsule ( $\mathrm{H}-\mathrm{E}$ $\times 50)$.

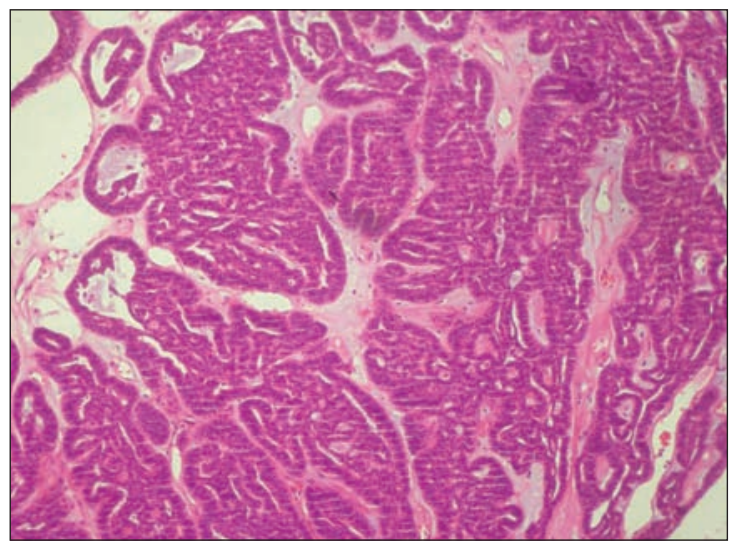

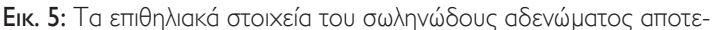

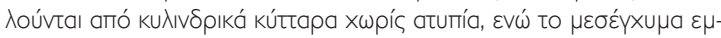

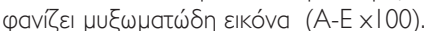

Fig. 5: The epithelial element of canalicular adenoma is composed of cylindrical cells without atypia, while mesenchymal element is myxoid $(H-E \times \mid 00)$.

Histological examination of the surgically excised swelling confirmed the diagnosis of CA.

The main histological appearance of CA comprises solid structures, trabeculae, tubules, and cribriform or membranous patterns (Samar et al. 2014). More specifically, CA appears to be often encapsulated and multifocal, and it is composed of isomorphic columns of columnar and cuboidal cells, which constitute strands or ducts in a loose highly vascular stroma with small cystic spaces (Dayisoylu et al. 2012, Peraza et al. 2017, Ortega et al. 20।8). Moreover, the nuclei are monomorphic with scattered, stippled chromatin (Peraza et al. 2017). Mitoses are infrequent as well as necrosis (Peraza et al. 2017). A study detected intraluminal squamous balls in $61 \%$ of their cases and microliths in 50\% (Thompson et al. 20 I5). Immunohistochemical markers have also been used for diagnosis of a CA. The most useful tools include positivity for p 16, CDI5, cytokeratin AEI/AE3 and S- 100 protein (Oliviera-Santos et al. 20 I2, Ortega et al. 20 I8), as well as negativity for vimentin, A-SMA, CK5/6 and p63 (Dayisoylu et al. 2012, Thompson et al. 2017, Ortega et al. 2018). However, the necessity of this examination remains questionable (Peraza et al. 2017).

In some cases, CA appears to be multifocal and either partially encapsulated or even unencapsulated, which may lead in a misdiagnosis (Oliviera-Santos et al. 20 I2). Extra caution is needed in order to distinguish CA from malignant tumors. Differential diagnosis includes polymorphous low grade adenocarcinoma, adenoid cystic carcinoma, mucoepidermoid carcinoma. Among benign swellings sialolithiasis with secondary sialadenitis, vascular anomalies, lipomas, mucocele are referred (Sivolella et al. 2014, Wang et al. 20।5, Bhagde et al. 2016).

The treatment of choice includes the thorough surgical excision of the lesion (Dayisoylu et al. 2012). As regards

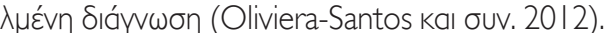

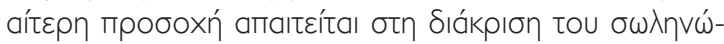




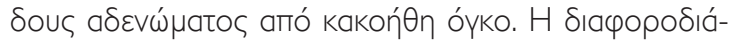

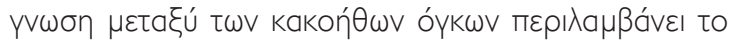

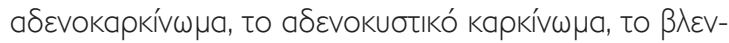

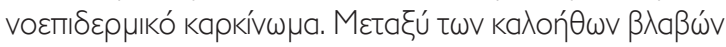

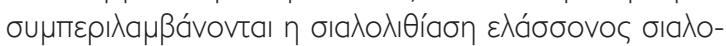

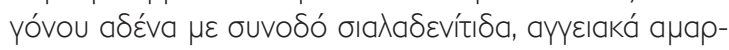

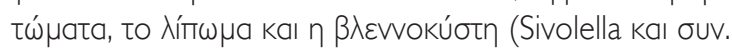
20।4, Wang kal ouv. 20।5, Bhagde kaı ouv. 2016).

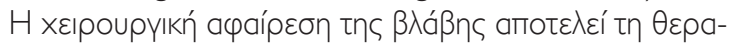

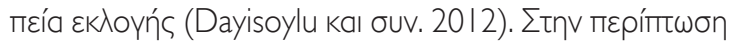

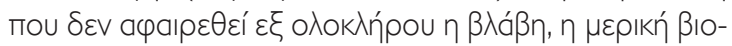

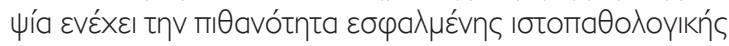

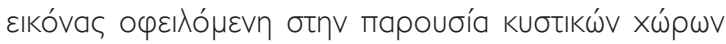
(Sivolella kal ouv. 2014). H пıӨavótnta uпотропńs aпó

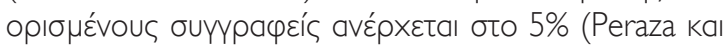
ouv. 2017).

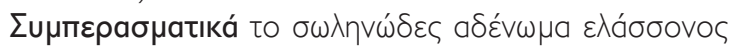

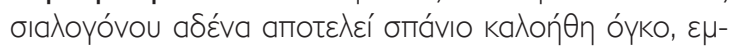

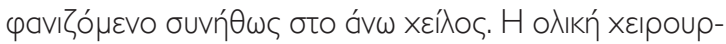
үIкń а

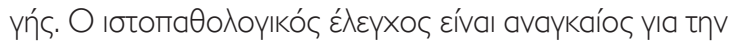

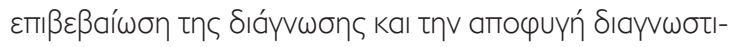

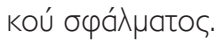

\section{BIBAIOГPAФIA/REFERENCES}

Bhagde PA, Barpande SR, Bhavthankar JD, Humbe JG: Basal cell adenoma of maxillary sinus mimicking ameloblastoma. J Oral Maxillofac Pathol 20: 142-46, 2016

Dayisoylu EH, Pampu AA, Mungan S, Taskesen F: Intra-mandibular canalicular adenoma: report of a rare case. J Pak Med Assoc 62: 1239-41, 2012

McFarland J: The histopathologic prognosis of salivary gland mixed tumors. Am J Med Sci 203: 502-19, 1942

Oliveira-Santos C, Freitas-Faria P, Damante JH, Consolaro A: Asymptomatic nodules of the upper lip: report of a canalicular adenoma with immunoprofile presentation. Gerodontology 29(2): el I2I24,2012

Ortega RM, Bufalino A, Almeida LY, Navarro CM, Travassos DC, Ferrisse TM et al: Synchronous Polymorphous Adenocarcinoma and Canalicular Adenoma on the Upper Lip: An Unusual Presentation and Immunohistochemical Analysis. Head Neck Pathol I2 (I): I4549, 2018

Peraza AJ, Wright J, Gómez R: Canalicular adenoma: A systematic review. J Craniomaxillofac Surg 45: 1754-58, 2017

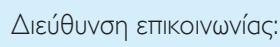

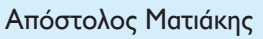

Тбıнıки́ 93,

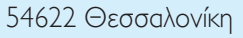

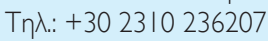

e-mail: amatiakis@dent.auth.gr incisional biopsy, it should not be indicated due to the possibility of histological artefacts and the low risk of fragmented specimens owing to the cystic or multifocal structure of CA (Sivolella et al. 20I4). CA shows a recurrence rate of $5 \%$ of all surgically excised lesions (Peraza et al. 2017).

In conclusion CA is a rare minor salivary gland benign tumor, usually growing on the upper lip. The thorough surgical excision of the tumor constitutes the treatment of choice. The histological examination confirms the diagnosis and it should be conducted carefully, in order to avoid a misdiagnosis.

Rauch S, Seifert G, Gorlin RJ: Diseases of the salivary glands: tumors. In: Gorlin RJ, Goldman HM. Thoma's Oral Pathology, 6th ed. St. Louis: CV Mosby Company 1970, pp. 997- 1003

Samar ME, Avila RE, Fonseca IB, Anderson W, Fonseca GM, Cantín M.: Multifocal canalicular adenoma of the minor labial salivary glands. Int J Clin Exp Pathol 7: 8205-10, 2014

Sivolella S, Valente M, De Biagi M, Mazzoleni S, Stellini E: Canalicular adenoma immunoprofile: a case report. Gerodontology 31: 32024, 2014

Thompson LD, Bauer JL, Chiosea S, McHugh JB, Seethala RR, Miettinen $M$ et al: Canalicular adenoma: a clinicopathologic and immunohistochemical analysis of 67 cases with a review of the literature. Head Neck Pathol 9:181-95, 2015

Tyralik D, Dzierwa-Gawron A, Ryś ]: Canalicular adenoma of the upper lip. Metachronous (multifocal) canalicular adenoma of the upper lip: a case report of an unusual finding. Pol J Pathol 64: 7I 74, 2013

Wang XD, Meng LJ, Hou TT, Zheng C, Huang SH: Frequency and distribution pattern of minor salivary gland tumors in a northeastern Chinese population: a retrospective study of 485 patients. J Oral Maxillofac Surg 73: 81-91, 2015

\section{Address:}

Apostolos Matiakis

93, Tsimiski Str.,

54622 Thessaloniki, Greece

Tel.: +302310 236207

e-mail: amatiakis@dent.auth.gr 



\title{
A rare case report of metastatic breast carcinoma in the Oral mucosa and literature review
}

\author{
Dobromira NIKOLOVA', Spyros PAPACHARALAMBOUS², Efrosini IACOVOU ${ }^{3}$, \\ Yiola MARCOU ${ }^{4}$, Nicos KATODRITIS ${ }^{5}$ \\ Private Oral and Maxillofacial Clinic Nicosia, Cyprus (Head: Dr Spyros Papacharalambous)

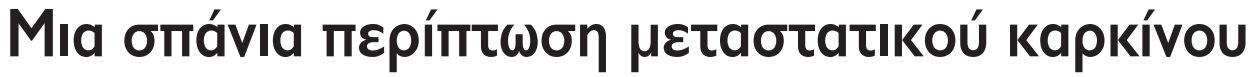

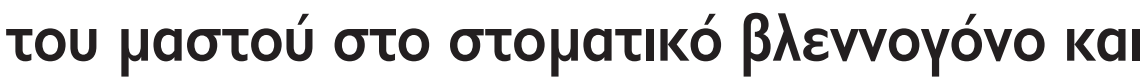

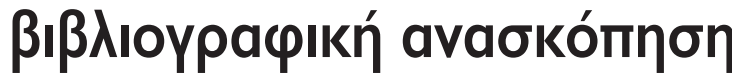

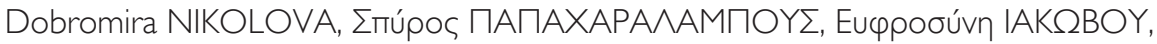

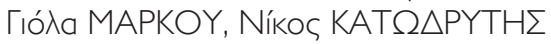

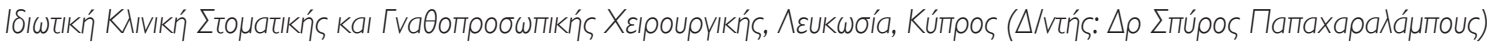

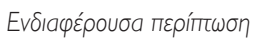

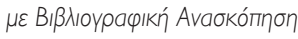
Case Report with Literature Review
${ }^{1} \mathrm{MD}$, Faculty of Dentistry, Ludwig-Maximilians-University, Munich, Germany ${ }^{2} \mathrm{MD}$ DDS, PhD, University of Nicosia Medical School, Nicosia, Cyprus ${ }^{3} \mathrm{MD}$, Consultant Histopathologist, ECCLabs, Nicosia, Cyprus ${ }^{4} \mathrm{MRCP}, \mathrm{FRCR}$, Consultant Medical Oncologist, Breast Unit, Bank of Cyprus Oncology Centre, Nicosia, Cyprus ${ }^{5} \mathrm{MD}$, Consultant in Radiation Oncology, Dept. of Radiation Oncology, Bank of Cyprus Oncology Centre, Nicosia, Cyprus
SUMMARY: Metastatic lesions in the oral cavity are rare, representing $1-3 \%$ of all malignant neoplasia in this region. Within this rate, there is a distribution in the literature among affected tissue, gender, and the origin of the metastases. The minority of the presented cases are describing metastatic lesions of breast cancer located in the oral cavity soft tissues in female patients.

Thus, we are presenting a case of a 47-year-old female patient who has reached the final stage of breast cancer with systematically spread metastatic disease, including lesions in the oral soft tissues. The exophytic growth of these tumors was causing difficulties in essential oral functions, such as mastication and articulation. For this reason, a palliative surgical excision of the metastases was performed, resulting in a significant improvement of the patient's quality of life during her final palliative care treatment.

Metastatic lesions in the oral cavity are a rarity and can appear within an already known systematic disease. Furthermore, during the final stage of breast cancer, it is highly uncommon for lesions to spread in the oral mucosa; however, the latter should be considered as a possible metastatic location during clinical examination and tumor staging.

KEY WORDS: metastatic breast cancer, oral metastases, oral mucosa, jawbones, palliative care

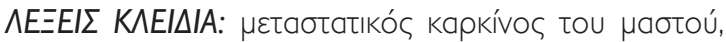

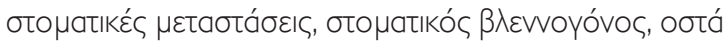

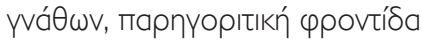

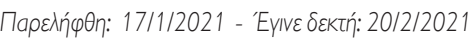

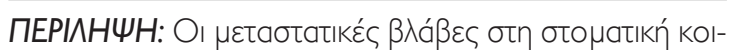

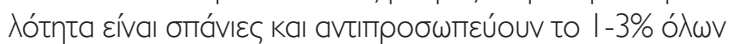

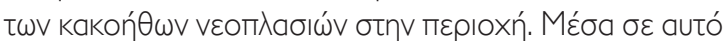

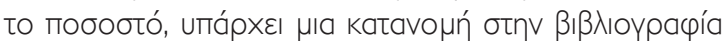

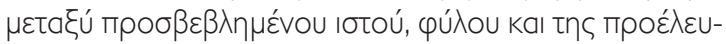

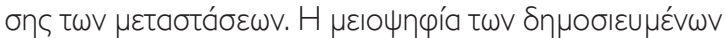

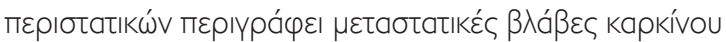

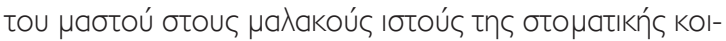

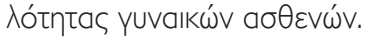

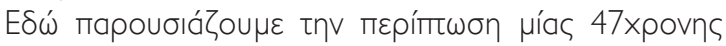

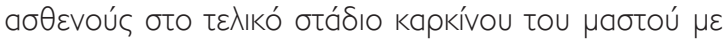

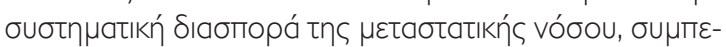

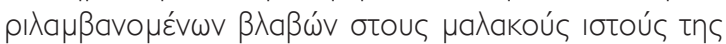

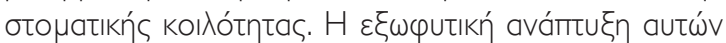

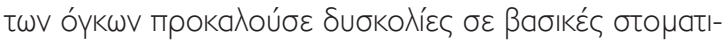

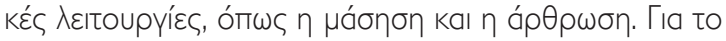

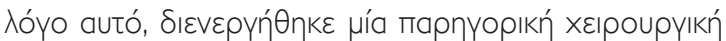

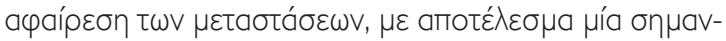

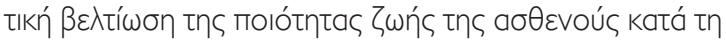

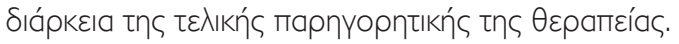

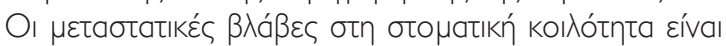

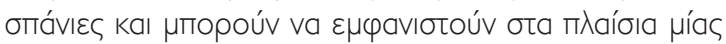

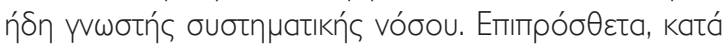

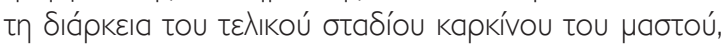

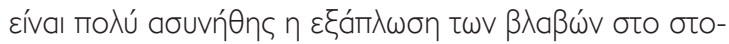

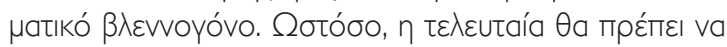

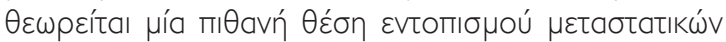

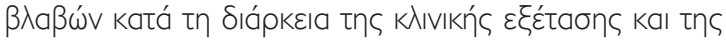
бабіопоínøns tou óykou.

Paper received: 17/1/2021 - Accepted: 20/2/2021 


\section{INTRODUCTION}

Metastatic lesions of the oral cavity are a rarity with I$3 \%$ of all neoplasia in this area. Metastases may occur in the jawbones, in the oral soft tissues or both osseous and soft tissues. The jawbones, particularly the mandible, are affected twice as often as the oral soft tissues. Among the soft tissue lesions, the attached gingiva proved to be the most affected site. Across genders, the soft tissue metastases are distributed in the ratio of $2: 1$ between male and female patients, respectively. In most cases, the origin of metastatic lesions in the oral cavity stems from lung, breast, or kidney cancer (Hirshberg et al. 2008, Kumar and Manjunatha 2013).

Literature reviews report that breast cancer oral metastases in female patients occur most commonly in the jawbones and their incidence in the soft tissues is five times less likely to occur (Hirshberg et al. 2008). Here, we present the case of a female patient suffering from breast cancer at the final stage, with local spreading and metastases to the lungs and pleura, as well as cutaneous metastases of the scalp and metastatic lesions of the oral mucosa. The patient underwent surgical excision of the oral lesions as part of her palliative therapy. This intervention significantly improved the patient's quality of life, allowing her to masticate and articulate properly during end-of-life care.

\section{PRESENTATION OF THE CASE}

In August 2017, a 44-year-old female patient was presented at the Oncology Centre in Nicosia, with a large aggressive triple-negative carcinoma of the left mammary gland (meaning cancer cells did not exhibit, estrogen, progesterone receptors staining and also were negative for HER2-protein staining). As per the guidelines the patient was submitted to neoadjuvant chemotherapy with antracyclines, a weekly regime of Taxol and carboplatin, followed by mastectomy and radiotherapy. During the mastectomy, she was found to have a $2 \mathrm{~cm}$ residual tumor. Axillary lymph nodes were negative. Radiotherapy to the chest wall as well as eight more cycles of capecitabine oral chemotherapy (as per the protocol for residual triple negative disease post neoadjuvant chemotherapy) were undertaken. In February 2019 lung metastatic disease was detected, therefore palliative chemotherapy was initiated.

In February 2019, lung metastatic disease was detected, therefore palliative chemotherapy was initiated. Despite the many lines of chemotherapy, the patient had further progression with multiple cutaneous nodules in the scalp and pleural effusion. Furthermore, she developed large exophytic lesions in the oral cavity that affected her ability to masticate and articulate, consequently impairing her life quality. Initially, radiotherapy to the oral cavity was suggested as a treatment option. However, due to the

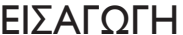

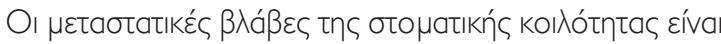

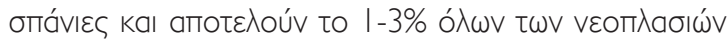

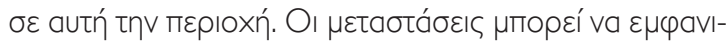

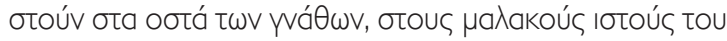

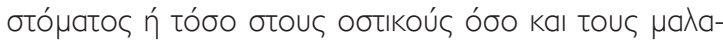

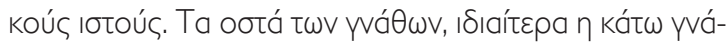

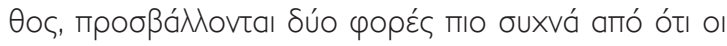

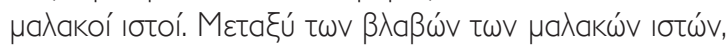

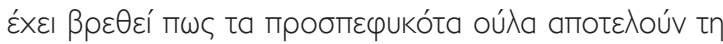

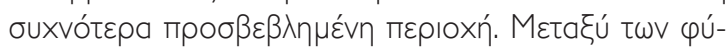

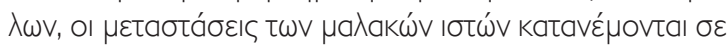

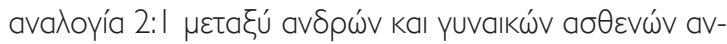

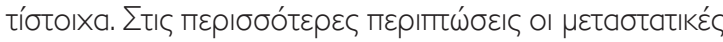

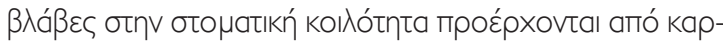

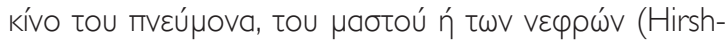
berg kaı ouv. 2008, Kumar kaı Manjunatha 20 I3).

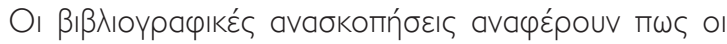

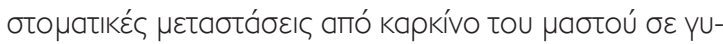

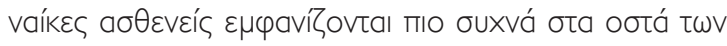

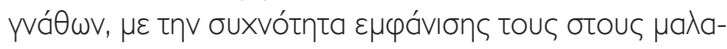

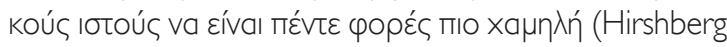

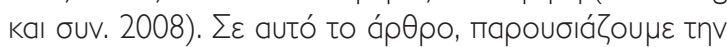

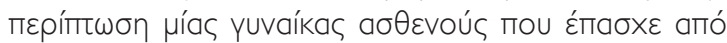

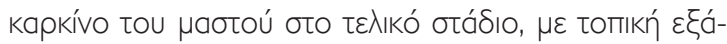

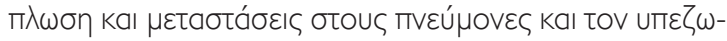

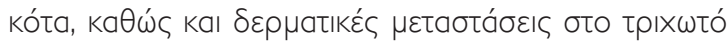

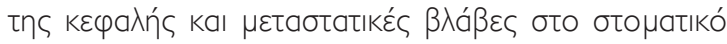

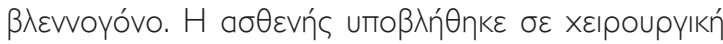
a

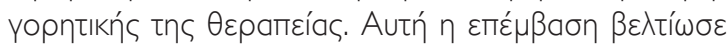

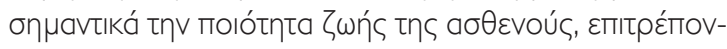

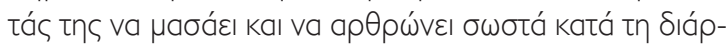

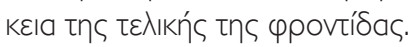

\section{ПАРОY $\Sigma \mathrm{AA} \Sigma \mathrm{H}$ TH $\Sigma$ ПЕРІПT $\Omega \Sigma \mathrm{H} \Sigma$}

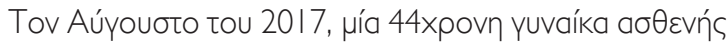

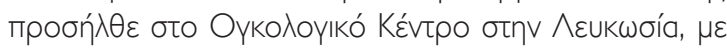

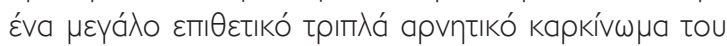

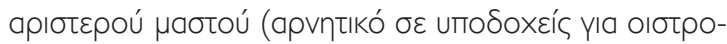

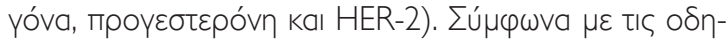

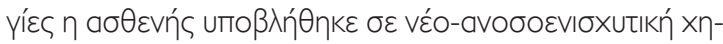

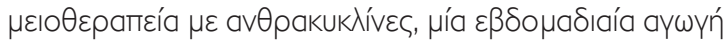

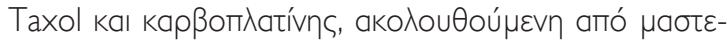

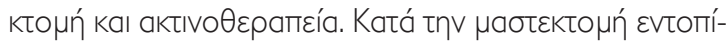

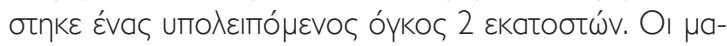

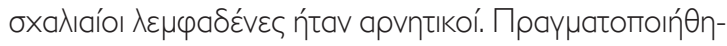

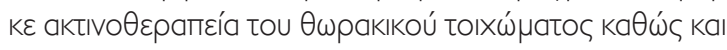

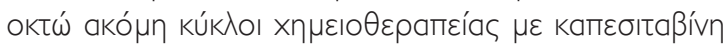

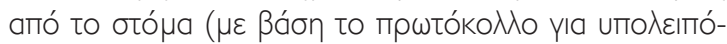

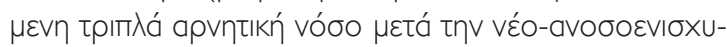

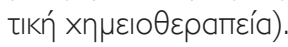

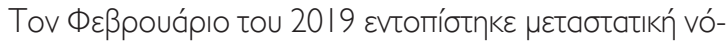

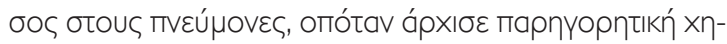



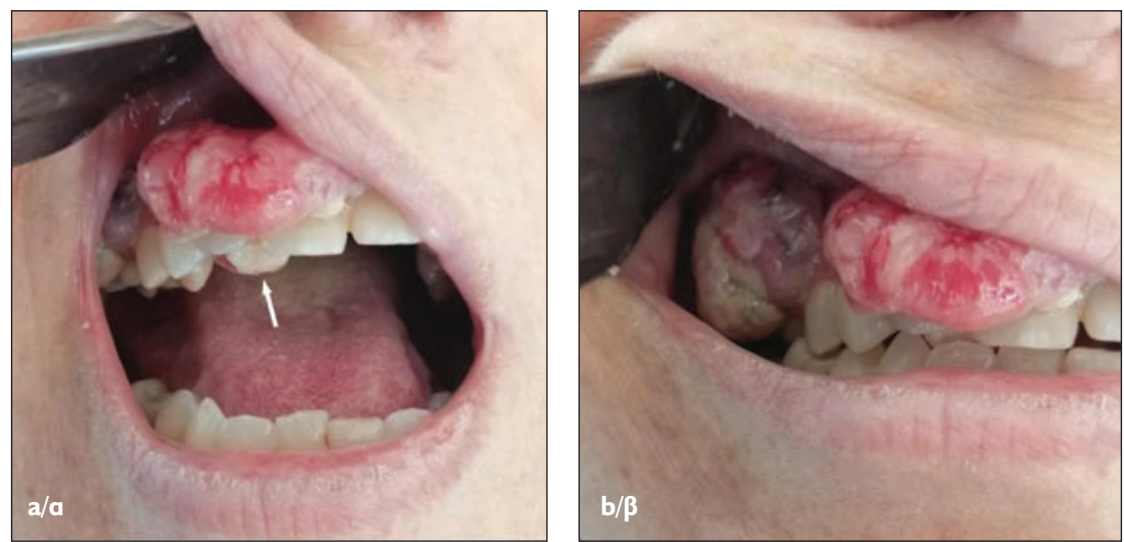

Fig. Ia and Ib: Metastatic lesions of the maxillary mucosa, growing into the mucolabial and mucobuccal fold, as well as on the palate. Arrow shows the palatal extension of the lesion.

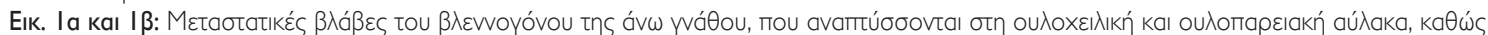

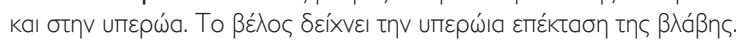

size of the lesions, the required radiation dose would have been highly toxic. Therefore, in February 2020, the patient was referred to our Maxillofacial Surgery Clinic for surgical removal of the oral cavity lesions.

The clinical examination revealed two separate tumorous masses, located at the anterior and distal right maxilla, measuring $4.0 \times 3.0 \mathrm{~cm}$ and $4.0 \times 3.5 \mathrm{~cm}$, respectively. The masses were growing into the vestibule, mucolabial and mucobuccal fold, as well as on the palate. Both lesions were passing to the hard palate through an isthmus of metastatic tissue, between adjacent teeth (Fig. Ia and Ib). Mastication, articulation as well as phonation were seriously affected. Moreover, three other smaller lesions, measuring from 0.6 to $1.2 \mathrm{~cm}$, were found on the right and left mandibular alveolar mucosa (Fig. 2). The lesions were painful, exophytic, ulcerating, highly vascularized and hemorrhagic. Because of the presence of a progres-

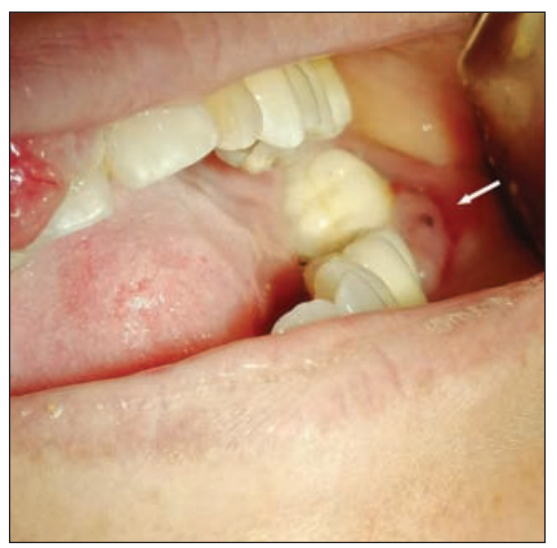

Fig. 2: Arrow shows one of the three metastatic lesions of the mandibular mucosa.

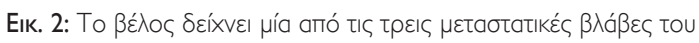

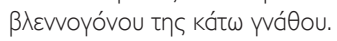

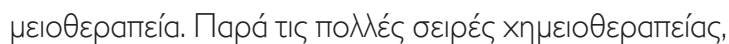

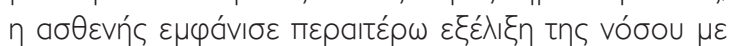

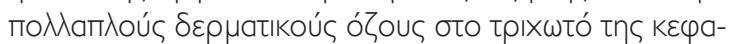

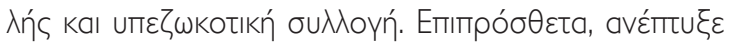

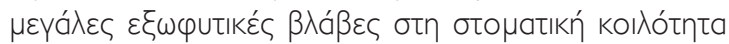

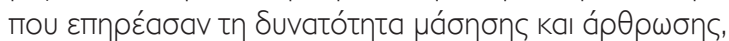

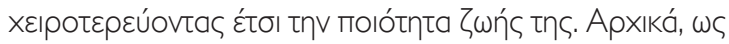

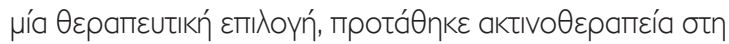

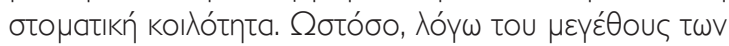

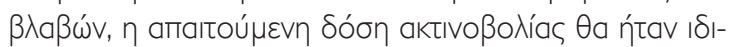

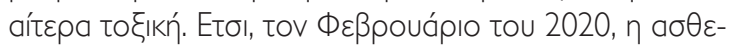

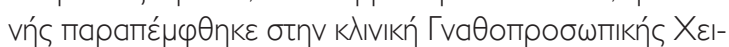

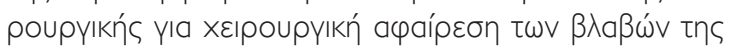

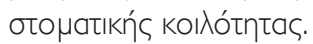

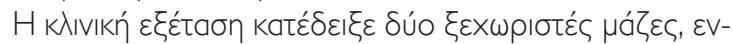

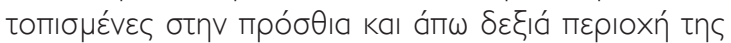

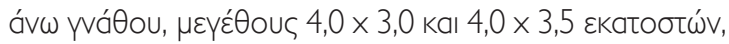

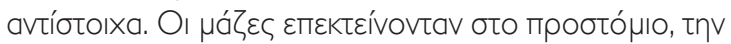

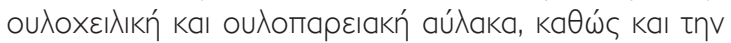

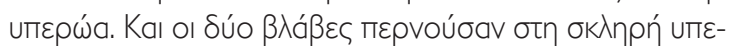
р

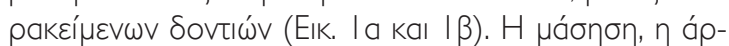

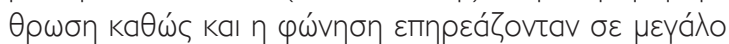

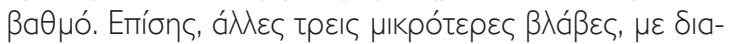

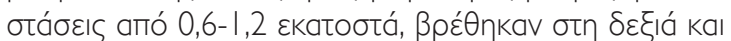

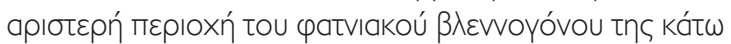

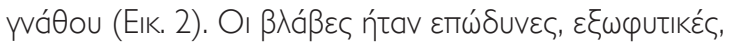

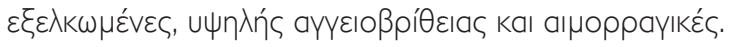

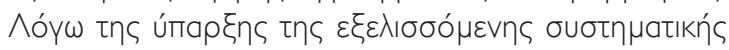

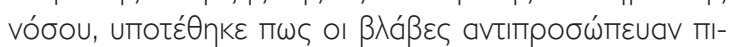

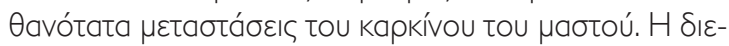

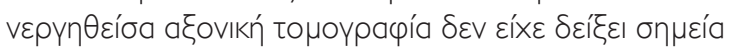

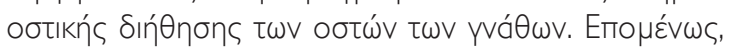

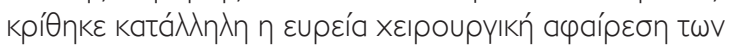

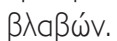

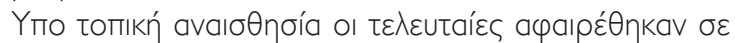



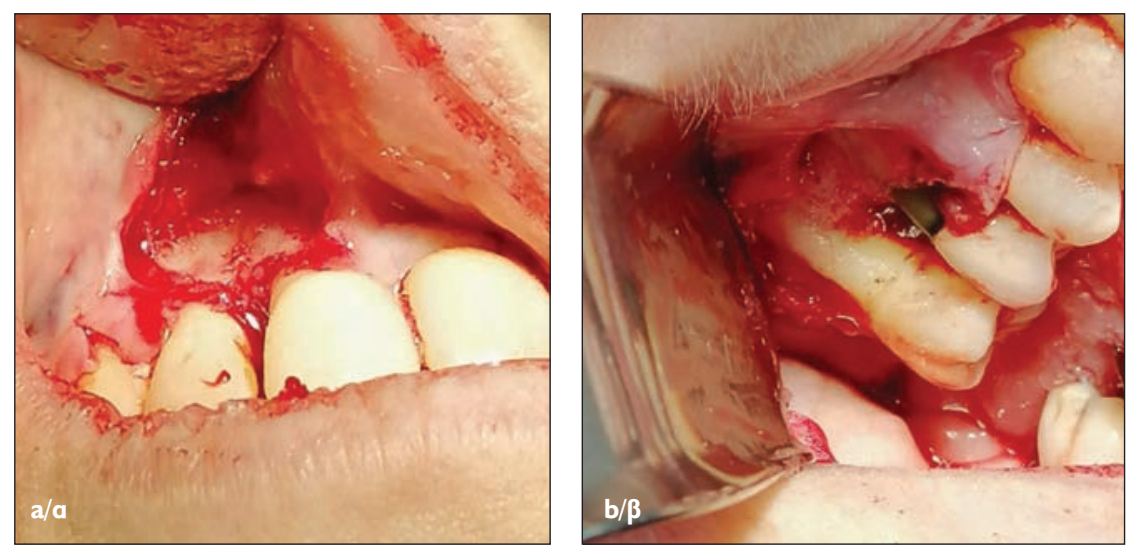

Fig. 3a and 3b: The maxillary surgical defects after lesions removal. No macroscopic bone involvement is observed.

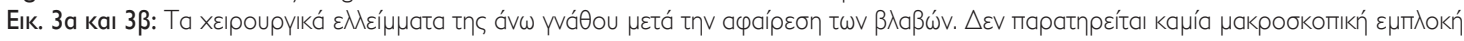
tou oøtoú.

sive systematic disease, it was assumed that the lesions were most likely representing metastases of breast cancer. The performed Computed Tomography Scan had shown no signs of osseous infiltration of the jawbones. Therefore, wide surgical excision of the lesions was deemed appropriate.

Under local anesthesia, the lesions were excised in two sessions; one for the maxillary lesions and another for the mandibular lesions. Macroscopic lack of underlying bone involvement was observed in both surgical interventions (Fig. 3a and 3b). The surgical defects, following the lesion removal, were closed either by direct suturing, where possible, or by buccal flaps after periosteum release incisions (Fig. 4). The post-operative period was uneventful, and the sutures were removed on the 7 th day.

The histopathology report showed fragments of oral mu-

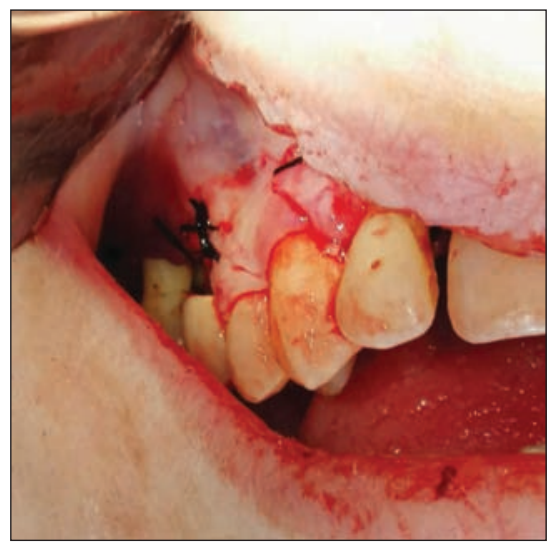

Fig. 4: Mucoperiosteal reconstruction after lesion removal.

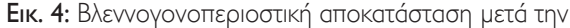

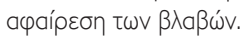

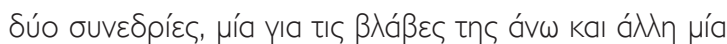

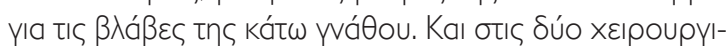

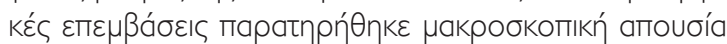

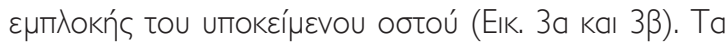

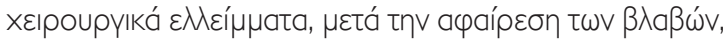

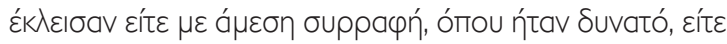

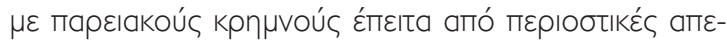

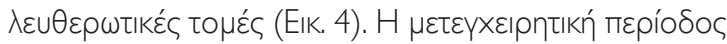

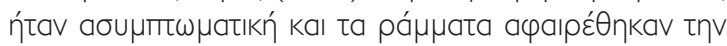

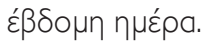

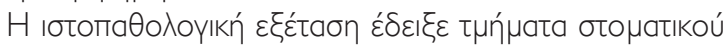

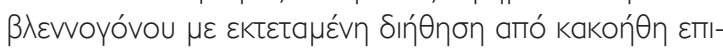

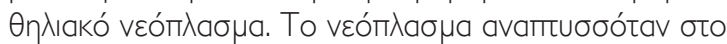

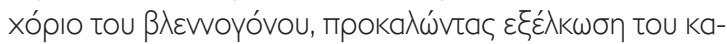

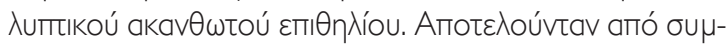

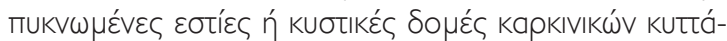


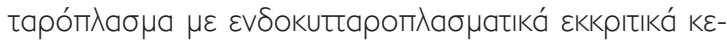

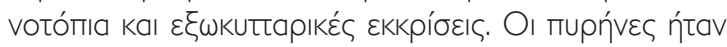

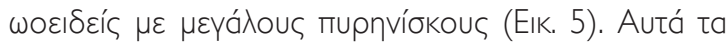

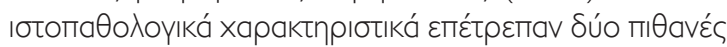

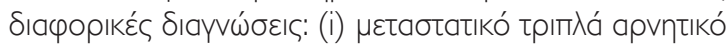

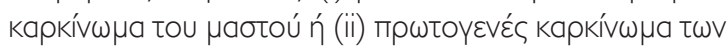

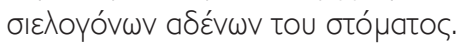

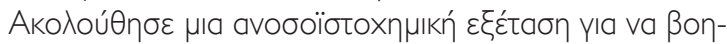

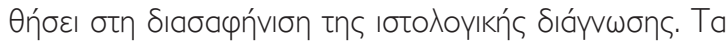

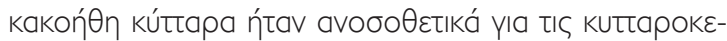
patíves AEI/3, CAM5, 2, CK7, SIO0 kaı SOXIO (EIK. 6a,

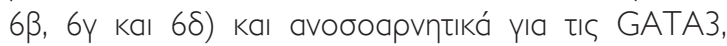

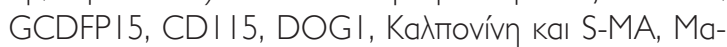

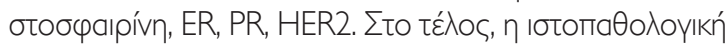

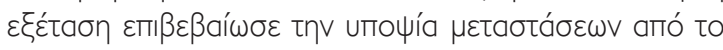

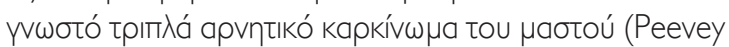
kaı ouv. 20।5, Tozbikian kaı Zynger, 2019).

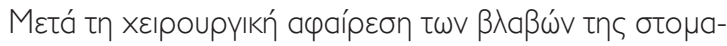

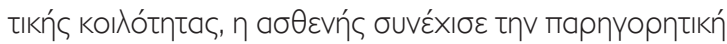




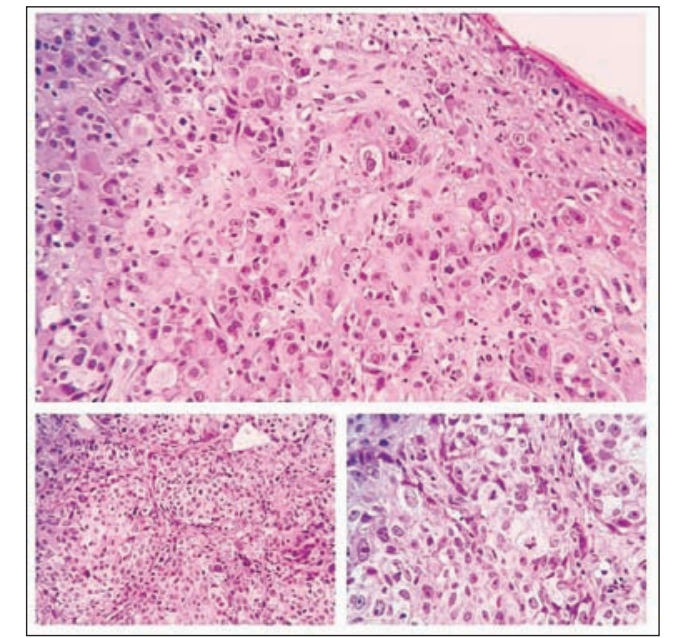

Fig. 5: Illustrations of the histopathological examination. The sample was composed of closely packed nests of cystic structures of tumor cells. These cells were found to contain abundant eosinophilic cytoplasm with intracytoplasmatic secretory vacuoles and extracellular secretion (haematoxylin-eosin, original magnification $\times 20$ ).

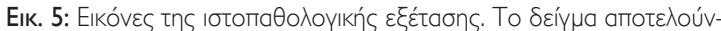

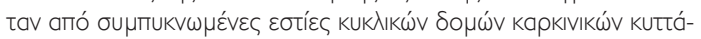

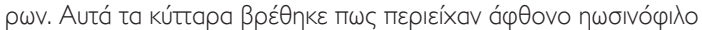

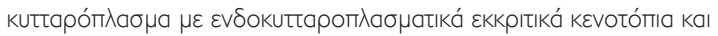

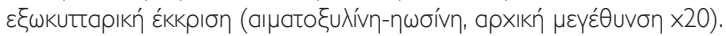

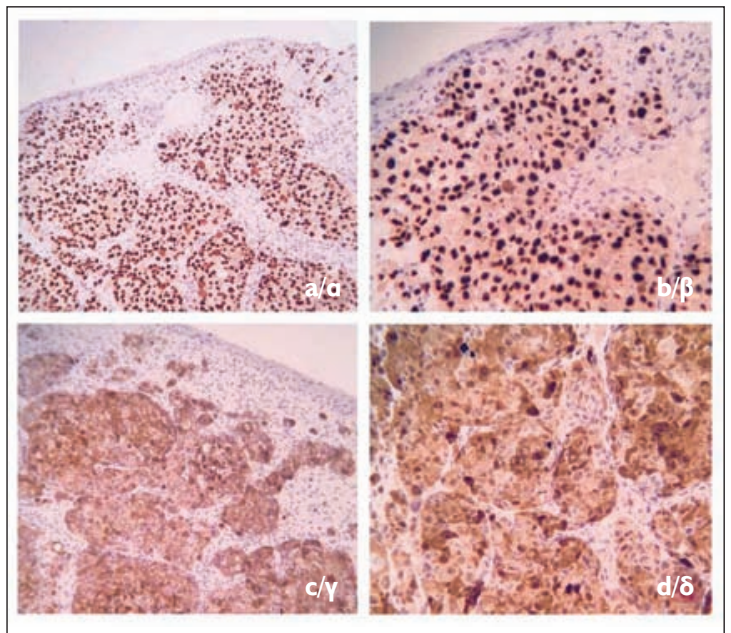

Fig. 6a, 6b, 6c and 6d: Illustrations of the immunohistochemical examination. The malignant cells were immunopositive for cytokeratins AEI/3, CAM5,2, CK7, SIO0 and SOxI0, confirming the suspicion of metastases from the known triple negative breast carcinoma (a and b: SOx 10, c: K7, d: S100, original magnification $\times 20$ ).

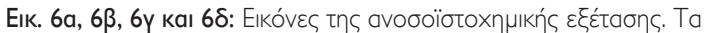

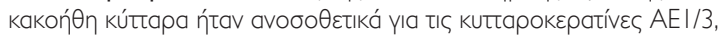

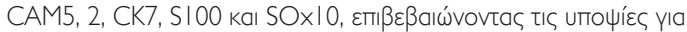

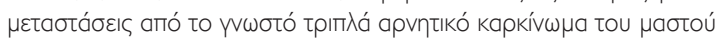

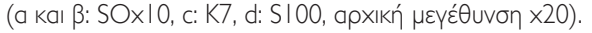

cosa extensively infiltrated by malignant epithelial neoplasm. The neoplasm was growing in the lamina propria, causing ulceration of the lining squamous epithelium. It was composed of densely packed nests or cystic structures of tumor cells. The latter had abundant eosinophilic cytoplasm with intracytoplasmic secretory vacuoles and extracellular secretions. The nuclei were oval with large nucleoli (Fig. 5). The aforementioned pathological features, allowed for two possible differential diagnoses: (i) metastatic triple-negative carcinoma of the breast or (ii) primary carcinoma of the oral salivary glands.

An immunohistochemical examination was then performed in order to assist in the clarification of the histological diagnosis. The malignant cells were immunopositive for cytokeratins AEI/3, CAM5, 2, CK7, SI00 and SOXIO (Fig. 6a, 6b, 6c and 6d) and immunonegative for GATA3, GCDFPI5, CDI I5, DOG I, Calponin and SMA, Mammaglobin, ER, PR, HER2. In conclusion, the histopathology report confirmed the suspicion of metastases from the known triple-negative breast carcinoma (Peevey et al. 2015, Tozbikian and Zynger, 2019).

Following the surgical excision of the oral cavity lesions, the patient continued her palliative chemotherapy. She passed away 5 months after the maxillofacial procedure with no relapse of her oral cavity lesions. The cause of death was deemed to be the widespread metastatic triple negative disease.

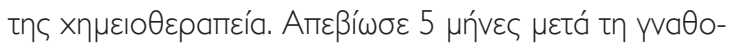
проб

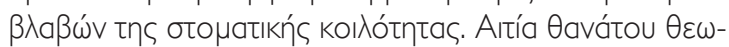

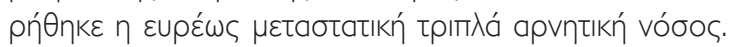

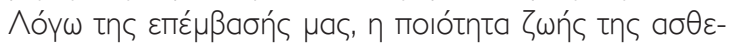

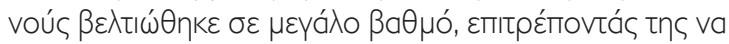

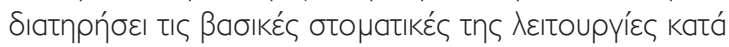

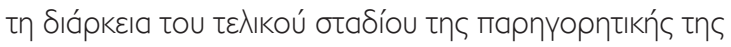

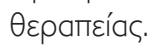

\section{$\Sigma \mathrm{YZHTH} \Sigma \mathrm{H}$}

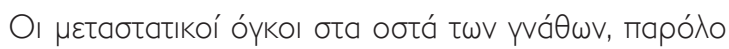

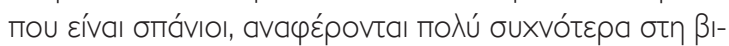

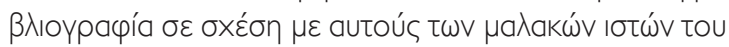
oтópatos (Van der Waal kaı ouv. 2003, Hirshberg kaı ouv. 2008, Kumar kaı Manjunatha 2013, Irani 20 I6). Пo-

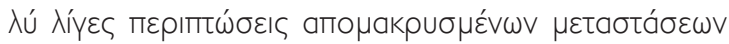

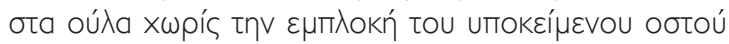

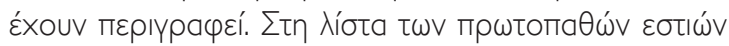

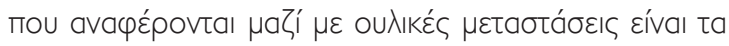

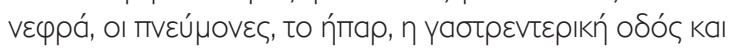

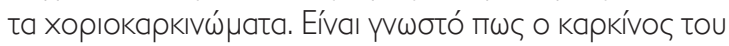

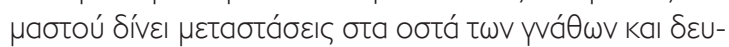

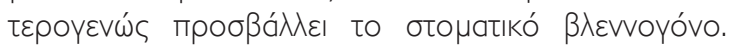

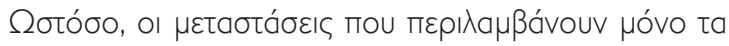

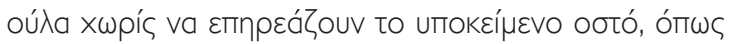


Due to our intervention, the patient's quality of life improved to a great extent, allowing her to maintain her essential oral functions during the final stage of palliative care.

\section{DISCUSSION}

Metastatic tumors in the jawbones, although rare, are much more frequently reported in the literature than those in the oral soft tissues (Van der Waal et al. 2003, Hirshberg et al. 2008, Kumar and Manjunatha 20 I3, Irani 2016). Very few cases of distant metastasis to the gingiva without the involvement of the underlying bone have been described. Among the list of primary locations reported along with gingival metastases are the kidney, lung, liver, gastrointestinal tract, and choriocarcinomas. Breast cancer is known to metastasize to the jawbones and secondarily involve the oral mucosa. However, metastases that solely involve the gingiva with sparing of the underlying bone, as seen on a CT scan, are rare (Shah and Mehta 2009, Irani 2016). Hirshberg et al. (2008) in their latest review of 673 cases of metastatic tumors in the oral cavity revealed that breast cancer metastases in female patients show a 5-fold higher probability to occur in the jawbones than to the oral soft tissues. In addition, this study group in an earlier review of 390 patients suggested that the presence of teeth could correlate with the developing and existence of jawbone metastasis. However, in the case we are presenting, while several metastatic lesions to the oral mucosa were evident, and involved different sites of the attached gingiva and alveolar mucosa, there were no clinical or radiological signs of metastatic lesions to the jawbones. Therefore, we could not confirm the connection between the presence of teeth and the metastatic lesions to the jawbones, as our patient was dentulous, and had no osseous metastases. Furthermore, breast cancer is considered an aggressive form of cancer, with greater affinity towards bone tissue as a possible metastatic target. The bone marrow is an essential growth medium for tumor cells in the bone tissue. Nonetheless, jawbones, especially during old age, are poor on hematopoietic active bone marrow (Mirra 1989, Hirshberg et al. 1993, Hirshberg et al. 1994). We are therefore inclined to assume that in our case, the absence of metastatic lesions to the jawbones can be also explained by the absence of hematopoietic active bone marrow in the jawbones: on the one hand, due to the age of our patient, and on the other due to chemotherapy and its possible side effects, such as damage of vital bone marrow (Dreizen et al. 2016).

Further to the above, we are also inclined to suggest that there is a connection between the pattern of metastatic colonization to the oral soft tissue and the gingival inflammation processes, something that has been already discussed in the literature (Liotta et al. 1980, Hirshberg et al. 1993, Hirshberg et al. 1994, Müller et al. 200 I ). Fre-

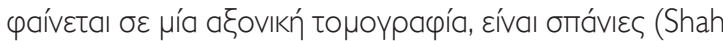
kal Mehta 2009, Irani 2016). Oı Hirshberg kal ouv.

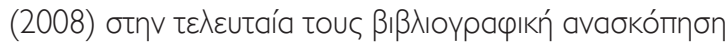

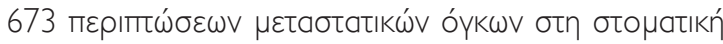

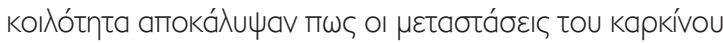

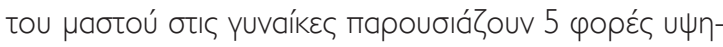

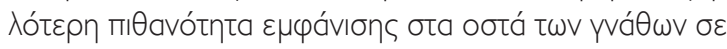

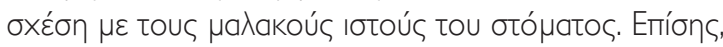

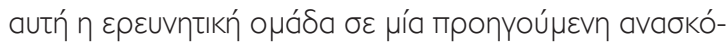

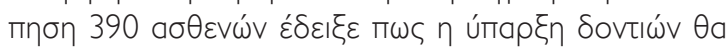

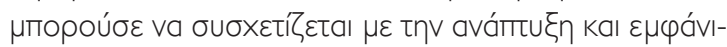

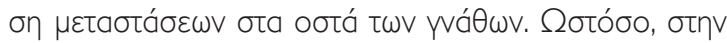

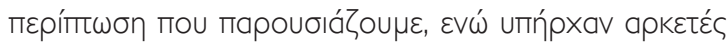

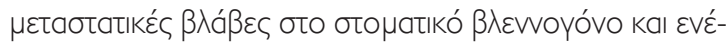

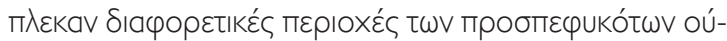

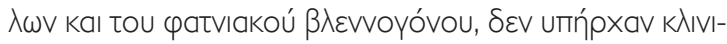

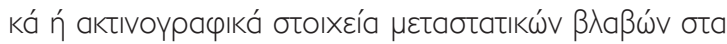

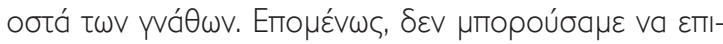

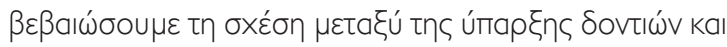

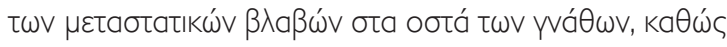

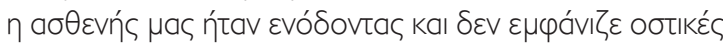

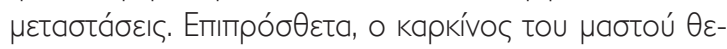

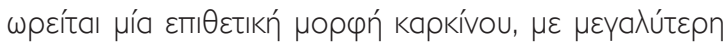

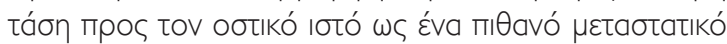

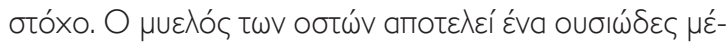

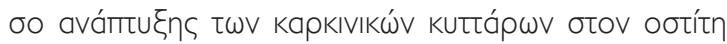

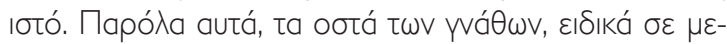

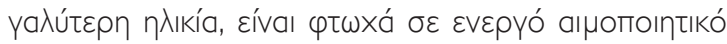

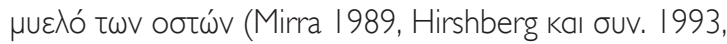

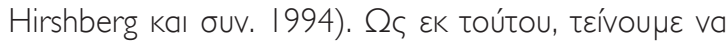

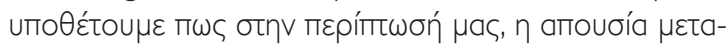

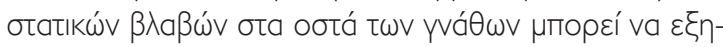

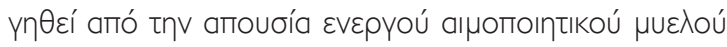

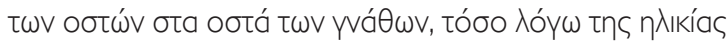

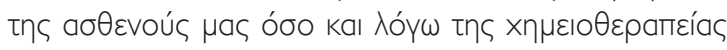

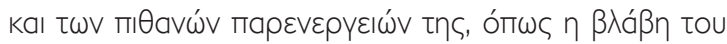

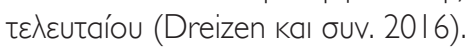

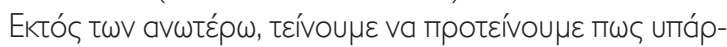

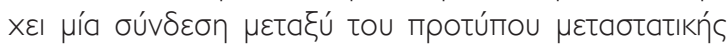
aாоíkı

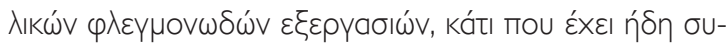

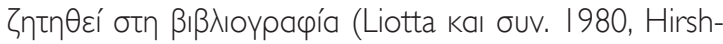
berg kal ouv. 1993, Hirshberg kaı ouv. 1994, Muller kaı

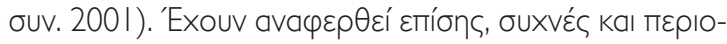

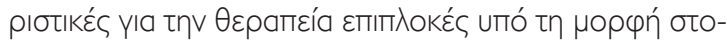

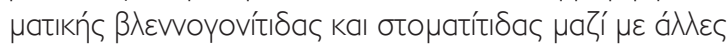

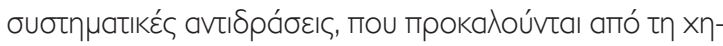

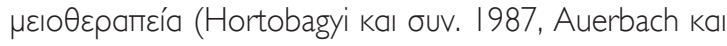
ouv. 1987, Han kaı ouv. 2015, Dreizen kaı ouv. 2016).

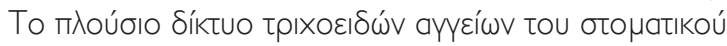

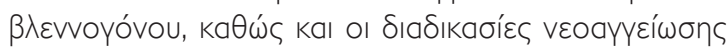

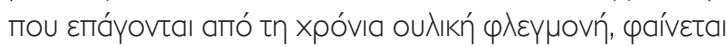

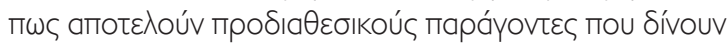

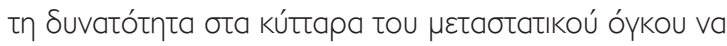

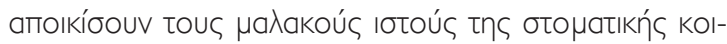


quent and therapy-limiting complications in the form of oral mucositis and stomatitis together with other chemotherapy-induced systematic reactions, were also reported. (Hortobagyi et al. 1987, Auerbach et al. 1987, Han et al. 2015, Dreizen et al. 2016). The rich capillary network of the oral mucosa, as well as the neovascularization processes induced by chronic gingival inflammation, appear to be predisposing factors enabling the metastatic tumor cells to colonize oral cavity soft tissues (Rice at al. 1988, Lester and McCarthy 1992, Hirshberg et al. 1994, Müller et al. 200 I). Metastatic lesions of the oral cavity are rare findings and are very often a sign of a wide-spread disease, in its final stage, as in the case with our oncological patient. However, they cannot be initially ruled out as the first sign of a malignant process developing elsewhere. Therefore, it is crucial for the patients to undergo a proper and extended clinical examination, as well as necessary additional scans (Kumar and Manjunatha, 2013).

\section{CONCLUSIONS}

Metastases of breast cancer in the final stage can be found in the oral cavity as exophytic growing and reactive lesions, infiltrating the oral soft tissues. The patients developing the unusual metastatic patterns are very often experiencing impaired oral function, including interference of mastication, dysphagia, disturbed articulation and even phonation. In conclusion, young patients with a history of breast cancer need to be followed up regularly and any lesion developing in the oral mucosa should be biopsied no matter how benign it may appear clinically. Histologically, positive metastasis of breast cancer to gingiva is suggestive of a poor prognosis (Shah and Mehta, 2009). Therefore, the early detection and proper treatment of the lesions is an important part of the supportive care for the patients in the terminal stage. 入ótntas (Rice kaı ouv. 1988, Lester kaı McCarthy 1992,

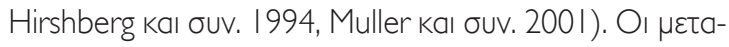

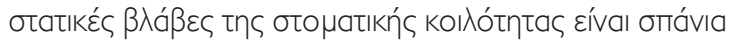

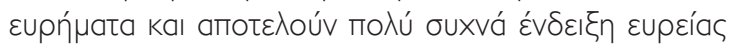

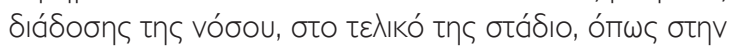

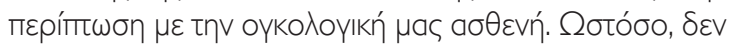

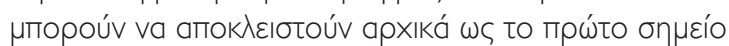

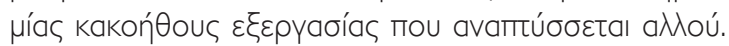

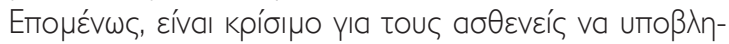

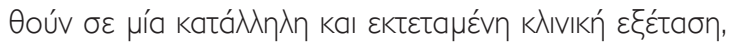

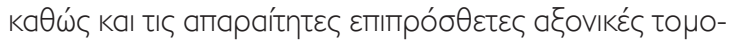
үрачíєs (Kumar kaı Manjunatha, 20।3).

\section{¿YMПЕРА $\Sigma$ MATA}

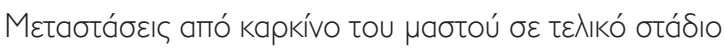

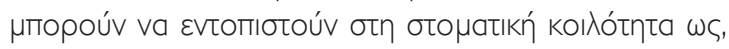

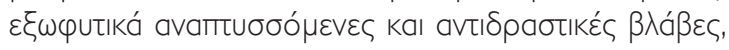

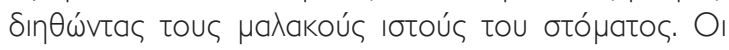

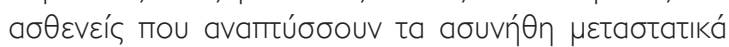

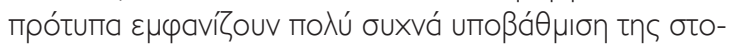

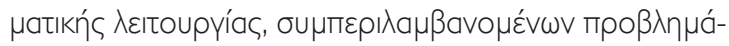

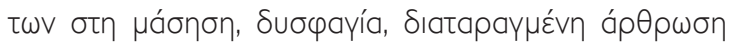

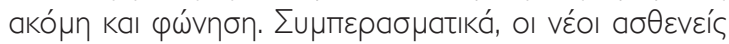

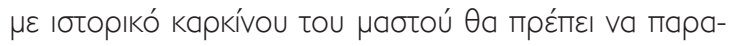

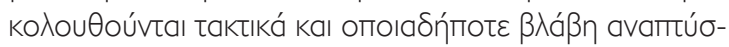

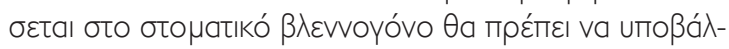

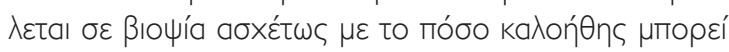

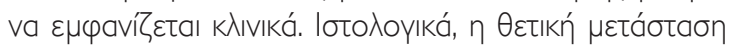

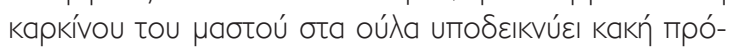

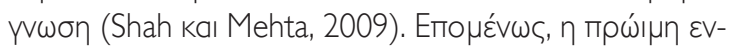

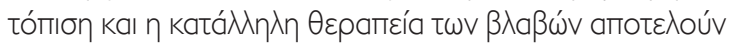

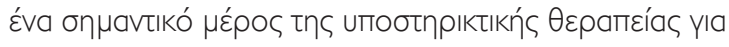

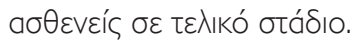




\section{ВIВАІОГРАФIA/REFERENCES}

Auerbach R, Lu WC, Pardon E, Gumkowski E, Kaminska G, Kaminski $M$ : Specificity of adhesion between murine tumor cells and capillary endothelium; an in vitro correlate of preferential metastasis in vivo. Cancer Res. 47: | 492 - |496, 1987

Dreizen S, Bodey GP, Rodriguez V: Oral Complications of Cancer Chemotherapy. Journal Postgraduate Medicine 58: 75 - 82, 2016

Hirshberg A, Leibovich P, Buchner A: Metastases to the oral mucosa: analysis of I 57 cases. J Oral Pathol Med 22: 385-390, 1993

Hirshberg A, Leibovich P, Buchner A: Metastatic tumors to the jawbones: analysis of 390 cases. J Oral Pathol Med 23: 337-34I, 1994

Hirshberg A, Shnaiderman-Shapiro A, Kaplan I, Berger R: Metastatic tumours to the oral cavity - Pathogenesis and analysis of 673 cases. Oral Oncology 44: 743- 752, 2008

Hortobagyi GN, Bodey GP, Buzdar AU, Frye D, Legha SS, Malik R, Smith TR, Blumenschein GR, Yap HY, Rodriguez V: Evaluation of high-dose versus standard FAC chemotherapy for advanced breast cancer in protected environment units: a prospective randomized study. J Clin Oncol 5: 354-64, 1987. doi: 10.1200/JCO. | 987.5.3.354

Irani S: Metastasis to the oral soft tissues: A review of 412 cases. J Int Soc Prevent Communit Dent 6: 393-40 I, 2016

Kumar GS, Manjunatha BS: Metastatic tumors to the jaws and oral cavity. J Oral Maxillofac Pathol. 17: 7I-75, 2013. doi: 10.4103/0973029X.110737

Lester BR, McCarthy JB: Tumor cell adhesion to the extracellular matrix and signal transduction mechanisms implicated in tumor cell motility, invasion and metastasis. Cancer and Metastasis Reviews I I: 31-44, 1992

\section{Address:}

Dobromira Nikolova, M. D.

Faculty of Dentistry, LMU Munich, Germany

Landsbergerstr. 488, 81241, Munich, Germany

Tel.: $+4917761 \mid 6680$

e-mail: Dobromira.Evtimova@campus.Imu.de
Liotta L, Tryggvason K, Garbisa S, Hart I, Foltz CM, Shafie S: Metastatic potential correlates with enzymatic degradation of basement membrane collagen. Nature 284: 67-68, 1980. doi.org/I0.1038/ 284067a0

Ma H, Chen M, Liu J, Li Y, Li J: Serious stomatitis and esophagitis: a peculiar mucous reaction induced by pegylated liposomal doxorubicin. An Bras Dermatol. 90: 209-21I, 2015. doi:10.1590/ abd I 806-484I.20I53708

Mirra JM: Metastasis: Bone tumors. Ist edition Philadelphia and London: Lea \& Febiger, $1495-1517,1989$

Müller A, Homey B, Soto H, Ge N, Catron D, Buchanan ME, McClanahan T, Murphy E, Yuan W, Wagner SN, Barrera JL, Mohar A, Verástegui E, Zlotnik A, Homey B: Involvement of chemokine receptors in breast cancer metastasis. Nature 410:50 - 56, 200 I. doi: $10.1038 / 35065016$

Peevey L, Sumpter I, Paintal A, Laskin W, Sullivan M: SOXIO Is a Useful Marker for Triple Negative Breast Cancer. American Journal of Clinical Pathology I44: 299 - 299, 2015

Rice GE, Gimbrone Jr MA, Bevilacqua MP: Tumor Cell-Endothelial Interactions. Increased Adhesion of Human Melanoma Cells to Activated Vascular Endothelium. Am J Pathol I33: 204 - 10, 1988

Shah MY, Mehta AR: Metastasis from breast cancer presenting as an epulis in the upper gingiva. J Oral and Maxillofac Pathol. 13: 3840, 2009

Tozbikian GH, Zynger DL: A combination of GATA3 and SOXIO is useful for the diagnosis of metastatic triple-negative breast cancer. Hum Pathol 85:221 - 227, 2019

Van der Waal RIF, Buter J, van der Waal l: Oral metastases: report of 24 cases. British Journal of Oral and Maxillofacial Surgery 4I: 3 6,2003

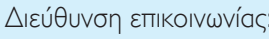

\section{Dobromira Nikolova, M. D.}

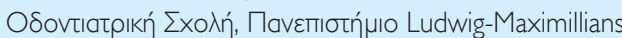

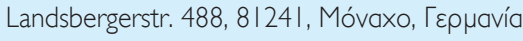

$T \eta \lambda .:+49|776| 16680$

e-mail: Dobromira.Evtimova@campus.Imu.de 


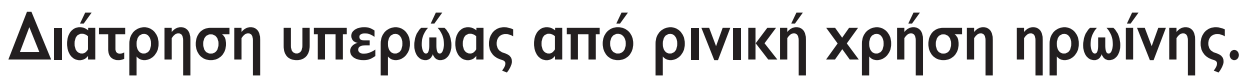

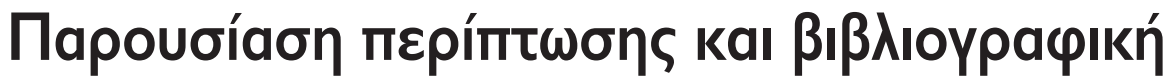

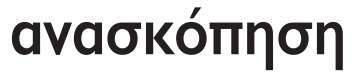

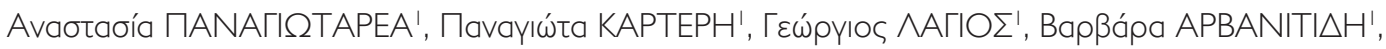

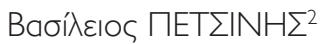

\section{Palatal perforation from intranasal abuse of heroin. Case report and literature review}

Anastasia PANAGIOTAREA, Panagiota KARTERI, Georgios LAGIOS, Barbara ARVANITIDI, Vassilios PETSINIS

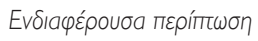

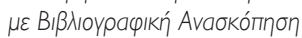
Case Report with Literature Review

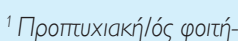

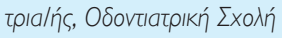
EKПА

${ }^{2} \Sigma \Gamma \Pi X$, Eпां́oupos

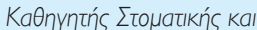

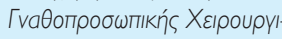

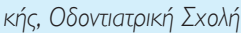
ЕКПА

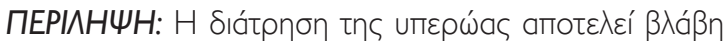

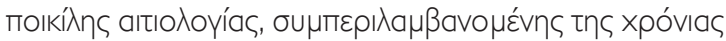

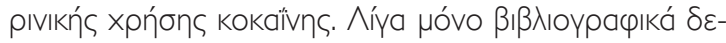

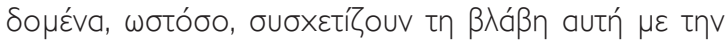

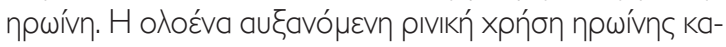

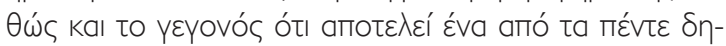

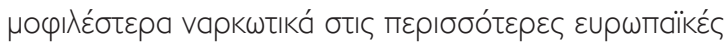

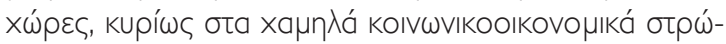

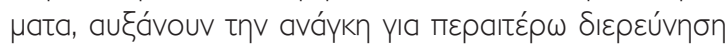

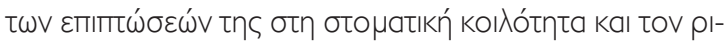

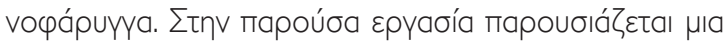

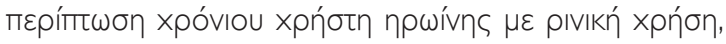

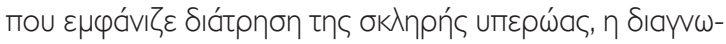

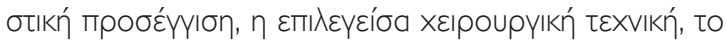

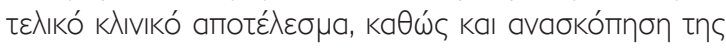

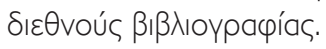

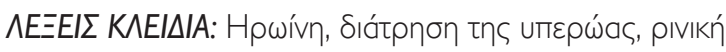

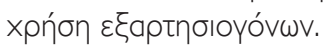

SUMMARY: Palatal perforation is a lesion of various etiologies, including chronic intranasal abuse of cocaine. Only a few data, however, correlate this damage with heroin. The growing intranasal abuse of heroin and the fact that it is one of the five most popular drugs in most European countries, especially in the lower social classes, increase the need for further investigation of its effects on the oral cavity and nasopharynx. This report presents a case of chronic snorting of heroin, which caused perforation of the hard palate, the diagnostic approach, the selected surgical technique, the final outcome, as well as a review of literature.

KEY WORDS: Heroin, palatal perforation, nasal use of drugs. 


\section{EI $\Sigma \mathrm{A} Г \Omega Г H$}

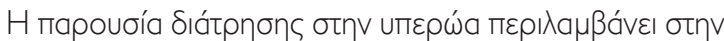

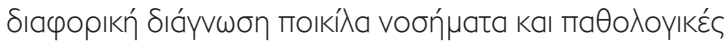

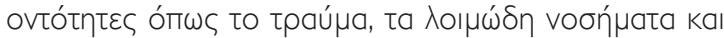

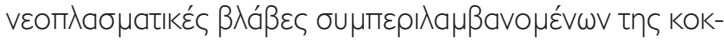

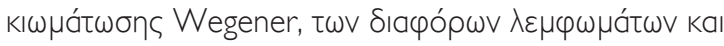

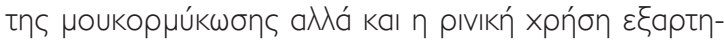

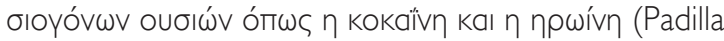

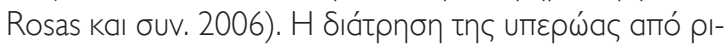

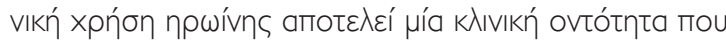

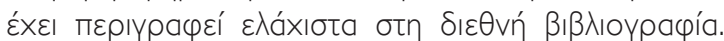

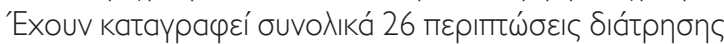

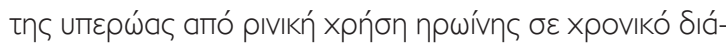

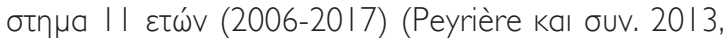
Zhang kal ouv. 20 17, El Charkawi kaı Nasar, 2015). O।

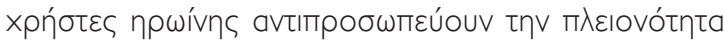

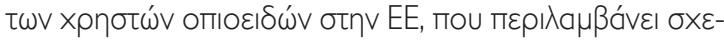

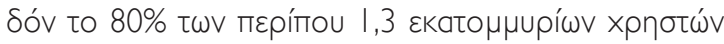

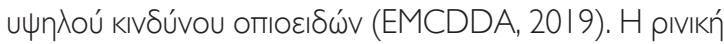

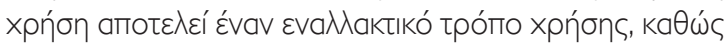

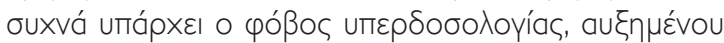

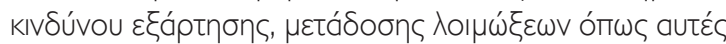

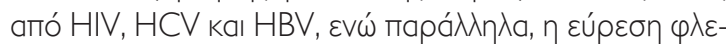

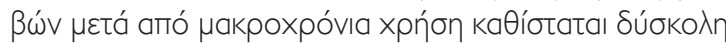
(Peyrière kaı ouv. 20 I3, Hines kal ouv. 20 I7, Bakhshaee

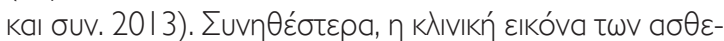

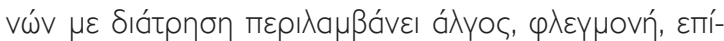

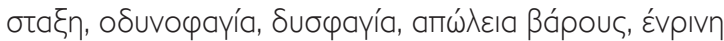
o

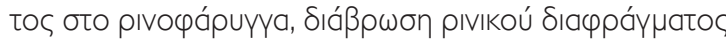
kal á $\lambda \omega \omega v \delta o \mu \omega ́ v$ (Chhabra ka Abraham, 20 I3, Yewell kal ouv 2002). 'Oбov a

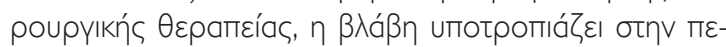

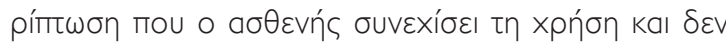

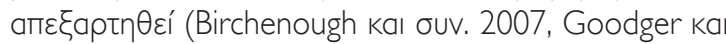

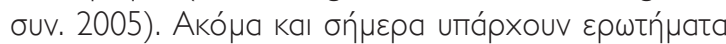

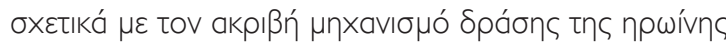

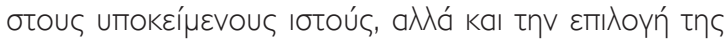

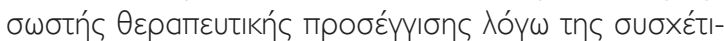

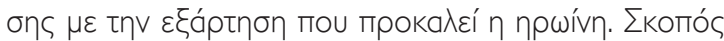

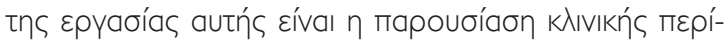

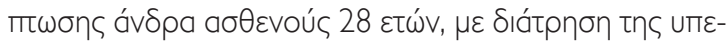

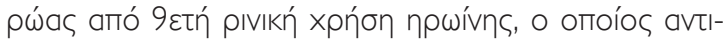

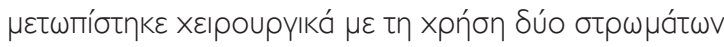

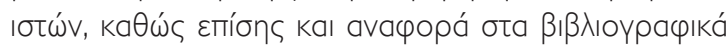

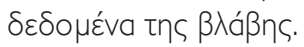

\section{ANAФOPA ПЕРІПT $\Omega \Sigma \mathrm{H} \Sigma$}

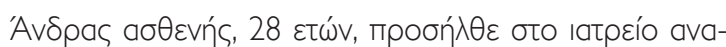

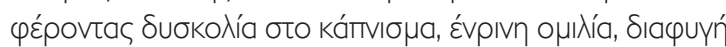

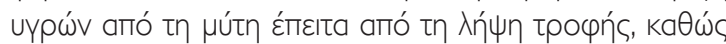

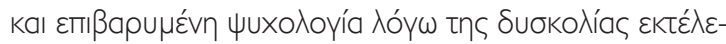

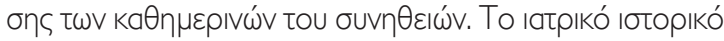

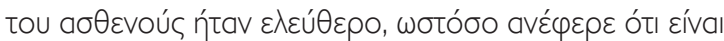

\section{INTRODUCTION}

The presence of palatal perforation includes various diseases and pathological entities in its differential diagnosis, such as trauma, infectious diseases and neoplastic lesions. Those include Wegener's granulomatosis, various lymphomas and mucormucosis, as well as intranasal use of drugs such as cocaine and heroin (Padilla Rosas et al. 2006). Palatal perforation from intranasal use of heroin is a clinical entity rarely described in the international literature. A total of 26 cases of palatal perforation had been reported from intranasal use of heroin in an I I year old period (2006-2017) (Pevriere et al. 2013, Zhang et al. 2017, El Charkawi and Nasar, 2015). Heroin users represent the majority of opioid users in the EU, which includes almost $80 \%$ of about 1.3 million of high risk opioid users (EMCDDA, 2019). Intranasal use is an alternative way of use, since there is the common danger of overdose, increased risk of addiction, infection transmission such as HIV, HCV and HBV, while at the same time venupuncture after long-term abuse is difficult (Pevriere et al. 20 I3, Hines et al. 2017, Bakhshaee et al. 2013). The usual clinical presentation of patients with palatal perforation includes pain, inflammation, epistaxis, odynophagia, dysphagia, weight loss, nasal speech, nasal reflux, burning sensation in the oropharynx, erosion of the nasal septum and other structures (Chabra and Abraham, 2013, Yewell et al. 2002). Regarding the surgical treatment prognosis, the lesion regresses in case of discontinuation of the abuse by the patient (Birchenough et al. 2007, Goodger et al. 2005). Even today there are many questions regarding the precise mechanism of action of heroin in the underlying tissues, as well as the selection of the right therapeutic approach due to the correlation with the addiction caused by heroin. The purpose of this article is to present of a clinical case of a 28 year old male patient, with a palatal perforation after 9 year intranasal abuse of heroin, who was surgically treated using two tissue layers, as well as a literature review of the lesion.

\section{CASE REPORT}

A 28 year old male patient came to the private office reporting difficulty in smoking, nasal speech, liquids leaking from the nose after eating and being burdened psychologically due to the difficulty in the execution of his daily habits. The medical history of the patient was unremarkable, but he reported intranasal abuse of heroin for 9 


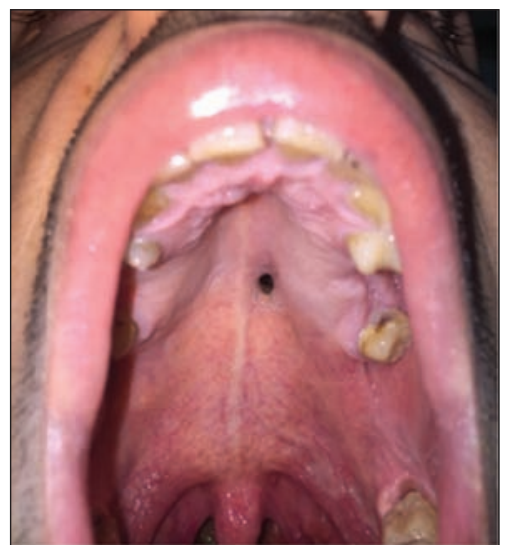

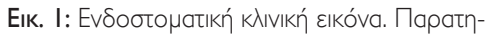

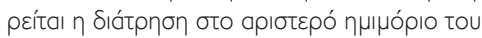

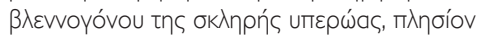

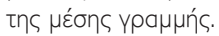

Fig. I: Intraoral clinical view. The perforation in the left half of the hard palate's mucosa is being observed, near the midline.

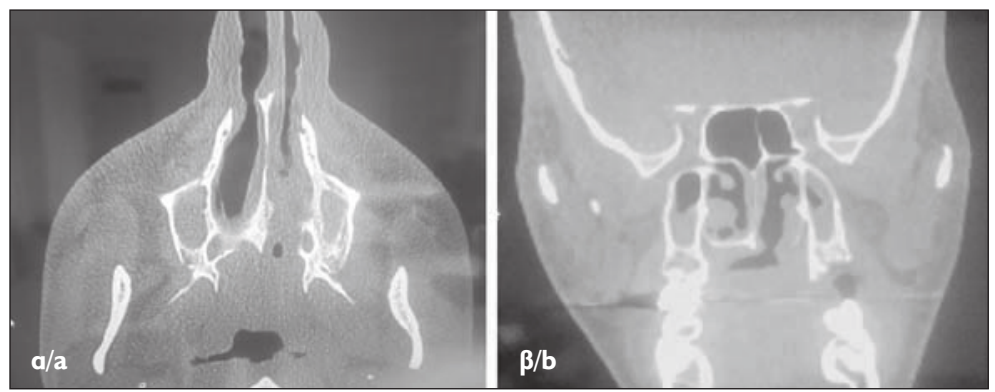

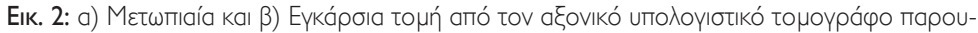

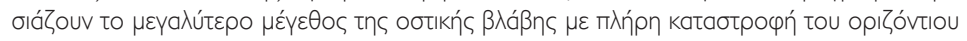

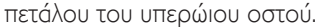

Fig. 2: a) Frontal and b) Transverse section from the CT present the largest size of the bone lesion with complete destruction of the horizontal plate of the palatal bone.

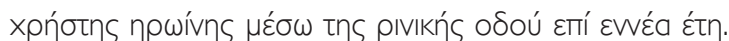

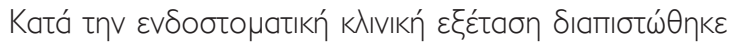

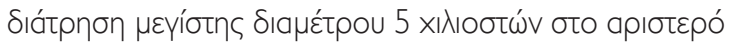

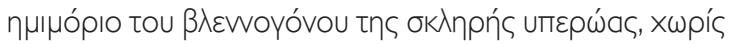

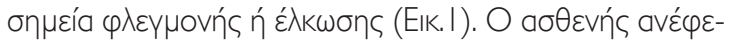

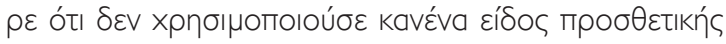

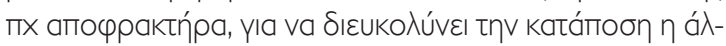

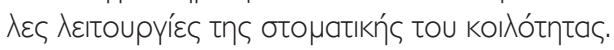

$\sum$ Tov ап

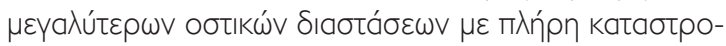

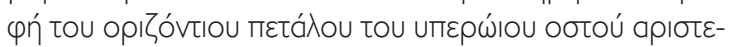

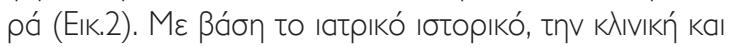

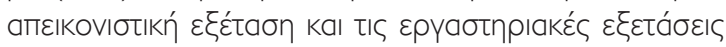

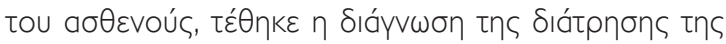

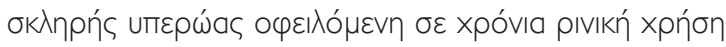

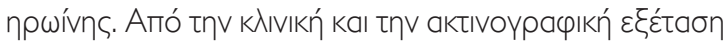

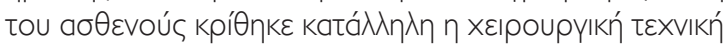

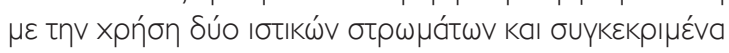

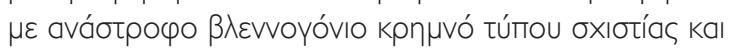

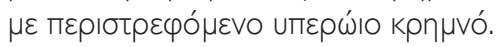

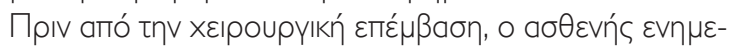
р

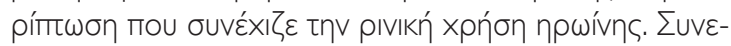

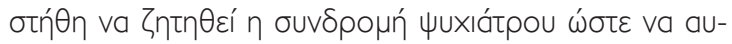

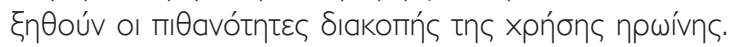

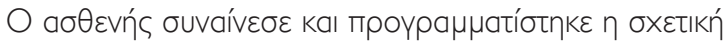

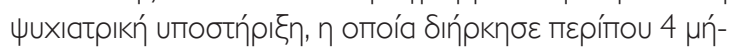

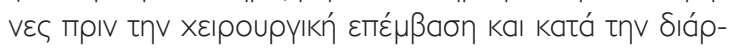

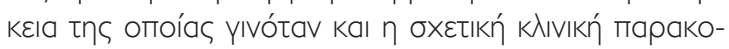

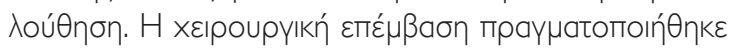

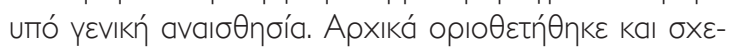

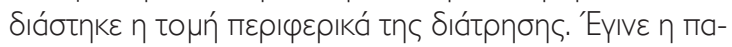

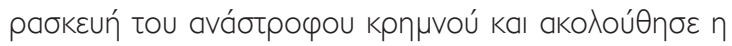

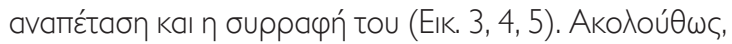

years. During intraoral clinical examination a $5 \mathrm{~mm}$-diameter perforation was identified in the left half of the hard palate, without signs of inflammation or ulceration (Fig. I). The patient reported that he didn't use any kind of prosthetic device to facilitate ingestion or other oral functions.

During imaging control a much bigger bone lesion was discovered with complete deterioration of the palatal horizontal bone plate on the left (Fig. 2). According to his mecical history, clinical and imaging examination and lab tests of the patient, a diagnosis of palatal perforation due to chronic intranasal abuse of heroin was made. Based on the clinical and radiographic examination of the patient, a surgical technique with the use of two tissue layers was selected, and with a reverse mucosal cleft type and a rotating palatal flap, in particular.

Before the surgical procedure, the patient was informed about the serious possibility of relapse in case he continued intranasal use of heroin. We recommended the help of a psychiatrist in order to increase the probability of discontinuation of the abuse of heroin. The patient consented and the relevant psychiatric support was programmed, which lasted about 4 months before surgery and during which the patient was clinically monitored. The surgical procedure was made under general anesthesia. Initially, the incision was demarcated and designed peripherally of the perforation. The reverse flap was prepared and then reflected and sutured (Fig. 3, 4, 5). The design of the palatal flap followed tangent with the surgical trauma position on the palatal mucosa, in such a way as to protect the palatal artery. The flap was one of full thickness and releasing incisions were made in order to rotate it without tension. The rotation of the flap followed next, placed in the new position and followed by the final su- 


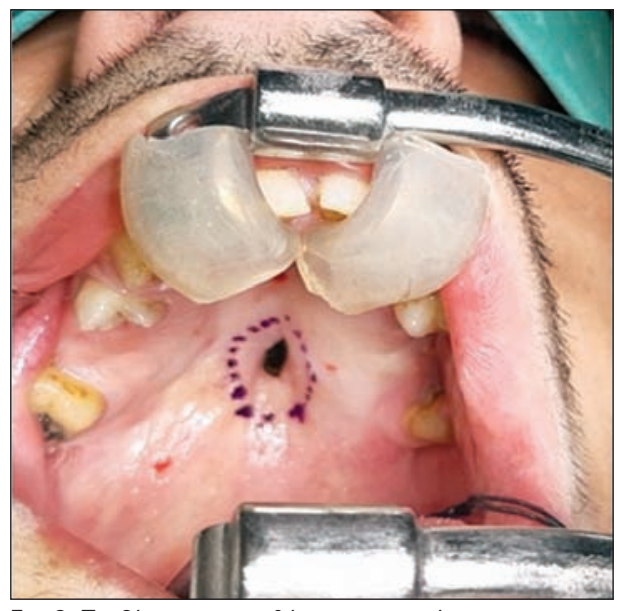

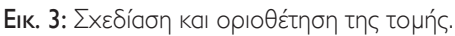

Fig. 3: Design and orientation of the incision.

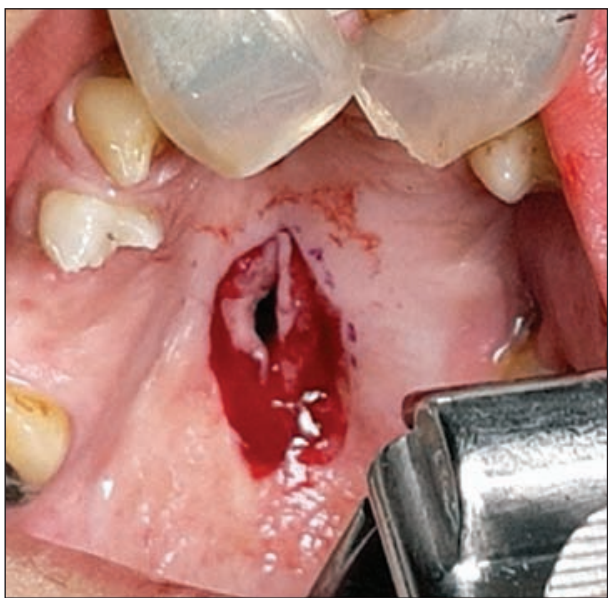

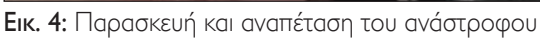

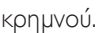

Fig. 4: Preparation and raising of the reverse flap.

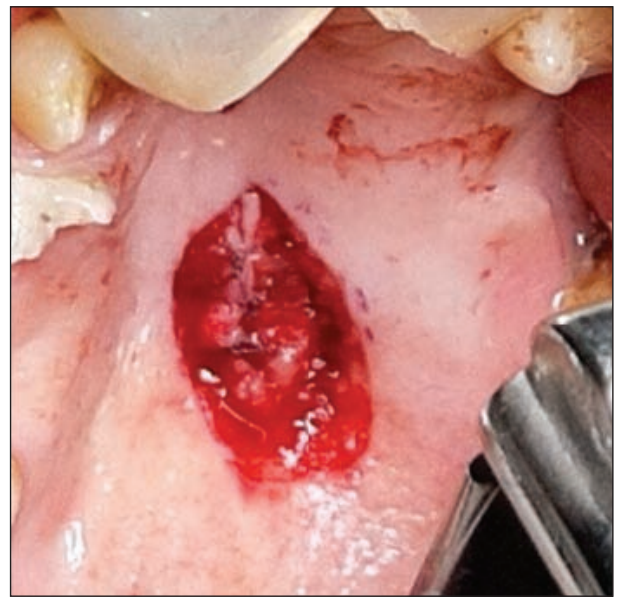

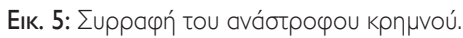
Fig. 5: Suture of the reverse flap.

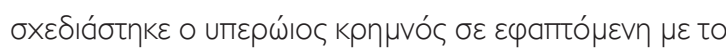

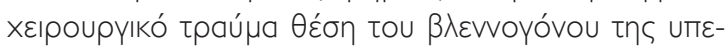

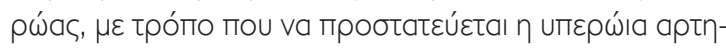

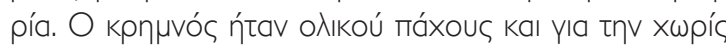

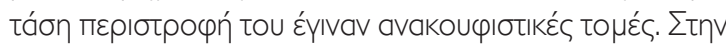

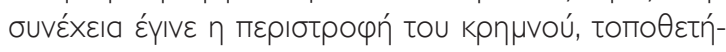

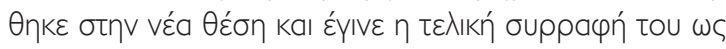

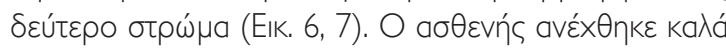

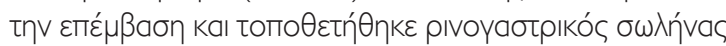

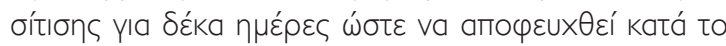

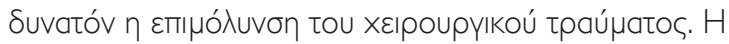

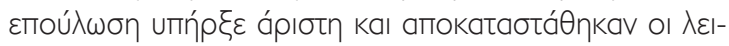

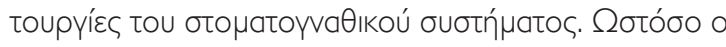

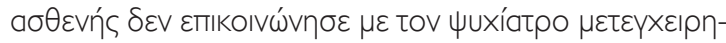

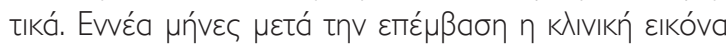

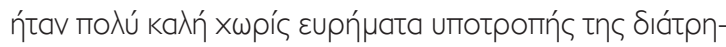

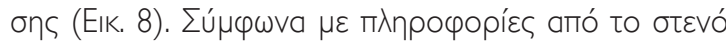

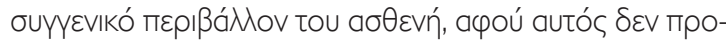

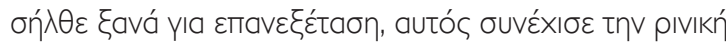

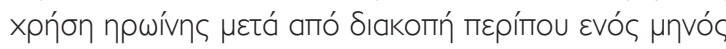

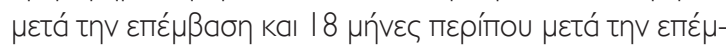

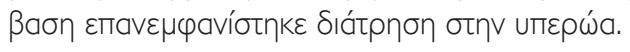

\section{$\Sigma Y Z H T H \Sigma H$}

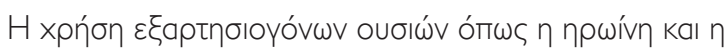

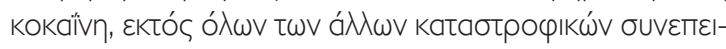

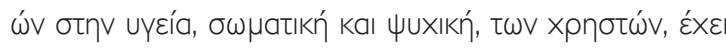

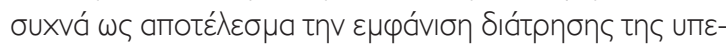

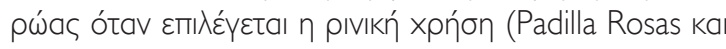

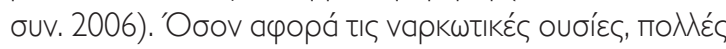

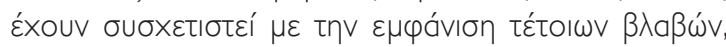

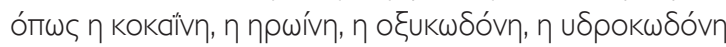

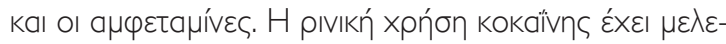

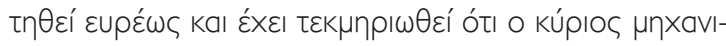

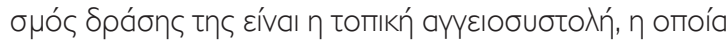

ture as a second layer (Fig. 6, 7). The patient tolerated the surgery well and a nasogastric feeding tube was placed for 10 days, in order to prevent the re-infection of the surgical trauma. Healing was excellent and the oral functions were fully restored. However, the patient did not communicate with the psychiatrist postoperatively. Nine months after the surgery clinical presentation was very good without signs of regression of the perforation (Fig. 8). According to information from the patient's relatives, since he did not return for reevaluation, he continued intranasal abuse of heroin after a cessation of about one month after the surgery and about 18 months after the surgery a palatal perforation reappeared.

\section{DISCUSSION}

The use of drugs such as heroin and cocaine, except from all the other devastating physical and mental health issues of the addicts, often results in a palatal perforation when intranasal use is being selected (Padilla Rosas et al. 2006). Regarding drugs, many of them have been related with these lesions, such as cocaine, heroin, oxycodone, hydrocodone and amphetamines. Intranasal abuse of cocaine has been studied extensively and it has been documented that the basic mechanism of action is the local vasoconstriction, that causes ischemia and necrosis when it becomes chronic. On the other hand, the drugs men- 


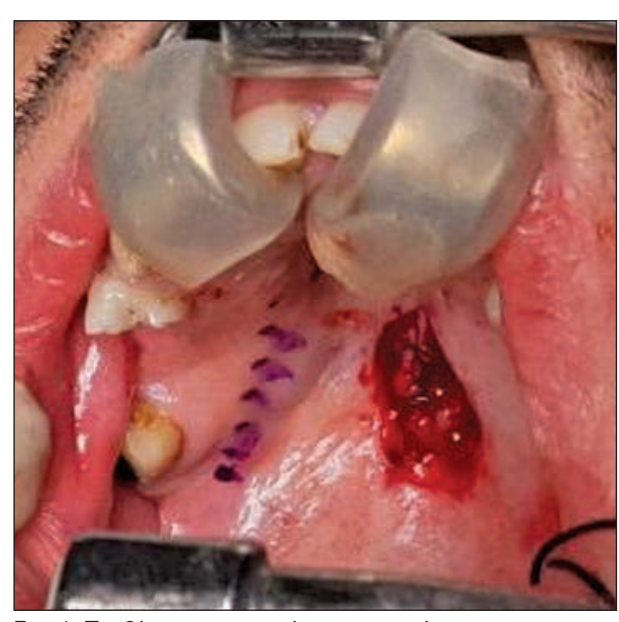

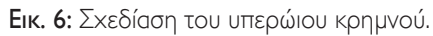

Fig. 6: Palatal flap design.

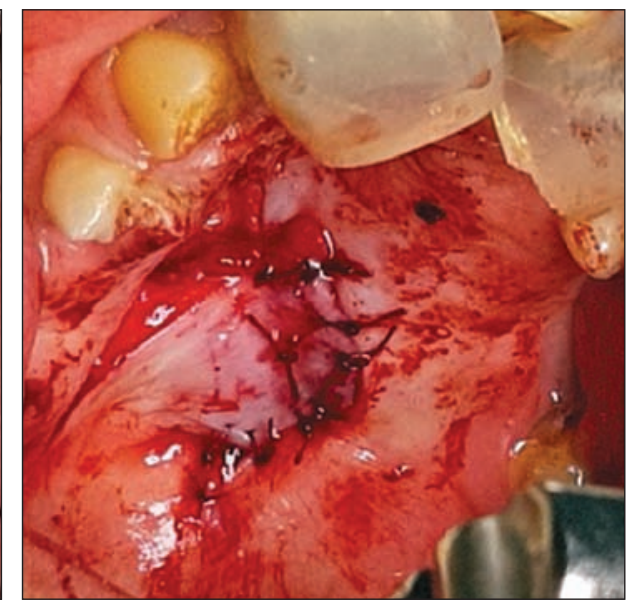

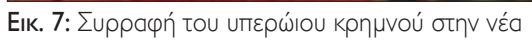

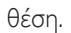

Fig. 7: Suture of the palatal flap in the new position.

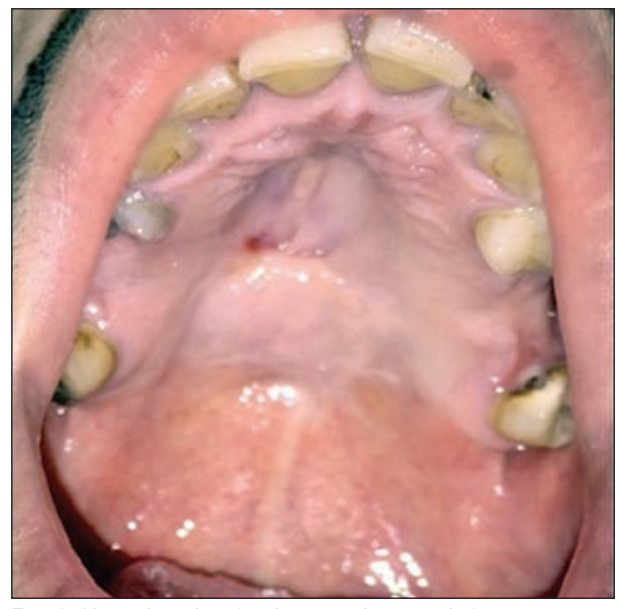

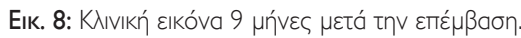
Fig. 8: Clinical view 9 months postoperatively.

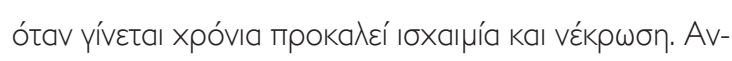

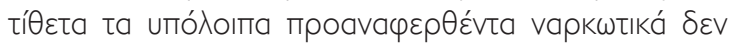

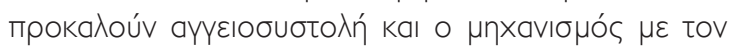

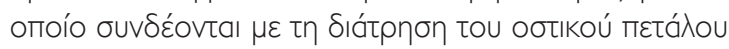

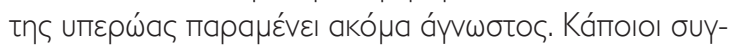

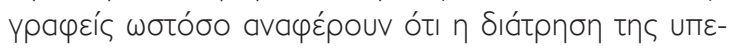
 кokaï̀nৎ (Peryiere kaı ouv. 20।3).

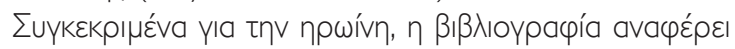

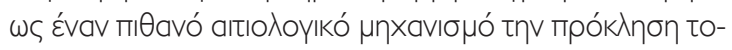

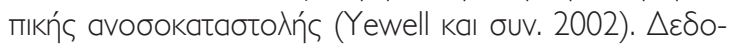

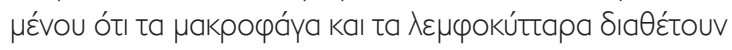

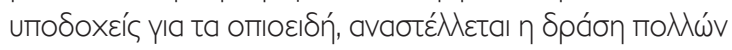

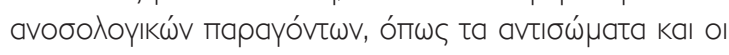

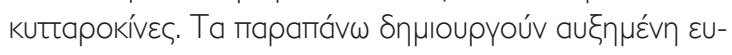

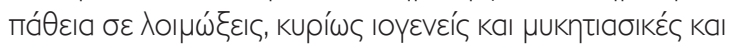

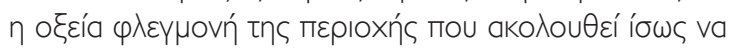

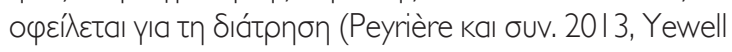

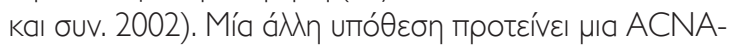

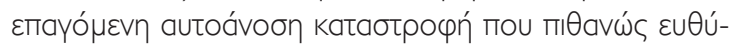

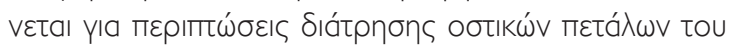

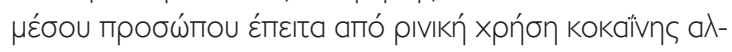

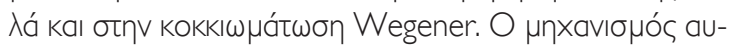

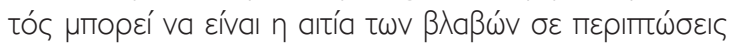

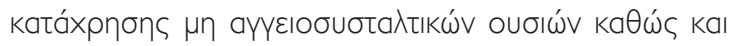

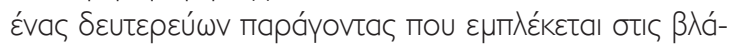

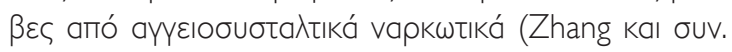

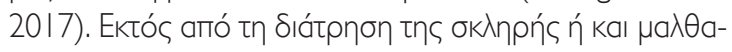

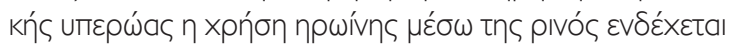

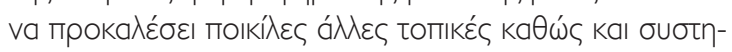

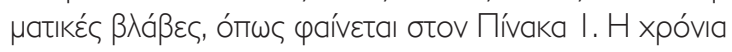

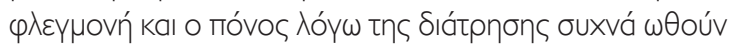

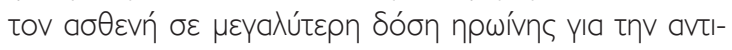

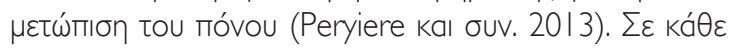

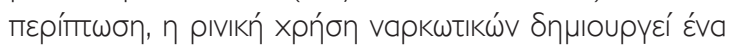

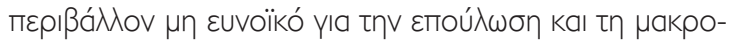

tioned above do not cause vasoconstriction and the mechanism which causes the perforation of the palatal bone plate remains unknown. However, some researchers report that the palatal perforation occurs mainly after the abuse of opioids rather than cocaine (Perviere et al. 2013).

For heroin, in particular, local immunosuppression has been reported in the literature as a possible causal mechanism (Yewell et al. 2002). Due to the fact that macrophages and lymphocytes have opioid receptors, many immunologic factors are inhibited, such as antibodies and cytokines. All the above lead to increased susceptibility to infection, primarily of viral and fungal origin and the acute inflammation of the region that follows might be responsible for the perforation (Peyriere et al. 2013, Yewell et al. 2002). Another hypothesis suggests an Anti-Neutrophilic Cytoplasmic Autoantibody (ANCA)-induced autoimmune deterioration that is possibly responsible in cases of perforation of bone plates in the middle face after intranasal abuse of heroin, but also in Wegener granulomatosis. This mechanism might be the cause of lesions in cases of abuse of vasoconstrictor factors as well as a secondary factor in lesions by vasoconstrictor drugs (Zhang et al. 2017). Except from the perforation of the hard and/or soft palate, the intranasal abuse of heroin might cause various other local as well as systematic lesions, as seen in Table I. Chronic inflammation and pain due to perforation often lead the patient in a higher dose of heroin to alleviate the pain (Peryiere et al. 2013). In any case, intranasal abuse of drugs creates a non-accommodating environment for healing and long-term success of the surgical restoration of the perforation (Peyiere et al. 2013, Zhang et al. 2017). Consequently, the basic step for the success of these patients' treatment is the cessation of abuse and drug detoxification, while the cessation of smoking is also 


\section{Пívakas 1}

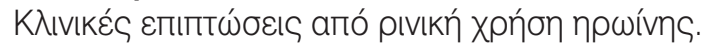

\begin{tabular}{|c|c|c|}
\hline \multirow[t]{3}{*}{ 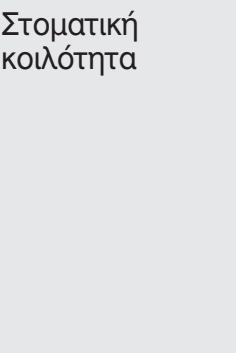 } & $\Delta o ́ v t ı$ каı пєрıобóvтıо & 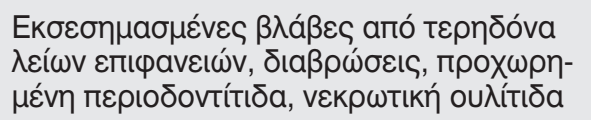 \\
\hline & 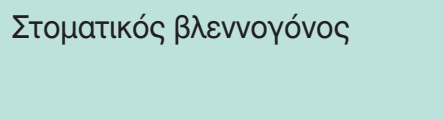 & 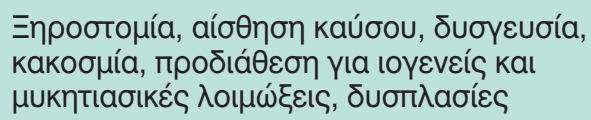 \\
\hline & Үпєрш́а & 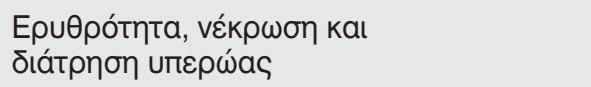 \\
\hline \multirow[t]{2}{*}{$\begin{array}{l}\text { Pivopapuүүikń } \\
\text { oঠóc }\end{array}$} & Pıvıкń коıло́тпта & 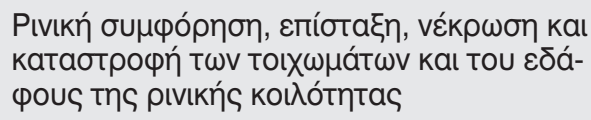 \\
\hline & Фápuyyas & 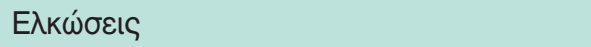 \\
\hline \multirow[t]{3}{*}{ 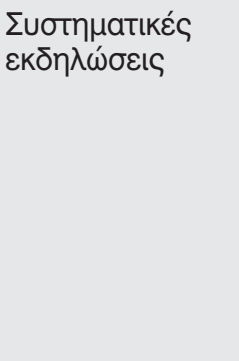 } & 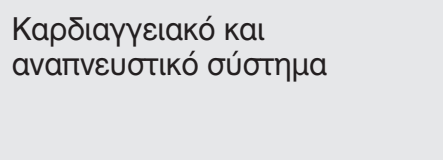 & 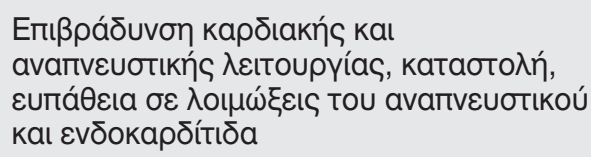 \\
\hline & 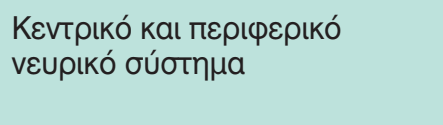 & 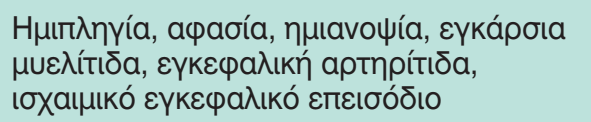 \\
\hline & 'Нпар кaı vعфроі́ & 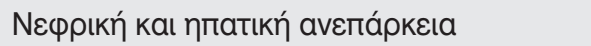 \\
\hline 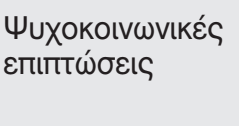 & 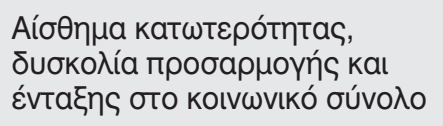 & \\
\hline
\end{tabular}

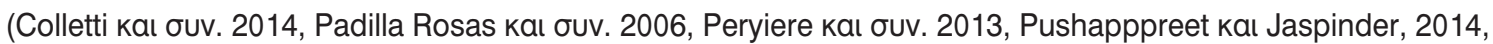

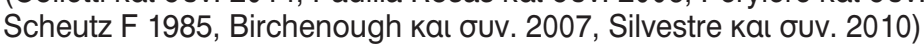

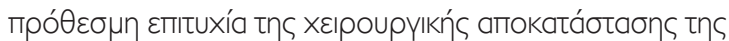

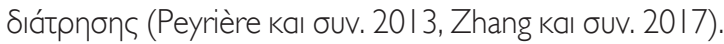

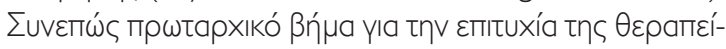

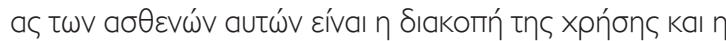

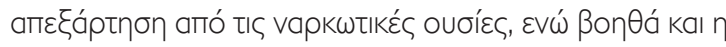

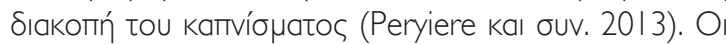

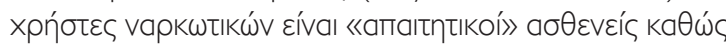

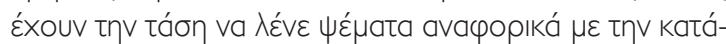

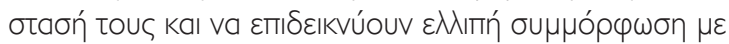

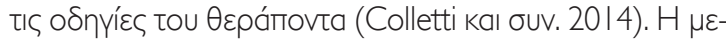

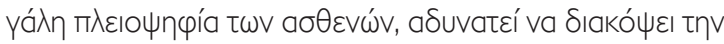

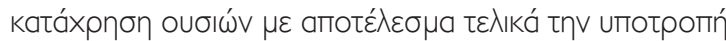

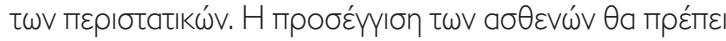

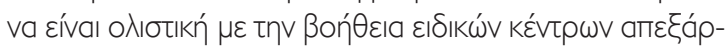

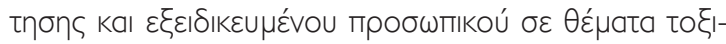

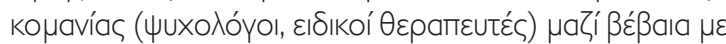

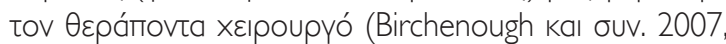
Goodger kal ouv. 2005, Peyrière kal ouv. 2013). Kánoı

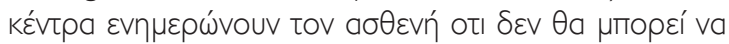

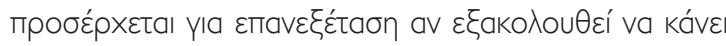

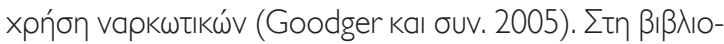

helpful (Peryiere et al. 20 I3). Drug users are demanding patients as they tend to lie regarding their condition and to show lower levels of commitment with the doctor's instructions (Colletti et al. 20/4). The vast majority of the patients is unable to stop the abuse of drugs, resulting in the regression of the cases. The patients should be approached holistically with the aid of special rehabilitation centers and specialized personnel in drug addiction (psychologists, expert therapists) in collaboration with the operating surgeon (Birchenough et al. 2007, Goodger et al. 2005, Peyriere et al. 20 13). Some centers inform the patient that he will not be able to come for reevaluation if he continues drug abuse (Goodger et al. 2005). In the literature it is reported that a therapeutic choice is the delay of the surgical restoration for about a year up to 18 months, in order to monitor, stabilize the patient and treat the possible inflammation with antibiotics (Peyriere et al 2013, El Charkawi and Nasar, 2015). The cessation of abuse is verified through lab tests, such as urine test (Colletti et al. 20 14). However, this is not always possible since the patient is not cooperating every time for a long 


\section{Table 1}

Clinical consequences from intranasal abuse of heroin.

\begin{tabular}{|c|c|c|}
\hline \multirow[t]{3}{*}{ Oral cavity } & Teeth and periodontium & $\begin{array}{l}\text { Marked lesions from smooth surface caries, } \\
\text { erosions, severe periodontitis, necrotic } \\
\text { ulcerative gingivitis }\end{array}$ \\
\hline & Oral mucosa & $\begin{array}{l}\text { Dry mouth, burning sensation, dysgeusia, } \\
\text { halitosis, susceptibility to viral and fungal } \\
\text { infections, dysplasia }\end{array}$ \\
\hline & Palate & $\begin{array}{l}\text { Redness, necrosis and palatal } \\
\text { perforation }\end{array}$ \\
\hline \multirow[t]{2}{*}{$\begin{array}{l}\text { Nasopharyngeal } \\
\text { airway tract }\end{array}$} & Nasal cavity & $\begin{array}{l}\text { Nasal congestion, epistaxis, necrosis and } \\
\text { deterioration of the walls and floor of the } \\
\text { nasal cavity }\end{array}$ \\
\hline & Pharynx & Ulcerations \\
\hline \multirow[t]{3}{*}{$\begin{array}{l}\text { Systemic } \\
\text { manifestations }\end{array}$} & $\begin{array}{l}\text { Cardiovascular and } \\
\text { respiratory system }\end{array}$ & $\begin{array}{l}\text { Decrease of cardiac and respiratory } \\
\text { function, respiratory depression, } \\
\text { susceptibility to respiratory infections } \\
\text { and endocarditis }\end{array}$ \\
\hline & $\begin{array}{l}\text { Central and peripheral } \\
\text { nervous system }\end{array}$ & $\begin{array}{l}\text { Hemiplegia, aphasia, hemianopsia, } \\
\text { transverse myelitis, cerebral vasculitis, } \\
\text { ischemic stroke }\end{array}$ \\
\hline & Liver and kidneys & Liver and kidney failure \\
\hline $\begin{array}{l}\text { Psychosocial } \\
\text { consequences }\end{array}$ & $\begin{array}{l}\text { Feeling of inferiority, difficulty } \\
\text { with social adjustment and } \\
\text { establishment }\end{array}$ & \\
\hline
\end{tabular}

(Colletti et al. 2014, Padilla Rosas et al. 2006, Peyriere et al. 2013, Pushappreet and Jaspinder et al. 2014, Scheutz F 1985, Birchenough et al. 2007, Silvestre et al. 2010)

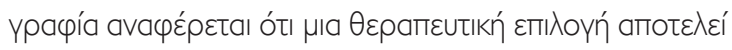

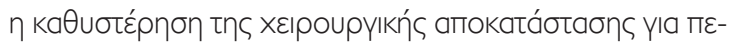

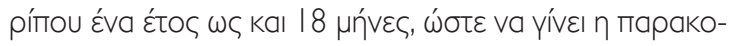

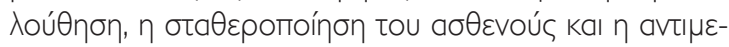

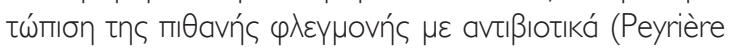

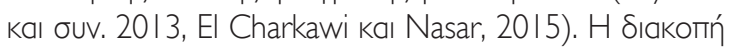

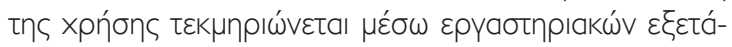

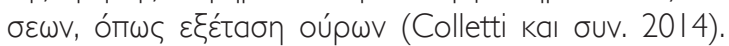

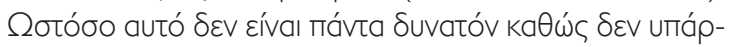

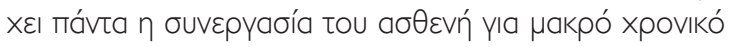

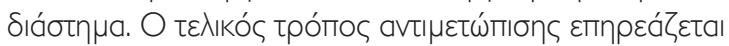

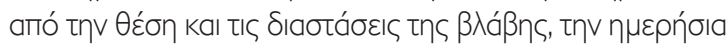

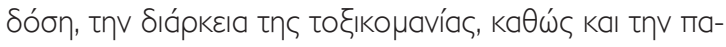

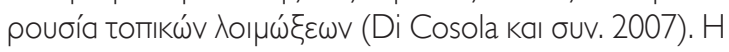

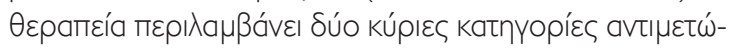

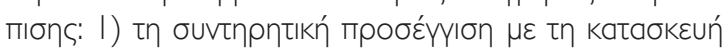

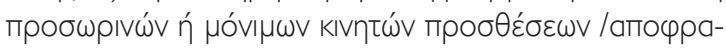

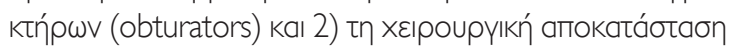

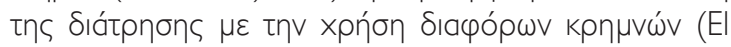
Charkawi kaı Nasar, 20 I5, Goodger kaı ouv. 2005, Di

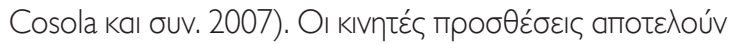

period of time. The final treatment choice depends on the location and the dimensions of the lesion, the daily dose, the duration of drug abuse as well as the presence of local infections (Di Cosola et al. 2007). Treatment includes two main choices: I) the conservative approach with the fabrication of temporary or permanent removable prosthetic devices/obturators and 2) the surgical restoration of the perforation with the use of various flaps (El Charkawi and Nasar, 2015, Goodger et al. 2005, Di Cosola et al. 2007). Removable prosthetic devices are mainly temporary solutions of sealing the palate until the surgical restoration, as well as in cases where the patient refuses surgical treatment. Before the decision to use of an obturator as a restoration method it would be better to observe a stabilization of the size of the perforation (Goodger et al. 2005). Prosthetic restorations also present important disadvantages. Some of them are poor oral hygiene, poor fit/retention, speech difficulties and chronic irritation of the mucosa of the oropharynx from the prosthetic device's fit (El Charkawi and Nasar, 20I5, Di Cosola et al. 2007). Surgical techniques resemble 


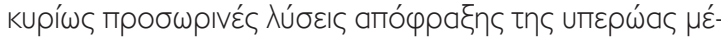

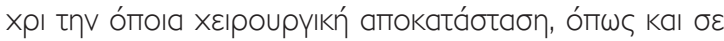

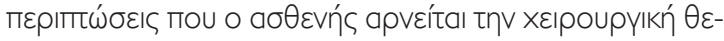

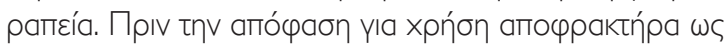

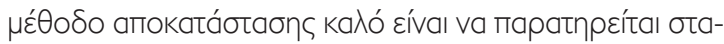

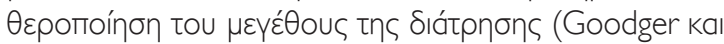

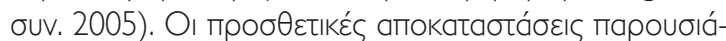

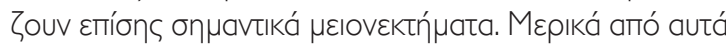

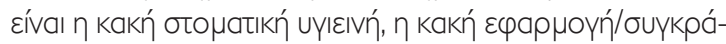

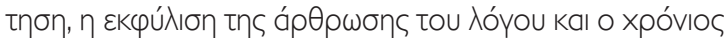

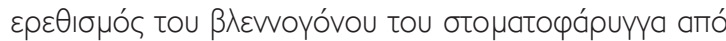

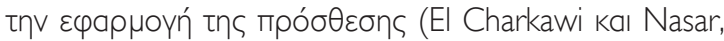

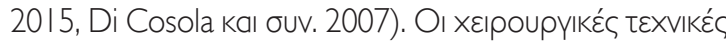

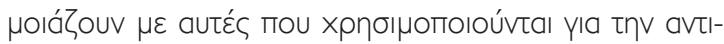

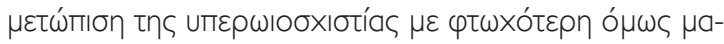

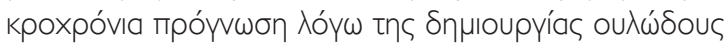

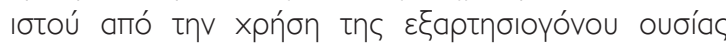

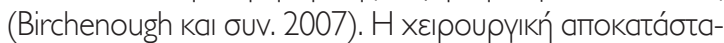

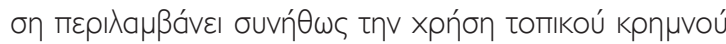

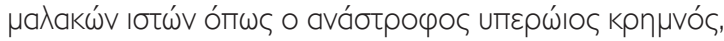

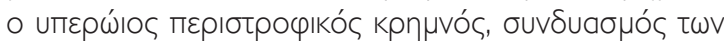

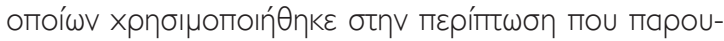

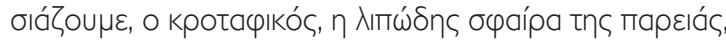

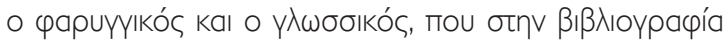

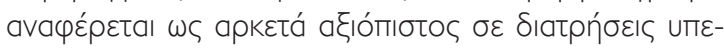

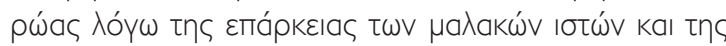

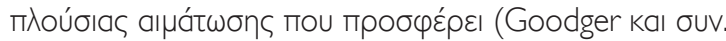

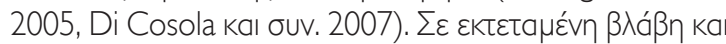

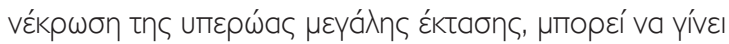

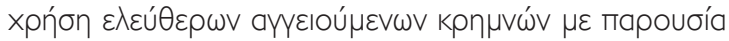

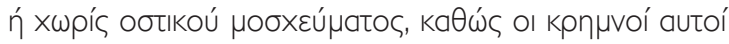

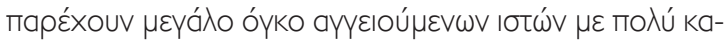

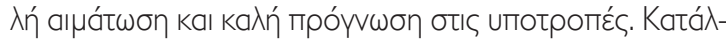

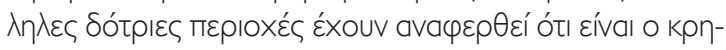

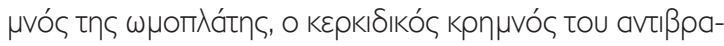

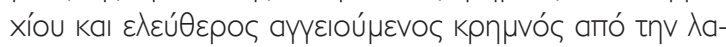

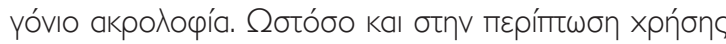

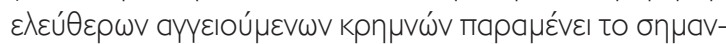

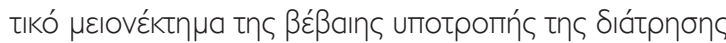

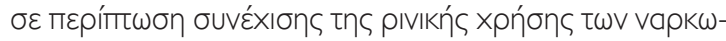

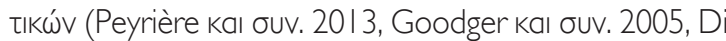

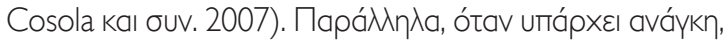

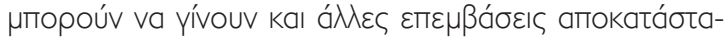

those applied for the treatment of cleft palate, however, with a poorer long-term prognosis due to the formation of scar tissue from the abuse of the drug (Birchenough et al. 2007). Surgical restoration usually includes the use of a local soft tissue flap, such as the reverse palatal flap, the rotating palatal flap, a combination of which was used in the presented case, the buccal fat pad, the pharyngeal and the lingual, which is reported in the literature as fairly reliable in palatal perforations due to the abundance of soft tissues and the rich vascularization that it offers (Goodger et al. 2005, Di Cosola et al. 2007). In extended lesions and necrosis of a large surface of the palate, free vascularized flaps can be used with or without a bone graft, since these flaps offer a large volume of vascularized tissues with very good vascularization and good prognosis in regressions. As appropriate donor areas, the scapular, the radial of the forearm and the free vascularized flap from the iliac crest bone, have been reported. However, the main disadvantage of a certain regression of the perforation in case of continuation of intranasal abuse of drugs still remains in the case of free vascularized flaps (Peyriere et al. 2013, Goodger et al. 2005, Di Cosola et al. 2007). At the same time, other restorative surgeries might be performed when needed, such as rhinoplasty, but often there is a disruption of the tissues' blood flow which makes for a poorer prognosis. Therefore, it is recommended that they are performed separately (Colletti et al. 20 I4). The training of the patient in speech, mastication and swallowing is important in order to obtain a more complete nutrition (Myon et al. 2010).

\section{CONCLUSIONS}

Palatal perforation from intranasal abuse of heroin is a rare lesion that significantly affects well-being of the patient. The selection of the appropriate surgical technique depends on many factors and mainly from the condition of the local tissues. An important factor in the preservation of the final result is the cessation of the addiction effort and the commitment of the patient to the instructions. This effort should be aided by expert therapists such as psychiatrists or psychologists always in collaboration with the operating surgeon. 


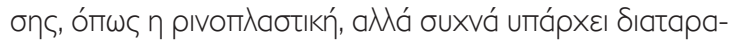

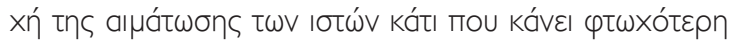

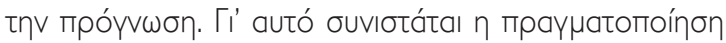

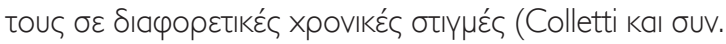

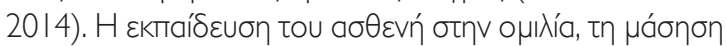

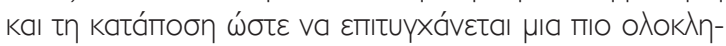

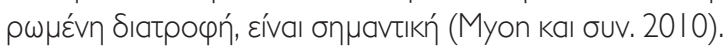

\section{¿YMПЕРА $\Sigma$ MATA}

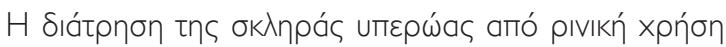

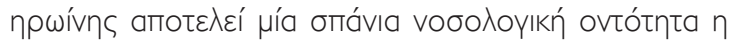

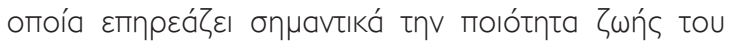

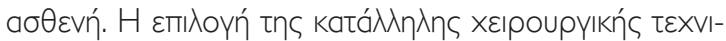

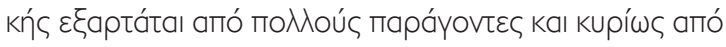

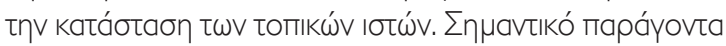

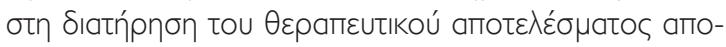

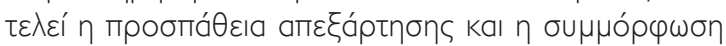

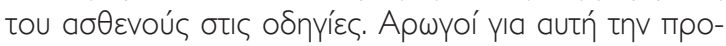

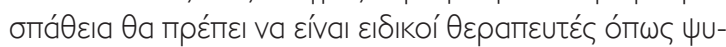

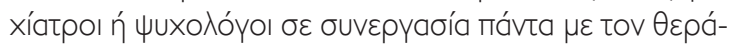
поvта хعıрoupyó.

\section{ВІВАIOГРАФIA/REFERENCES}

Bakhshaee M, Khadivi E, Sadr MN, Esmatinia F: Nasal septum perforation due to methamphetamine abuse. Iranian journal of otorhinolaryngology 25:53-56, 2013

Birchenough SA, Borowitz K, Lin KY: Complete soft palate necrosis and velopharyngeal insufficiency resulting from intranasal inhalation of prescription narcotics and cocaine. J Craniofac Surg 18: I 4821485, 2007

Chhabra L, Abraham GM: An unusual oro-naso-sinus communication resulting from heroin and cocaine snorting, BMJ Case Rep doi: $10.1136,2013$

Colletti G, Autelitano L, Chiapasco M, Biglioli F, Giovanditto F, Mandalà $\mathrm{M}$, Allevi F: Comprehensive surgical management of CIMDL. Journal of Oral and Maxillofacial Surgery 72:el - I0, 2014

Di Cosola M, Turco M, Acero J, Navarro-Vila C, Cotelazzi R: Cocainerelated syndrome and palatal reconstruction: report of a series of cases. International Journal of Oral and Maxillofacial Surgery 36:721-727, 2007

El Charkawi H, Nasar H: Prosthetic management of palatal perforation in heroin abuse patient. Dent Oral Craniofac Res doi: 10.1576I, 2015

European Monitoring Centre for Drugs and Drug Addiction, EU Drug Markets: Impact of Covid-19, May 2020

Goodger NM, Wang J, Pogrel MA: Palatal and nasal necrosis resulting from cocaine misuse. Br Dent J 198:333-334, 2005

Hines LA, Lynskey M, Morley Kl, Griffiths P, Gossop M, Powis B, Strang J: The relationship between initial route of heroin administration and speed of transition to daily heroin us. Drug Alcohol Rev 36:633-638, 2017

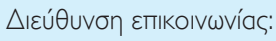

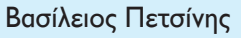

'Apvnৎ 2,

| 1528 A日ńva

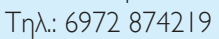

e-mail: vasipets@yahoo.gr
}

Iqbal I, Alam Khan MA, Ullah W: Can inhaled heroin be a cause of bilateral globus pallidus ischemic injury? Turk J Emerg Med 19:3941, 2018

Myon L, Delforge A, Raoul G, Ferri JQ: Palatal necrosis due to cocaine abuse. Rev Stomatol Chir Maxillofac I | 1:32-35, 2010

Padilla Rosas M., Jiménez Santos Cl, García González CL: Palatine perforation induced by cocaine. Med Oral Patol Oral Cir Bucal I I:e239-342, 2006

Peyrière H, Léglise Y, Rousseau A, Cartier C, Gibaja V, Galland P: Necrosis of the Intranasal Structures and Soft Palate as a Result of Heroin Snorting: A Case Series. Substance Abuse 34:409-414, 2013

Pushappreet K, Jaspinder K: Oronasal Fistula and Complete Edentulism: What to Do? Dent J 2: I 42- I54, 2014

Scheutz F: Dental Habits, Knowledge, and Attitudes of Young Drug Addicts. Scand I Soc Med I3:35-40, 1985

Shekarchizadeh H, Khami MR, Mohebbi SZ, Ekhtiari H, Virtanen Jl: Oral Health of Drug Abusers: A Review of Health Effects and Care. Iran J Public Health 42:929-940, 2013

Silvestre FJ, Perez-Herbera A, Puente-Sandoval A, Bagán JV: Hard palate perforation in cocaine abusers: a systematic review. Clinical Oral Investigations 14:621-628, 2010

Smith JC, Kacker A, \& Anand VK: Midline Nasal and Hard Palate Destruction in Cocaine Abusers and Cocaine's Role in Rhinologic Practice. Ear, Nose \& Throat Journal 81:172-177, 2002

Yewell J, Haydon R, Archer S, Manaligod JM, Complications of intranasal prescription narcotic abuse. Ann Otol Rhinol Laryngol | | |:| 174- |77, 2002

Zhang D, Patel, K. B., Cass, LM, Foster, AE, Guntupalli L, Brunworth JD: Heroin-induced nasal necrosis and septal perforation. Acta Oto-Laryngologica Case Reports 2: I45-149, 2017

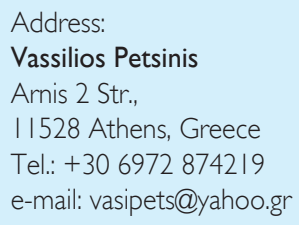





\section{Mucormycosis. Case report and literature review}

Shunmugavelu KARTHIK', Arasu SHANMUGAM², Evangeline Cynthia DHINAKARAN³,

Shenbagasavari Perumal JANANI ${ }^{4}$, Raghavelu Narendran MUGUNDAN ${ }^{5}$

1,3,4,5 Dentistry/Oral and Maxillofacial Pathology, Mercy Multispeciality Dental Centre, Chrompet, Chennai, Tamilnadu, India

${ }^{2}$ Oral and maxillofacial surgery, Fortis Hospital, Vadapalani, Chennai, Tamilnadu, India

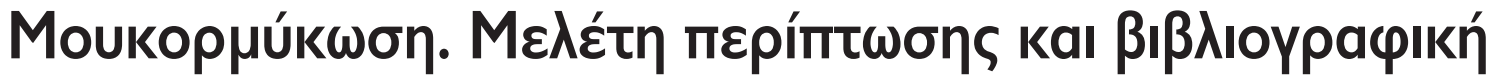

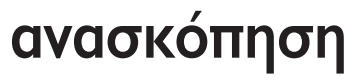

Shunmugavelu KARTHIK', Arasu SHANMUGAM², Evangeline Cynthia DHINAKARAN²,

Shenbagasavari Perumal JANANI ${ }^{4}$, Raghavelu Narendran MUGUNDAN ${ }^{5}$

1,3,4,5 Dentistry/Oral and Maxillofacial Pathology, Mercy Multispeciality Dental Centre, Chrompet, Chennai, Tamilnadu, India

2 Oral and maxillofacial surgery, Fortis Hospital, Vadapalani, Chennai, Tamilnadu, India

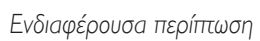
$\mu \varepsilon$ Bıß入оурачіки́ Avaбкómпоп Case Report with Literature Review
'BDS, MSC (London), MDS OMFP, MFDS RCSENG, MCIP, FIBMS (USA), MASID (Australia)

Director - Dentistry/Oral and

Maxillofacial Pathology

${ }^{2}$ BDS MDS Oral and

Maxillofacial Surgery

Lecturer

${ }^{3}$ BDS MDS OMFP Consultant - Oral and Maxillofacial Pathology

${ }^{4} \mathrm{MBBS} P \mathrm{PGDMCH}$ FUSOBG MD Pathology Consultant Pathology

${ }^{5}$ BDS MDS OMFP

Consultant - Oral and Max-

illofacial Pathology
SUMMARY: Mucormycosis the life-threatening opportunistic fungal infection affects primarily immuno-compromised patients in an aggressive manner. Mucormycosis in the oral cavity is not common. The case we report presented with infra orbital swelling and pain with radiographic appearance of small area of bone destruction in maxillary anterior region. The patient also had uncontrolled type 2 diabetes. The patient underwent extraction of his anterior teeth 10 days back before he developed the swelling and pain. The primary diagnosis was osteomyelitis. After the histopathology diagnosis of mucormycosis the patient was immediately started with Amphotericin-b and surgical debridement of the involved site was done. The combination of medical and surgical treatment of mucormycosis will have good prognosis.

KEY WORDS: mucormycosis, amphotericin-b, type 2 diabetes, surgical debridement.

Paper received: 6/3/2021 - Accepted: 8/3/2021

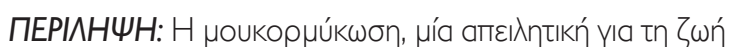

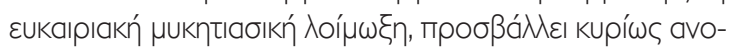

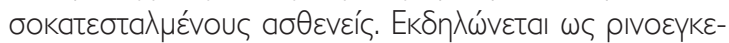

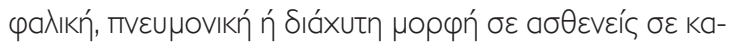

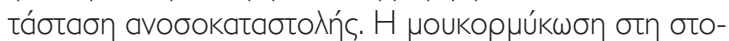

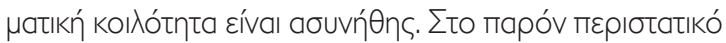

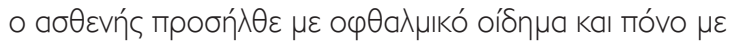

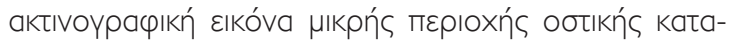

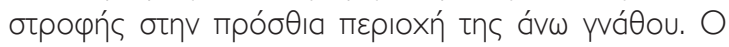

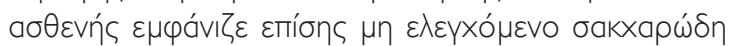

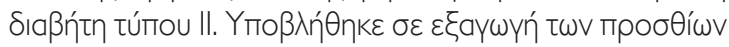

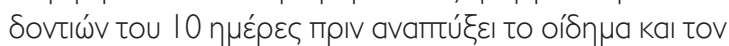

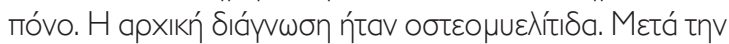

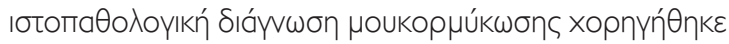

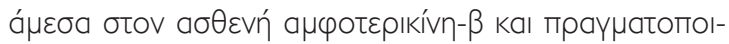

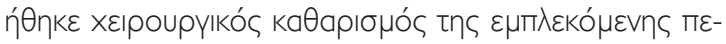

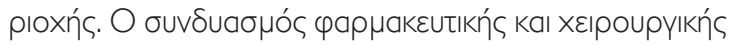
Ө

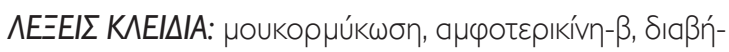

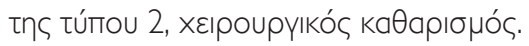




\section{INTRODUCTION}

Mucormycosis is an invasive disease caused by a group of filamentous molds. The most common causative organism associated with Mucormycosis are Rhizopus species (Reid et al.). It has poor prognosis. It is a rare terminal complication of uncontrolled diabetes and other chronic debilitating disease. The incidence of the disease increased due to widespread use antibiotics and steroids. The fungi are normally avirulent and are able to invade the tissue only when the general resistance is low. The pathogenesis of mucormycosis involves inhalation or ingestion of sporangiospores of conidia. The nosocomial outbreaks of mucormycosis have been associated with medical waste, contaminated bandages, medical equipment, and ventilation systems (Kancharu et al.). By oxidative and non-oxidative killing mechanisms the mononuclear cells eliminate the fungal spores in healthy individuals. The various risk factors associated with mucormycosis are diabetes mellitus (poorly controlled and ketoacidosis), organ transplantation, autoimmune disorders, immunosuppressive therapy, HIV, burns, iron overload and malnutrition (Kancharu et al.). Mucormycosis can be classified based on anatomical location as: rhino orbital - celebral - mucormycosis, pulmonary, cutaneous, gastrointestinal tract, disseminated and uncommon sites (bones, peritoneum, heart) (Prabhu et al., Palacios et al.).

\section{CASE DESCRIPTION}

A 55 year old male patient came with the chief complaint of pain and swelling in upper front teeth region for the past 4 days and the also complained of foul smell and discharge from the nose. On examination the patient was well nourished and no lymph node enlargement was seen on palpation. There was slight infraorbital swelling and nasal blockage on the right side. There was no nasal discharge. The patient had type 2 diabetes and hypertension for the past 15 years and was taking medication. There was no history of trauma on the affected side.

On intraoral examination, there was swelling and ulcer in relation to 12, 13 and 14 region. Probing on bleeding was seen, and upper right buccal mucosa with black necrotic gingival tissue extending to maxillary central incisor was seen (Figure 1\&2). Dental history of the patient revealed that the patient had undergone uneventful extraction of right maxillary canine and lateral incisors 10 days back. Panoramic radiograph showed small area of bone destruction in right maxillary tooth region and generalized horizontal bone loss. Laboratory examination of blood sugar level, $\mathrm{HbAlc}$, full blood count, erythrocyte sedimentation rate, retroviral screening was done. Gingival biopsy was taken for the histopathology diagnosis. Before laboratory and histopathology results, the patient with the provisional diagnosis of osteomyelitis was started with cephalexin, metronidazole and analgesic.

\section{$\operatorname{EI} \Sigma \mathrm{A} \Gamma \Omega \Gamma \mathrm{H}$}

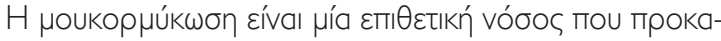

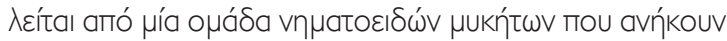

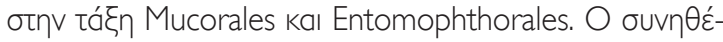

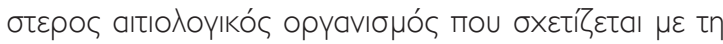

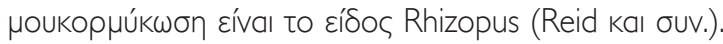

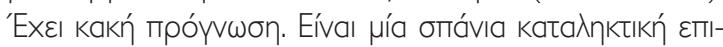

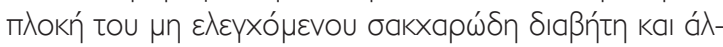

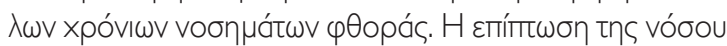

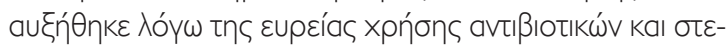

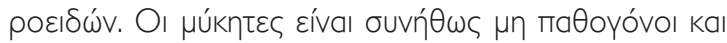

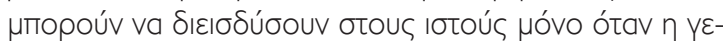

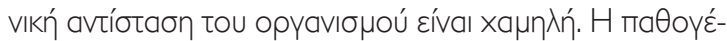

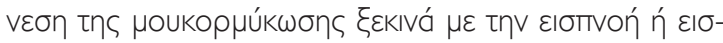

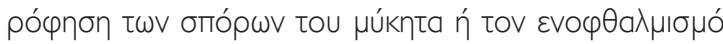

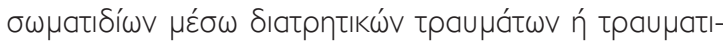

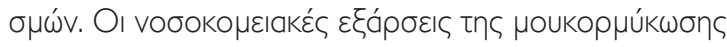

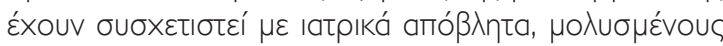

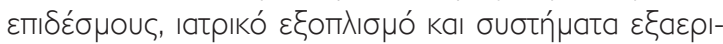

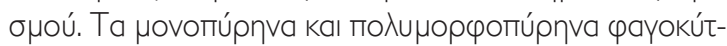

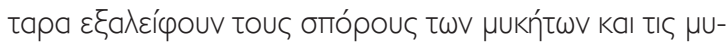

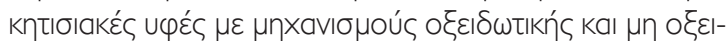

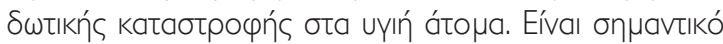

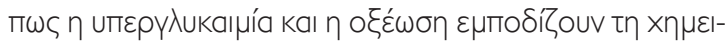

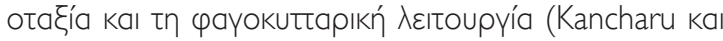

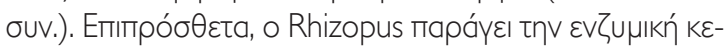

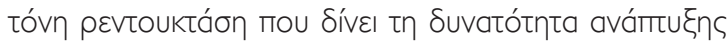

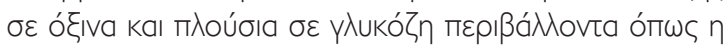

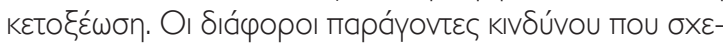

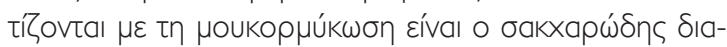

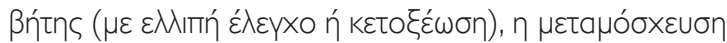

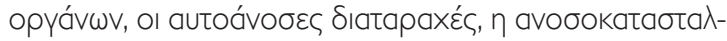

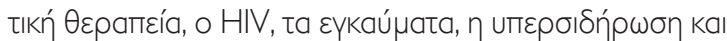

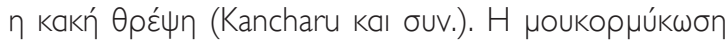

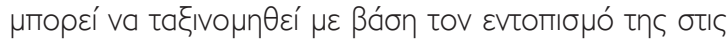

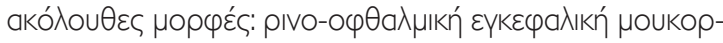

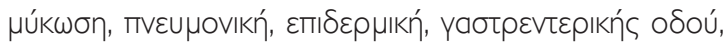

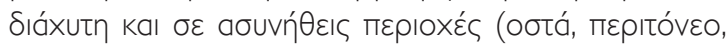

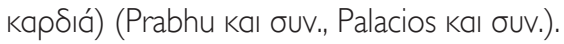

\section{MEАЕTH ПЕРІПТ $\Omega \Sigma H \Sigma$}

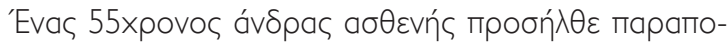

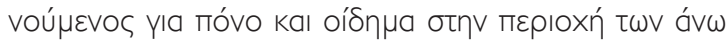

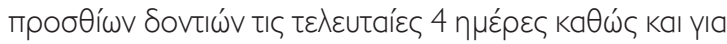

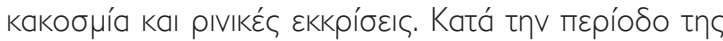

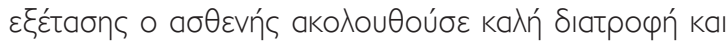

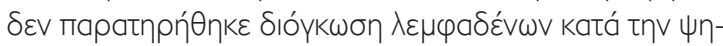

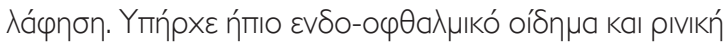

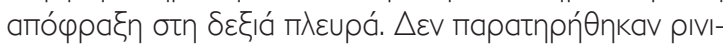

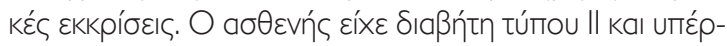

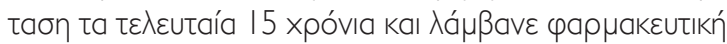

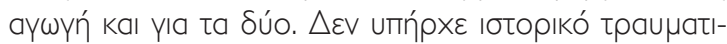

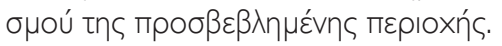

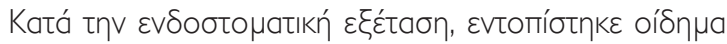




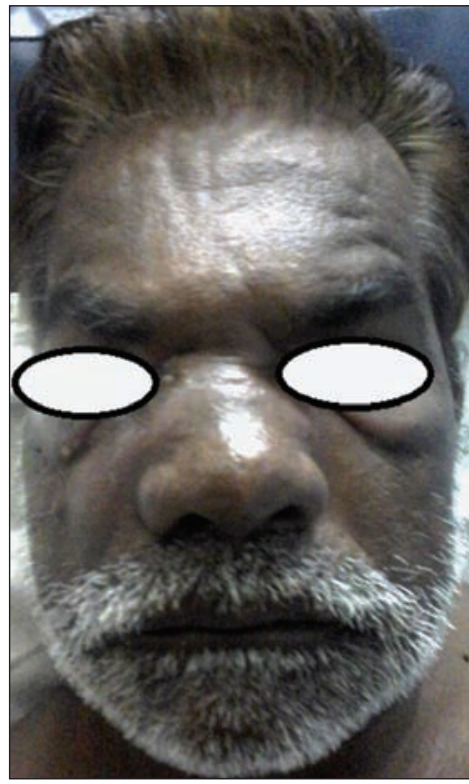

Fig. I: Facial asymmetry with infraorbital swelling

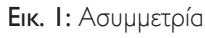
пробஸ́по $\mu \varepsilon$ пврı-

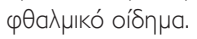

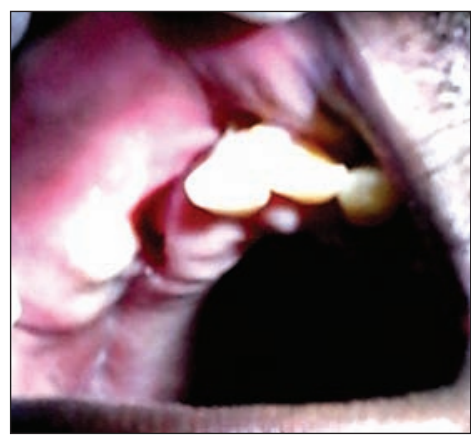

Fig. 2: Intraoral swelling and ulcer in maxillary anterior region

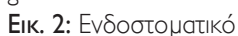

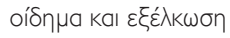

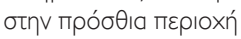

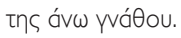

The blood sugar levels were elevated and $\mathrm{HbAlc}$ level was 9, retroviral screening turned out negative, WBC and ESR levels were elevated. The histopathology result came as mucormycosis. The patient was immediately started with amphotericin B and the surgical debridement involved removal of the maxillary right central incisor and curettage of all necrotic tissues. Bismuth lodine Paraffin antiseptic pack was placed. The sinus was irrigated with $0.2 \%$ Chlorhexidine and $3 \%$ hydrogen peroxide solutions and the pack was regularly changed every 7 days for a period of 3 weeks till the wound healed completely. In between the patient was also referred to endocrinologist on the basis of laboratory results before the surgical debridement. The patient was asked to take insulin to control the diabetes by the endocrinologist. The patient was followed up for another 2 weeks and the wound was completely healed.

\section{DISCUSSION}

Oral mucormycosis is a rare disease mostly seen in immuno compromised patients as studied in the literature. Hard palate has been reported to be the most most

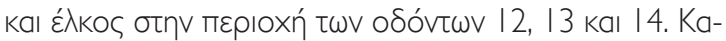

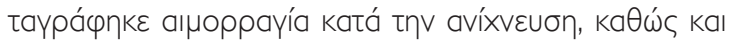

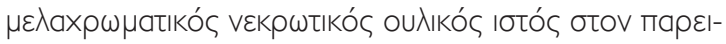

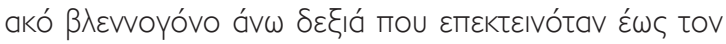

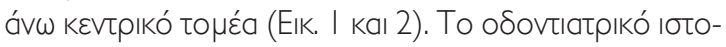

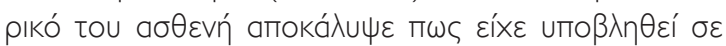

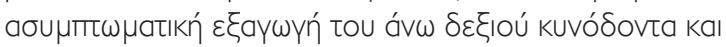

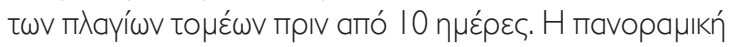

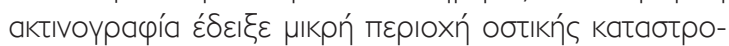

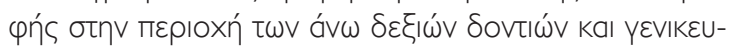

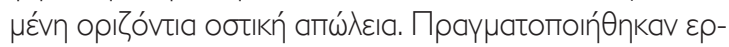

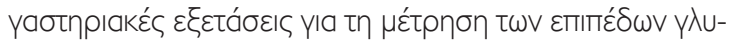

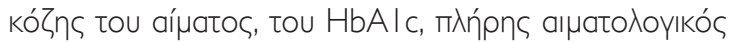

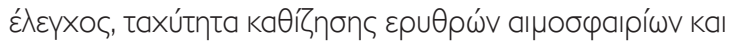

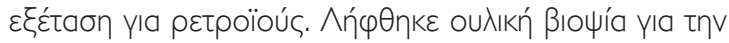

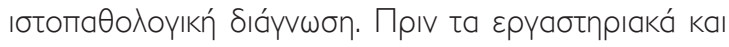

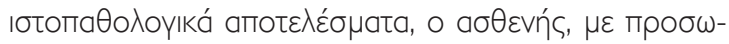

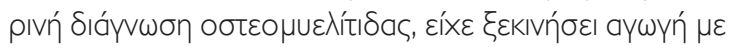

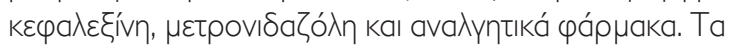

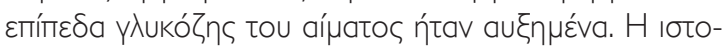

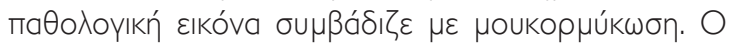

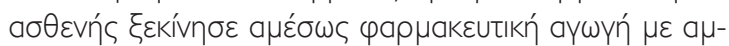

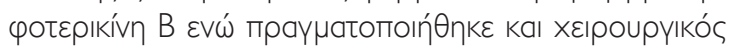

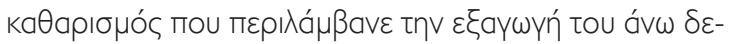

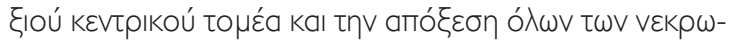

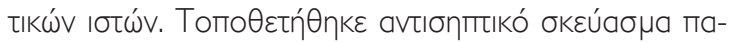

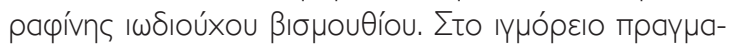
топоı́́Ө

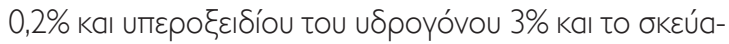

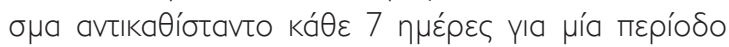

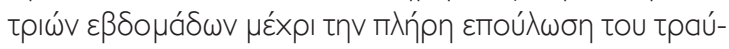

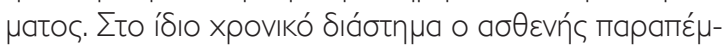

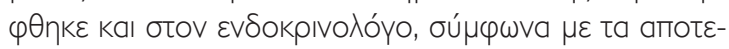

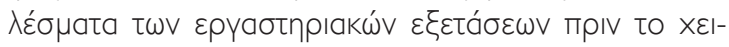

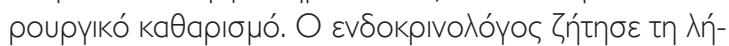

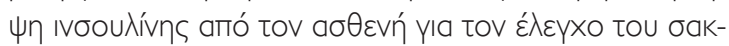

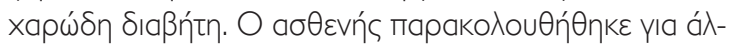

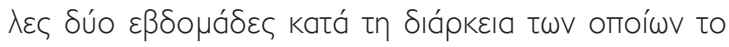

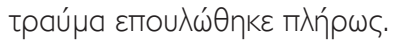

\section{$\Sigma Y Z H T H \Sigma H$}

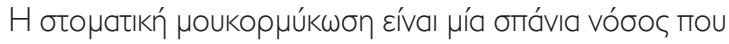

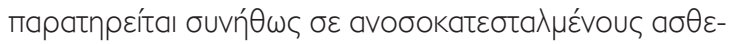

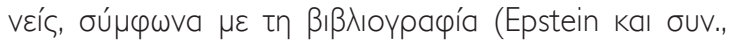

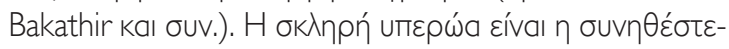

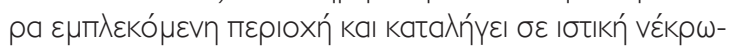

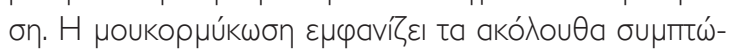

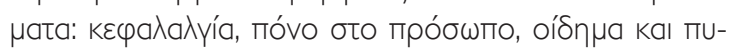

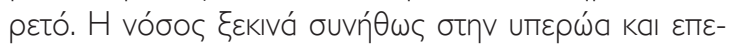

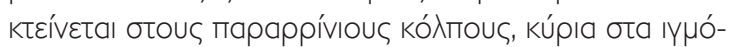

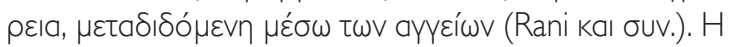

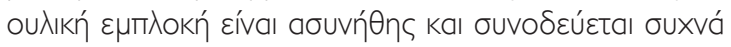

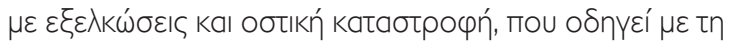

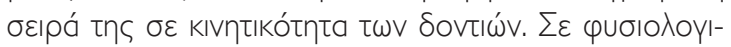


common site of involvement leading to tissue necrosis (Epstein et al., Bakathir et al.). Mucormycosis has the following symptoms headache, facial pain, swelling and fever. The disease most commonly begins in the palate and extends to the paranasal sinuses spreading through the surrounding vessels (Rani et al.). Gingival involvement is not common, which is usually accompanied with ulceration and bone destruction which in turn leads to mobility of the teeth. In normal hosts, Rhizopus are eliminated by mononuclear and polymorphonuclear phagocytes by the production of oxidative metabolites and cationic peptides. The oxidative capacity is lost in patients with diabetic ketoacidosis. The reduced chemotaxis and phagocytic efficiency in these patients permit the growth of innocuous organisms. The hyperglycemic state patients are highly susceptible to mucormycosis since they promote fungal growth (Shastri et al.).

Once it begins to grow, invasion of human host takes place through attaching of the fungus to the endothelial cell lining of blood vessels leading to haematogenous spread, thrombosis, bleeding or infarction (NicolatouGalitis et al.). This leads to the formation of black necrotic eschars that are formed on the nasal or palatine mucosa, characteristic feature of mucormycosis. There is also evidence that an area of ulceration or an extraction socket in the mouth in an immuno compromised patient can also be the port of entry for mucormycosis (Cohen et al., Shastri et al.). Histologically, mucormycosis is characterized by tissue necrosis, the presence of numerous large thin-walled fungal hyphae size ranges between 5-30um, which are non-septate, branched at right angles and have a ribbon-like appearance (Rani et al., Cheong et al.).

As the disease progresses aggressively, immediate therapy and medication for the underlying disease is essential (Kudo et al.). For the treatment of mucormycosis to be successful it should include aggressive and repeated surgical debridement of necrotic tissue, antifungal therapy, and immediate control of the underlying systemic diseases. Amphotericin B is most commonly used along with the surgical debridement according the literature review (Rai et al., Swain et al.).

\section{CONCLUSION}

The early diagnosis of mucormycosis and immediate start of antifungal therapy and surgical debridement along with underlying systemic disease treatment helps to reduce mortality and morbidity of this disease.

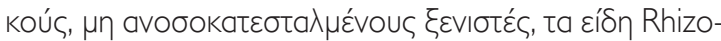

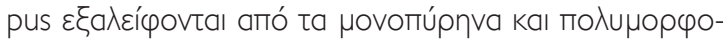

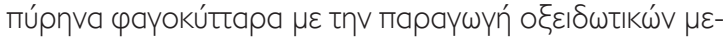

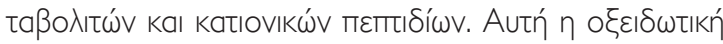

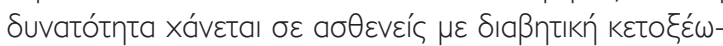

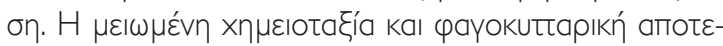

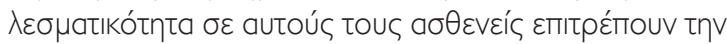

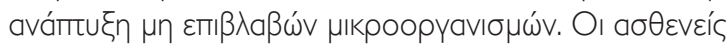

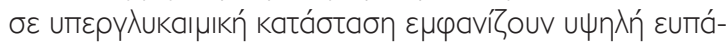

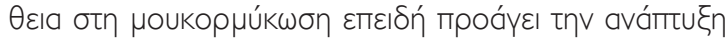

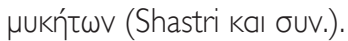

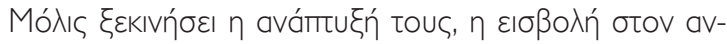

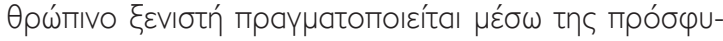

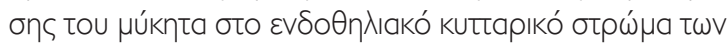

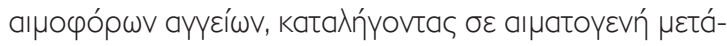

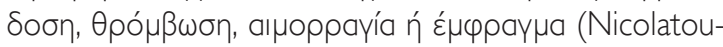

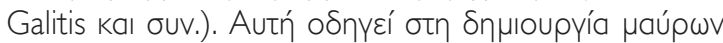

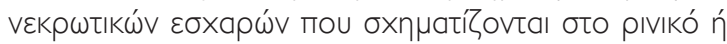

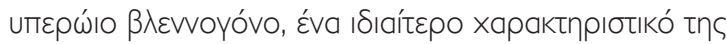

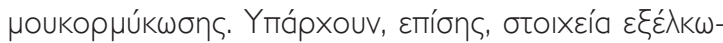

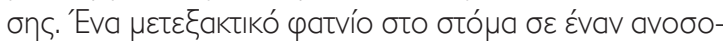

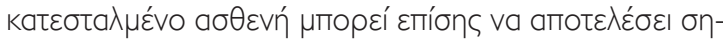

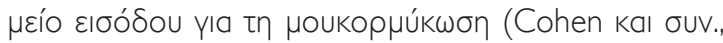

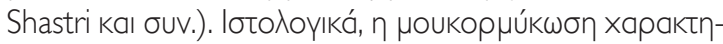

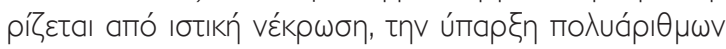

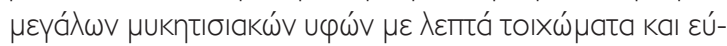

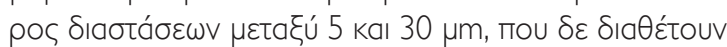

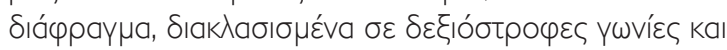

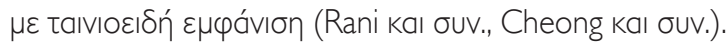

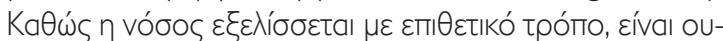
бı

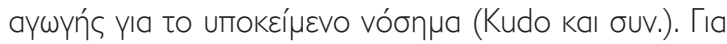

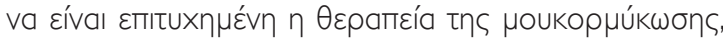

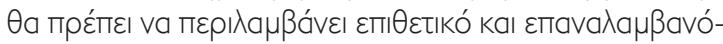

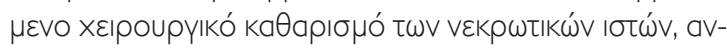

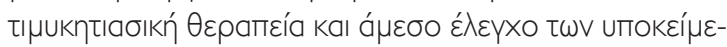

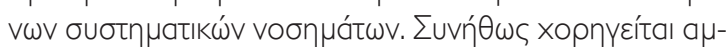

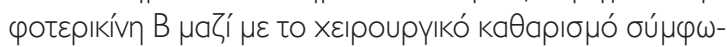

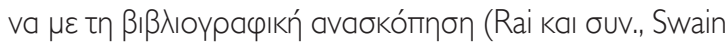
kal ouv.).

\section{¿YMПЕРА}

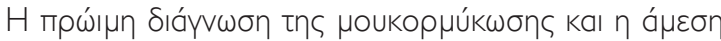

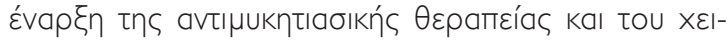

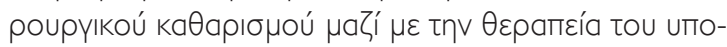

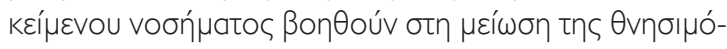

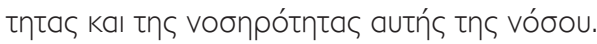




\section{ВIВАIOГРАФІA/REFERENCES}

Reid G, Lynch III JP, Fishbein MC, Clark NM. Mucormycosis. InSeminars in respiratory and critical care medicine 2020 Feb (Vol. 4I, No. 01, pp. 099-1 | 4). Thieme Medical Publishers.

Kancharu FK, Viswam V, Sreeram P, Warrier A, Karunakaran A. Mucormycosis of Neck a Rare Presentation. Indian Journal of Otolaryngology and Head \& Neck Surgery. 2020 Aug 5:I-5.

Prabhu RM, Patel R. Mucormycosis and entomophthoramycosis: a review of the clinical manifestations, diagnosis and treatment. Clinical Microbiology and Infection. 2004 Mar; 1 0:31 -47.

Palacios J], Hanson EV, Rendon MA, Infante RS. Reconstruction of Head and Neck Mucormycosis: A Literature Review and Own Experience in Immediate Reconstruction. Journal of Reconstructive Microsurgery Open. 2019 Jul;4(02):e65-72.

Epstein JB, Kupferman SB, Zabner R, Rejali A, Hopp ML, Lill M, Tzachanis $\mathrm{D}$. Early diagnosis and successful management of oral mucormycosis in a hematopoietic stem cell transplant recipient: case report and literature review. Supportive Care in Cancer. 2016 Aug 1;24(8):3343-6.1

Bakathir AA. Mucormycosis of the jaw after dental extractions: two case reports. Sultan Qaboos University Medical Journal. 2006 Dec;6(2):77.

Rani SU, Sivaranjani Y, Kumar MP, Rao GV. Rhinocerebral mucormycosis associated with actinomycosis in a diabetic patient: A rare presentation. Journal of Oral and Maxillofacial Pathology: JOMFP. 2019 Feb;23(Suppl I):122.

Nicolatou-Galitis O, Sachanas S, Drogari-Apiranthitou M, Moschogiannis M, Galiti D, Yiakoumis X, Rontogianni D, Yiotakis I, Petrikkos $G$, Pangalis $G$. Mucormycosis presenting with dental pain and

\section{Address:}

\section{Dr. Karthik Shunmugavelu}

8/27, Parvathipuram Ist Street, Thiruneermalai Main Road, Chrompet, Chennai - 600034, Tamilnadu, India

Tel.: 009|-9789885622/9840023697

e-mail: drkarthiks1981@gmail.com palatal ulcer in a patient with chronic myelomonocytic leukaemia: case report and literature review. JMM Case Reports. 2015 Feb l;2(I):e0000। 4 .

Cheong HS, Kim SY, Ki HK, Kim JY, Lee MH. Oral mucormycosis in patients with haematologic malignancies in a bone marrow transplant unit. Mycoses. 2017 Dec;60(I2):836-4I.

Cohen A, Shoukair FL, Korem M, Shaulov A, Casap N. Successful Mandibular Mucormycosis Treatment in the Severely Neutropenic Patient. Journal of Oral and Maxillofacial Surgery. 2019 Jun I;77(6): | 209-el.

Shastry S, Murthy P, Jyotsna T, Kumar N. Cone beam computed tomography: A diagnostic aid in rhinomaxillary mucormycosis following tooth extraction in patient with diabetes mellitus. Journal of Indian Academy of Oral Medicine and Radiology. 2020;32(I):60-4

Rai S, Misra D, Misra A, Jain A, Jain P, Dhawan A. Palatal mucormycosis masquerading as bacterial and fungal osteomyelitis: A rare case report. Contemporary clinical dentistry. 2018 Apr;9(2):309.

Kudo K, Hasegawa H, Sato E, Kaneko T, Ishida D, Kanno C, Endo M. A case of rhinocerebral mucormycosis extending into the skull. Journal of oral and maxillofacial surgery, medicine, and pathology. 2017 Jan 1;29(I):61-4.

Swain SK, Behera IC, Mohanty JN. Mucormycosis in head-and-neck region-Our experiences at a tertiary care teaching hospital of Eastem India. Annals of Indian Academy of Otorhinolaryngology Head and Neck Surgery. 2019 Jul I;3(2):58.

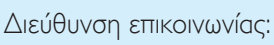

\section{Dr. Karthik Shunmugavelu}

8/27, Parvathipuram Ist Street, Thiruneermalai Main Road, Chrompet, Chennai - 600034, Tamilnadu, India

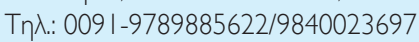
e-mail: drkarthiks1981@gmail.com 



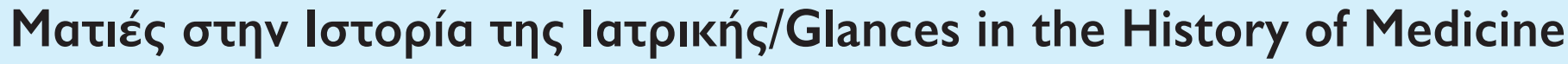

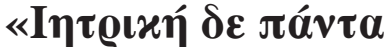 \\ $\pi \alpha ́ \lambda \alpha \iota ~ v \pi \alpha ́ \varrho \chi \varepsilon l . . . »$

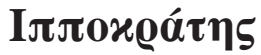

Vilray Papin Blair:

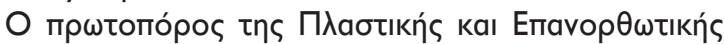

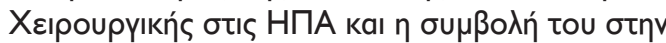

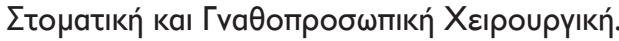

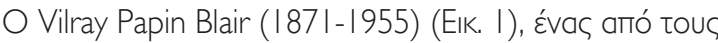

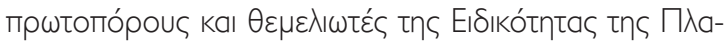

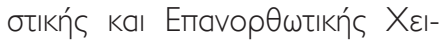

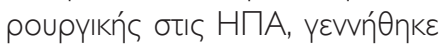
бo St. Louis tou Missouri, ouı 15 louvíou 187I, anó yoveíc amoyó-

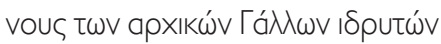

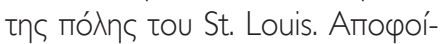
тทбє to 1890 amó to Christian

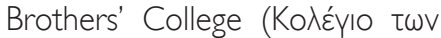

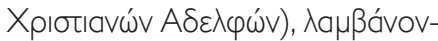
taৎ to muxío Bachelor of Arts

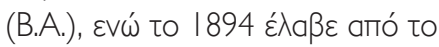
í́ı Koגéyı to muxío Master of

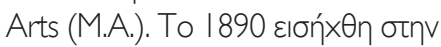

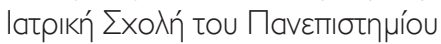
Washington tou St. Louis, an'

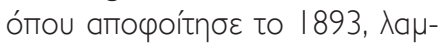
ßávovtas to muxío tou Iatpoú

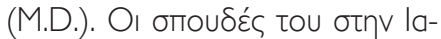

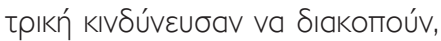

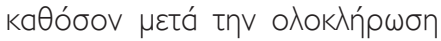
tou при́tou ह́tous o Vilray Blair

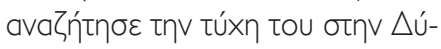

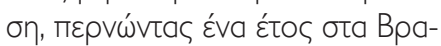

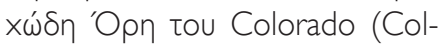
orado Rockies), ómou epyaßótav

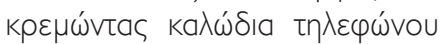

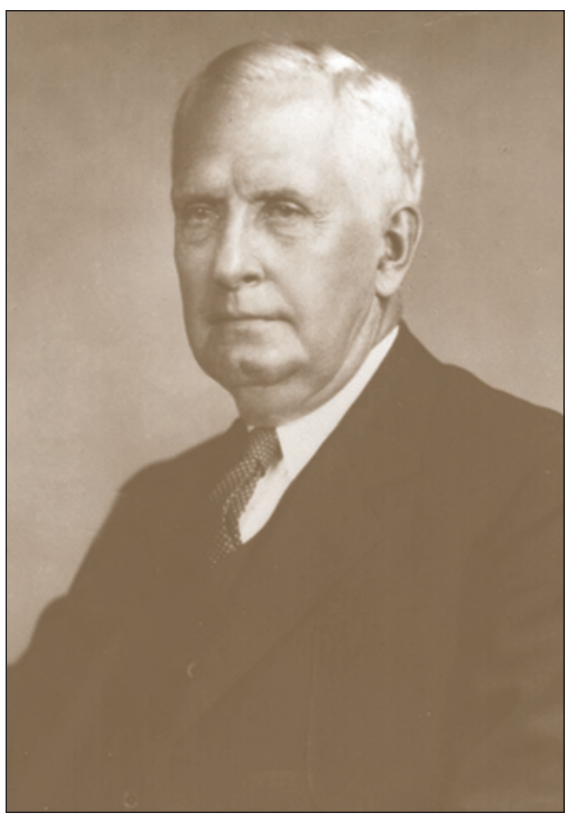

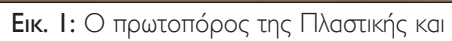

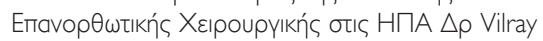
Papin Blair (|87| - |955).

Fig. I: The pioneer of Plastic and Reconstructive Surgery in the USA Dr. Vilray Papin Blair (|87|-1955).

\author{
"But all these requisites \\ belong of old to Medicine..." \\ Hippocrates
}

Vilray Papin Blair:

The pioneer of Plastic and Reconstructive Surgery in the USA, and his contribution in Oral and Maxillofacial Surgery.

Vilray Papin Blair (I87|-1955) (Fig. I), one of the pioneers and founders of the Specialty of Plastic and Reconstructive Surgery in the USA, was born in St. Louis, Missouri, on June |5th, |87|, from parents descendants of the original French founders of the city of St. Louis. He graduated in 1890 from the Christian Brothers' College, receiving a Bachelor of Arts (B.A.) degree, and in 1894 he received a Master of Arts (M.A.) degree from the same College. In 1890 he was admitted to the Washington University School of Medicine in St. Louis, where he graduated in 1893 with a degree in medicine (M.D.). His medical studies were in danger of being interrupted, as Vilray Blair sought his fortune in the West after completing his first year, spending a year in the Colorado Rockies, where he worked hanging telephone wires for highpower hydroelectric installations. Upon his return to St. Louis he thought of giving up his medical studies and attending the Westinghouse Electrical Engineering

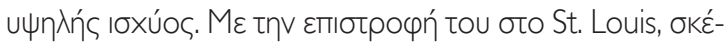

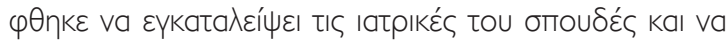

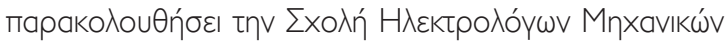
Westinghouse (Westinghouse Electrical Engineering

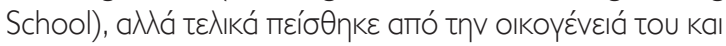

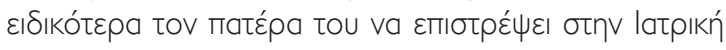

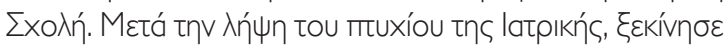

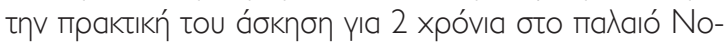
боко $\varepsilon_{i ́ o}$ Mullanphy tou St. Louis (Mullanphy Hospital),

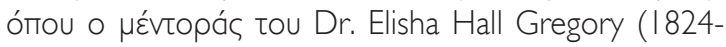
1906), KaӨnyntńs tns Xelpoupyikńs ka tns Avatouías

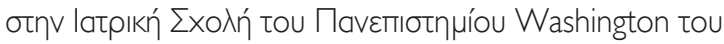

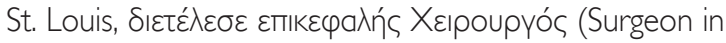

School, but he was eventually persuaded by his family, and in particular by his father, to return to Medical School. After receiving his medical degree, he began his internship for 2 years at the old Mullanphy Hospital in St. Louis, where his mentor Dr. Elisha Hall Gregory (1824-1906), Professor of Surgery and Anatomy at the University of Washington School of Medicine in St. Louis, served as Surgeon in Chief for fifty years. In 1894 he began his academic career at University of Washington School of Medicine in St. Louis, as an instructor in Practical Anatomy and taught Anatomy as well as Surgery for the first eighteen years of his medical career, which earned him many distinctions, such as his promotion to 


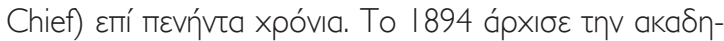

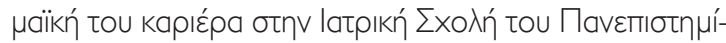

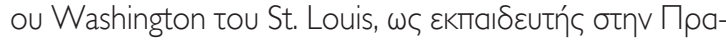

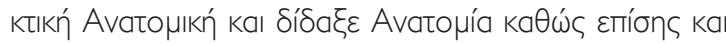

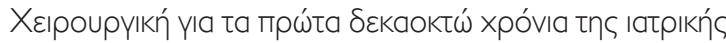

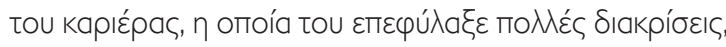

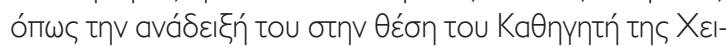

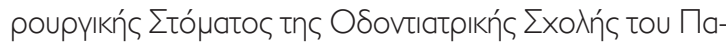

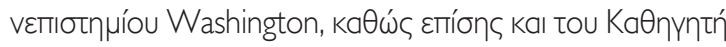

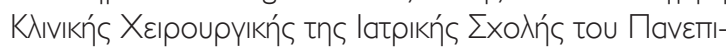

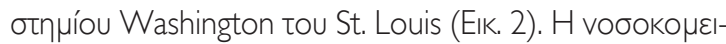

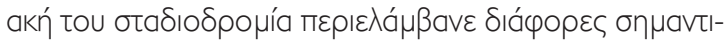

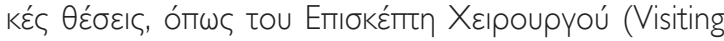

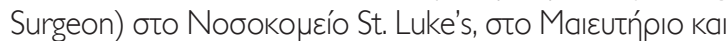

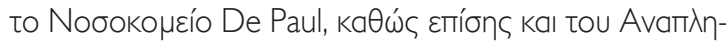

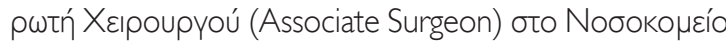

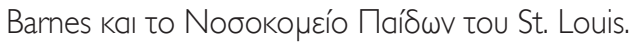

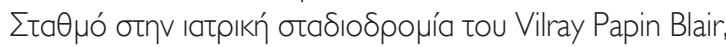

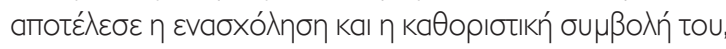

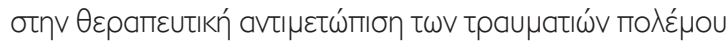

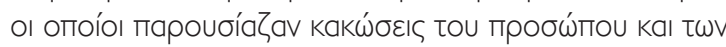

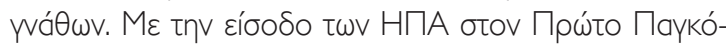

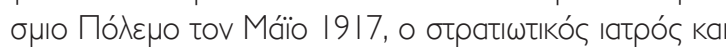

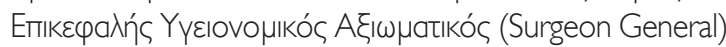

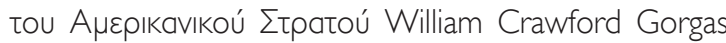

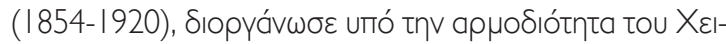

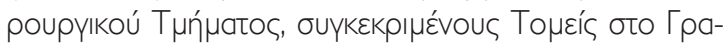

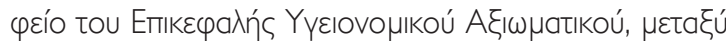

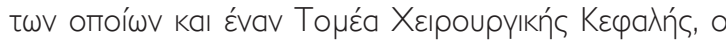

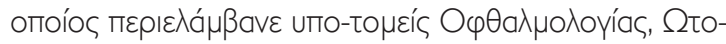

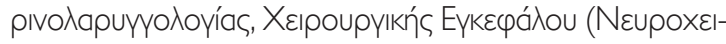

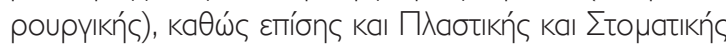

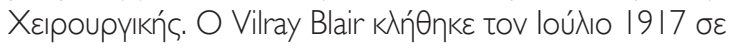

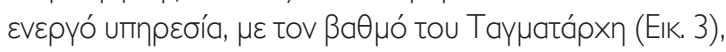

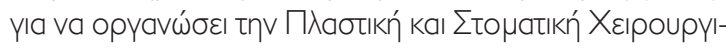

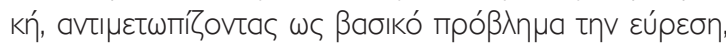

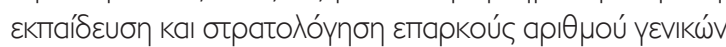

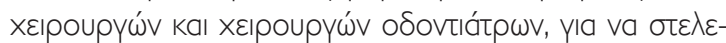

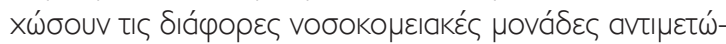

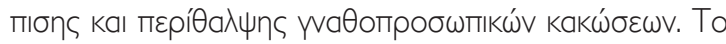

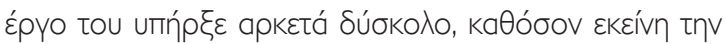

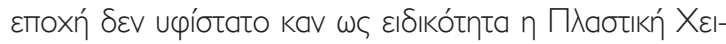

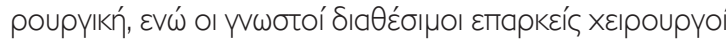

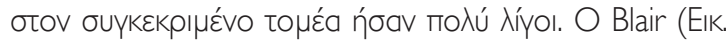

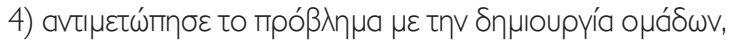

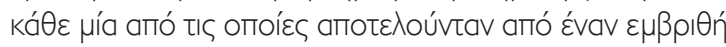

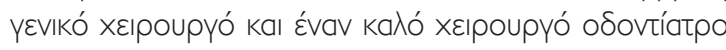

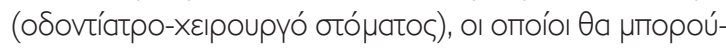

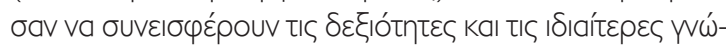

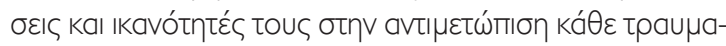

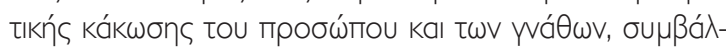

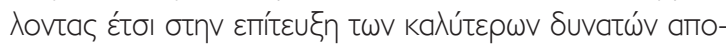

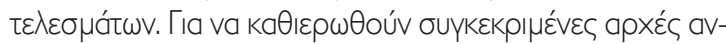

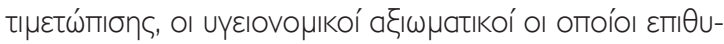

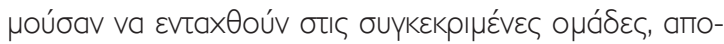

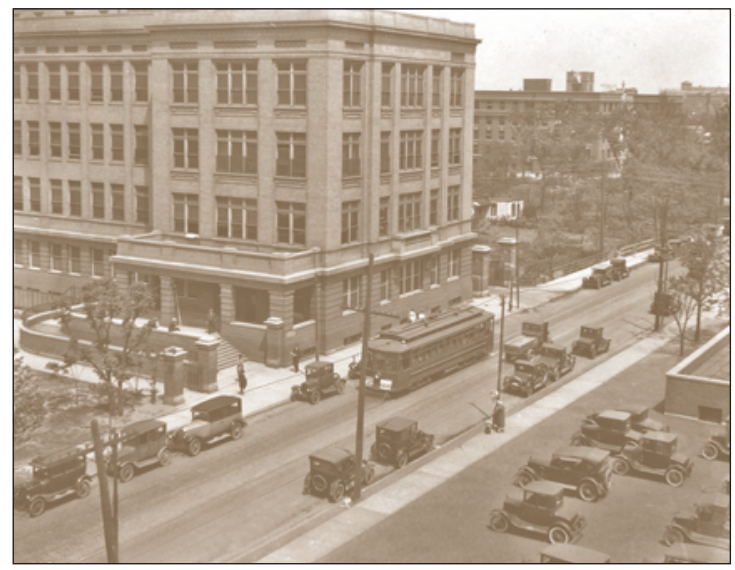

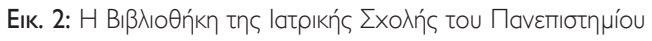
Washington oto St. Louis, yúpw oto $19 \mid 4$.

Fig. 2: Washington University School of Medicine Library in St. Louis, circa 1914.

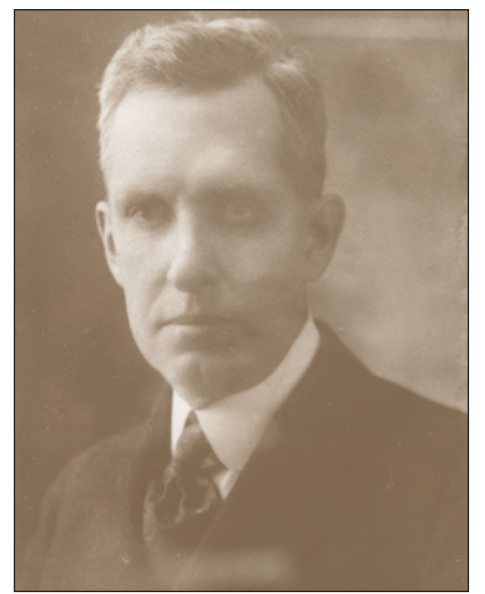

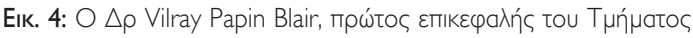

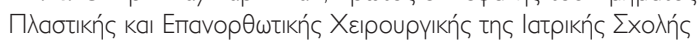

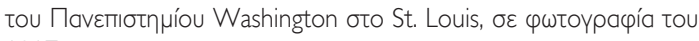
1917.

Fig. 4: Dr. Vilray Papin Blair, the first Division Chief of Plastic and Reconstructive Surgery at Washington University School of Medicine in St. Louis, in a 1917 photograph.

Professor of Oral Surgery at the University of Washington School of Dentistry, and also to Professor of Clinical Surgery at the University of Washington School of Medicine in St. Louis (Fig. 2). His hospital career included a number of important positions, such as Visiting Surgeon at St. Luke's Hospital, at De Paul Hospital and Maternity Hospital, as well as Associate Surgeon at Barnes Hospital and St. Louis Children's Hospital.

A milestone in Vilray Papin Blair's medical career, was his involvement and decisive contribution to the treatment of war wounded men who suffered facial and jaw injuries. With the entry of the USA into the First World War in May 1917, the military doctor and Chief Health Officer (Surgeon General) of the US Army William Crawford Gorgas (1854-1920), organized under the auspices of the Division of Surgery, certain sections in the Office of

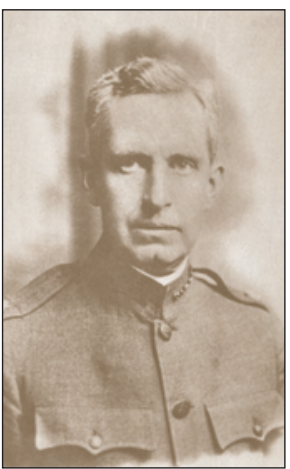

Eıк. 3: $\bigcirc \triangle \rho$ Vilray Papin

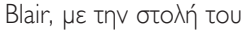

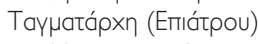
tou Yyeı ¿únatos tou

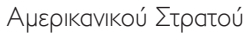

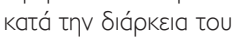
При́tou Паүкобні́ou

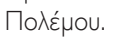

Fig. 3: Dr. Vilray Papin Blair, in uniform of Major of the U. S. Army Medical Corps, during World Warl. 


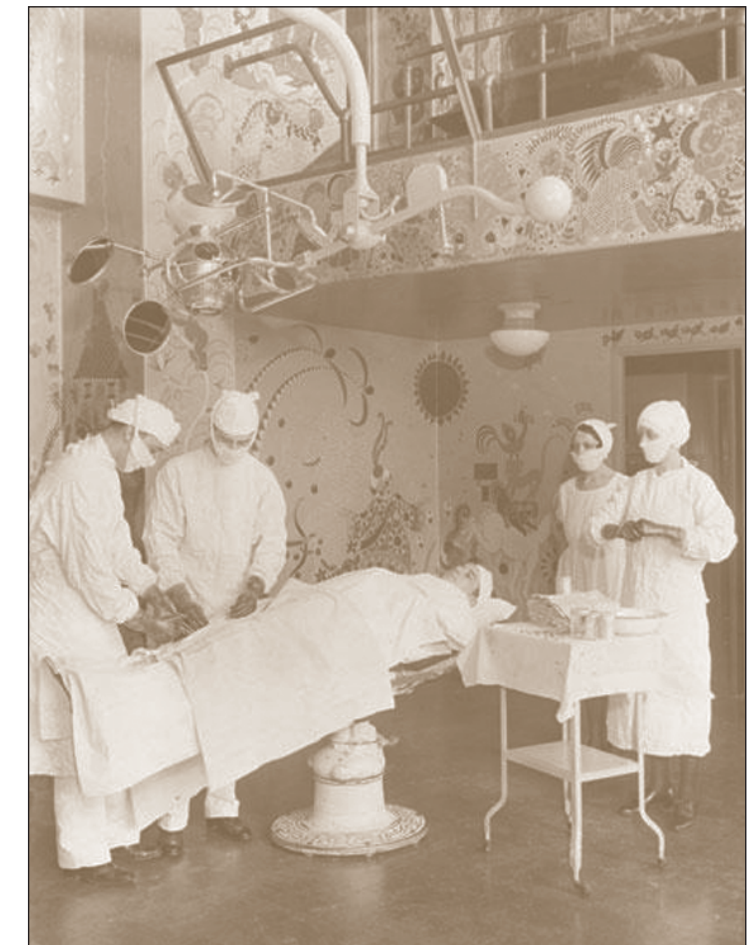

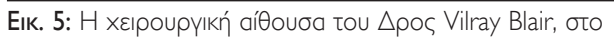

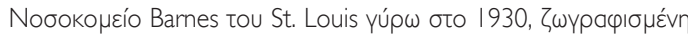

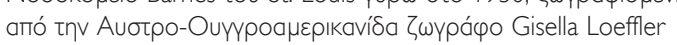
(1902-1977).

Fig. 5: Dr. Vilray Blair's operating room, at Barnes Hospital in St. Louis circa 1930, painted by the Austro-Hungarian-American painter Gisella Loeffler (1902-1977).

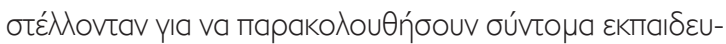

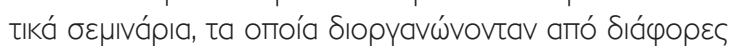

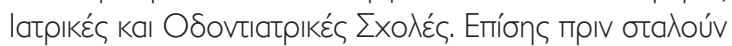

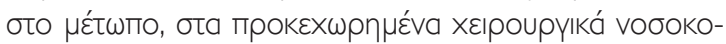

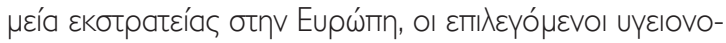

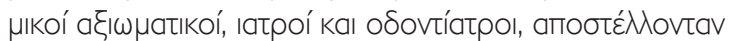

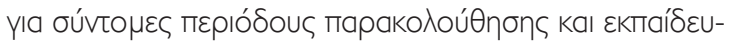

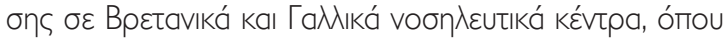

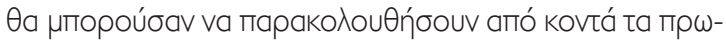

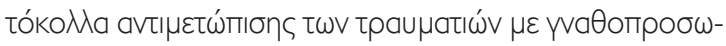

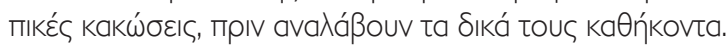

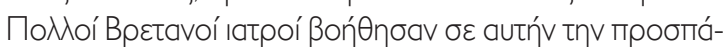

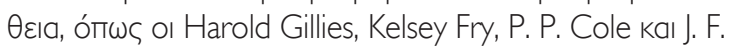

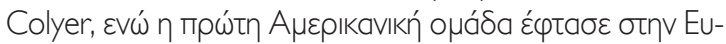

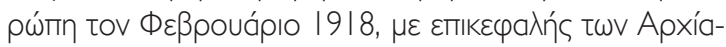

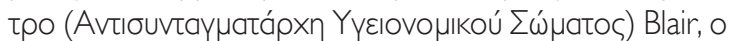

the Surgeon General, including a Department of Head Surgery, which included sub-sections of Ophthalmology, Otorhinolaryngology, Brain Surgery (Neurosurgery), as well as Plastic and Oral Surgery. In July 1917, Vilray Blair was called into active duty, with the rank of Major (Fig. 3), to organize Plastic and Oral Surgery, facing the main problem of finding, training and recruiting a sufficient number of general surgeons and dental surgeons, for staffing the various hospital units for the treatment and care of maxillofacial injuries. His work was quite difficult, as at that time Plastic Surgery did not even exist as a specialty, while the known available sufficient surgeons in this field were very few. Blair (Fig. 4) addressed the problem by creating teams, each consisting of an in-depth general surgeon and a good dental surgeon (dentist-oral surgeon), who could contribute skills, knowledge, and their ability to deal with any traumatic injury to the face and jaws, thus helping to achieve the best possible results. In order to establish specific treatment principles, the health officers who wished to join the specific groups were sent to attend short training seminars, which were organized by various Medical and Dental Schools. Also before being sent to the front, to the advanced mobile army surgical hospitals (MASH) in Europe, the selected health officers, physicians and dental surgeons, were sent for short periods of attending and training to British and French hospital centers, where they could closely monitor the treatment protocols for wounded patients with maxillofacial injuries, before taking up their duties. Many British doctors assisted in this effort, including Harold Gillies, Kelsey Fry, P. P. Cole and J. F. Colyer, while the first American team arrived in Europe in February 1918, led by Dr. Blair, Lieutenant Colonel of the Medical Corps, who then became Chief Consultant of Maxillofacial Surgery of the American Expeditionary Forces, with his headquarters in the community of Neufchateau, France. There he organized and recruited personnel for several American Hospital Centers of the American Expeditionary Forces, where the wounded men with maxillofacial surgical injuries were transferred for immediate treatment, before being transferred to the USA for final rehabilitation. Upon his return to the United States in June 1919, Dr. Blair retired from active military service, having first set up several centers across the country for the late treatment of wounded men with maxillofacial surgical injuries, and ran such a center at the Jefferson Barracks Military Post in Missouri, continuing to actively offer his services for several years.

From the first years of his surgical career at St. Louis, Vilray Blair was an awesome student of Anatomy, and became widely known for undertaking to operate, with great success, many difficult cases, which had been abandoned by other surgeons (Fig. 5). With regard to oral and maxillofacial surgery, Blair very early showed a particular interest in surgical conditions of the head and 


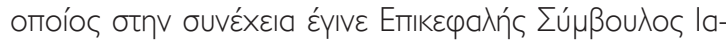

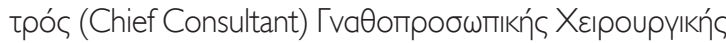

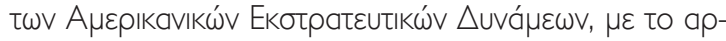

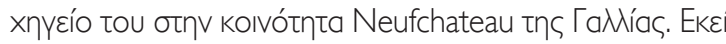

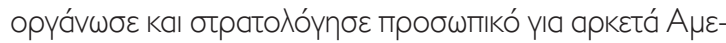

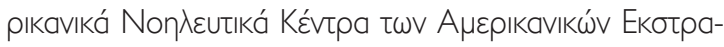

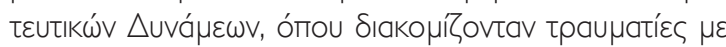

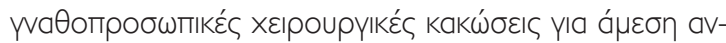

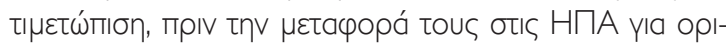

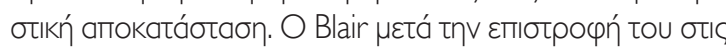

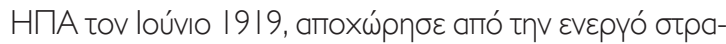

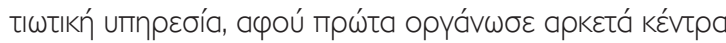

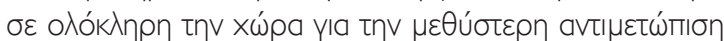

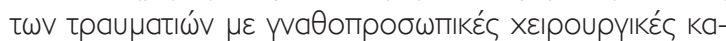

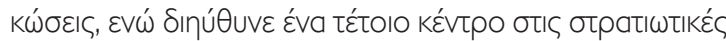

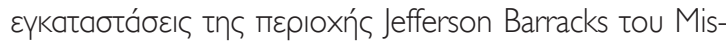

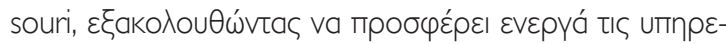

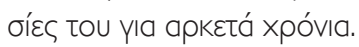

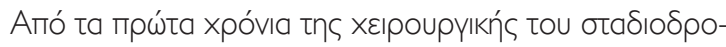

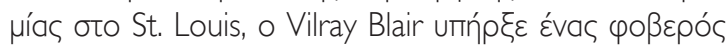

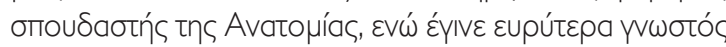

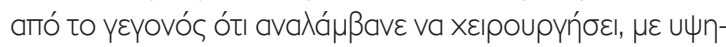

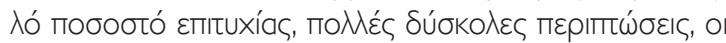

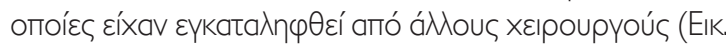

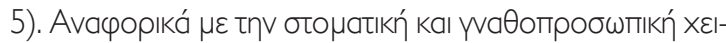

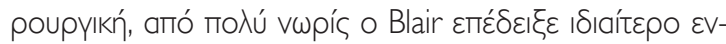

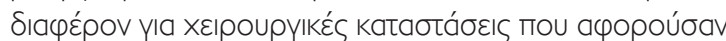

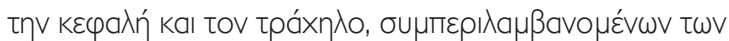

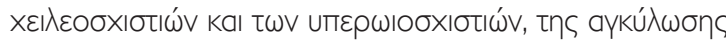

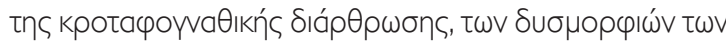

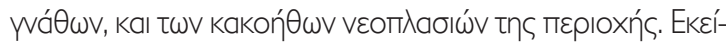

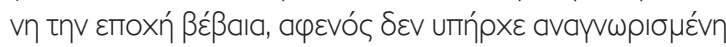

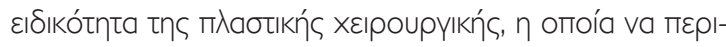

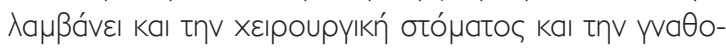

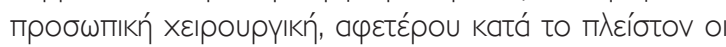

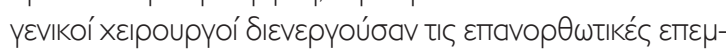

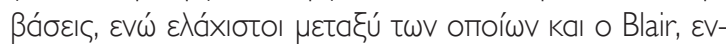

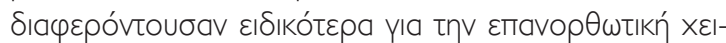

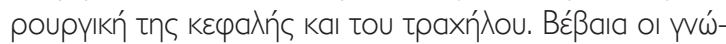

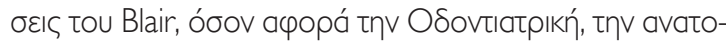

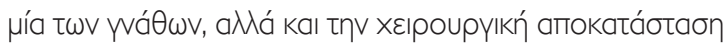

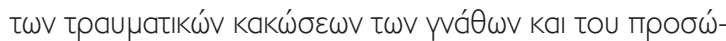

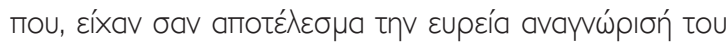

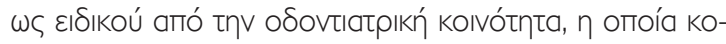

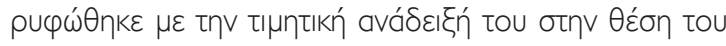

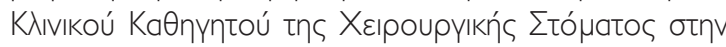

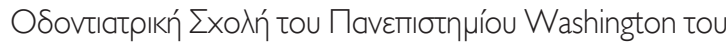

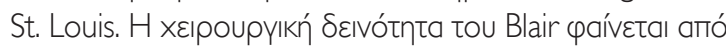

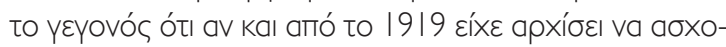

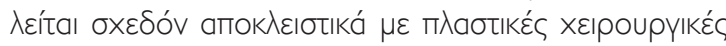

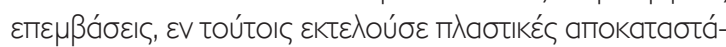

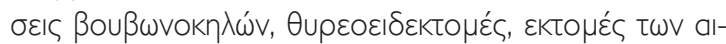

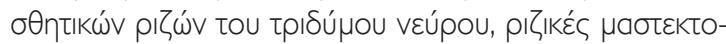

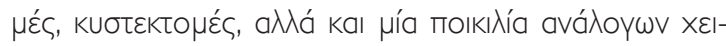

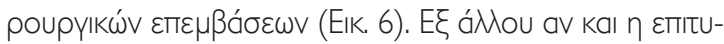

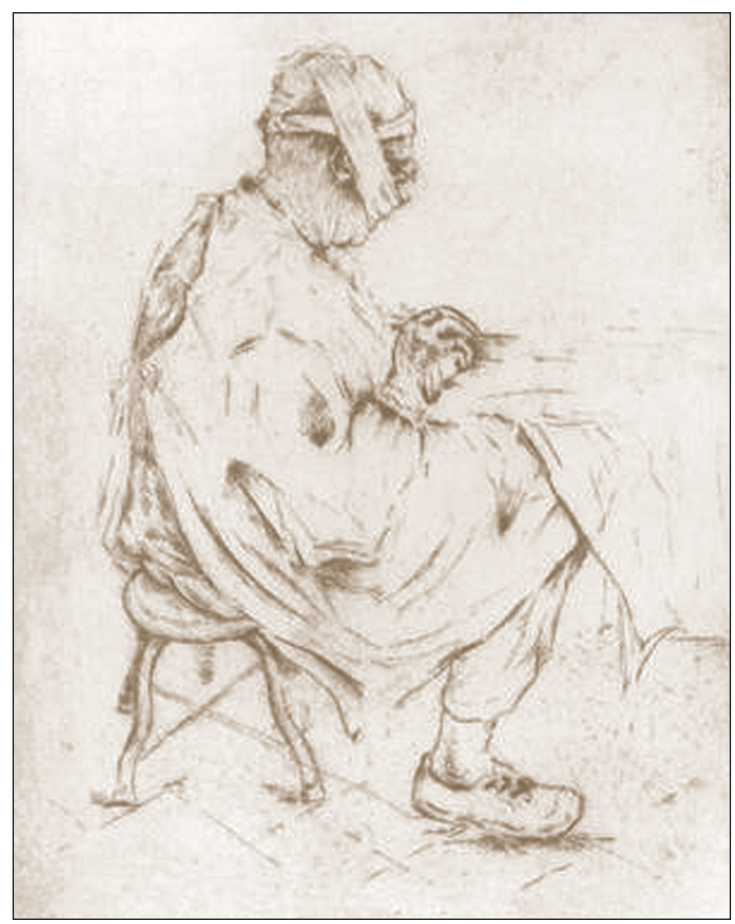

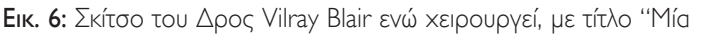

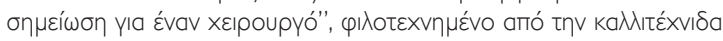
Gertrude Hance.

Fig. 6: Sketch of Dr. Vilray Blair while operating, entitled "A note on a surgeon", drawn by artist Gertrude Hance.

neck, including cleft lip and palate, temporomandibular joint ankylosis, jaw malformations, and malignant neoplasias of the area. At that time, of course, on the one hand there was no recognized specialty of plastic surgery, including oral and maxillofacial surgery, on the other hand general surgeons mostly performed reconstructive operations, while few, including Blair, were particularly interested in reconstructive surgery of the head and neck. Of course Blair's knowledge, concerning Dentistry, the anatomy of the jaws, but also the surgical repair of traumatic injuries of the jaws and face, resulted in his wide recognition as a specialist by the dental community, which culminated in his honorary promotion to the post of Clinical Professor of Oral Surgery at the University of Washington School of Dentistry in St. Louis. Blair's surgical ability is shown by the fact that although from 1919 he had begun to deal almost exclusively with plastic surgery, he nevertheless performed plastic repairs of inguinal hernias, thyroidectomies, excisions of the aesthetic roots of the trigeminal nerve, radical mastectomies, cystectomies, but also a variety of similar surgical operations (Fig. 6). On the other hand, although the successful surgical correction of temporomandibular joint ankylosis is

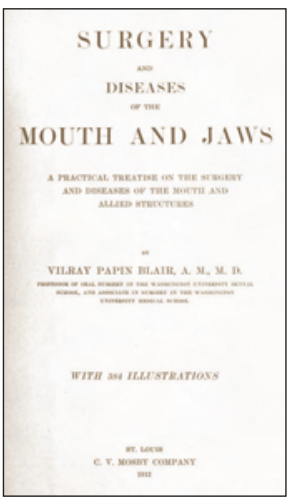

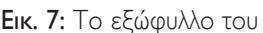
$\mu v \eta \mu \varepsilon i \omega ́ \delta$ ouc Épyou tou $\triangle$ pos Vilray Papin Blair "Surgery and Diseases of the Mouth and Jaws" (Xeıроupүikń kaı Nóool

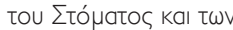

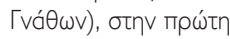

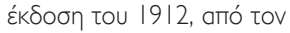

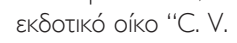
Mosby Company" oto St. Louis.

Fig. 7: The cover page of the monumental work of Dr. Vilray Papin Blair

"Surgery and Diseases of the Mouth and Jaws", in the first edition of 1912 , by the publisher " $\mathrm{C}$. V. Mosby Company" in St. Louis.

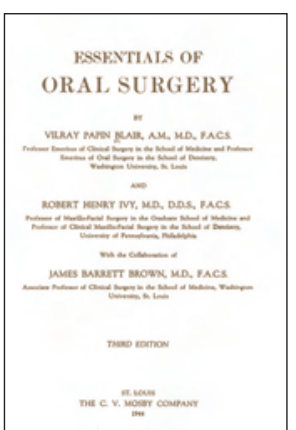

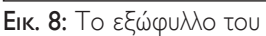

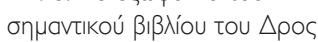
Vilray Papin Blair "Essentials of Oral Surgery" (Baøıká

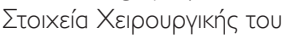

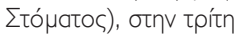

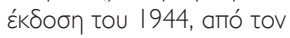

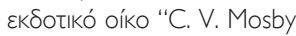
Company" oto St. Louis. Fig. 8: The cover page of the important book of Dr. Vilray Papin Blair "Essentials of Oral Surgery", in the third edition of 1944, by the publisher " $\mathrm{C}$. V. Mosby Company" in St. Louis. 


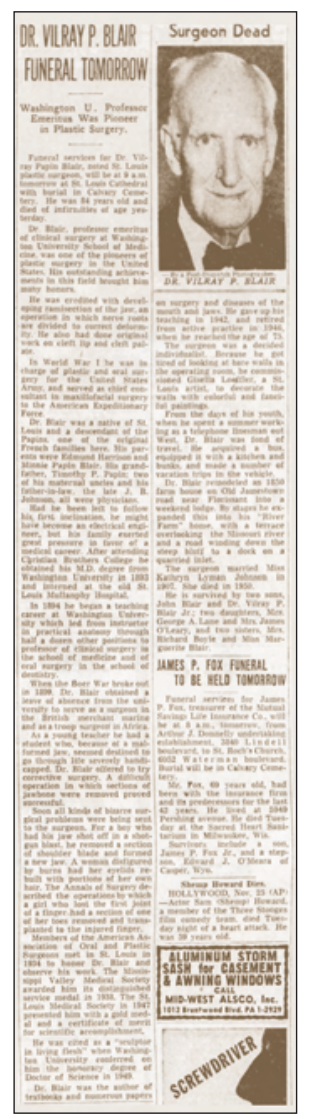

Eıк. 9: Neкро入оүía үıа tov $\triangle p a$ Vilray Papin Blair,

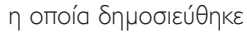

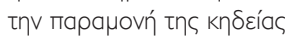

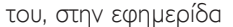
"St. Louis Post-Dispatch",

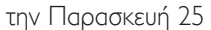

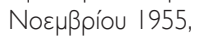

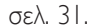

Fig. 9: Obituary for Dr. Vilray Papin Blair, which was published the day before his funeral, in the newspaper "St. Louis PostDispatch", on Friday, November 25, 1955 , p. 31 .

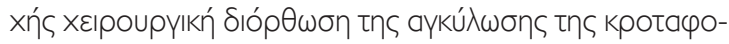

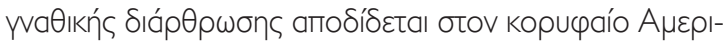
kavó xeıpoupyó John Benjamin Murphy (1857-1916) anó

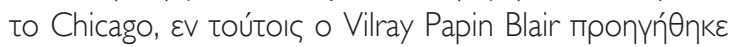

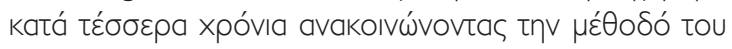
ornv latpıkń Etaıpía tou St. Louis (St. Louis Medical So-

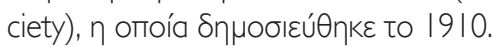

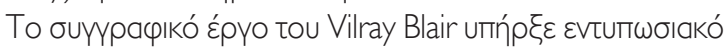

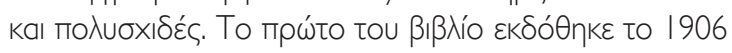

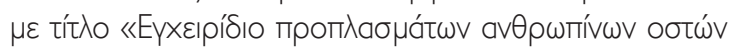

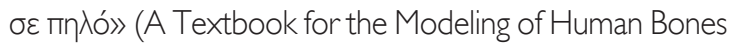

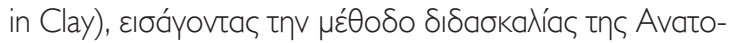

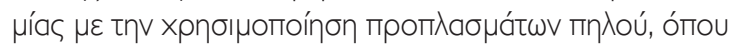

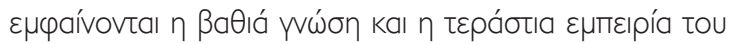

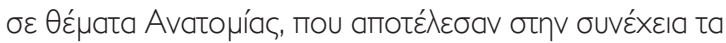

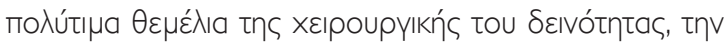

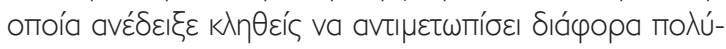

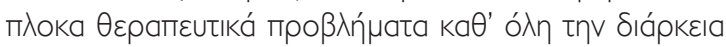

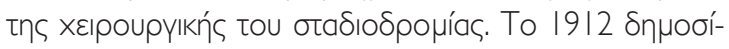

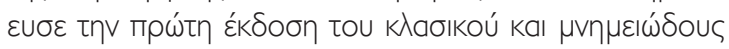

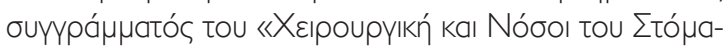

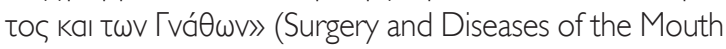

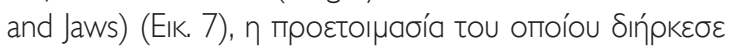

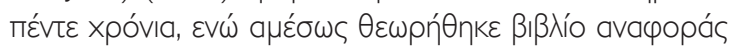

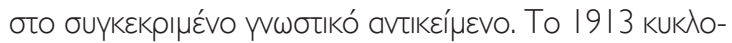

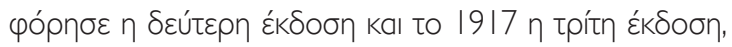

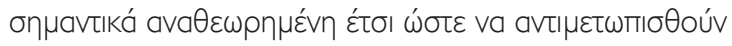

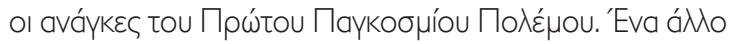

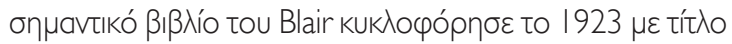

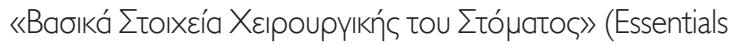

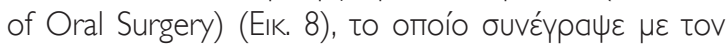

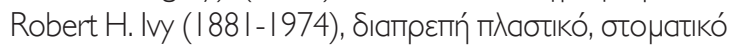

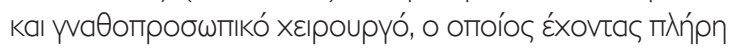

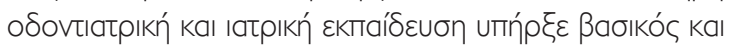

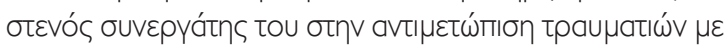

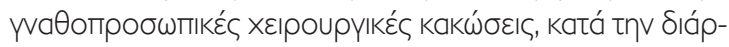

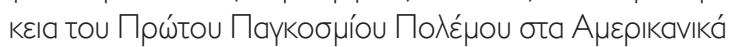

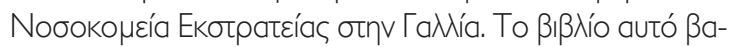

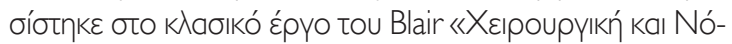

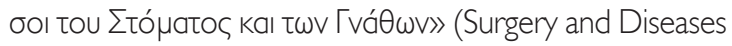

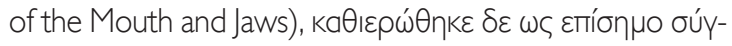

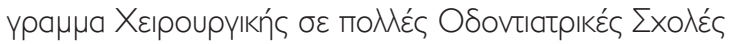

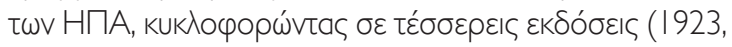

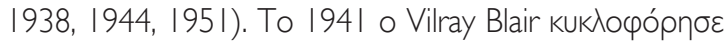

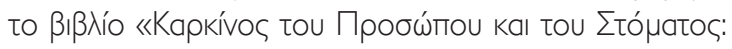

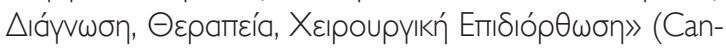
cer of the Face and Mouth: Diagnosis, Treatment, Surgical

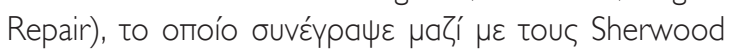

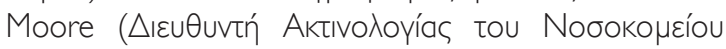

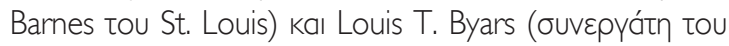

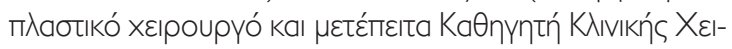

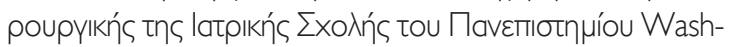

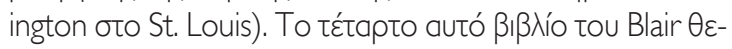

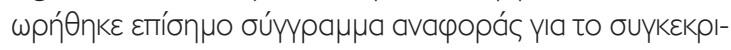

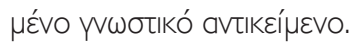

attributed to the leading American surgeon John Benjamin Murphy (1857-1916) from Chicago, however Vilray Papin Blair was four years ahead in announcing and presenting his method before the St. Louis Medical Society, which was published in 1910 .

Vilray Blair's writing work has been impressive and diverse. His first book was published in 1906 entitled "A Textbook for the Modeling of Human Bones in Clay", introducing the method of teaching Anatomy using clay models. This textbook shows his deep knowledge and vast experience in Anatomy, which later became the valuable foundation of his surgical skill, a unique characteristic employed by him in dealing with various complex therapeutic problems throughout his surgical career. In 1912 he published the first edition of his classic and monumental book "Surgery and Diseases of the Mouth and Jaws" (Fig. 7), which took him five years to prepare it, and was immediately considered a book of reference on the specific subject. In 1913 the second edition was released and in 1917 the third edition, significantly revised to meet the needs of the First World War. Another important book by Blair was published in 1923 entitled "Essentials of Oral Surgery" (Fig. 8), which he co-authored with Robert H. Ivy ( 88 I- 1974), an eminent plastic, oral and maxillofacial surgeon, who having a thorough dental and medical education, was a key and close associate of him in treating wounded men with maxillofacial surgical injuries during World War I, at the American Military Field Hospitals in France. This book was based on Blair's classic work "Surgery and Diseases of the Mouth and Jaws", and has been the official textbook of Surgery in many US Dental Schools, circulating in four editions (1923, 1938, 1944, 195 I). In 194I Vilray Blair published the book "Cancer of the Face and Mouth: Diagnosis, Treatment, Surgical Repair", which he co-authored with Sherwood Moore (Director of Radiology at Barnes Hospital in St. Louis) and Louis T. Byars (a plastic surgeon, one of his associates, and later Professor of Clinical Surgery at the University of Washington School of Medicine in St. Louis). This fourth book by Blair, was considered an official reference book on this subject.

Vilray Papin Blair published several important monographs on various surgical topics, such as: "The Delayed Transfer of Long Pedicled Flaps" [1921], "Pyogenic Infection of the Parotid Gland and Ducts" (with E. C. Padgett) [1923], "The Full-Thickness Skin Graft" [1924], "Use and Uses of Large Split-Skin Grafts of Intermediate Thickness) (with J. B. Brown) [1929], "Mirault Operation for Single Hare Lip" (with J. B. Brown) (1930). Of unsurpassed value and importance in the literature of Plastic Surgery, was the paper he presented with Gordon S. Letterman in 1950, entitled "The Role of the Switched Lower Lip Flap in Upper Lip Restorations", on the occasion of being awarded the First Special Award of the American Society of Plastic and Reconstructive Surgery, 


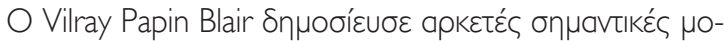

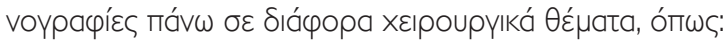

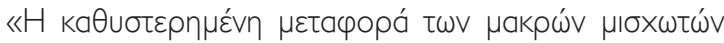

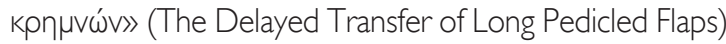

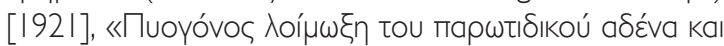
$\tau \omega \vee$ пó $\rho \omega \vee »$ (Pyogenic Infection of the Parotid Gland and

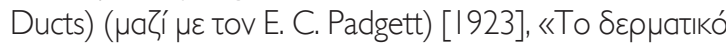

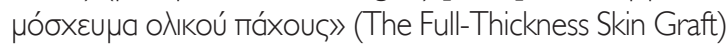

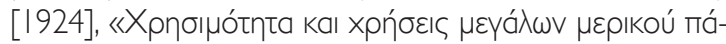

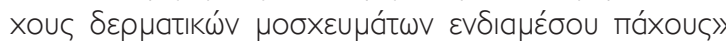
(Use and Uses of Large Split-Skin Grafts of Intermediate

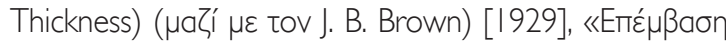

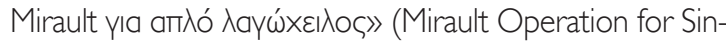

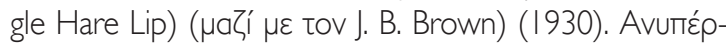

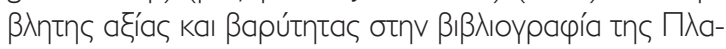

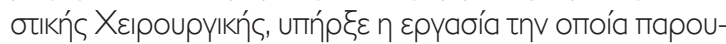

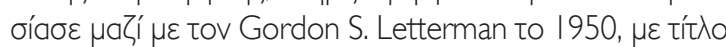

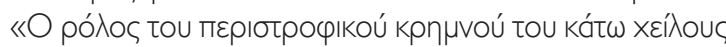

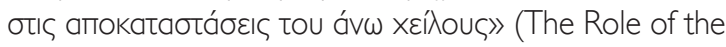
Switched Lower Lip Flap in Upper Lip Restorations), $\mu \varepsilon$

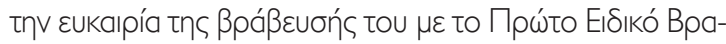

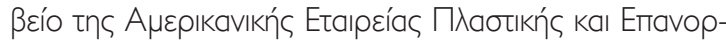

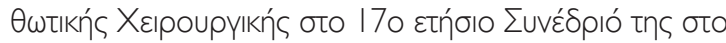

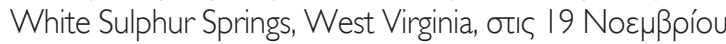

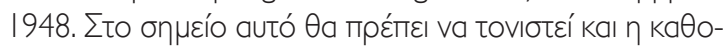

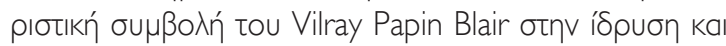

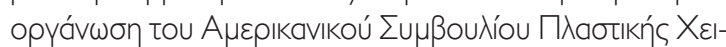
poupyıkńs (American Board of Plastic Surgery). Yпó тпv

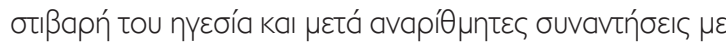

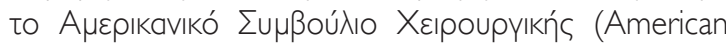

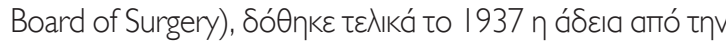

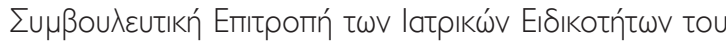

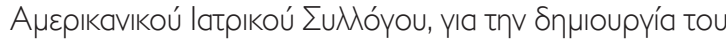

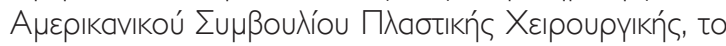

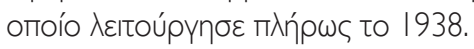

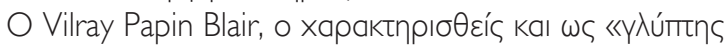

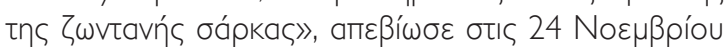

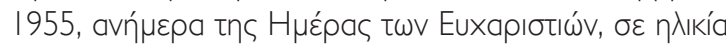

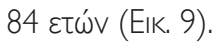

\section{О}

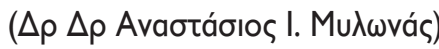

at its 17th Annual Meeting in White Sulfur Springs, West Virginia, on November 19, 1948. At this point it should be emphasized the decisive contribution of Vilray Papin Blair to the establishment and organization of the American Board of Plastic Surgery. Under his strong leadership and after countless meetings with the American Board of Surgery, in 1937 the Advisory Board of Medical Specialties of the American Medical Association finally approved the formation of the American Board of Plastic Surgery, which became fully operational in 1938.

Vilray Papin Blair, also described as the "sculptor of the living flesh", passed away on November 24, 1955, on Thanksgiving Day, at the age of 84 years old (Fig. 9).

The filistor

(Dr Dr Anastassios I. Mylonas)

\section{BIBAIOГРАФIA/REFERENCES}

Graham EA: Memoir of Vilray Papin Blair. Trans Am Surg Assoc. $74: 491,1956$

Shedd DP, Jurkiewicz MJ, DeLacure MD: The Role of Vilray Blair in Head and Neck Oncology, In Shedd DP: Historical Landmarks in Head and Neck Cancer Surgery. The American Head and Neck Society 1999, pp. 57-62

Webster J: In memoriam: Vilray Papin Blair, I87| - 1955. Plast Reconstr Surg 18 (2): 83-112, 1956 


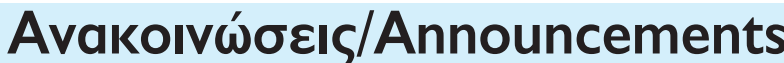

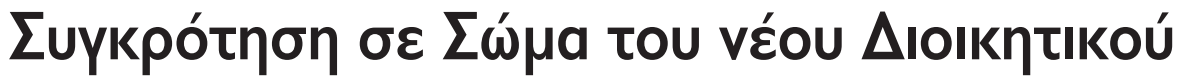

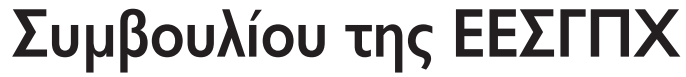

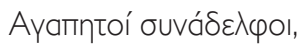

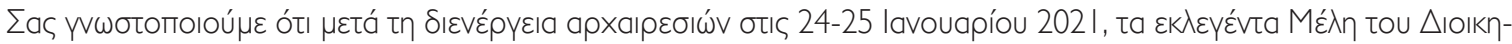

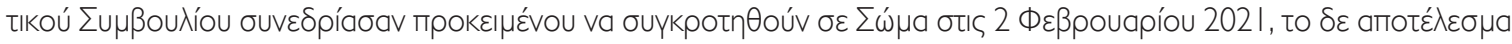
ńtav to akódouӨo:

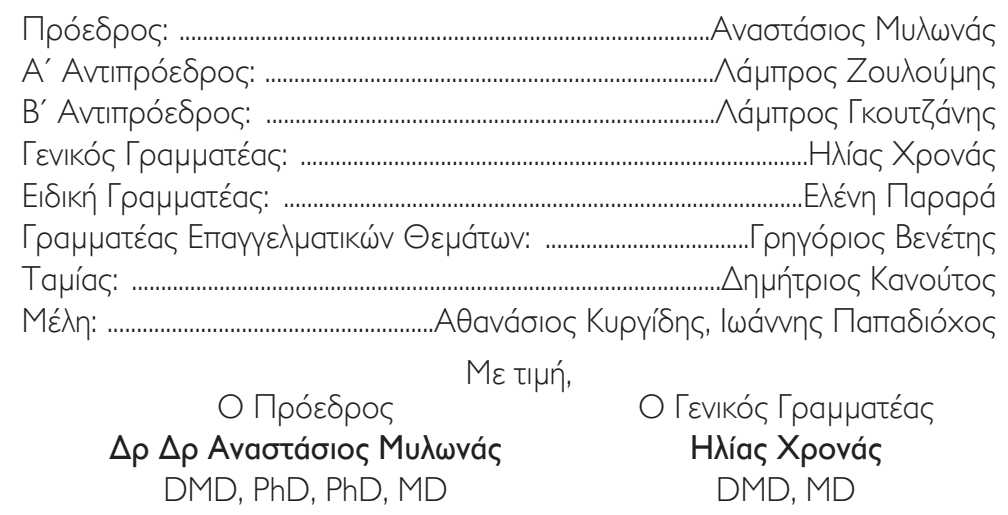

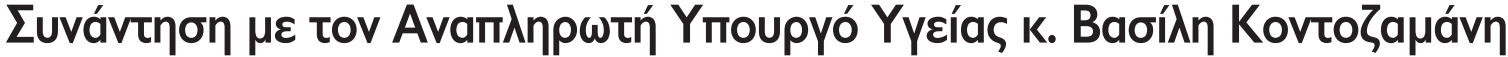

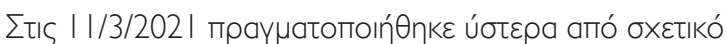

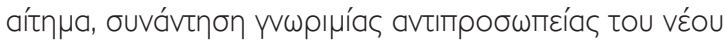

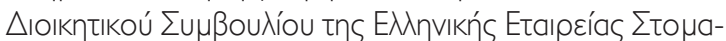

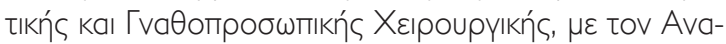

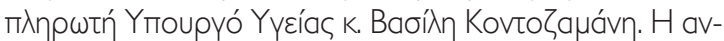

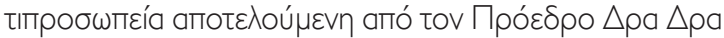

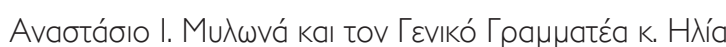

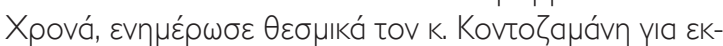

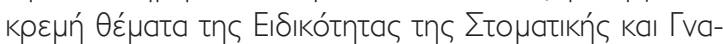

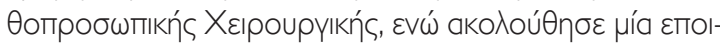

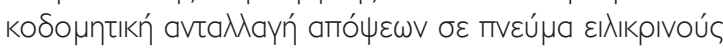

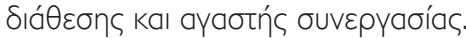

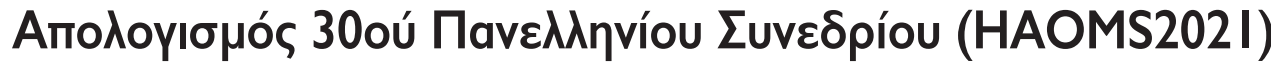

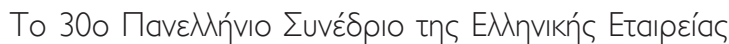

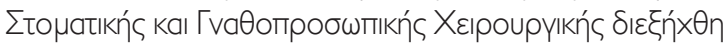

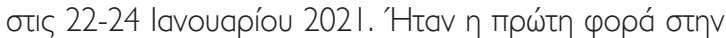

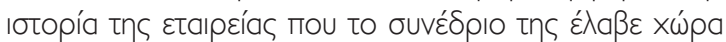

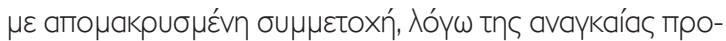

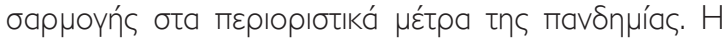

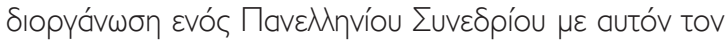

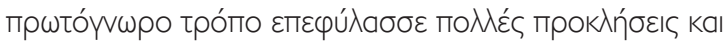

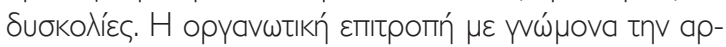

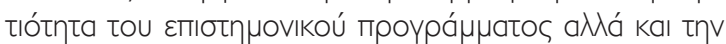

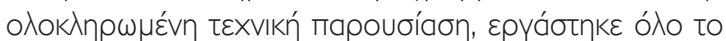

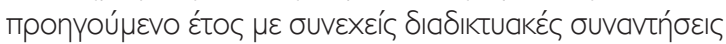

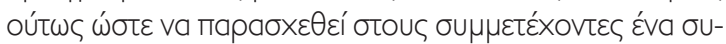

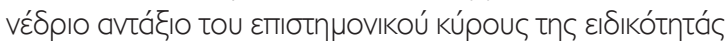

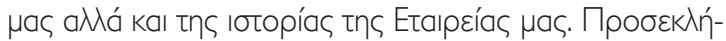

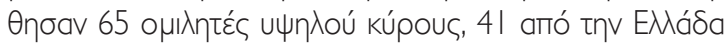

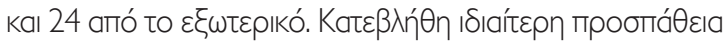

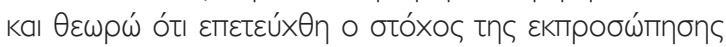

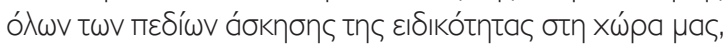

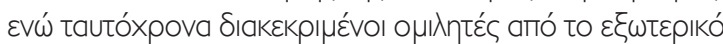

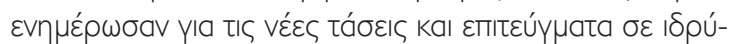

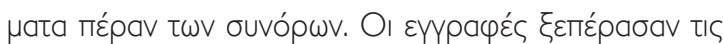

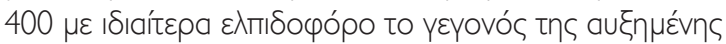

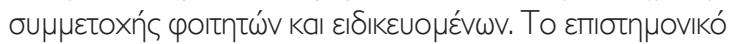

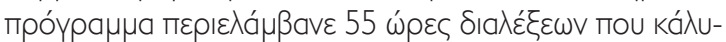

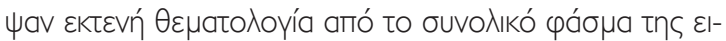

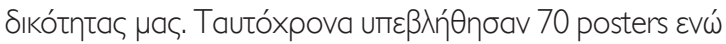

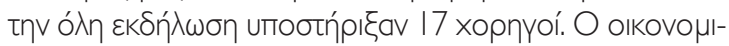

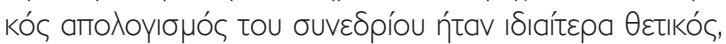

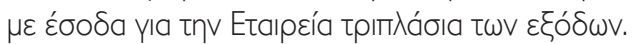

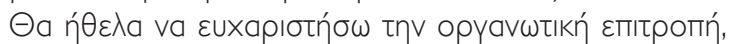

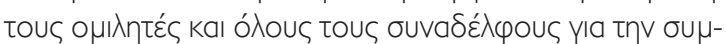

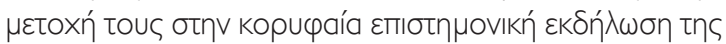

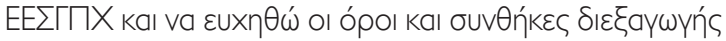

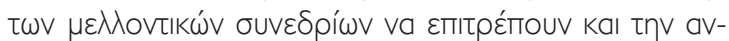

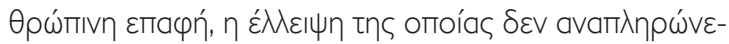

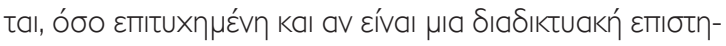

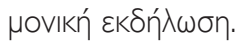

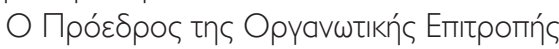

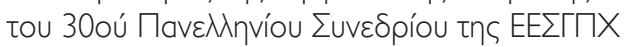

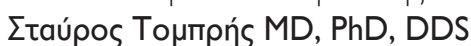

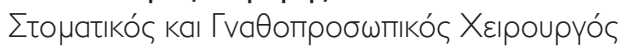




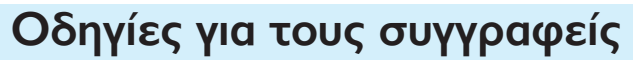

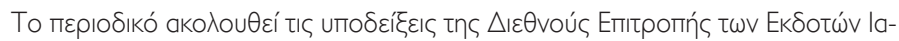

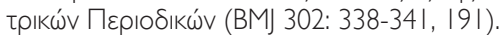

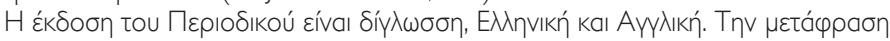

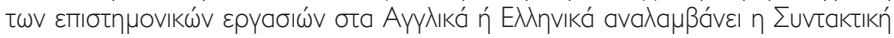

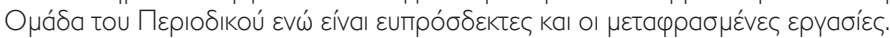

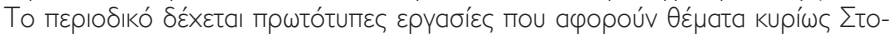

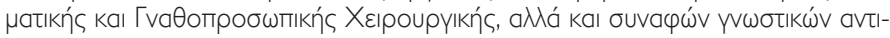

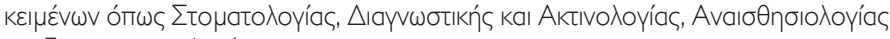

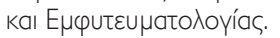

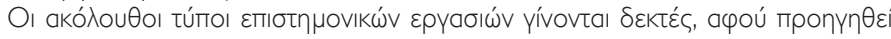

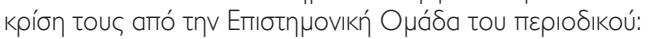

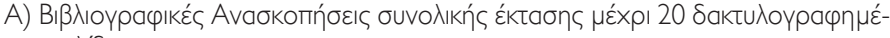

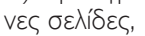

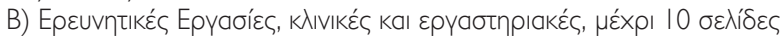

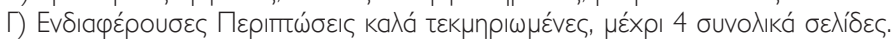

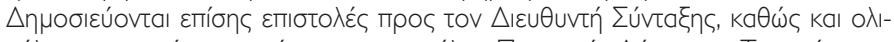

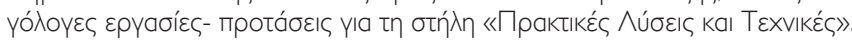

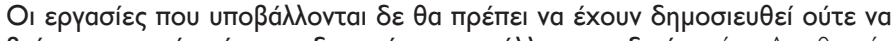

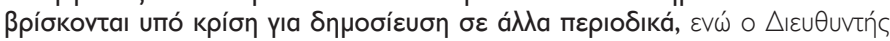

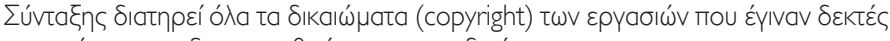

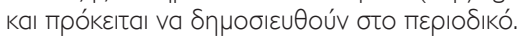

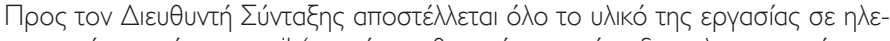

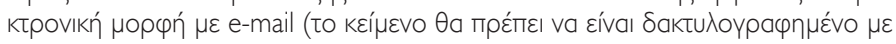

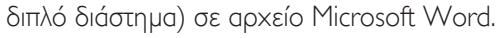

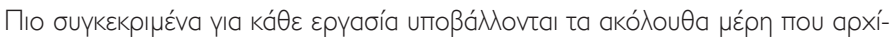

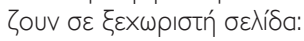

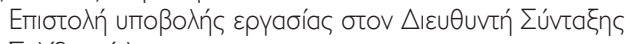

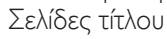

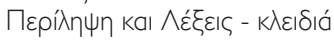

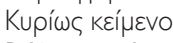

- Bıß入ıорарі́

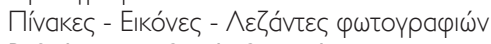

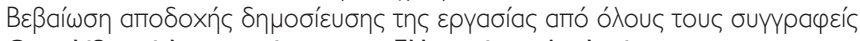

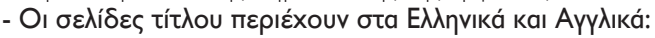

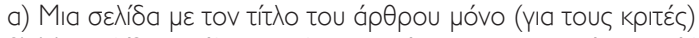

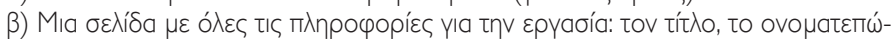

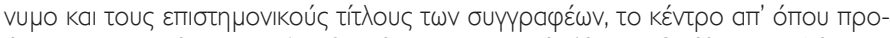

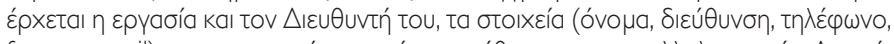

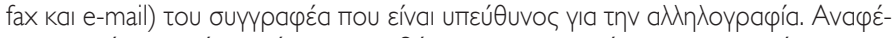

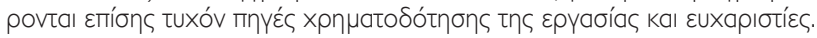

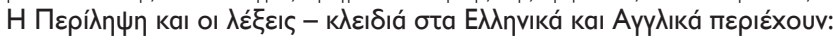

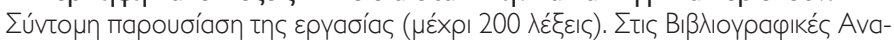

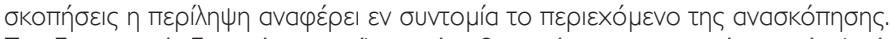

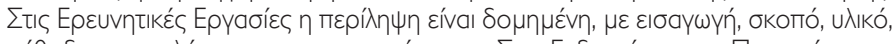

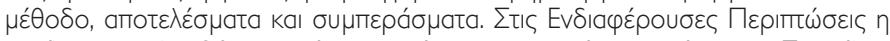

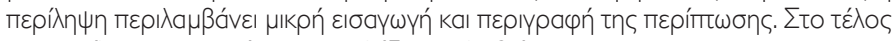

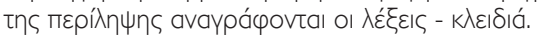

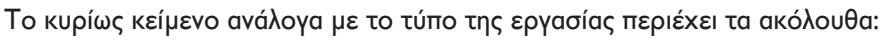

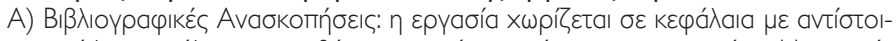

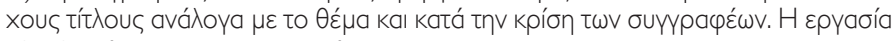

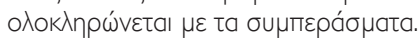

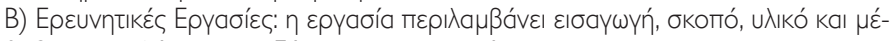

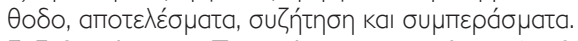

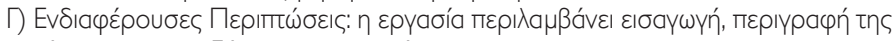

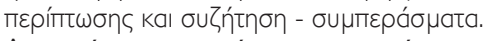

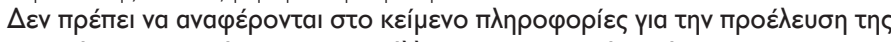

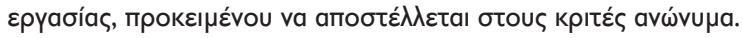

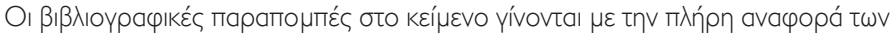

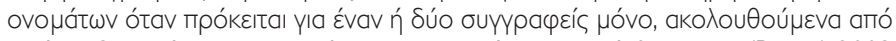

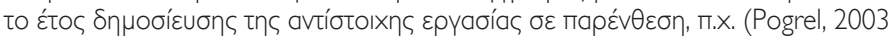

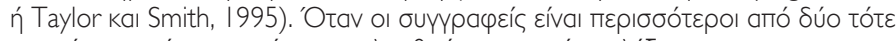

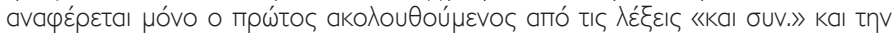

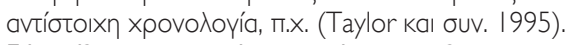

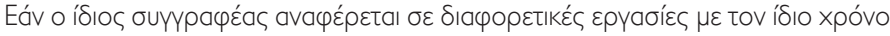

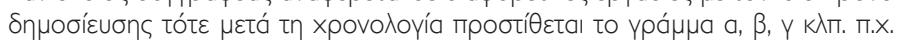

\section{Instructions to Authors}

The triannual medical journal "Hellenic Archives of Oral and Maxillofacial Surgery - HAOMS" is the official journal of the Hellenic Association for Oral \& Maxillofacial Surgery, and it is a forum for medical and dental scientists. Its official languages are English and Greek and publishes articles on basic, clinical and epidemiological research, as well as interesting case reports with literature review and letters. Topics of interest include but are not limited to Oral \& Maxillofacial Surgery, Oral Surgery, Oral Medicine, Oral Pathology, Head \& Neck Oncology, Ear-Nose-Throat Surgery, Plastic and Reconstructive Surgery, Dermatological Oncology, Dermatology, Craniofacial Surgery, Neurosurgery. Thematology of submitted articles should be of interest to Medical and Dental practitioners who are competent in diagnosing and treating pathologies of the maxillofacial / head \& neck region.

Publication is free of charge. HAOMS journal will consider for publication:

I. Editorials and invited keynote articles.

2. Systematic Review articles. These should adhere to the principles of Evidence Based Medicine and follow the PRISMA Guideline and its extensions. They must include a structured abstract, which should be less than 300 words long. The article should be no more than 4000 words long excluding the references (we recommend minimum 30 and preferable 40 for systematic reviews).

3. Original articles. These should be of experimental, clinical or epidemiological character. They should include: a structured abstract, introduction, in which the recent developments on the subject of the research and the scope for the undertaken study should be reported; description of the Material and Methods; report of the Results; and Discussion, which should include the conclusions of the study. The article should be no more than 3200 words long excluding references (we recommend minimum 20 and preferable 30 for original articles).

4. Case Report articles with Systematic Review. Rare clinical cases with interesting presentation, diagnosis or treatment should be described in them. To document the rarity of the case a systematic review of the relevant literature is obligatory for a case report to qualify as a full text article. They should include Abstract; short Introduction, Description of case, Systematic Review including a table summary of already published cases and a short Discussion (we recommend minimum 15 and preferable 25 references for Case Report Articles).

5. Letters to the Editor should be concise and less than 1000 words [up to I figure (with sub-legends) / table allowed]. Case reports may also be submitted as letters to the editor (up to 10 references).

6. Glances in the History of Medicine. Short articles submitted in either Greek or English, referring to the History of Oral \& Maxillofacial Surgery and neighboring medical specialties.

7. The editorial board of the journal has the right to publish the abstracts of Congresses, Seminars etc.

All reported clinical trials must have been registered in an international Clinical Trial Registry, and the registration number must be provided. Reports of randomized trials must conform to the revised CONSORT guidelines, and should be submitted with their protocols. Randomized trials that report harms must be described according to the extended CONSORT guidelines. Studies of diagnostic accuracy must be reported according to the STARD guidelines. Observational studies (cohort, case-control, or cross-sectional designs) must be reported according to the STROBE statement. Genetic association studies must be reported according to the STREGA guidelines. Systematic reviews and meta-analyses must be reported according to the PRISMA guidelines. Case reports and case report letters should adhere to the CARE Guideline and its extensions. HAOMS Journal endorses the EQUATOR Network.

\section{Manuscript preparation}

HAOMS Journal complies with the Uniform Requirements for Manuscripts by the International Committee of Medical Journal Editors (BMJ 302: 338-34I, 191). Articles submitted for publication should be written in either Greek or English language (see above, limitations pertain to certain article type). The copy-editor of the journal has the right to change the language structure of the manuscript without transforming its meaning by the author. Number pages consecutively in this order: title page, abstract, text, references, legends, and tables. Figures should be provided separately. a. On the title page provide the title of the article, list each author's name and institutional affiliation, and indicate the corresponding author. In case, the study has been reported in abstract form elsewhere, indicate the respective scientific meeting. b. On the abstract page provide the abstract (background, methods, results, conclusions) and 3-7 key-words. 


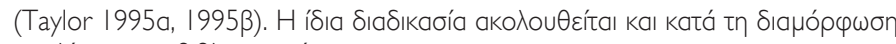

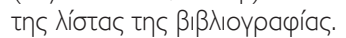

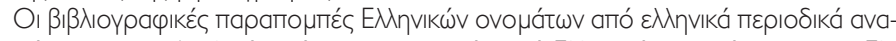

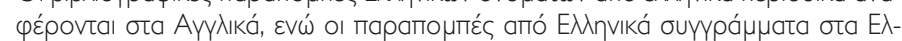

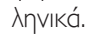

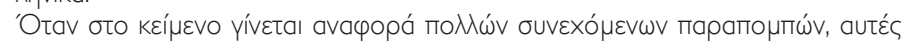

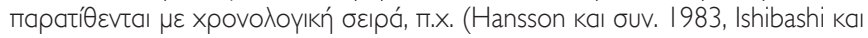
ouv. 1995, Widmalm kaı ouv. 1994, Wiberg ka Wanman, 1998, Emshoff ka ouv. 2002, Toure kaı ouv. 2005, Alexiou kaı ouv. 2009).

\section{H Bıßльоүрачі́a}

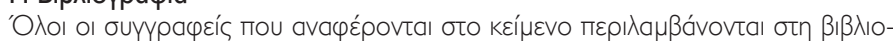

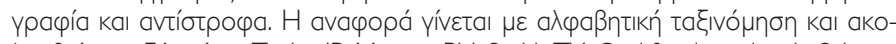

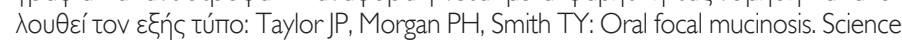
189:503-506, 1998

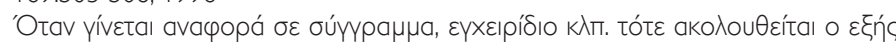
túnoৎ: Taylor JP: Oral focal mucinosis, In: Morgan and Smith: Oral Pathology. Mosby 1989, pp. 509-512

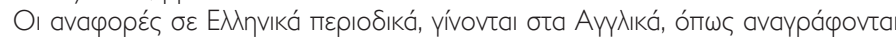

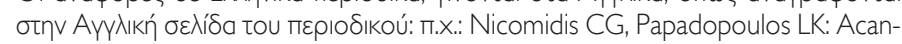
thosis. Hellenic Arch Oral Maxillofac Surg 12: 234-245, 2010

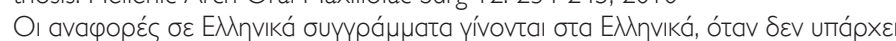

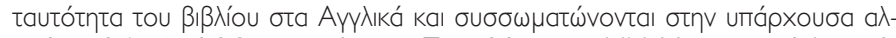

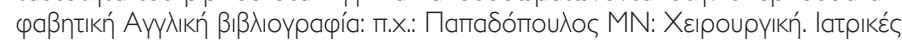

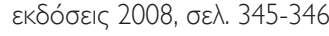

\section{Оı Пі́vaкєৎ}

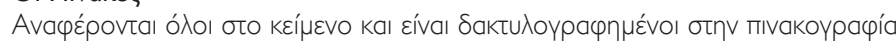

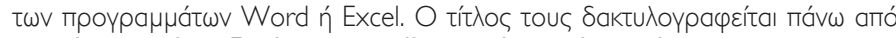

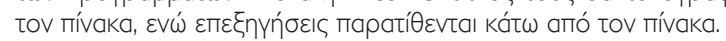

\section{Оı Eıкóveৎ}

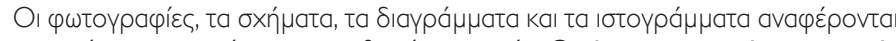

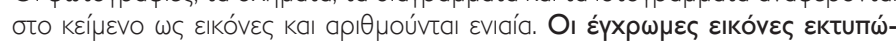

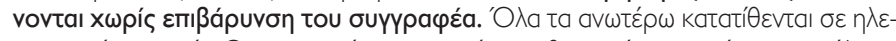

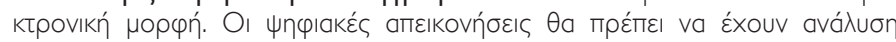

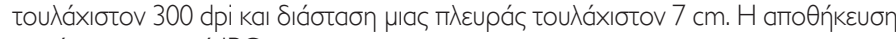

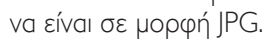

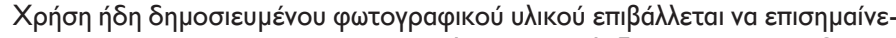

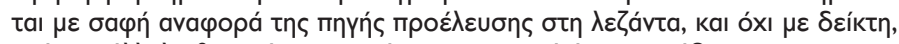

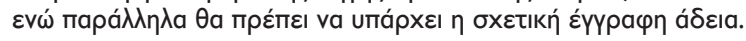

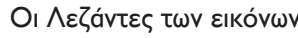

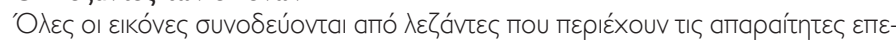

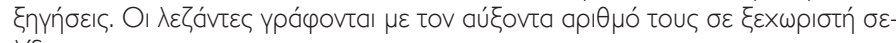
入í́a. c. Figure and Table preparation. Figures: For reproduction in the journal you will be required, to supply high resolution .tiff images in separate files (I 200 dpi for line drawings and $300 \mathrm{dpi}$ for color and half tone work at intended display size column width of $76 \mathrm{~mm}$ or page width of $160 \mathrm{~mm}$ ). It is advisable to create your high resolution images first as they can easily converted into low resolution images for on line submission. Line drawings, graphs, and charts should be professionally drawn or computer generated and printed on a high resolution laser printer. Any lettering in the figures should be large enough to stand photographic reduction. Authors should prepare their figures for either one column $(76 \mathrm{~mm})$ or the entire page width $(160 \mathrm{~mm})$. The editors reserve the right to reduce the size of illustrated material. Authors may, however, specifically request a larger reproduction.

Figures should be numbered consecutively with Arabic numerals, in the order in which they appear in the text. Reference should be made in the text to each figure. Each figure must be accompanied by an explanatory legend, typewritten with double spacing and the legends to all figures should be typed together on a separate sheet at the end of the manuscript. Any photomicrographs, electron micrographs or radiographs must be of high quality. Photomicrographs of histopathological specimens should provide details of staining technique and magnification used (or use an internal scale bar). All micrographs must carry a magnification bar. Explain all symbols used in the figure. Patients shown in photographs should have their identity concealed or should have given their written consent to publication of the photographs. For a photograph of a minor, signed parental permission is required.

Tables should be added at the end of the manuscript and not interspersed throughout the manuscript. They should be submitted as part of the Word document, typed neatly, each table on a separate page in double spacing, with the title above and a clear legend below. The legend should contain all the necessary information so that the table and legend may stand alone, independent of the text. Explain all abbreviations. Standard abbreviations of units of measurement should be added between parentheses. A table must have at least two columns. Column headings should be brief, but sufficiently explanatory. Lists are to be incorporated into the text. Do not use patient initials in tables. Patients should be referred to by sequential Arabic numerals, not by their initials.

d. References: Use et al after the 6th author name. Put a full stop after the journal's name and after the last page. Refer year (i), volume (:), and first and last page. The author is responsible for obtaining written permission to reproduce previously published material (illustrations, tables) from the copyright holder. The consent of the senior author must also be acquired.

The submitted manuscript must be accompanied by a cover letter which should specify:

I. A statement that the submission is not under consideration by any other journal or published previously (apart from abstracts);

2. A statement by the responsible author certifying that all co-authors have seen and agree with the contents of the manuscript. It is a policy of the journal that submissions are not returned back to the authors.

A letter for articles accepted for publication accompanied by the reviewers' comments is sent to the authors for final corrections. Proofs can be accompanied by a document for ordering a specified number of reprints by the authors.

Transfer of copyright to the journal "HAOMS" is a requisite condition of publication. The corresponding author must include a Conflict of Interest Statement on behalf of all authors at the end of the article. If there is no conflict of interest it must be stated.

The manuscript can be submitted, by e-mail only to Editor-in-Chief Athanassios Kyrgidis (email: archives@haoms.org)

Submissions will be screened for Plagiarism / Similarity to other publications / internet sources / student papers prior to Section Editor assignment. A threshold of less than $30 \%$ similarity excluding the references for the whole submitted document is required.

Label emails with the title of the manuscript. File names: Submit the whole manuscript (abstracts, text, references, tables, legends) as a single file. Name each file with your last name (up to eight characters). Text files should be given the threeletter extension that identifies file format. Submit figures as separate files from text files. Tables and charts should be adjuncts to the text and must not repeat material already presented. They should be numbered consecutively, with Roman numerals in the order in which they appear in the text.

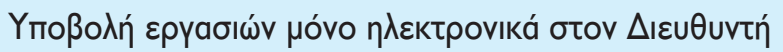

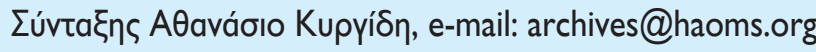

Paper submission electronically only to Editor-in-Chief Athanassios Kyrgidis, e-mail: archives@haoms.org 


\title{
ПIEPIEMФYTEYMATITIAA
}

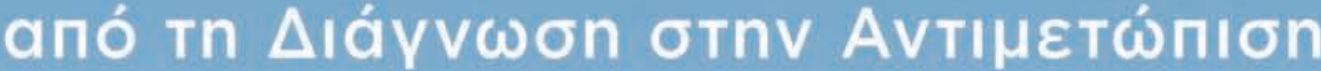

\author{
I AANNH $\Sigma$ K. KAPOY $\Sigma H \Sigma$

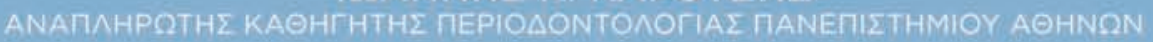 \\ ¿Uvepvadia \\ $\triangle P$. MANATIRTA E. NTOKOY \\ MEPIOAONTOAOTOE
}

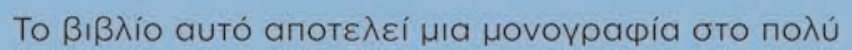

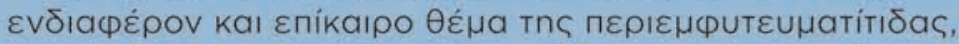

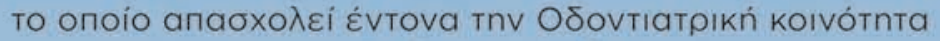

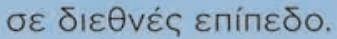

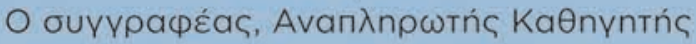

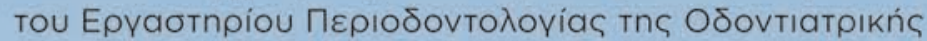

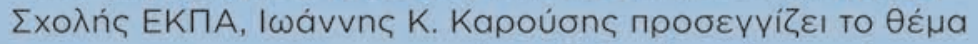

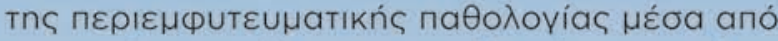

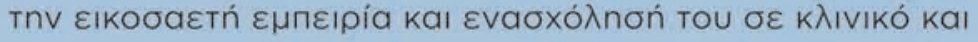

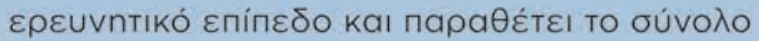

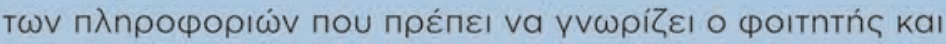

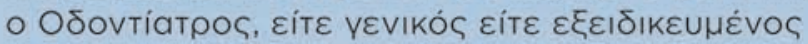

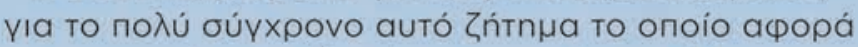

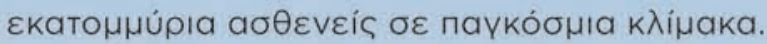

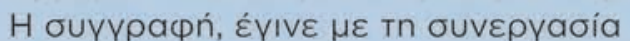

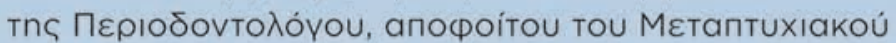

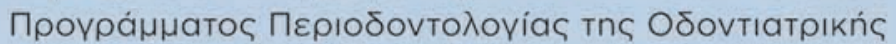

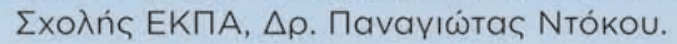

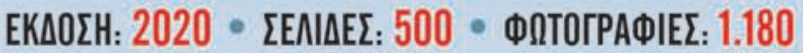

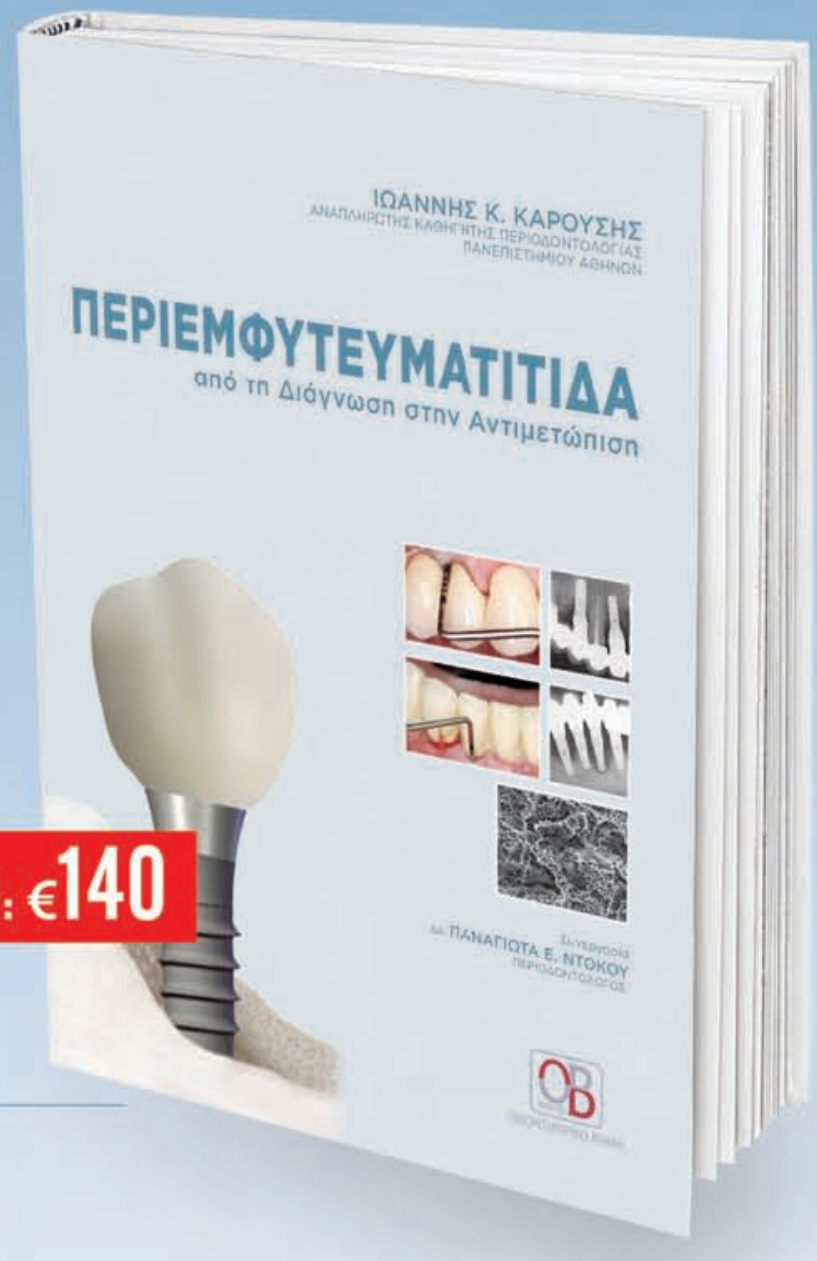

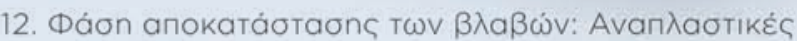
TEXVIKÉৎ

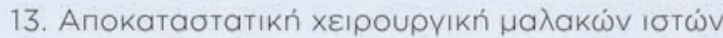

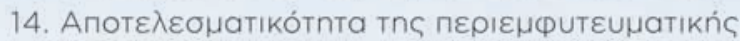
Өврапвías

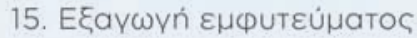

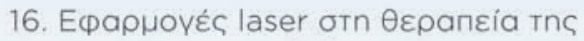

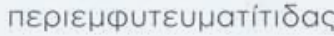

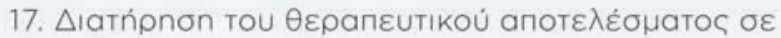

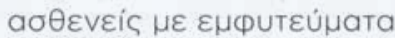

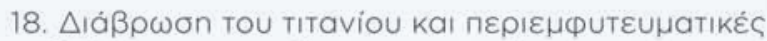

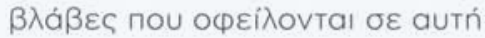

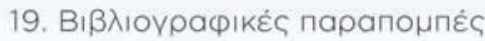

20. Eupetńpio 

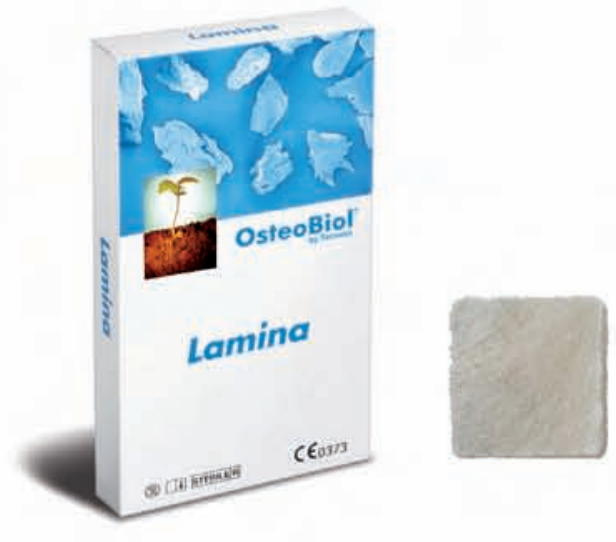

\section{Lamina}

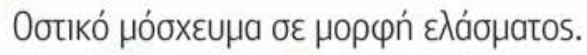

\section{lotós npoźdeưns}

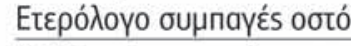

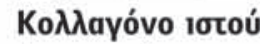

\latnpnpźvo

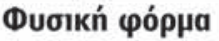

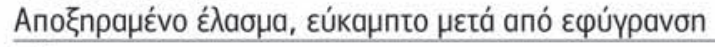

\section{Пáxos}

Kavovikó (2-4mm) - גentó (0,4 - 0,6mm)

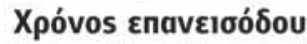

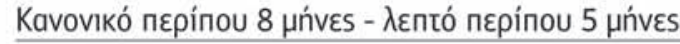

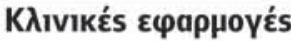

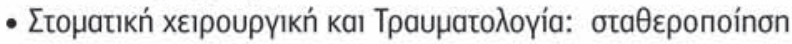

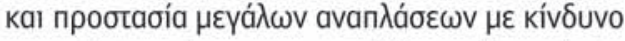

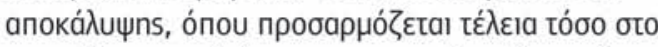

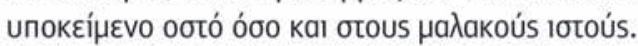

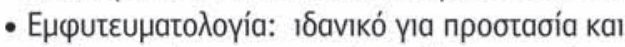

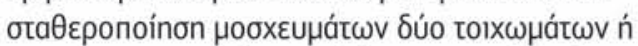

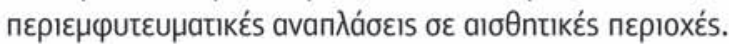
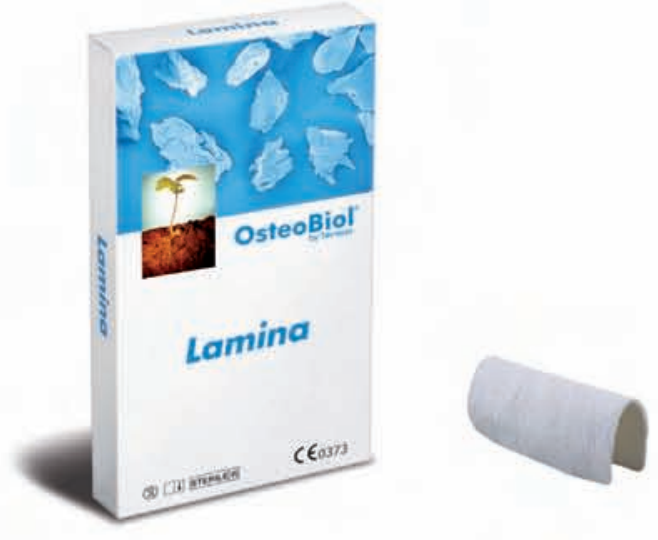

\section{Curved Cortical Lamina}

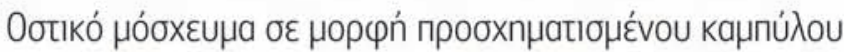

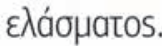

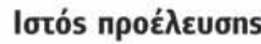

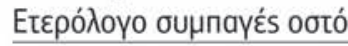

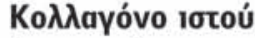

$\triangle$ latnpnpévo

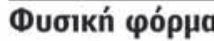

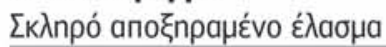

\section{Пáxos}

Meøaío $1,0 \mathrm{~mm}( \pm 0.1)$

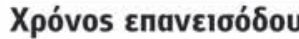

Пєрínou 6 нńves

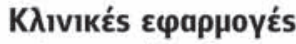

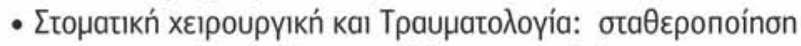

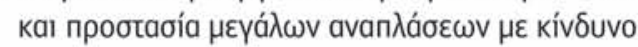
anokáduथns.

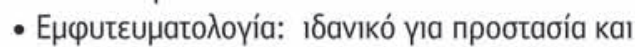

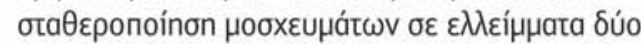

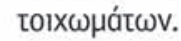

\section{MıAтıáōns} Bitoapónouגos A.E.

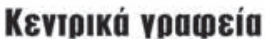

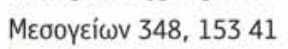

Aү. Парабкєuń, AӨńva

(C) 2106541340

○) 2106541618

ㅈinfo@vitsaropoulos.gr

\section{Yпokaráornua}

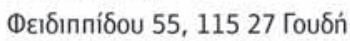

(C) 2107795747

(-) vitsaropoulos.gr

ff facebook.com/vitsaropoulos 


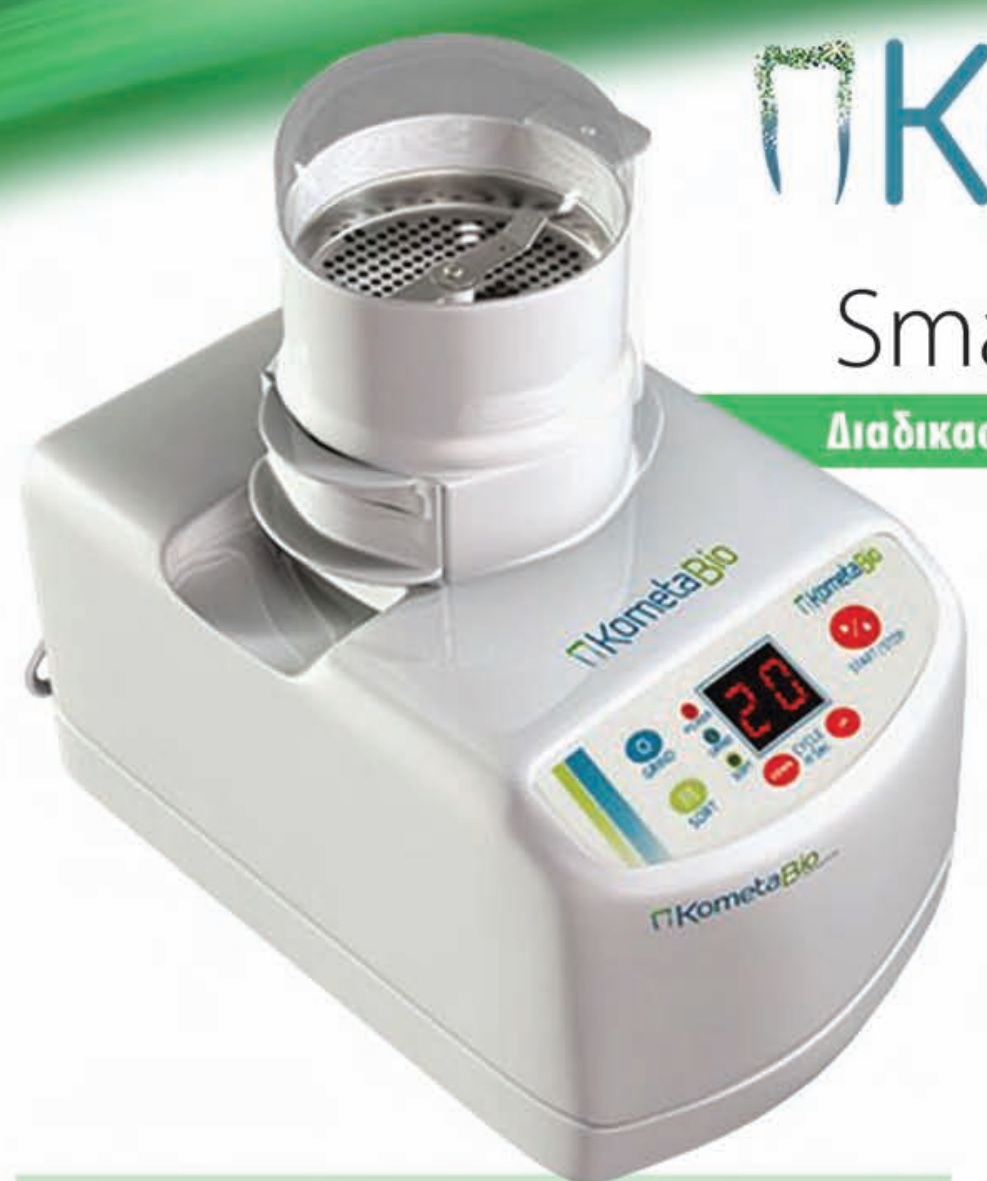

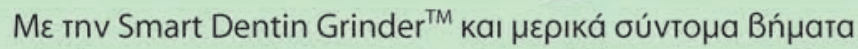

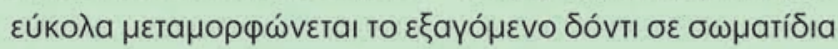

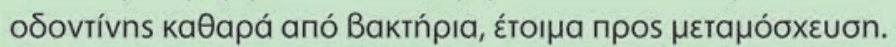

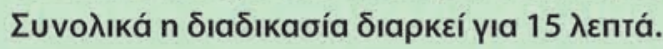

Me inv Smart Dentin Grinder ${ }^{\mathrm{TM}}$,

о обоvті́atpo нпороúv

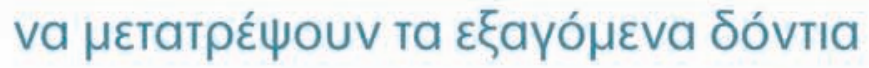

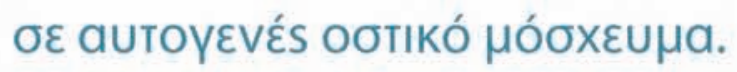

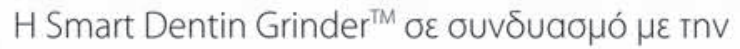

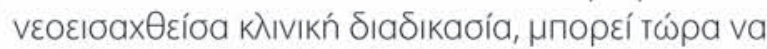

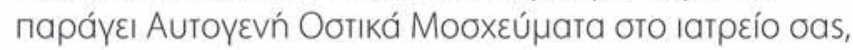

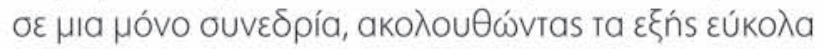
Bńmata:

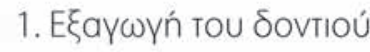

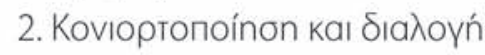

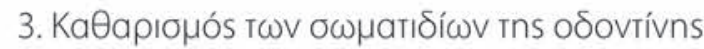

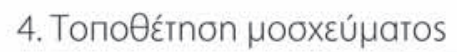

\section{Xpńon}

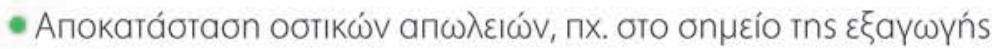

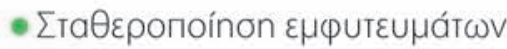

- Aúznon patviakńs akpoגopías

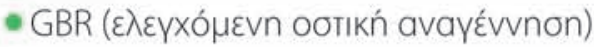
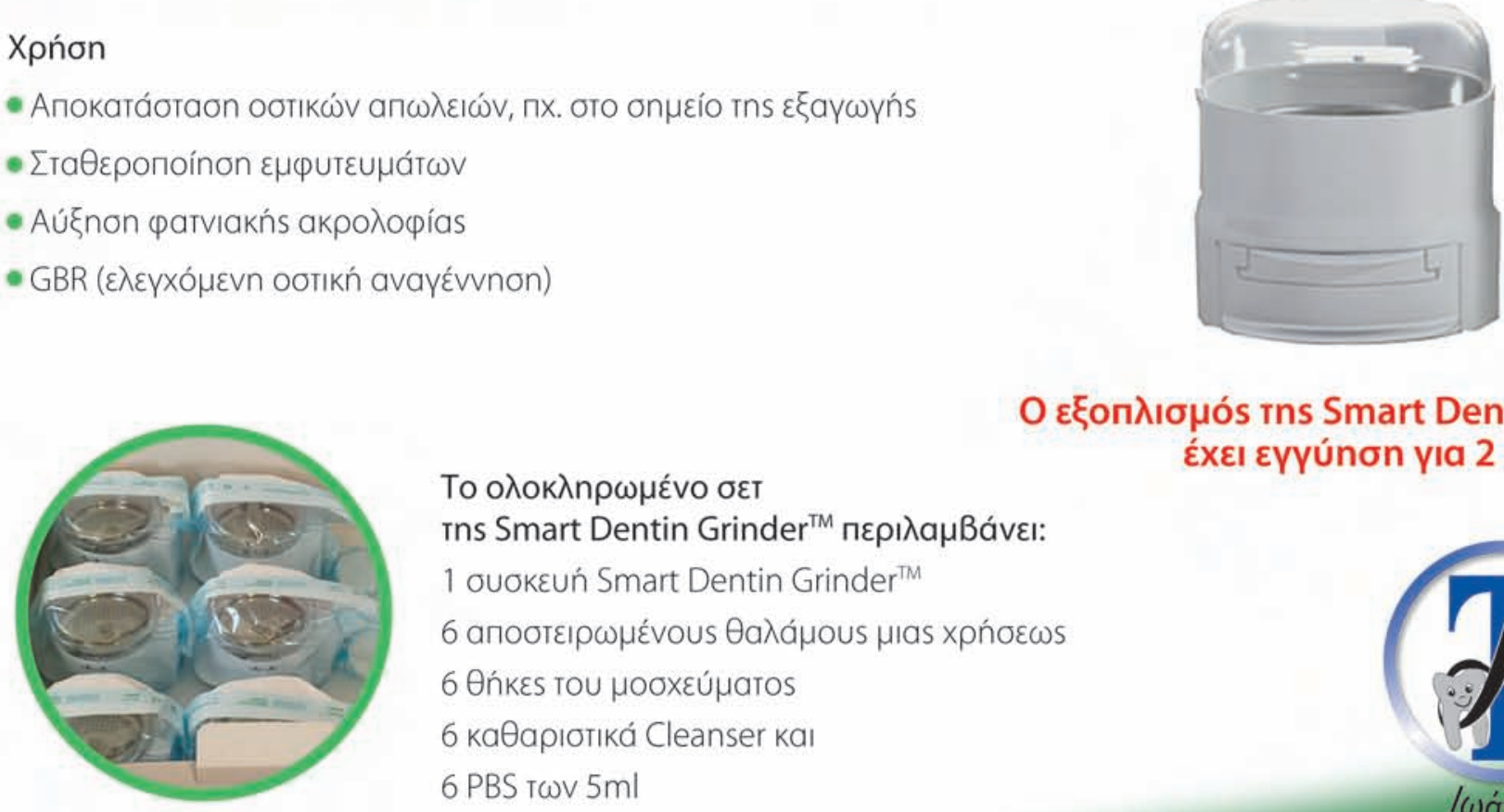

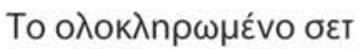

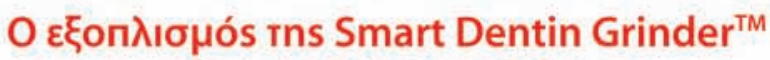

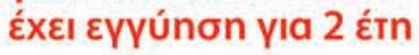

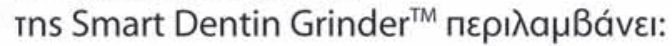

1 бUбкєuń Smart Dentin Grinder ${ }^{\mathrm{TM}}$

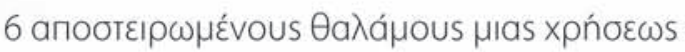

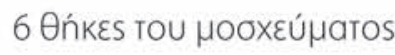

6 kaӨapı тıкá Cleanser kaı

6 PBS TwV $5 \mathrm{ml}$

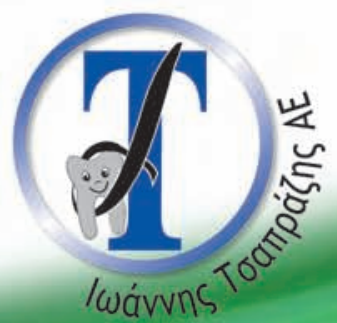

